EXPLORING EDITORIAL LEADERSHIP: A QUALITATIVE STUDY OF

SCHOLASTIC JOURNALISM ADVISERS TEACHING LEADERSHIP

IN MISSOURI SECONDARY SCHOOLS

A Dissertation
presented to
the Committee Faculty of the Graduate School
at the University of Missouri - Columbia
In Partial Fulfillment
of the Requirements for the Degree
Doctor of Education
by
JULIA LEWIS
Dr. Sandy Hutchinson, Dissertation Supervisor
MAY 2020


(C) Copyright by Julia Lewis 2020

All Rights Reserved 
The undersigned, appointed by the dean of the Graduate School, have examined the dissertation entitled

\section{EXPLORING EDITORIAL LEADERSHIP: A QUALITATIVE STUDY OF SCHOLASTIC JOURNALISM ADVISERS TEACHING LEADERSHIP IN MISSOURI SECONDARY SCHOOLS}

presented by Julia Lewis

a candidate for the degree of doctor of education, and hereby certify that, in their opinion, it is worthy of acceptance.

Dr. Sandy Hutchinson

Dr. Barbara N. Martin

Dr. Bryan McDonald

Dr. Nicole Freeman 


\section{ACKNOWLEDGEMENTS}

In the last years, many people were instrumental in shaping my academic potential. It was hardly possible to thrive in my journey without their support. First and foremost, my special thanks to my forever interested, encouraging and always enthusiastic daughters Elise, Sloane, and Lydia. You have each in your own ways been keen to know what I was doing and how I was proceeding. I adored your screams of joy with each significant accomplishment. I hope that you will see this as an example of what you can accomplish with support, determination, and hard work. I am excited to see what the Lord has in store for each of your journeys. My gratitude will always be with my husband, Drew. Your continuous support has grounded my doctoral studies, with your patience, motivation, and enthusiasm. Your support helped me through all the research and writing of this dissertation. From reading early drafts, to budgeting gas money to drive all over Missouri rather than buy a couch, you were always ready to make this journey our top priority.

I would also like to thank my dissertation committee Dr. Sandy Hutchinson, Dr. Barbara Martin, Dr. Bryan McDonald and Dr. Nicole Freeman. I appreciate the time and effort you put forward to me. Your feedback and support throughout this process was irreplaceable and has made this accomplishment possible. This work would not have been possible without the guidance of Dr. Hutchinson, whose passion, drive, and audacious spirit are indeed contagious.

While in the field, I was introduced to outstanding individuals in journalism. I wish to extend a heartfelt thank you to all who assisted me in my research. I appreciate your openness and willingness to take the time to share your thoughts about leadership in 
journalism. Each of you gave your time, energy, and expertise. I have been personally inspired by your professionalism and level of commitment to journalism.

Finally, I am thankful to God for granting me the opportunity and capacity to complete such an immense undertaking. This journey has constantly reminded me of how much He desires us to be immeasurably more. 


\section{TABLE OF CONTENTS}

ACKNOWLEDGEMENTS .............................................. Ii

LIST OF TABLES .....................................................

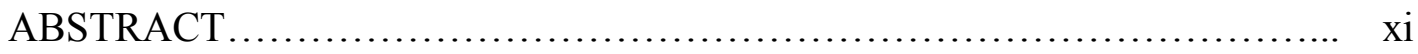

Section

I. INTRODUCTION TO THE BACKGROUND OF THE STUDY ......... 1

Introduction...................................................... 2

Statement of the Problem.......................................... 4

Problems of Practice.................................... 5

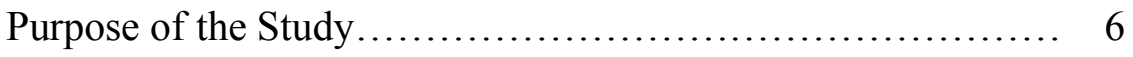

Research Questions..................................... 8

Theoretical Framework........................................... 8

Conceptual Framework ......................................... 8

Definitions of Key Terms...................................... 12

Design of the Study ........................................... 15

Setting ........................................................... 15

Participants........................................... 16

Respondent Data........................................ 18

Location................................................ 19

Total Years of Teaching ................................ 21

Education Background................................ 22

Certification Background.............................. 23

Journalism Classes Taught............................ 26 
Data Collection Tools.......................................... 30

Data Analysis............................................. 31

Limitations, Assumptions and Design Controls................... 33

Summary of Findings and Research Questions Answered........... 35

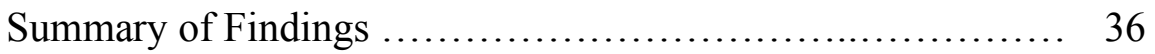

Research Questions Answered............................ 39

RQ1 What role does leadership play in K-12 journalism education?

RQ2 What leadership skills are important in K-12 journalism education?

RQ3 What are high school advisers' perspectives regarding teaching leadership skills?

RQ4 How do K-12 journalism advisers teach journalism skills?

RQ5 What components of the transformational leadership theory are present within scholastic journalism?

Discussion and Implications

Discussion of the Results

Implications 98

Implications for Practice............................ 98

Recommendation One: Engage Student Leaders........ 99

Recommendation Two: Teach Leadership.............. 103

Recommendation Three: Empower Student Leaders..... 107

Recommendation Four: Impact Student Leaders......... 111 
Implications for Future Research....................... 113

Significance of the Study............................................ 114

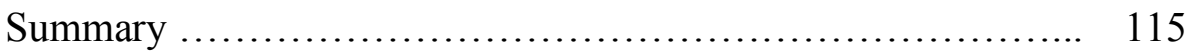

II. PRACTITIONER SETTING FOR THE STUDY ....................... 117

Introduction.................................................... 118

Historical Background......................................... 119

The Advent of Journalism Education........................... 119

The Emergence of Scholastic Journalism..................... 121

Scholastic Journalism's Impact............................... 122

Scholastic Journalism Today.................................. 126

Organizational Analysis......................................... 129

Analysis of News Labs through the Structural Frame........... 129

Analysis of News Labs through the Human Resource Frame.... 139

Leadership Analysis............................................. 148

Modeling the Way........................................ 152

Inspire a Shared Vision.................................. 153

Challenge the Process.......................................... 153

Enable Others to Act..................................... 154

Encourage the Heart......................................... 155

Implications for Research in the Practitioner Setting............... 156

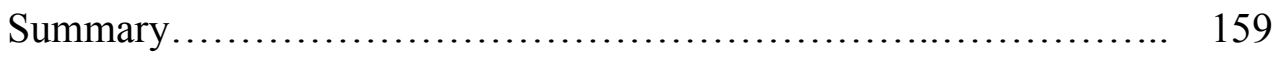

III. SCHOLARLY REVIEW FOR THE STUDY ......................... 160

Introduction.................................................... 161 
Theoretical Framework......................................... 162

Literature Summary ............................................ 165

Historical Changes in Journalism Leadership........................ 166

Trends in American Journalism.................................. 166

Obstacles Faced when Changing the Tools of the Trade........ 167

The Role of Professional Newsrooms............................... 171

Higher Education's Student News Labs................................. 175

Higher Education's Journalism Education Standards........... 177

Practical Pedagogy ....................................... 178

Secondary Education's Student News Labs.......................... 180

Scholastic Journalism's Value.................................. 180

Leaders in Scholastic Journalism Classes..................... 181

Higher School Courses Taught as Journalism.................... 183

Limits on Scholastic Journalism Curriculum.................... 186

Editorial Leadership in Scholastic Journalism.................. 187

Current Gap in Editorial Leadership Research.................. 199

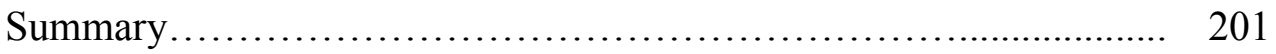

IV. CONTRIBUTION TO PRACTICE................................. 203

Plan and Rationale for Dissemination............................... 204

Executive Summary of the Study................................ 205

Results Presentation............................................... 207

V. CONTRIBUTION TO SCHOLARSHIP............................ 243

Plan and Rationale for Dissemination................................ 244 
VI. SCHOLARLY PRACTITIONER REFLECTION.................... 276

REFERENCES ................................................. 284

APPENDIX .......................................................... 303

APPENDIX A - IRB APPROVAL FORM........................... 303

APPENDIX B - INTERVIEW PROTOCALS.......................... 304

APPENDIX C - ACCESS PERMISSION LETTER FOR MIPA............ 306

APPENDIX D - PARTICPANT INTERVIEW REQUEST EMAIL........... 307

APPENDIX E - SCHEDULING CONFIRMATION EMAIL................ 308

APPENDIX F - INDIVIDUAL INTERVIEW CONSCENT FORM......... 309

APPENDIX G - INTERVIEW QUESTIONS LINKED TO RQ............. 310

APPENDIX H - THEMES........................................ 311

Theme I: Advisers Engaging Students........................... 311

Building a Community of Learners........................ 311

Establishing Teamwork.................................. 315

Meeting Student Learning Needs........................... 318

Theme II: Advisers Teaching Leadership........................ 323

Focusing on Accountability................................... 324

Establishing Editor Expectations.......................... 326

Motivating Leadership Instruction.......................... 326

Theme III: Advisers Empowering Students........................ 334

Creating a Safe Environment............................... 335

Taking Action.......................................... 338 
Theme IV: Advisers Impacting Students........................ 342

Harnessing Enthusiasm................................... 342

Building Trust.......................................... 346

Establishing Relationships............................... 346

APPENDIX I - VITA .............................................. 354 


\section{LIST OF TABLES}

Table

1. Northwest quadrant location, school size, and adviser pseudonym..... 19

2. Northeast quadrant location, school size, and adviser pseudonym..... 20

3. Southwest quadrant location, school size, and adviser pseudonym..... 20

4. Southeast quadrant location, school size, and adviser pseudonym..... 20

5. Total Years of Teaching Experience........................... 21

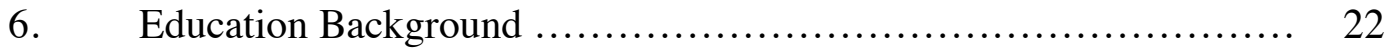

7. Certification Background................................... 23

8. Certification Background (continued)........................ 24

9. Certification Background (continued)........................... 25

10. Journalism Classes Taught in $2019-20 \ldots \ldots \ldots \ldots \ldots \ldots \ldots \ldots \ldots \ldots . \ldots \ldots$

11. Journalism Classes Taught in 2019-20 (continued)................. 27

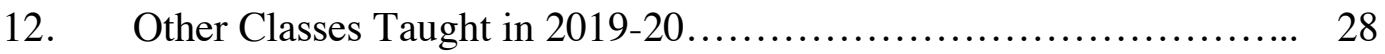

13. Other Classes Taught in 2019-20 (continued).................... 29 


\title{
A QUALITATIVE STUDY OF SCHOLASTIC JOURNALISM ADVISERS TEACHING EDITORIAL LEADERSHIP IN MISSOURI SECONDARY SCHOOLS
}

\author{
Julia Lewis \\ Dr. Sandy Hutchinson, Dissertation Supervisor
}

\begin{abstract}
This qualitative study explored advisers' perspectives on teaching leadership. This study identified the significant need for the role of leadership in scholastic journalism programs. Advisers illustrated soft skills provide many opportunities for students to grow into leaders. The leadership skills provide advisers opportunities to articulate their passion and genuine convictions with their students. This current study focused on editorial leadership practices in high school journalism news labs for a clearer understanding of how advisers utilize many leadership practices. The findings will benefit high school journalism teachers to develop leadership for effective production, encourage creativity, and foster decision making. Thus, leadership skills are important in journalism education.
\end{abstract}




\section{SECTION ONE}

INTRODUCTION TO THE BACKGROUND OF THE STUDY 


\section{Introduction to the Background of the Study}

In the 21 st century, nearly every norm, value, practice and role within journalism is being questioned (Ryfe, 2012). There is no doubt journalism leaders are currently facing unprecedented challenges (Örnebring, 2018). It is easy to sense a shudder from journalism leaders who love their craft and see the values of entrepreneurship are poor companions to rigorous journalism training (Mensing \& Ryfe, 2013). Under those consequences, research and investments are being made in professional journalism newsrooms across the country to train newsroom leaders to improve journalism (Callinan, 2001; Herndon \& Krueger, 2016; Killebrew, 2003; Mierzejewska, 2011; Mulrennan, 2018; Perez-Latre \& Sanchez-Tabernero, 2003). Until this study, little to no research has been conducted on high school journalism advisers and how they teach leadership. The premise is that high school journalism advisers teaching editorial leadership can further advance the future of media excellence.

There is a vital need to expose how high school journalism teachers are teaching leadership in their scholastic journalism programs, which is known as editorial leadership (Newton, 2018). Journalism education in U.S. secondary schools is referred to as scholastic journalism (Bobkowski, Cavanah, \& Miller, 2017). Similar to the profession, scholastic journalism advisers, develop soft leadership skills within their programs. Currently, scholars have analyzed leadership in professional newsrooms. There was also a need for leadership in scholastic journalism. The lack of leadership analysis in high school journalism newsrooms has been a disservice to future journalists by not equipping them with the tools needed to analyze their role in the media industries (Macdonald, 2006). 
The scholarly conversation in journalism education has focused on a twodirectional tension. In one direction, there has been an effort to educate both reporters and editors to bolster their contribution to democracy through improved journalism. On the other end, there has been an emphasis on training newsroom staff to function efficiently in their news environment (Folkerts, 2014). One way to dismantle the journalism crisis is to focus on innovative leadership training, which can further develop newsgathering approaches while informing and engaging audiences (Jaakkola, 2014; Posetti, 2018).

Some journalism education scholars connect interpersonal soft skills such as effective open communication. Recent scholarship argues that leadership plays a central role in positively shaping change-management outcomes (Herndon \& Krueger, 2016, Killebrew, 2003; Mierzejewska, 2011; Perez-Latre \& Sanchez-Tabernero, 2003). Nonetheless, journalism education research has focused on leadership being significantly lacking as it fails to address media management disciplines (Mierzejewska \& Hollifield, 2006). Under these circumstances, there was a need to fill the existing gap in literature with two specific concepts. First, little to no research has been conducted on high school journalism advisers teaching editorial leadership. Second, there was a need to understand advisers' perceptions of the role leadership plays within high school news labs. Furthermore, journalism education scholars suggested students develop successful leadership concepts and behaviors through news creation, production, editing and community distribution (Herndon, \& Krueger, 2016; Mensing, 2010).

Overall, it was unknown how high school advisers teach leadership in scholastic newsrooms. Scholars support the need for professional newsrooms to emphasize editorial leadership with the foundations of social sensibility, relevance, and accuracy (Kovach \& 
Rosenstiel, 2014). Journalism educators need leadership training because it offers the art of critical inquiry, real time exposition and high impact analysis (C. Carpenter, personal communication, 2019). When working with scholastic journalism news labs, emphasizing leadership is the most promising path for increasing students' success (Bronstein \& Fitzpatrick, 2015; Herndon, \& Krueger, 2016; Mensing, 2010; Newton 2018; Pavlik, 2013). The researcher explored advisers' perspectives on how advisers teach leadership in scholastic journalism news labs. As this is one of the first studies on editorial leadership, the findings may be considered transferable to other high school journalism news labs.

\section{Statement of the Problem}

Little was known about how high school journalism teacher were teaching their students professional leadership skills. So, many teachers were left unsure of how and which leadership skills to teach within their news labs. Similarly, there was a lack of research regarding leadership in high school news labs. According to Newton (2018), even after two decades, most journalism educators still resist the changes of the digital era as too many people, processes, policies and products are creatures of the past. Current practices reinforce a status quo by creating professionals with skills and techniques reinforcing one-way communication and socializing students for a newsroom more than engaging in critical inquiry, which reduces education's credibility and diminishes leadership within the field (Mensing, 2010). The challenge confronting journalism educators is how to prepare leaders for an industry in radical transformation (Pavlik, 2013). As there were no known leadership standards being taught within high school news labs, research was needed to explore how advisers prepared their students to be leaders. 


\section{Problem of Practice}

Journalism educators struggle to know what relevant curriculum is developed to prepare their students for professional newsrooms. Many believe advisers do not know what to teach because their goals are moving targets (Wenger, Owens, \& Cain, 2018). Advisers are missing opportunities to align with professional standards. Consequently, students have outdated skills (Mulrennan, 2018). The soft skills in journalism leadership are continually expanding as technology advances and news consumption preferences evolve (Küng, 2017; Pavlik, 2013; Posetti, 2018).

There was a need for research to explore high school advisers' perceptions of editorial leadership and how it was taught in order to add to the body of knowledge surrounding best practices in scholastic journalism. Throughout the last two decades, researchers have been systematically investigating leadership in many professional newsrooms (Mierzejewska, 2011). The current research demonstrates a link between pedagogy and best practices within the context of professional education and higher educational successes. However, professional newsrooms do not influence school policy or curriculum. Students are suffering from academia's slow reaction time to new professional leadership expectations (Newton, 2018; Örnebring, 2018).

The education and training of journalists is a subject much debated but rarely researched in scholastic journalism. A few published studies have addressed professional and higher education newsrooms leadership, but the number of scholarly studies on scholastic journalism leadership have been completely void. Educators need to transform media education at every level, from the nature and work of a media professional, to the 
content, organizational, and financial structure of media and their relationships with the public (Pavlik, 2013).

Currently, there are many reports on journalism education; however, there is a lack of empirical research among scholars. Additionally, the research reveals leadershipcurriculum components are missing from scholastic journalism. Further research is needed to address the foundational high school experience, which extended relevance into higher education and then to the professional world. Therefore, this study focused on the perceptions of editorial leadership and its role in the scholastic newsrooms. For scholastic news labs without editorial leadership strategies, this study provides a strong rationale for adding editorial leadership as part of a competitive, well- rounded curriculum. For those with established editorial leadership curriculum, this study offers methods for enhancing learning outcomes by exposing students to a diverse set of leadership communication expectations.

\section{Purpose of the Study}

The purpose of the study was to gain knowledge and insight to reveal editorial leadership teaching methods. The researcher investigated how advisers teach their students leadership. Additionally, acknowledging the significant role of journalism education in academic growth, this study stressed the need for school districts and higher education to invest in scholastic journalism initiatives.

This study showcased leadership dynamics involved in producing news in educational environments as well as the challenges of training, educating and building student leaders. In addition, this study addressed the editorial leadership gaps that exist between secondary education news labs and professional newsrooms (Collins, 2017). 
With this study, the researcher discovered skills to assist journalism educators by exploring scholastic journalism advisers' best practices to teach editorial leadership. Findings will be presented to administration, teachers and, ultimately, students will be encouraged and inspired to become leaders. This study may lead to recommendations for actionable editorial leadership training, policy and change within Missouri's high school journalism educators' curriculum.

Educators need to focus journalism education on the soft skills of leadership (Herndon \& Krueger, 2016; Killebrew, 2003; Mierzejewska, 2011; Perez-Latre \& Sanchez-Tabernero, 2003). According to Bronstein and Fitzpatrick (2015) the individuals who will be responsible for the journalism industry's needed transformations are sitting in advisers' classrooms today (Bronstein \& Fitzpatrick, 2015). Furthermore, this study can offer information for graduates to be prepared for a lifelong journey of adaptation in a relentlessly changing media landscape (Bronstein \& Fitzpatrick, 2015; Lynch, 2015). Recommendations can be established for mastery of a new set of intellectual skills that embrace and advance the centrality of media innovation and entrepreneurship within an ethical framework (Pavlik, 2013). Therefore, acquiring further scholastic journalism research can provide essential methods for editorial leadership instruction to train advisers.

\section{Research Questions}

The following research questions helped gain an understanding of how high school journalism advisers develop leadership in Missouri scholastic news labs:

1. What role does leadership play in K-12 journalism education?

2. What leadership skills are important in K-12 journalism education? 
3. What are high school advisers' perspectives regarding teaching leadership skills?

4. How do K-12 journalism advisers teach leadership skills?

5. What components of the transformational leadership theory are present within scholastic journalism news labs?

\section{Theoretical Framework}

Educators need to transform journalism education at every level. The tenets of the transformational leadership theory can guide educators in creating optimal learning experiences to develop newsroom leaders (Collins, 2017; Folkerts, 2014; Newton, 2018). Pavlik (2013) argued educators need to be prepared for a lifelong journey of adaptation in a relentlessly changing media landscape as the concept of what is a journalism course, and journalism's boundaries and method of delivery need transformation to better engage students.

\section{Conceptual Framework}

Since the 1980s, leadership theory has been recognized as a critical component of effective and successful organizations (Collins, 2001). Burns' (1978) work provided a solid conceptual footing for the work of Bass who, in 1985, presented a formal theory of transformational leadership as well as models and measurements of their factors in leadership behavior. Transformational leadership emphasizes the importance of the leader and key constituents sharing a common vision and overall goals (Firestone \& Heller, 1995). The focus of this type of leadership is the change and transformation of people (Northouse, 2016). Transformational leadership is generally defined as including four 
leadership characteristics of idealized influence, inspirational motivation, intellectual stimulation, and individualized consideration (Northouse, 2016).

Transformational leaders use an exceptional form of influence that moves followers to accomplish more than what is usually expected of them. Thus, transformational leaders evoke participants to meet their maximum potential and beyond in order to move to a higher level of achievement and success (Bolman \& Deal, 2013). It is a process that often incorporates "charismatic and visionary leadership" (Head \& Alford, 2013, p. 161). It includes assessing followers' motives, satisfying their needs, and treating them as full human beings (Northouse, 2016).

In the same way, this transformational ideal is supported by the formal model of leadership, which emphasizes the importance of developing goals and pursuing specific objectives in order to benefit the organization as a whole (Bush, 2003). Bush (2003) recognized educational institutions as goal-oriented and consisting of members working toward the achievement of common goals. Achieving goals engages a person with others and creates a connection that raises the level of motivation and morality in both the leader and the follower. The leader is attentive to the needs and motives of followers to reach their fullest potential by emphasizing ideals, inspiration, innovations, and individual concerns (Northouse, 2016).

By building upon individual considerations and motivations, transformational leaders can identify strengths and weaknesses of individuals within an organization (Morgan, 1997; Yukl \& Van Fleet, 1992). In this way, transformational leadership also supports a common mission and vision for the organization (Bass, 1999; Bush, 2003; Schein, 1992; Yukl \& Van Fleet, 1992.) Transformational leaders understand and value 
that all individuals bring multiple perspectives, experiences, and bias to an organization, which is critical when recognizing the importance of individual goals and considerations prominent within transformational leadership behavior (Burns, 1978; Yukl \& Van Fleet, 1992).

Transformational leaders recognize and support intellectual stimulation and individual considerations in order to promote the overall organizational goals (Bass, 1990; Bolman \& Deal, 2013; Yukl \& Van Fleet, 1992). Transformational leaders support the idea of overall community goals as the defining purpose of an organization (Bass, 1990; Bush, 2003; Yukl \& Van Fleet, 1992). Yukl and Van Fleet (1992) also contended that leaders intentionally influence individuals to guide, structure, and facilitate activities within an organization to achieve the organization's goals. It is a reciprocal process based upon charisma and vision as both leader and follower are inspired and motivated to reach the highest levels of achievement (Northouse, 2016).

Goals exist at many levels within an organization and leaders must ensure personal goals are secondary to the institution's organizational goals (Bush, 2003). Yukl and Van Fleet (1992) further maintained leaders assist constituents in achieving their goals and providing them with direction and support to ensure individual goals support and sustain the overall goals of the organization. Transformational leaders coordinate efforts of followers toward the achievement of common goals by creating an environment which provides direction and support versus rewards and punishment found within transactional and charismatic leadership (Bass, 1990; Bolman \& Deal, 2013).

Kouzes and Posner (1987) further refined transformational leadership by showcasing the importance of producing exemplary leader follower trust, which is central 
for transformational leadership. Kouzes and Posner (2002) asserted that leading by example is visible management by enhancing accessibility and promoting the values and principles advocated by the leader. Therefore, leaders who lead by example serve as visible models for those committed to the course of action in the organization (Kouzes \& Posner, 2002).

Kouzes and Posner's Fundamental Practices of Leadership Model suggests that leadership is not a position, but a collection of practices and behaviors $(1987,2002)$. These practices serve as guidance for leaders to accomplish their achievements or "to get extraordinary things done" (Kouzes \& Posner, 1987, p. 9). Kouzes and Posner's practices are components of the concept of transformational leadership. These practices include challenging the process, inspiring a shared vision, enabling others to act, modeling the way, and encouraging the heart (Kouzes \& Posner, 1995, 2002).

Transformational leadership has been heavily researched; however, the research regarding effective editorial leadership as it relates to high school journalism is lacking. Therefore, this inquiry provides additional insights for advisers to teach effective leadership skills needed in high school news labs. The conceptual framework of transformational leadership allows for a refined approach to the study (Mertens, 2005). An analysis through the theoretical framework of leadership theory led to a greater understanding on how scholastic journalism advisers establish good decision-making techniques in student newsrooms.

\section{Journalism Teachers and Transformational Leadership Theory}

The researcher reviewed the skills and role of leadership in high school journalism newsrooms through the tenets of Transformational Leadership Theory 
(Collins, 2017). Reviewing the tenants of Transformational Leadership Theory, journalism advisers can transform, address, revise, and create curriculum as well as new pedagogical approaches in their news day practices. A journalism educator's transformational influence goes beyond normal role requirements (Cleveland, Murphy, \& Stockdale, 2000, p. 287; Yukl \& Van Fleet, 1992). According to Newton (2018), today's society is at the hundred-year flood mark when it comes to the spread of information. In fact, the internet linked more people to information than any other point in history (Newton, 2018). Scholars refer to the internet as having more influence on news than the printing press, radio, or television. Therefore, Transformational Leadership Theory can explain newsrooms' influence in motivating people beyond what is required of them by their jobs or situations (Cleveland et al., 2000, p. 319). Some scholars document a notion that goes as far as addressing a journalism educator's influence going beyond the normal teacher role requirements (Cleveland, et al., 2000, p. 287; Yuk1 \& Van Fleet, 1992).

Ultimately, journalism education is in urgent need of transformational leadership as the media are in the midst of change, and educators and professionals alike are "groping for a pathway to a future in which they play a vital role" (Pavlik, 2013, p. 211). An analysis through the transformational learning paradigm led to a greater understanding on how journalism educators establish a positive active learning pedagogy, as the challenge confronting journalism and educators is how to prepare future journalism leadership for an industry in radical transformation (Goh \& Kale, 2015; Pavlik, 2013).

\section{Definitions of Key Terms}

For the purpose of this study the following terms were defined to guide in understanding this inquiry: 
Adviser: While sometimes spelled professionally advisor, the term is spelled adviser to note a journalism teacher. (Froke, Bratton, Garcia, Minthorn, Ritter, \& Schwartz, 2017).

Deadline: The time at which a job must be handed in or completed to make issue of production.

Editors: Those provided with responsibility of deciding which news stories are produced in the news lab. Long before the production is complete, the editor assigns reporters to cover the news, checks for accuracy and fairness in the stories.

Editorial Leadership: Scholastic news labs organization goals, strategies, skills and practices used to develop students' leadership skills of communication style, management abilities and team focus. Students in news lab leadership positions are: editors in chief, managing editors, assistant editors, editorial directors, page (section) editors, sports editors, chief copy editors, and editorial page editor. These positions are designed for experienced news lab students who are in leadership roles on their respective productions.

Journalism: Journalism is referred to by many as a craft, which would justify a professional model of education. However, unlike the established professional programs of medicine and law, there is no entry standard for those wishing to become journalists (Commission on Freedom of the Press, 1947, p. 78).

Journalism Education: Programs teaching news and conducting research in journalism. While many journalism programs include public relations and advertising, the paper's focus will be to think specifically on journalists (Mensing, 2010). 
News lab: A classroom that also serves as a newsroom, using a grading criterion for assessment, without payment (Collins, 2017).

Newsroom: An environment also serving to gather and produce newscasts where journalists are provided with payment as incentive

Newsroom culture: A socialized set of norms and values embedded in the daily undertakings of the editors and staff in a newsroom (Erickson, Baranek, \& Chan, 1987).

Reporters: Reporters complete the basic work of writing the stories. They can either cover a beat, returning always to the same sources and subjects, or do general assignment work (Ferguson, Patten, \& Wilson, 2005). General assignment reporters cover whatever is necessary. The real eyes and ears of any production are its reporters (Streisel, 2007).

Production: The news gathering process through journalism objectives to make a story within the different journalism genres of newspaper, yearbook, broadcast or web site (Streisel, 2007)

Scholastic Journalism: Journalism education in U.S. secondary schools (Bobkowski, Cavanah \& Miller, 2017).

Soft skills: Skills such as critical thinking, problem solving, and team collaboration, problem solving, interpersonal, and work ethic needed to be successful in careers (Bronstein \& Fitzpatrick, 2015; Pavlik, 2013). Soft skills are critical to students' careers and student-run productions provide these necessary skills more so than classroom learning (Bush, Haygood, \& Vincent, 2017). 


\section{Design of the Study}

This qualitative study investigated the methods Missouri scholastic journalism advisers used to teach leadership skills. Data were collected on advisers' current skills, practices, and experiences to answer the research questions.

Qualitative research allows for the existence of multiple realities that are constructed in one of two ways, socially or individually (Heppner \& Heppner, 2004). Creswell's definition of qualitative research provided the foundation for this study. As Creswell (2007) stated, qualitative researchers strive for understanding. Creswell (2007) additionally noted that qualitative researchers try to develop a complex picture of the problem or issue under study. In the same way, this study involved reporting multiple perspectives, identifying the factors involved in advisers teaching leadership, and sketching the larger picture that emerged, bound not by cause-and-effect relationships among factors, but rather by identifying the complex interactions of factors in any adviser's situation (Heppner \& Heppner, 2004). Furthermore, qualitative research contends the knower interacts with the known and cannot be separated (Heppner \& Heppner, 2004). Therefore, qualitative research granted the researcher more involvement within the contextual situation of the study, creating the opportunity for understanding the contextual reality found within the research setting (Creswell, 2007; Heppner \& Heppner, 2004).

\section{Setting}

The setting was a representative sample (Creswell, 2014) of 24 public secondary schools with journalism news labs from across the state of Missouri. Each setting was determined by a set criteria and location for the researcher to collect data. The setting 
provided the researcher opportunities to observe, interview, and review artifacts within each adviser's high school news lab. For this study, journalism news labs were defined as a high school classroom serving as a newsroom, using a grading criterion for assessment, and without collecting payments for publications (Collins, 2017). The setting was also determined by the Missouri Interscholastic Press Association's (MIPA) membership. MIPA separates the state into four different regions. These four regions of Missouri are divided by Highway 50 and Highway 65 (MIPA, 2019). In addition to serving as boundaries within the state for its board leadership, these regions are commonly used to organize state level activities and competitions. Kansas City and St. Louis, primarily urban areas, are in two of the four regions. In contrast, the other two regions have a variety of rural, urban, and suburban student populations (Missouri Department of Elementary and Secondary Education, 2019).

Protections were put in place to ensure the participants' safety, security, and anonymity by requesting all interviews occur when the adviser was not teaching (Krueger \& Casey, 2015). Each interview was followed by an opportunity for the adviser's to show the researcher their news lab and production artifacts.

\section{Participants}

The study's sample was 24 journalism advisers. The researcher used a representative non-random and purposeful sample, all explained by Creswell (2016) as a sampling frame to "discover, understand, and gain insight and select a sample from which the most can be learned" (Merriam \& Tisdell, 2016, p. 96). The study's 24 participants were advisers from MIPA's membership, who received the All-Missouri 
award. The membership fees for MIPA may range from $\$ 40$ to $\$ 300$. The All-Missouri award is based on an award scale.

Only All-Missouri advisers were asked for an initial interview. Each adviser interviewed was granted the All-Missouri award in the last two years.

MIPA's highest placement is the All-Missouri award, which is earned by high school's productions meeting the highest standards in their journalistic coverage. The All-Missouri awards are granted in the following categories: newspaper, photography, yearbook, and broadcast and multi-media coverage. Each of those categories are divided by each school's population. MIPA recognizes many awards including the All-Missouri, as well as Superior, Excellent and Honorable Mention rankings. The students are awarded certificates at the annual Journalism Day (J-Day) celebration hosted at the University of Missouri's School of Journalism. The free day-long event includes an awards ceremony where the All-Missouri Award is the highest award, as MIPA judges choose roughly the top $10 \%$ of the entries to recognize as All-Missouri award winners.

The entries are judged on the news lab production's overall merits through a point system. In an effort for MIPA to increase the rigor in the state contest, MIPA follows the national Journalism Education Association standards regarding how the winners place at each award level. All contest entries are evaluated by an experienced professional using the same rubric-type rating system. Over 50 judges select the winners from approximately 1,400 entries. Judges range from journalism teachers and professors to professional journalists from across the country. The entries are ranked to determine their award using the following scale: All-Missouri 450-500 points; Superior 400-449 points; 
Excellent 350-399 points; Honorable Mention 300-349 points; and, No Award - below 299 points.

Size. The participating high schools were categorized by MIPA's overall school size with the following student population categories: extra-large schools $1,700+$ students; large schools 1,201-1,700 students; medium schools 701-1,200 students; and, small schools 1-700 students (MIPA, 2019).

Only All-Missouri advisers were selected to participate in the study. The participants represented multiple school sizes from all four quadrants of the state. The non-random selection of the All-Missouri advisers throughout the last two years provided for the selection of some of Missouri's most effective advisers. Thus, the participant selection and practical issues were strategic to ensure adequate sampling of advisers from all school sizes from parts of Missouri (Krueger \& Casey, 2015).

\section{Respondent Data}

The study's participants were All-Missouri advisers from MIPA's membership; however, the data reflects a variety of certifications. The Missouri Department of Elementary and Secondary Education (DESE) provides three methods of certification for educators to become high school journalism advisers (DESE, 2019):

a.) Complete Journalism Education coursework at a college/university, including passing the Journalism Missouri Educator Gateway Assessment (MEGA).

b.) Pass the MEGA in the Journalism field (Fall 2016).

c.) Add on journalism certification if already a state certified teacher in an English subject area (Fall 2017). 
The following tables show the expertise of the advisers in the study. Many of the respondents have worked at their current location for an extended period of time, and a number of them have been employed at only one school. Their length of experience and continued education indicate a pride in the school and a passion for the work. The tables further demonstrate those surveyed are not just advisers, but also life-long learners who strive to be leaders in their field.

Tables 1, 2, 3, and 4 illustrate each advisers location, school size and designated pseudonym as follows: E names represent extra-large (XL) schools 1,700+ students; L names represent large (L) schools 1,201-1,700 students; M names represent medium (M) schools 701-1,200 students; and, S names represent small (S) schools 1-700 students.

Table 1.

Northwest quadrant location, school size, and adviser pseudonym

\begin{tabular}{|c|c|c|}
\hline Region & $\underline{\text { Size }}$ & $\underline{\text { Name }}$ \\
\hline NW & $\mathrm{S}$ & Sam \\
\hline NW & M & Madison \\
\hline NW & $\mathrm{L}$ & Lucy \\
\hline NW & $\mathrm{L}$ & Leah \\
\hline NW & $\mathrm{L}$ & Lucas \\
\hline NW & $\mathrm{XL}$ & Ellen \\
\hline NW & $\mathrm{XL}$ & Elizabeth \\
\hline NW & XL & Emma \\
\hline
\end{tabular}


Table 2.

Northeast quadrant location, school size, and adviser pseudonym

\begin{tabular}{|c|c|c|}
\hline Region & $\underline{\text { Size }}$ & Name \\
\hline $\mathrm{NE}$ & $\mathrm{S}$ & Sandy \\
\hline $\mathrm{NE}$ & $\mathrm{M}$ & Mary \\
\hline $\mathrm{NE}$ & $\mathrm{M}$ & Mia \\
\hline $\mathrm{NE}$ & $\mathrm{L}$ & Laura \\
\hline $\mathrm{NE}$ & XL & Emily \\
\hline
\end{tabular}

Table 3.

Southwest quadrant location, school size, and adviser pseudonym

\begin{tabular}{|c|c|c|}
\hline Region & $\underline{\text { Size }}$ & Name \\
\hline SW & $\mathrm{S}$ & Sally \\
\hline SW & $\mathrm{L}$ & Lexy \\
\hline SW & $\mathrm{L}$ & Liza \\
\hline SW & XL & Elise \\
\hline SW & XL & Eli \\
\hline SW & XL & Erin \\
\hline SW & XL & Eva \\
\hline
\end{tabular}

Table 4.

Southeast quadrant location, school size, and adviser pseudonym

\begin{tabular}{ccc}
\hline Region & $\underline{\text { Size }}$ & Name \\
SE & S & Sloane \\
SE & S & Sally \\
SE & L & Lydia \\
SE & XL & Eleanor \\
\hline
\end{tabular}


Table 5 reflects the total years of experience and continuity ranging from three to 27 years. Many of the educators started teaching in their respective schools and continue to do so throughout career.

Table 5.

Total Years of Teaching Experience

\begin{tabular}{|c|c|c|c|}
\hline$\underline{\text { Name }}$ & $\begin{array}{c}\text { Total } \\
\text { Years } \\
\text { Teaching }\end{array}$ & $\begin{array}{c}\text { Total Years } \\
\text { Teaching } \\
\text { Journalism }\end{array}$ & $\begin{array}{c}\text { Total Years } \\
\text { Teaching Journalism } \\
\text { at Current High } \\
\underline{\text { School }}\end{array}$ \\
\hline Eleanor & 10 & 10 & 10 \\
\hline Eli & 16 & 16 & 16 \\
\hline Elise & 18 & 18 & 13 \\
\hline Elizabeth & 3 & 3 & 3 \\
\hline Ellen & 29 & 29 & 23 \\
\hline Emily & 31 & 16 & 16 \\
\hline Erin & 12 & 10 & 4 \\
\hline Eva & 15 & 12 & 12 \\
\hline Emma & 19 & 19 & 19 \\
\hline Leah & 20 & 14 & 14 \\
\hline Lexy & 9 & 3 & 3 \\
\hline Laura & 9 & 7 & 7 \\
\hline Liza & 16 & 13 & 13 \\
\hline Lucas & 25 & 25 & 25 \\
\hline Lucy & 20 & 20 & 20 \\
\hline Lydia & 6 & 6 & 5 \\
\hline Madison & 3 & 2 & 2 \\
\hline Mary & 37 & 33 & 27 \\
\hline Mia & 11 & 8 & 9 \\
\hline Sally & 10 & 3 & 3 \\
\hline Sarah & 15 & 15 & 13 \\
\hline Sam & 8 & 8 & 8 \\
\hline Sandy & 23 & 21 & 8 \\
\hline Sloane & 15 & 15 & 10 \\
\hline
\end{tabular}


Table 6 shows the advisers' educational background. All the advisers obtained a bachelor's degree. Of those, one adviser had two bachelor degrees, another had two master's degrees, and two had doctoral degrees.

Table 6.

Education Background

\begin{tabular}{cccc}
\hline Name & $\begin{array}{c}\text { Bachelor's } \\
\text { Degree }\end{array}$ & $\begin{array}{c}\text { Master's } \\
\text { Degree }\end{array}$ & $\begin{array}{c}\text { Doctoral } \\
\text { Degree }\end{array}$ \\
Eleanor & 1 & 2 & 0 \\
Eli & 1 & 1 & 0 \\
Elise & 1 & 1 & 0 \\
Elizabeth & 1 & 0 & 0 \\
Ellen & 1 & 1 & 0 \\
Emily & 1 & 1 & 0 \\
Erin & 1 & 1 & 0 \\
Eva & 1 & 1 & 0 \\
Emma & 1 & 1 & 0 \\
Leah & 2 & 1 & 0 \\
Lexy & 1 & 1 & 1 \\
Laura & 1 & 1 & 0 \\
Liza & 1 & 0 & 0 \\
Lucas & 1 & 1 & 0 \\
Lucy & 1 & 1 & 0 \\
Lydia & 1 & 1 & 0 \\
Madison & 1 & 0 & 0 \\
Mary & 1 & 1 & 1 \\
Mia & 1 & 2 & 0 \\
Sally & 1 & 1 & 0 \\
Sarah & 1 & 1 & 0 \\
Sam & 1 & 0 & 0 \\
Sandy & 1 & 1 & 0 \\
Sloane & 1 & 1 & 0 \\
\hline
\end{tabular}


Tables 7, 8, and 9 illustrate the adviser's certification areas, which vary

significantly. The advisers ranged from being certified in one to five areas, with one-third lacking any journalism certification.

Table 7.

Certification Background

\begin{tabular}{|c|c|c|c|c|}
\hline Name & $\begin{array}{c}\text { JEA } \\
\text { Certified } \\
\text { Journalism } \\
\text { Educator }\end{array}$ & $\begin{array}{c}\text { JEA } \\
\text { Master } \\
\text { Certified } \\
\text { Educator } \\
\end{array}$ & $\begin{array}{c}\text { DESE } \\
\text { Journalism } \\
\text { Certified }\end{array}$ & $\begin{array}{c}\text { English } \\
\text { Education } \\
\text { Certified }\end{array}$ \\
\hline Eleanor & 1 & 0 & 1 & 1 \\
\hline Eli & 0 & 0 & 0 & 0 \\
\hline Elise & 1 & 0 & 1 & 0 \\
\hline Elizabeth & 0 & 0 & 0 & 1 \\
\hline Ellen & 1 & 0 & 1 & 1 \\
\hline Emily & 1 & 1 & 1 & 1 \\
\hline Erin & 1 & 0 & 1 & 1 \\
\hline Eva & 1 & 0 & 0 & 0 \\
\hline Emma & 0 & 0 & 1 & 1 \\
\hline Leah & 0 & 0 & 0 & 1 \\
\hline Lexy & 0 & 0 & 0 & 1 \\
\hline Laura & 0 & 0 & 1 & 1 \\
\hline Liza & 0 & 0 & 0 & 1 \\
\hline Lucas & 1 & 0 & 1 & 1 \\
\hline Lucy & 0 & 1 & 1 & 1 \\
\hline Lydia & 1 & 0 & 0 & 1 \\
\hline Madison & 0 & 0 & 1 & 1 \\
\hline Mary & 1 & 0 & 1 & 1 \\
\hline Mia & 1 & 0 & 1 & 1 \\
\hline Sally & 0 & 0 & 0 & 2 \\
\hline Sarah & 0 & 0 & 1 & 1 \\
\hline Sam & 0 & 0 & 0 & 1 \\
\hline Sandy & 0 & 0 & 0 & 0 \\
\hline Sloane & 1 & 0 & 1 & 0 \\
\hline
\end{tabular}


Table 8 .

\begin{tabular}{|c|c|c|c|c|}
\hline \multicolumn{5}{|c|}{ Certification Background (continued) } \\
\hline \multirow[t]{3}{*}{ Name } & Business & Vocational & Spanish & 7- 12 \\
\hline & Education & Career & $\underline{\text { Certified }}$ & Guidance \\
\hline & Certified & Certified & & $\begin{array}{c}\text { Counseling } \\
\text { Certified }\end{array}$ \\
\hline Eleanor & 0 & 0 & 0 & 1 \\
\hline Eli & 1 & 0 & 0 & 0 \\
\hline Elise & 0 & 0 & 0 & 0 \\
\hline Elizabeth & 0 & 0 & 0 & 0 \\
\hline Ellen & 0 & 0 & 0 & 0 \\
\hline Emily & 0 & 0 & 0 & 0 \\
\hline Erin & 0 & 0 & 0 & 0 \\
\hline Eva & 0 & 0 & 1 & 0 \\
\hline Emma & 0 & 0 & 0 & 0 \\
\hline Leah & 0 & 0 & 0 & 0 \\
\hline Lexy & 0 & 0 & 0 & 0 \\
\hline Laura & 0 & 0 & 0 & 0 \\
\hline Liza & 0 & 0 & 0 & 0 \\
\hline Lucas & 0 & 0 & 0 & 1 \\
\hline Lucy & 0 & 0 & 0 & 0 \\
\hline Lydia & 0 & 0 & 0 & 0 \\
\hline Madison & 0 & 0 & 0 & 0 \\
\hline Mary & 0 & 0 & 0 & 0 \\
\hline Mia & 1 & 0 & 0 & 0 \\
\hline Sally & 0 & 0 & 0 & 0 \\
\hline Sarah & 0 & 0 & 0 & 0 \\
\hline Sam & 0 & 0 & 0 & 0 \\
\hline Sandy & 1 & 1 & 0 & 0 \\
\hline Sloane & 1 & 1 & 0 & 0 \\
\hline
\end{tabular}


Table 9.

Certification Background (continued)

\begin{tabular}{|c|c|c|c|c|}
\hline$\underline{\text { Name }}$ & $\begin{array}{c}\text { Speech and } \\
\text { Debate/Theater } \\
\text { Certified }\end{array}$ & $\begin{array}{c}\text { PE } \\
\text { Health } \\
\text { Certified } \\
\end{array}$ & $\begin{array}{c}\text { Principal } \\
7-12 \\
\text { Certified } \\
\end{array}$ & $\begin{array}{c}\text { Art } \\
\text { Certified }\end{array}$ \\
\hline Eleanor & 1 & 0 & 0 & 0 \\
\hline Eli & 0 & 0 & 0 & 0 \\
\hline Elise & 0 & 0 & 0 & 0 \\
\hline Elizabeth & 1 & 0 & 0 & 0 \\
\hline Ellen & 0 & 0 & 0 & 0 \\
\hline Emily & 0 & 0 & 0 & 0 \\
\hline Erin & 1 & 0 & 0 & 0 \\
\hline Eva & 1 & 0 & 0 & 0 \\
\hline Emma & 0 & 0 & 0 & 0 \\
\hline Leah & 1 & 0 & 1 & 0 \\
\hline Lexy & 0 & 0 & 0 & 0 \\
\hline Laura & 0 & 0 & 0 & 0 \\
\hline Liza & 0 & 0 & 0 & 0 \\
\hline Lucas & 0 & 0 & 0 & 0 \\
\hline Lucy & 0 & 0 & 0 & 1 \\
\hline Lydia & 0 & 0 & 0 & 0 \\
\hline Madison & 1 & 0 & 0 & 0 \\
\hline Mary & 0 & 0 & 1 & 0 \\
\hline Mia & 0 & 1 & 0 & 0 \\
\hline Sally & 0 & 0 & 0 & 0 \\
\hline Sarah & 0 & 0 & 0 & 0 \\
\hline Sam & 0 & 0 & 0 & 0 \\
\hline Sandy & 0 & 0 & 0 & 0 \\
\hline Sloane & 0 & 0 & 0 & 0 \\
\hline
\end{tabular}


Tables 10 and 11 illustrate journalism classes taught. The extra-large schools tend to teach fewer journalism courses. Small schools all teach yearbook with other classes.

Table 10

Journalism Classes Taught in 2019-20

\begin{tabular}{|c|c|c|c|c|}
\hline$\underline{\text { Name }}$ & Yearbook & $\underline{\text { Broadcast }}$ & Online News & $\begin{array}{l}\text { Live Sports } \\
\text { Broadcast }\end{array}$ \\
\hline Eleanor & $X$ & $X$ & $X$ & \\
\hline Eli & & X & X & \\
\hline \multicolumn{5}{|l|}{ Elise } \\
\hline Elizabeth & $\mathrm{X}$ & & & \\
\hline Ellen & & X & & \\
\hline Emily & X & X & & \\
\hline Erin & $\mathrm{X}$ & $\mathrm{X}$ & $\mathrm{X}$ & \\
\hline Eva & X & & $\mathrm{X}$ & \\
\hline Emma & & & X & \\
\hline Leah & & $\mathrm{X}$ & $\mathrm{X}$ & $\mathrm{X}$ \\
\hline Lexy & $X$ & & & \\
\hline Laura & $\mathrm{X}$ & & & \\
\hline Liza & & $\mathrm{X}$ & $\mathrm{X}$ & \\
\hline Lucas & & & $\mathrm{X}$ & \\
\hline Lydia & $X$ & & $\mathrm{X}$ & \\
\hline Lucy & & $\mathrm{X}$ & & $\mathrm{X}$ \\
\hline Madison & $\mathrm{X}$ & $X$ & $\mathrm{X}$ & \\
\hline Mia & & & $\mathrm{X}$ & \\
\hline Mary & $X$ & & & \\
\hline Sally & $X$ & & & \\
\hline Sam & $X$ & & & \\
\hline Sandy & $X$ & $X$ & & \\
\hline Sarah & $X$ & & $\mathrm{X}$ & \\
\hline Sloane & $X$ & & & \\
\hline
\end{tabular}


Table 11.

Journalism Classes Taught (continued)

\begin{tabular}{|c|c|c|c|}
\hline Name & Newspaper & $\begin{array}{c}\text { News } \\
\text { Magazine } \\
\end{array}$ & $\underline{\text { Journalism }}$ \\
\hline Eleanor & & & $\mathrm{X}$ \\
\hline \multicolumn{4}{|l|}{ Eli } \\
\hline Elise & $X$ & & $X$ \\
\hline \multicolumn{4}{|l|}{ Elizabeth } \\
\hline \multicolumn{4}{|l|}{ Ellen } \\
\hline Emily & $X$ & & $X$ \\
\hline Erin & & $X$ & $X$ \\
\hline Eva & & $X$ & $X$ \\
\hline Emma & $X$ & & \\
\hline Leah & & & $X$ \\
\hline Lexy & & $X$ & \\
\hline Laura & $X$ & $X$ & $X$ \\
\hline Liza & & & $X$ \\
\hline Lucas & $X$ & $X$ & $X$ \\
\hline Lydia & & $X$ & $X$ \\
\hline Lucy & $X$ & $X$ & $X$ \\
\hline Madison & & & $\mathrm{X}$ \\
\hline Mia & $X$ & $X$ & $X$ \\
\hline \multicolumn{4}{|l|}{ Mary } \\
\hline \multicolumn{4}{|l|}{ Sally } \\
\hline Sam & & $X$ & $X$ \\
\hline \multicolumn{4}{|l|}{ Sandy } \\
\hline Sarah & $X$ & & \\
\hline Sloane & & & \\
\hline
\end{tabular}


Tables 12 and 13 show the courses advisers teach that are not journalism classes.

The majority of advisers teach English and Advanced English courses.

Table 12.

Other Classes Taught in 2019-20

\begin{tabular}{|c|c|c|c|c|}
\hline$\underline{\text { Name }}$ & English & $\begin{array}{c}\text { Adv. } \\
\text { English }\end{array}$ & $\begin{array}{l}\text { Speech } \\
\text { Debate }\end{array}$ & Theatre \\
\hline Eleanor & $X$ & & $\mathrm{X}$ & $\mathrm{X}$ \\
\hline \multicolumn{5}{|l|}{ Eli } \\
\hline Elizabeth & $X$ & & & \\
\hline \multicolumn{5}{|l|}{ Elise } \\
\hline \multicolumn{5}{|l|}{ Ellen } \\
\hline Emily & $X$ & & & \\
\hline \multicolumn{5}{|l|}{ Erin } \\
\hline \multicolumn{5}{|l|}{ Eva } \\
\hline Emma & $\mathrm{X}$ & $X$ & & \\
\hline Leah & $\mathrm{X}$ & & & \\
\hline Lexy & $\mathrm{X}$ & $\mathrm{X}$ & & \\
\hline \multicolumn{5}{|l|}{ Laura } \\
\hline \multicolumn{5}{|l|}{ Liza } \\
\hline Lucas & $X$ & $X$ & & \\
\hline Lucy & $X$ & & & \\
\hline Lydia & $X$ & & & \\
\hline Madison & $X$ & & $X$ & \\
\hline \multicolumn{5}{|l|}{ Mary } \\
\hline Mia & $X$ & $X$ & $\mathrm{X}$ & \\
\hline Sally & & & $X$ & $\mathrm{X}$ \\
\hline Sam & $X$ & $X$ & & \\
\hline \multicolumn{5}{|l|}{ Sandy } \\
\hline Sarah & $\mathrm{X}$ & & $X$ & \\
\hline Sloane & & & & \\
\hline
\end{tabular}


Table 13.

Other Classes Taught (continued)

\begin{tabular}{|c|c|c|c|}
\hline \multirow{2}{*}{\multicolumn{4}{|c|}{$\frac{\text { Name }}{\text { Eleanor }}$}} \\
\hline & & & \\
\hline \multicolumn{4}{|l|}{ Eli } \\
\hline \multicolumn{4}{|l|}{ Elizabeth } \\
\hline \multicolumn{4}{|l|}{ Elise } \\
\hline Ellen & $X$ & & \\
\hline \multicolumn{4}{|l|}{ Emily } \\
\hline \multicolumn{4}{|l|}{ Erin } \\
\hline \multicolumn{4}{|l|}{ Eva } \\
\hline \multicolumn{4}{|l|}{ Emma } \\
\hline Leah & $X$ & & \\
\hline \multicolumn{4}{|l|}{ Lexy } \\
\hline \multicolumn{4}{|l|}{ Laura } \\
\hline Liza & $X$ & & \\
\hline \multicolumn{4}{|l|}{ Lucas } \\
\hline \multicolumn{4}{|l|}{ Lucy } \\
\hline \multicolumn{4}{|l|}{ Lydia } \\
\hline \multicolumn{4}{|l|}{ Madison } \\
\hline \multicolumn{4}{|l|}{ Mary } \\
\hline \multicolumn{4}{|l|}{ Mia } \\
\hline Sally & $X$ & & \\
\hline \multicolumn{4}{|l|}{ Sam } \\
\hline Sandy & & & $X$ \\
\hline \multicolumn{4}{|l|}{ Sarah } \\
\hline Sloane & & $X$ & $X$ \\
\hline
\end{tabular}




\section{Data Collection Tools}

The researcher used the study's criteria to select 24 journalism news labs with representation from each of Missouri's four geographic quadrants. This qualitative study explored advisers' leadership interpretations, perspectives, and experiences (Creswell, 2014; Merriam, 2015). After IRB approval from the University of Missouri, the researcher triangulated data through a series of systematic observations, interviews, and artifact review (Appendix A, Creswell, 2016; Merriam \& Tisdell, 2016).

Data were collected from 24 respondents via interviews, observations, and artifacts during a two-month period (Appendix B). Secondary schools were selected from MIPA's All-Missouri advisers from the past two years. Permission was acquired from MIPA through an email to gain access to their data base (Appendix C).

Additionally, the MIPA Director provided the MIPA's member's contact information. The initial research stage addressed scheduling interviews to gain advisers leadership perspectives. Participants were contacted by email to set up and confirm the personal interviews (Appendix D \& E).

Twenty-three interviews took place at high school journalism news labs and one by phone. At the beginning of each interview, the researcher received the adviser's consent for the study and permission to audio record (Appendix F). Each interview was recorded and then transcribed verbatim. The interview questions were based upon the research questions and focused on editorial leadership, teaching journalism, and advising their various news labs (Appendix G). The conceptual framework influenced this stage through Kouzes and Posner's practices of transformational leadership, which guide leaders "to get extraordinary things done" (Kouzes \& Posner, 1987, p. 9). The interviews 
were designed in a semi-structured nature, so that the researcher could keep some control of the proceedings, while participants were able to "pursue their own interests" (HesseBiber, 2004, p. 277). The original goal of the study was to strive to collect data from 20 advisers throughout all four quadrants. Although saturation occurred after fourteen interviews, the researcher had 24 advisers participate in the study to ensure all high school sizes and quadrants were represented.

Throughout each interview, the adviser observed social behaviors in the news lab as they occurred by gathering field notes. At no time did the researcher interfere or include herself as an active member of the advisers' culture during situations of day-today operations. The researcher focused on the advisers' actions connected to both the person and the professional position and the news lab environment. The observations further explored the advisers' leadership pedagogy "that the body, history, and power are doubly articulated in classrooms" (Bell \& Blaeuer, 2006, p. 18). Therefore, both the role of leadership and editorial leadership skills were explored in the advisers' news lab setting. Current artifacts of the adviser's curriculum, assignments, student publications, and productions were also reviewed. The purpose was to further observe how the adviser's editorial leadership aspects reflected students' work. The documents enabled the researcher to obtain the language and words of the participants. Also, it was a way for the advisers to directly share their instructional reality (Creswell, 2014).

\section{Data Analysis}

The qualitative study analysis systematically incorporated reliable and valid strategies through the triangulated data. Validity was increased using interviews, artifact analysis, and observations (Yin, 2003). The researcher gathered data from interviews, 
observations, and artifacts to enhance the researcher's ability to assess the findings' accuracy (Creswell, 2014).

Throughout the data analysis process, all relevant evidence was valued and treated fairly in order to produce compelling conclusions (Yin, 2003). Furthermore, the study's qualitative research produced a vast amount of data, so it was important to have the data organized to allow for timely analysis (Creswell, 2007; Merriam, 1998).

The data analysis process ensued immediately after collection of the data (Merriam, 1998). Transcriptions were made of all the interviews. Once all transcriptions were completed, the researcher emailed each adviser to ensure the validity and reliability of their background data was correct. The accuracy check provided participants the opportunity to review the data for accuracy (Merriam, 1998).

The researcher read through transcriptions and noted common trends and themes. Then, "working back and forth between the themes and data" until a "comprehensive set of themes" surfaced. Next, the researcher ensured the participants' voices were clear to make recommendations (Creswell, 2014, p. 186). Various themes emerged, were assigned codes, and were labeled on the transcripts. The practice of coding included the identification of each item in the research and then organizing them into individual themes (Creswell, 2007; Emerson, 1995; Merriam, 1998). Initial codes were determined by connecting aspects of the five research questions. The coding process allowed for the identification of emergent themes and was completed in a logical manner and conducted by the researcher in order to increase consistency throughout the data (Creswell, 2007; Merriam, 1998; Yin, 2003). Themes and patterns were established through checked transcripts, field notes and artifacts. Next, the themes were connected to the research 
questions. Finally, the researcher began the process of answering the research questions through further analysis and the triangulation of data. Triangulation refers to the use of various sources of data and of data collection methods to confirm the emergence of data (Creswell, 2007; Fowler, 2008). The implementation of triangulation increased the reliability and validity of the data collected during the study (Creswell, 2007; Fowler, 2008; Merriam, 1998). The researcher completed this process to have a systematic and meaningful conclusion within the findings. Furthermore, Stake (1995) suggested qualitative data should be interpreted as a reflective process and a researcher should be committed to the reevaluation process and continually reinterpret the data. Thus, the data analysis process was ongoing throughout the research study and through the use of multiple sources of data for a clearer picture to capture and identify the key elements of editorial leadership.

\section{Limitations, Assumptions and Design Controls}

In this research study, certain limitations were considered. The researcher prepared for those possible occurrences in the setting, study design, participants, limited resources and the process of analysis.

\section{Limitations}

The researcher identified possible considered limitations that could have impacted the magnitude and scope of the study. Although these limitations were minor when compared to the greater impact of the study, they are still worth discussing. Particularly, the limitations included the fact that many advisers within small high schools worked an overload schedule with before and after school duties, which did not provide them with ample time to connect for an interview. 
Advisers were ready to showcase other advisers' leadership strengths and shared many additional contacts; however, many were outside of MIPA awardees. Furthermore, the researcher's past experience did not cause bias. Rather than a hinderance, it was a positive as the researcher was able to instantly understand the adviser's culture and language.

A limitation of the study was that the data collected were only representing responses from Missouri high schools' advisers, so the responses may not be completely replicable to other areas of the country. However, as a qualitative study, the goal was to not generalize to all journalism advisers. Another limitation included the researcher's bias toward perspectives of advisers, given that the researcher was previously an awardwinning adviser for over a decade within urban, rural and suburban districts. The researcher did her best to remain objective in her interpretation and analysis of data and not allow personal bias to interfere with results.

\section{Design Control Challenges}

The researcher piloted the questions in an alternate setting, taking into account feedback from pilot participants, and revised accordingly. Additionally, the researcher interpreted the complex and varied data by remaining objective and keeping the emphasis on the views of the participants. Regarding the study's design control, since the research was a qualitative study, the researcher collected the data in a natural setting. The researcher conducted the interviews face to face in the environment where the participants were employed to observe behaviors and actions of the participants in their own context (Creswell, 2014). Many sources of data collection were used such as interviews, artifacts, and observations. Data were organized inductively by building and organizing patterns and themes from responses and then deductively determining whether 
themes were justified (Creswell, 2014). The research process was an emergent design, also consistent with qualitative research. The plan for the research was flexible, as phases of the process can shift or change (Creswell, 2014). Therefore, the researcher strived "to be comfortable with the ebb and flow of a qualitative investigation and trust in the process" (Merriam \& Tisdell, 2016, p. 18).

The study undertook significant constraints on scholarly resources, which specifically address editorial leadership. The researcher originally set out to identify several examples in editorial leadership; however, it became evident that there were limited resources on the topic. Therefore, the researcher instead looked for patterns in available research on best practices in journalism leadership development in professional newsrooms and higher education. In writing this paper, limited resources led to a further constraint on what the researcher could use to reasonably define editorial leadership. Therefore, there was a profound need to gather qualitative data to reflect best practices in editorial leadership.

\section{Summary of Findings and Answered Research Questions}

As previously mentioned, this study explored the editorial leadership practices of scholastic journalism advisers who teach editorial leadership in Missouri secondary schools. This section will answer the research questions that guided this study. The major segments of this section summarize the findings and discuss their implications. Specifically, recommendations will be directed toward practitioners in the field and professionals interested in pursuing additional research to exceed the scope and findings of this study. 


\section{Summary of Findings}

This study identified the significant role leadership plays in Missouri high school scholastic journalism programs. When an adviser established leadership, news lab production increased, creativity was fostered, and decision making was delegated to the students. Thus, advisers revealed leadership skills are important in journalism education. Advisers shared soft skills provided opportunities for students to grow into leaders. The student leaders then provided advisers opportunities to articulate their passion and genuine conviction. The advisers interviewed for this study were transformational leaders, creating trust and consensus around their news lab's common vision (Northouse, 2016). A majority of transformational leadership theory components were present within Missouri's scholastic journalism news labs. Kouzes and Posner's (1987) fundamental practice of inspiring a shared vision was the most utilized.

This study's findings were based upon collected data via interviews, observations, and artifacts. The interviews consisted of 24 MIPA All-Missouri advisers from Missouri's high schools from 2017 to 2019 . For any interested party, the full results organized thematically, which include a deeper level of analysis and more evidence in the form of quotations garnered from the study, will be provided in Appendix $\mathrm{H}$.

The purpose of the study was to gain knowledge and insight, and reveal editorial leadership teaching methods. The researcher investigated Missouri's news labs by citing skills students could gain from participating in leadership training programs. This study showcased adviser leadership dynamics involved in producing news while in educational environments, as well as the challenges of training, educating and building student leaders. 
Throughout the entire period of the study, leadership played a role in K-12 journalism education in a variety of ways. Leadership has an established role in journalism education throughout Missouri. Advisers use transformational processes to influence their news labs and meet production goals. As seen through all the interviews, advisers had established leadership positions and training. All advisers interviewed continually articulated the role of leadership throughout their news lab. The leadership of each adviser was clear throughout deadlines, work sessions, and decision making.

In addition, this study addressed the editorial leadership gaps that exist between secondary education news labs and professional newsrooms. A majority of transformational leadership theory components were present within Missouri's scholastic journalism news labs; shared vision was the most used. When advisers were asked to recall peak leadership experiences, the interviews revealed similar patterns of transformational behavior, such as idealized influence, inspirational motivation, individualized consideration, and innovative creativity. The data indicated as advisers utilized transformational behaviors related to Kouzes and Posner's Fundamental Leadership Practices, scholastic journalism news labs improved production, creativity, relationships, and standards of excellence (Kouzes \& Posner, 2002).

With this study, the researcher discovered skills to assist journalism educators by exploring scholastic journalism advisers' effective practices in teaching editorial leadership. In reviewing the successful methods, advisers teach soft skills training after first teaching ethics and hard skills. The soft skills, when fully developed, created the most successful news lab environments. 
Additionally, journalism advisers teach leadership skills throughout years of development. Through observation, interviews, and artifacts, it was evident advisers begin teaching leadership by engaging a community of learners and establishing partnerships throughout their news labs. Over time, they progressively building upon each student's strengths.

Essentially, in a safe environment, journalism advisers teach towards student strengths to develop healthy news lab partnerships. These partnerships are healthy when there are clearly defined roles. The leaders and staff are set in roles to have effective workflow structure, where production is delegated and processes are honored. The data provided were clear: teaching leadership presents rigorous opportunities for students to transform into leaders. Also, advisers developing leadership skills motivates students to exhibit desirable qualities in order to promote news lab goals, enforce high expectations, and discover their leadership potential.

In reviewing the results of the study, successful high school advisers exhibit a vital need to teach leadership skills. Respondents clarified their genuine convictions for students to master said skills. Advisers teach leadership skills to not only meet production goals, but to provide opportunities for students to become leaders. As seen through all the interviews, advisers are motivated to teach leadership and have a passion to develop their students. Ultimately, high school advisers distinguish teaching leadership as a fundamental way to empower students. Leadership skills provide advisers opportunities to articulate their passion and genuine convictions with their students. The taught leadership skills provide a shared vision for the news lab's passion for journalism, and 
the need to practice journalism and apply editorial leadership skills as they continue to learn.

The study's findings will be presented to administration, teachers and, ultimately, students to encourage and inspire future journalism leaders. This study may lead to recommendations for actionable editorial leadership training, policy and change within Missouri's high school journalism educators' curriculum. Additionally, acknowledging the significant role of journalism education in academic growth, this study stressed the need for school districts and higher education to invest in scholastic journalism initiatives.

\section{Research Questions Answered}

The following section answers the research questions that guided the study:

\section{RQ1 What role does leadership play in K-12 journalism education?}

Leadership plays a significant role in K-12 journalism education to empower students. The role of leadership empowered students to be trusted and effectively meet expectations on their own. The advisers interviewed for this study created trust and consensus around their news lab's common vision to inspire students. The importance of this role was evident in supporting the students to do their best and reach their goals.

Empowering students does not happen overnight. Leadership training plays an important role within the news labs, as advisers in this study specifically establish not only leadership positions among their staffers, but create training as well. Advisers considered the role of leadership as a behavioral process influencing their students towards set goals. As such, advisers have the dual function of steering their students to produce a high-quality product while ensuring strong student relationships. Overall, when 
leadership is exhibited the adviser is striving for an established goal through built trust and built consensus.

\section{Inspiring Students Toward Goals}

When asked, "How do you inspire a shared leadership vision?” the advisers disclosed concepts directing the news lab's overall production workflow. In fact, leadership plays such a strong role among news lab practices that all of the advisers articulated the importance of teaching leadership in deadlines, work sessions, and decision making. The advisers in this study built their award-winning practices off one common foundational component: a vision statement. Advisers and students developing their vision together demonstrates the significant role leadership plays in news labs.

Advisers and students gain a mutual understanding of their goals through collaborating on a vision. Advisers inspire their students to work with them to create success. Effective advisers shared they have a clear outline of goals and what they need to accomplish through their vision. Leadership plays a supporting role in helping advisers establish common goals to motivate their student productions. Advisers considered leadership as a behavioral process that influences their students and whole news lab towards set goals. As such, an adviser has the dual function of ensuring each student's satisfaction while steering the news lab to success.

Advisers revealed that leadership skills can be taught, practiced and improved. An adviser's primary role is to enable the success of everyone in the news lab. All the advisers commented they continually appealed to each student by articulating production goals and their editors pronounced their shared vision to their news lab. The data 
supported the benefits of inspiring creativity and loyalty because it is helpful for effective production.

Effective advisers explained they share their production goals with their students by calling it a vision. The vision is used to raise the students' aspirations and devise a plan for what they want to become. Common news lab slogans, positions, and procedures are essential for advisers to influence their students effective production. Advisers use their news lab motto to inspire their entire staff. Students will consult their shared vision for what to do, or say to make sure all they do meet the mottos ideals.

News labs develop leadership beliefs in purposeful ways. At the beginning of each school year, advisers facilitate traditions for students to create their news lab motto. The advisers lead their student editors to decide on a catch phrase and ideas to motivate their news lab. All the interviews, observations, and artifacts revealed news lab mottos were promoted through room decorations, posters, student t-shirts, and the overall news lab productions. Some of the advisers reported they reach outside of their news lab through books, music, and social media for their news lab inspiration. Advisers went as far as to facilitate their traditions at national conferences, leadership retreats, leadership retreats, and boot camps. These camps and retreats are structured to provide the student editors training to make the motto for the upcoming year. There was not one specific way to do this, but once the school year began, each news lab motivated the students through the continued use of their common vision. The different mottos enforced the news lab's shared vision. The data revealed many news lab mottos, including: Story is King, Create Magic, Hands off, Journalist 24/7, Beacon of Light, Make Good Choices, Get Out of the 
Way, Everyone has a Story, Be Coachable, For Us by Us, News For Students by Students, and Journalism Matters.

Specifically, Liza's "Story is King" motto inspires her students to reach their goal to focus on the people and places they cover in stories. She commented that her news lab earned her trust by continually producing high quality work. She explained, "Story is king. If students can't tell me a good story with a beginning and middle and end, I don't care how much your camera costs or what you're editing with. Story is what drives everything." The data illustrate the students are invested in their news labs and are empowered to put a name on their work.

Advisers are intentional in designing their shared vision. Elise's student editors attend a summer camp each year. She explained how her shared vision of, "Hands Off" was found during the students' summer camp and translated into having a completely student driven news lab, "My editors organize our coverage. Our staff wants to all be part of our Friday night football games. The editors know where the staffers can be on the field and how to get the good shots. I just love watching. They definitely are like little moms helping our young ones." Elise further stated the editors know their common vision and the staffers can be intimidated, but they mentor them. She said, "They don't mind going to a softball game by themselves because they face their fear and learn how journalism works. It's huge growth that can't be taught in a classroom. Just watching it is perfection. We're showing them how to be leaders."

Similarly, Lucas has his student editors annually attend a national conference to make their motto. Recently, in preparation for their national conference at Disneyland they read the book "Creating Magic: 10 Common Sense Leadership Strategies from a 
Life at Disney" by Lee Cockerell. The book inspired the students to create their catch phrase of Create Magic. He explained how the book led to their news lab's vision to be a wonderful publication:

Disney was their answer because everybody wanted to go to Disney and be part of an idea that it's a wonderful, wonderful world. They wanted that wonderful, wonderful publication. They worked to create that magic and make their publication magic essentially. Something that everyone would want to be a part of and talk about.

The traditions that were put in place for the news lab's motto also helped advisers provide agreed upon structure for positions and procedures. The advisers facilitate their student editors to decide on their assigned editor positions based upon the ideals of their shared vision. Leah believes an understanding of their "News for Students by Students" slogan has transformed her students into their leadership positions. She believes the students understanding of their shared vision elevated the students to take ownership and effectively lead their workflow. Leah explained the vision helps her editors lead. She further explained her students develop their positions and the news lab procedures. As a result, her editors oversee the news lab before she becomes personally involved. She said, "The editors put out the fires all the time. The kids are aware of it and they understand the dynamic of it because they helped decide it." The importance of the student editor position was reflected through interviews as advisers marked time by their editor's name, rather than publication name or date. Throughout interviews advisers referred to their previous editors. For instance, Leah explained how each editor puts their stamp on the year's production, product, and overall morale throughout the news lab. She further 
illustrated, "I've had those great student editors throughout my whole career. Each has been part of a thread of students that have built our program throughout the years."

Advisers believe teaching leadership motivates students. The advisers revealed following a common vision and expectations helps students produce creative work based upon their genuine convictions. Advisers nurture their student leaders who, in turn, further build consensus to nurture a next generation of student leaders. The role of leadership was evident in supporting the students to make their own vision to take ownership and produce a high-quality product. Ultimately, high quality programs have a continuous cycle of leadership development that appears effortless.

\section{Building Trust}

Trusting relationships between advisers and their students are significant in the role of leadership in journalism education. Advisers shared personal connections with their editors helps the news labs' production and their teaching experience. Specifically, the study found that advisers established their most effective student leaders through deliberate processes designed to encourage students in direct and personal ways. Advisers shared strong relationships and ongoing communication maximize the trust throughout their news lab.

Madison believes her editors trust her because she puts trust in them and they feel they have a personal stake in their news lab and it is more than just a class. Other advisers had similar perspectives. Like Madison, Eva commented, "You can actually trust to take the reins off. It is amazing what they will do if you just say, 'I believe in you, go do it and I'm here if you fall down. I probably won't pick you up, but I'm going to be here if you fall down.' It's really cool to just see what they do." 
Establishing Relationships. Through relationships, advisers establish their most effective student leaders. Essentially, the data showed trust boosts a news lab's ability for students to effectively meet expectations on their own. For example, Emily's trust in her students deepened during a long absence. Her editors were able to keep the workflow moving and produce quality work while she was on leave due to a surgery. She shared, "Everything kept moving. I think in education a lot of times, it's the dream of a lot of educators to trust their students to keep moving forward and thrive, even when they are not there." Eva also trusted her editors during a bereavement leave to attend a family funeral. She explained, "Initially, I was filled with anxiety. Then, I realized my editors know the programs and would handle the heavy lifting to keep us moving. When they see me as an adult just going, 'Let's do this,' then I think they learn adaptation skills and that they are trusted." In the same way, when Sloane's baby was soon to be delivered, her first call outside of her family was to her editor-in-chief ensuring the completion of their upcoming deadlines. She further explained how much she trusted and depended upon her editor in that moment throughout the delivery and the following weeks of maternity leave. She commented, "I was not going to be there, and I needed to call her to let her know because we were on deadline. So, it was a little stressful for me, but good to know they were prepared for it and in safe hands with my editor." The role of leadership empowered the students to be trusted and effectively meet expectations on their own.

Open Communication. Trust is built upon ongoing communication. Mia explained, "If our arrows are all pointed in the right direction, we can be a more effective collective." As a result of clearly defining the vision and goals, the staff developed a strong mutual trust. She welcomed conversations on culture, emphasized publication 
importance, developed reasons to care, and desire to participate. Through all of this, she said, "We came to the central idea, 'The bearers of light,' to shine a light on good in the community. The positive we want to see more. Sometimes it means shining a light on things that are like, 'Man, this is really messed up, or this could be better, or how do we create change?' If you're doing it well, you create proof to live your central mission."

Numerous advisers revealed their appreciation and emphasis on the importance of trust. Advisers establish trust through ongoing communication and providing freedoms based upon the news lab's common vision. Earned trust permits students to make independent decisions. Advisers articulated they trust their students to work throughout their news lab and community.

\section{Building Consensus}

Leadership plays a role in advisers building a consensus throughout journalism news labs. After advisers create a common vision and trust, the advisers' role shifts from decision making to empowering students to make decisions. Advisers revealed intentionally influencing news labs towards consensus enhanced their ability to reach goals.

Advisers shared once they first shape the news lab to be productive and creative, the students shape the news lab's goals from a collaborative consensus. Twenty-two advisers shared the fundamental practice of establishing professional habits, where the student editors lead the news lab by, leading budget meetings, enforcing expectations, rubric reviews, and establishing work session goals. Through this student leadership at the beginning of each class time, advisers shared it is much easier to gain consensus. 
In fact, advisers commented they rely on student buy-in to establish leadership roles and encourage proper decision making. Mary explained how the role of leadership helps her trust editor decisions. She explained, "Our editors have the leadership opportunity to stand up for what they believe in. Our kids have great pride and respect for what they do. They know Hazelwood versus Kuhlmeier, and the kids respect that they have the ability to make decisions." Similar to Mary, Elizabeth explained how she builds consensus around journalism values and skills to teach her staff the big picture of future news lab leadership. Elizabeth said, "I can teach you all the skills you need, but you can't teach passion about something, or working hard until it works, because that's a lot of what journalism is. Because you're going to have the bad days, the bad interviews. But when it does finally click and come all together, it's really cool to be part of that with all of my students." So, whether advisers are building consensus around law, ethics, values, morals, or skills, the bottom line is that these learning communities are firmly planted in the solid ground of a common set of higher ideals.

The data revealed the role of leadership generates consensus as advisers and students share convictions for their productions and program. Additionally, Elizabeth continually directs her students towards their shared purpose. Each year, she sees her students return to her news lab. She illustrated, "All come in as novices, but by the time they're done, they'll be an amateur or expert. I feel like if they take my class a second year they become a professional level." The news lab's shared decision making grows students into leaders. Similarly, Elise explained, "I always have my editors as returning staff members. They've been on staff before and know what's expected. I feel like they have a good grasp on it and just have to use their knowledge.” Likewise, Erin believes 
her editors are invested and want their news lab to be a reflection of their agreed upon decisions. She explained:

They have a personal investment in this program. It's not just me, it's not just my program. It doesn't belong to anybody but them. They have that personal stake in

it. I just put some structure to it. They want to have a say in what happens.

Because they know that if they're not there, the kids who are there will decide how to steer the boat and they want that stake in it.

The role of leadership within their news lab supports the students opportunity to invest in their work. Similarly, Leah believes her students are invested and strive to be part of the news lab's big picture, starting at their beginning steps as staffers. She explained, "The editors get it and they understand how they are part of the big picture because they took those first two years and they were in an environment that allowed them to take their time to learn the process to become a leader not only for themselves, but for other people, and other people will want to be them."

Advisers indicated the leading role of leadership within journalism education. It cultivates effective production, encourages creativity, and fosters shared decision making. The role of leadership helps support students empowering their ideas and actions to establish a quality journalism program.

\section{RQ2 What leadership skills are important in K-12 journalism education?}

Leadership skills are important in journalism education. The leadership skills in journalism education can be best analyzed in two distinct categories: hard skills and soft skills. Soft skills are the "people skills" essential for advisers to teach when training students leadership, while hard skills are the "technical tasks" necessary to successfully 
perform camera work and computer software in a news lab. Soft skills are necessary to create a positive and functional work environment as the staffers and editors work. For this reason, advisers teach students soft and hard skills.

Essentially, developing effective hard skills is the first step to teaching leadership skills in news labs. While the summer boot camp and crash course examples provide a glimpse into the urgent need to teach hard skills, advisers implement a key approach to communicate their support as a central leadership facet. On one level, the advisers' support comes from the need to help their students learn to gain the confidence to be leaders. The advisers considered their hands-on support throughout their hard skills training as the most important aspect of beginning to teach leadership.

All the advisers also agreed that hard skills must be mastered to be a news lab leader. A journalism leader must know most aspects of a news lab to lead it. Advisers use a learning process to first lay their foundation through learning hard skills, then become a leader through mastering soft skills. Ultimately, advisers teach leadership by developing the important soft skills of building trust, open communication, establishing relationships, and problem solving.

\section{Essential Expectations}

Key to scholastic journalism's uniqueness is that leadership and soft skills are not dictated within curriculum standards. Advisers can use almost any curriculum and instructional methods they want to teach leadership. Advisers use their independence to craft unique leadership curriculum, resources, and culture. Soft skills are a central part of advisers' leadership training. Sandy explained how soft skills are essential for her news lab: "The basics essentially come down to the soft skills, the people skills. We talk so 
much about them in business classes, but not always in journalism classes. We cover our standards to be on time, help others, set a good example, and be confident."

Soft skills curriculum is taught in high school business classes, but is not addressed in journalism education curriculum. Advisers pride themselves in taking every opportunity to explicitly teach the soft skills of leadership. In fact, all advisers commented they designate students in editor positions throughout their news labs. They provide them with specialized training and duties. Twelve of the advisers responded they used an Editorial Leadership class to teach editors to be leaders. One respondent is working with school district curriculum directors to develop advanced leadership classes. Advisers are teaching leadership skills even though it is not required. Many believe it is the way to create a more functional news lab.

\section{Hard Skills}

When advisers teach leadership, they start by handing students cameras and a tripod to first master their technical skills. While advisers indicated soft skills provide many opportunities for students to grow into leaders, all of the advisers in this study also teach hard skills. The students start during their first class with hard skills then become part of the next generation of leaders through soft skills. All advisers highlighted the importance of initially teaching basic journalism objectives within a student's first weeks to establish the news lab's standards.

Foundational Practical Skills. Hard skills were evident in the observation and artifacts of posters, worksheets and exercises covering areas such as law, ethics, word processing, editing, page-design, audio, photography, and videography. Advisers shared it is important to teach leadership skills by starting with the basics. Many shared they first 
teach the practical skills. There is a need for new students to initially become proficient in hard skills. A student proficient in hard skills is then expected to mentor and teach others in the news lab. Advisers believe it is imperative that once a student learns a hard skill they mentor other students to also become proficient. Elise explained the process: "Once the students learn the basics they start to become a leader in the room. They help and teach new students to take photos or do interviews. That is when you see them becoming leaders because they are communicating and motivating the new students."

Madison explained, "I think it really begins in their first class. The first couple weeks, I really hit it hard the second they walk in the door. In the beginning, it is a traditional teacher-led class as we work through media law, ethics, and basic reporting. Then, it dramatically shifts. Now, the students going out there, interview and do their first stories." Eleanor begins her year similarly, "I work the first four to six weeks of every school year to give them those tools, to build the scaffolding, to build those lessons before I force them out into the world, and say go," she said. Advisers shared they teach hard skills first. More importantly the order matters because journalism skills build upon themselves. Ellen has her students pass a journalism law and ethics test during their first weeks of the class. Her students are not permitted to progress through the class until they pass the exam. Ellen said, "A student needs to know the law and ethics of journalism so they know why we are journalists and what stories to cover. Then they can learn how to use the tools." What each of these advisers' experiences and observations indicate is that hard skills matter because they set the norms and foundation for the news lab's production process. All students are expected to know the basic hard skills before they can progress to continue in the class or have the opportunity to become a leader. 
Technical Practical Skills. Once journalism standards are mastered, advisers teach their students hard skills of shooting, writing, and editing. For instance, Sam sees the importance of hard skills training to the point she requires each of her students to attend a summer journalism boot camp. She explained, "We learn the basics at boot camp and it's all hands on. When the school year starts up, they need the time to constantly work on their spreads to go out and get interviews, to build captions, and to build stories." Sam stressed she provides continual guidance and praise. She further shared perhaps the most important in accomplishing student mastery of hard skills is providing hands-on help to support her staffers. While the students begin to master their hard skills, they begin to also learn soft skills. Advisers shared they are sure to provide hands on teaching throughout the hard skills training. The hands-on training is devised to model soft skills to the new students.

This practice was frequently repeated, and it was the basis for many advisers to implement hard skills. Lydia teaches hard skills as a crash course in the beginning of each fall semester, then launches her news lab into production. She provided hands on teaching throughout by modeling how to communicate, interact, problem solve, and critically think. She explained, "The first deadline is always like a little bit hesitant, so I am sure to provide a lot of hands-on support, which helps a lot because they're always nervous about going and finding kids and interviewing for the first time." The hands-on teaching of hard skills is the first step for the students to experience their leadership training. 


\section{Soft Skills}

Advisers identified soft skills as critical to teaching journalism. While hard skills are necessary to successfully perform the practical and technical tasks in a news lab, soft skills are necessary to create a positive and functional work environment. Elise explained how soft skills training can be devised to move students into being leaders. She said, "That's what I love the most about the process. Knowing the first semester is about laying that foundation for them to be confident enough in their skills to be able to start as a freshman and become part of the next generation of leaders - that is where I get a lot of joy from my job". Throughout students' leadership training they learn the important soft skills of building trust, open communication, establishing relationships, and problem solving.

Building Teamwork. Advisers shared, even throughout their hard skills training, the beginnings of leadership training was subtly reinforced by the adviser's hands on teaching. The new students begin to see the adviser lead the class and begin to work with the advisers coaching and start to become a team. For example, Leah believes her beginner students need support. "In the beginning, there's several basic skills, and then they have to move on and then they think, 'Oh, my gosh, it is so hard,"' she said. Advisers continually gave praise to their first-year students by reinforcing the soft skill of building teamwork. Ellen gave an example of how she strives to not over push the firstyear students as they need praise:

I try really hard to not just focus on what needs to be improved. I really try to focus on, 'Okay so here's what you did really well, and you need to keep doing that but let's look at what do we need to do to improve here? What can we do?' 
And so, they might want to work on their interviewing skills or their voiceover skills or something like that. Then, they will start to identify what they need to work on and that's where I can come in also and say, 'Okay, why don't you try doing this or try doing that?' It's all about starting those conversations.

Ellen praising her students work models for her students the soft skill of teamwork. She shows her students that she cares and appreciates their work through her positive critique. Advisers shared they build teamwork with their news students helping them throughout the news labs' production and their teaching experience. Specifically, the researcher found that advisers established their most effective student leaders through deliberate processes designed to encourage students in direct and personal ways. Advisers shared strong relationships and ongoing communication maximize the teamwork throughout their news lab.

Open Communication. Advisers revealed teamwork is built upon ongoing communication. Advisers articulated a focus on open communication with their editors to create a team. A focus on communication helps advisers create a positive news lab, which is encouraging to students. Ellen's hands-on approach begins to teach the important soft skill of open communication through her praise. Sandy also has a hands-on approach to show the students how to be leaders through her praise. Sandy provided an example: I go out and demonstrate photography to them. I'm always demonstrating to them what they're expected to do. I'm not always telling them, "Here, go do it," until they know the process. Then, once they know the process then they're like, "We got it." Really, they know what they want, they just don't know how to get there. And so, I have to step in, and since they haven't had the background, I have to 
step in and actually get my hands into the work and draw up what I think they want and tweak it. Then, they can go from there.

Sandy's example best illustrates how to use specific words and mottos. During their photography lesson she showed the actions of taking photographs and revealed the words to use to teach the students teamwork skills by providing positive feedback when saying, "We got it". Her communication and social standards are cornerstones in advisers leadership teaching. Sloane illustrates this as she also teaches soft skills. She believes the pedagogy gives her students the opportunity to better communicate and work with other people. "Kids lack the social skills and coping skills because they can just do everything electronically. I do not allow them to do all their interviews by email. I set the standards that interviews must be scheduled to be face-to-face and other basic skills to hone-in those leadership skills." She further explained. "I push them with old school situations to have skills to give criticism and think critically, which you or I have been taught, they lack that very much." Liza echoed professional soft skills dominate much of her students' experiences:

Today, I teach students to write an interview request and turn it in. Ten years ago, kids did that on their own. Now, they can't, and I have to take time and teach how an interview request looks and sounds. I have them practice because they don't think about what to say until the person answers the phone. Then, I have kids that are scared to death to make phone calls. I do think it's kind of weird, but I have to teach them the skills.

Mia explained how she uses soft skills training to help her news lab communicate their goals, "If our arrows are all pointed in the right direction, we can be a more effective 
collective." As a result of clearly communicating their goals, the staff developed a strong mutual trust. She welcomed conversations on culture, emphasized publication importance, developed reasons to care, and instilled a desire to participate. Establishing ongoing communication impacted students and advisers be a team with each other. Their teamwork helps the news lab to reach their goals. Advisers articulated a focus on open communication with their editors to create a culture of trust.

Establishing Relationships. That teamwork builds strong relationships between advisers and their students is worth emphasizing, due to the significance an adviser has in being a leader in journalism education. Through relationships, advisers establish their most effective student leaders. Additionally, the interviews revealed teaching hard skills provided opportunities for veteran-staff members, as student editors, to teach the firstyear students. Many news labs have the new and veteran students work within the same class period and their production time is together. The new and veteran students build rapport with each other. The soft skill of teamwork is instilled through their relationships.

Essentially, teamwork boosts a news lab's ability for students to effectively meet expectations on their own. The advisers' interviews suggested the veteran staff members are provided with the opportunity to teach and support the new students. The veteran students become leaders through this process. Advisers believe it is imperative for students to teach other students once they become proficient at a skill. Leah illustrated this perspective when she explained, "The best way to really learn something is to teach it. And a big way to start learning to be a leader is to help someone learn by showing empathy and working well together." 
Problem Solving Skills. The adviser's leadership expectations helps their students to be independent and gain the self-sufficiency needed in later journalism courses. For example, Eleanor complements each of her student's and builds into their work ethic. She further explained, "The students must determine if journalism is their path. I say, 'If you are the type of student, when given an hour of free time, will sit and just watch Netflix, this is not a path for you. And don't expect me to make you get to work." Eva reminds her students through their work sessions that their work ethic counts. She explained, "Once I tell the staff our objectives, I sit at my desk. If a student has a specific question, they can approach me and I will happily visit. But, I'm not going to walk around the classroom and tap students on the shoulder and say, 'Okay now, you don't have your notebook out. Is that a good choice?' That's not what I'm going to do."

Advisers use soft skills for opportunities to cultivate effective production, encourage creativity, and foster shared decision making. Advisers articulated a focus on open communication with their editors to create a team culture. Establishing ongoing communication impacted students and advisers to teamwork each other to reach their news lab and personal goals.

\section{RQ3 What are high school advisers' perspectives regarding teaching leadership} skills?

High school advisers expressed they do teach leadership skills in their journalism classes. Advisers said teaching leadership in their journalism classes helped them and their students have shared convicted feelings and passionate beliefs for their work. Advisers indicated their convictions and passion were key elements in leading their students and impacted their news lab's practice. Advisers said their own belief and 
feelings influenced the students' satisfaction in the news lab's standards, purpose, and production process.

Advisers not only teach leadership through practical skills to meet production goals, but teach behavioral skills providing opportunities for students to become leaders far beyond the classroom experience through teaching behavioral skills. In every interview, advisers were not only feeling passionate to teach leadership but expressed a genuine conviction to develop their students into leaders. Ultimately, high school advisers distinguish teaching leadership as a fundamental way to empower students' commitment to the news lab.

\section{Genuine Conviction}

Advisers model their strong convictions when teaching journalism leadership. Specifically, all the advisers make a stand ensuring their news labs are student driven. They believe it is important to advise a student-led news lab where the students complete all the news lab practices and are the primary decision makers. Advisers believe that their responsibility is to provide feedback and guidance, rather than to dictate the students' decisions in directing the news labs. The interviews revealed that the genuine conviction to advise a student led new lab could not be swayed by the challenges of a deadline driven work environment. Lucy follows her conviction to have her news lab be student led by trusting her editors' work. She explained:

Their work is student-produced. I'm the adviser, but I don't help them, I don't shoot for them, I don't write for them, I don't do this. I very much respect that and don't do their work. They do their things because I think it has to be student work or it's not really student work. 
The advisers conviction to provide feedback and guidance empowers the student's production to be their own.

Self-Motivated. Many advisers shared their need for their student-led new labs to have self-motivated leaders. Elise said, "I don't really have to convince them at all. I really think for most journalism kids, it is more an intrinsic motivation of, 'I want to do a good job because I feel responsible to my adviser, staff, and school.'” Ellen supports her student led news lab and believes her students want to do well and be present. She stated, "There is that innate desire in them, even though it might be a lot of work, but it's also a lot of fun, and the leaders have to continually ask 'What can I do to stay in' and 'Why did I take this class?" In the same way, Lucy and Mia commented on wanting students to have a personal commitment for their goals. Mia strives to find students with the same belief and same goals to be in service to the community. She explained, "The goal for me is to find the students who believe in what I believe in and what we believe is supposed to be in service of this globe community. Like what sort of service are we putting forward into the world?" Most participants considered teaching an organic approach to guiding students into not only developing skills to become a better student, but embedding a sense of purpose into their lives and, more importantly, a lens through which to see the world. Lucy said, "They have to want it. When they're just handed something, or if they don't really have a passion for it, they're not always going to step up." Additionally, Lucy explained it can take time to hold a genuine conviction for journalism. "I think it comes with time. I think it comes with experience.”

Advisers believe that part of their responsibility is developing student leaders to share in their passion and be motivated towards their same goals have a sense of purpose. 
Supporting Student Decisions. Advisers revealed they strive for their editors to take ownership of their news labs' production and decisions. All advisers revealed ways they empower their students by making sure all the decisions are left to be the news lab leaders. Sarah said, "These editors are second teachers in the classroom. They really are because there is no way I can get to everyone specifically during our class period. They are teaching the new kids, by helping me because there's only one of me." In a similar fashion, Lucy wants her editors to make decisions making each production better. She supports her editors' decisions by letting them make them on their own. She shared, "It's all about improving. A lot of it is letting them try." The advisers support editors' decisions to make the news lab a safe environment. The advisers believe nurturing editor decisions within their student-led news lab helps build the students into leaders.

Promoting student autonomy of story ideas and supporting those decisions is a common way that advisers empower students. For instance, students are taught to generate story ideas and make their own decisions on how the stories will be produced. Advisers give their student editors a great deal of ownership and choice in deciding how to do their work and select story topics.

Similarly, Lexy's editors are empowered throughout their work process. She explained, "The kids do the approvals before they ever go out to work and so, by the time I see it on a magazine, it's pretty good." Likewise, Elizabeth gets out of her editors' way and empowers them to teach the class. She said, "Yes, I'm the adviser. Yes, I'm the adult in charge, but at the end of the day, it's the kids that really take over and run everything." Empowering the students to take charge shows the students their adviser supports their 
decisions. The adviser is continually overseeing the production process, but only comes into the process when the students ask or the process is in jeopardy.

Six advisers illustrated how they gave students opportunities to make their own decisions about how to present their work. Liza finds one of the best ways to empower her students is to give them options for how they might present their stories. She shared an instance when a student did not know how to identify interviewed students: "She did not know what to do, so I asked her how do you think we can make it work? I don't want to tell them here's how you need to do it, but I want them to figure it out." She further explained, "When you get out of their way and give them the storytelling and tell them 'just do what you need to do to tell your story. If you're uncertain, if you think it's breaking any rules, come talk to me."' Ellen also makes sure the student editors lead her news lab processes. She explained, "I have some guidelines that I want, but for the most part, they go out and they bring it together. Everybody will pitch their ideas. Then the editors go through and tell me what they choose. They choose their own partners or work alone. They put it all together." Supporting the students decisions starts at the conception of the productions idea. Advisers getting out of their students way helps the student not only take ownership of the process, but also helps them take pride in their work.

Developing a Sense of Pride. Enthusiasm helps advisers and students have a shared pride in their news lab practices and behaviors. Many advisers have significant pride in teaching journalism and say they prefer teaching over any other class they teach. For Lucy, advising means that you get to step back: "You have to step back or it's not their publication. I think that misperception is out there. They don't understand that in the yearbook, yes, you have to cover all the things, but how you cover them and how you 
choose to cover them is up to the students. They choose the story lines, the photos". Lucy further explained, "I take the word adviser seriously. There's a difference between being a journalism adviser and being a journalism teacher." Similarly, many advisers believe their advising position differs from teaching, and it is superior and preferred. Emily articulated, "It's the hardest job you're ever going to love, but you're going to hate it when you're going through it because it's on your shoulders and this is so much responsibility. It's so different because what you're doing for the first time ever, for many of these kids, really matters. Real people read our stuff."

As a result, advisers described how their beliefs and strategic goals helped them gain enthusiasm in their decision-making processes, as well as in setting priorities and evaluating the progress throughout each deadline.

Finding Significance. Advisers revealed how their continual appeal to the importance of their journalism standards contributed to the news lab significance. Advisers established several strategic directions for each production to generate importance by supporting the news labs shared enthusiasm for the students to be journalists. Erin provides choices and autonomy while helping her editors focus their energies and engage in significant practices. Moreover, the adviser's pedagogy was a strong driving force to establish a culture favoring effective production, encouraging creativity, and fostering group decision making.

\section{Sharing Passion}

While further explaining their leadership philosophy, all 24 respondents clarified their passion for advising journalism. The advisers articulated their love for their profession and serving their school for the greater good of journalism. Sam shared she's 
passionate to teach her students. She said, "I love my job. Most teachers are in it because they love kids and they love their job. And we all know that we don't get paid a ton of money. But that's not necessarily why we're in it. It's about, for me, for sure, the journey and how you feel while you go through the journey." Similarly, Lexy commented, "I love journalism, I'm passionate about storytelling. I think the relationship piece is the most important part to me." Advisers impact their students through their personal passion for teaching the craft of journalism.

Sarah loves teaching journalism because she wants to see editors grow as leaders. She said, "I love journalism and I love teaching it. I want them to be successful. I've seen how much their success helps them blossom. In journalism, you get to know those kids so much more than just in English class or another class, that's why I love it. I really do love it." Like Sarah, Sandy shared she has always had a passion for journalism. She said: I'm always excited about yearbook. I am one of those few and rare yearbook advisers that loves yearbook. A lot of advisers that are asked to do the yearbook have it dumped in their lap. I knew whenever I was hired, I was going to have that responsibility, and I was fine with it. I actually love the process of putting together a yearbook, seeing it come together, seeing the kids working together, and seeing them grow in the process.

Passion Projects. Many advisers articulated their love for teaching journalism. Advisers further shared their passion for teaching leadership leads them to be fueled for one specific area. When advisers are passionate about teaching leadership, they also may enhance their news lab by embracing a specific area to make an impact with their students. 
The advisers revealed that to have a passionate, inspired news lab, it had to begin with themselves as the leader. Similarly, Lexy adores the bonds made throughout her news lab's creative process, while teaching leadership. "I love journalism, I'm passionate about storytelling. I think the relationship piece is the most important part to me." Advisers impact their students through their personal passion for teaching the craft of journalism. In addition to being repetitive, the fact that the same piece of data can appear verbatim in two separate points of discussion sheds light on the relative lack of analysis offered to explain how this point of data connects to passion projects - and to establish how "passion projects" is uniquely distinct from "sharing passion".

Advisers tap into the student's knowledge and skills to point the news lab toward their common goal and draw out a commitment to achieve results. Advisers do this by influencing their students through their own passion. The advisers do not command results, rather, they inspire their students to independently desire their goals. Part of the advisers shared passion for journalism was including students from all areas of the high school. News labs have high standards but are not exclusive to one type of student. Many advisers shared they are passionate about enrolling students with diverse backgrounds because it leads to stronger journalism and authentic connection with audiences. Sandy shared she strives to find many different students to be part of her staff to grow their shared beliefs and love for journalism:

My passion is why I gravitate towards journalism. I gravitate toward teaching those journalism leaders. My staff needs a variety of kids on the staff. I have three band kids. I have one former soccer player. I have a tennis player. I have one girl in art, and so she's very strong with design ideas and photography. There's just a 
wide variety that you need in yearbook, and a couple of them are really strong in writing. You need that to come together to put together a good yearbook. I kind of look for kids that have these abilities, and putting them together sometimes works, and this year so far, it's working.

Almost every adviser shared a story centering around their specific passions in teaching leadership. When advisers and students share their passion for journalism the news lab is stronger. The shared passion inspires the news lab to be an energized and productive atmosphere.

When an adviser teaches journalism leadership practices and behaviors, those skills can be used throughout many areas outside of the journalism news lab. For example, Lydia also teaches English with her class load and finds ways to bring Journalism into that class. She has witnessed many students' communication skills develop within her Journalism classroom. She explained, "Seeing the students' growth as communicators and becoming prepared for the outside world is amazing. I think our students would be better leaders and even better writers and readers, and more prepared for college if every student in English would do a Journalism class.” Journalism leadership skills and behaviors help students communicate to meet professional expectations. Emily stated she believes the best part of being an adviser to helping her students reach their goals. She said:

The best part is when they actually open the book and realize how good it is and they like it. One year was really hard. I mean, we were pushing and pushing and, honestly, it ended up being one of the best books we've ever done. I love that book. It's one of my favorites. 
Students experiencing a met deadline and their final product helps advisers teach leadership skills because the students accomplish their goal as a team and celebrate together. Like Emily, Elise elaborated her passion is seeing her students reach their goals: Success for me is seeing the students open that first box of yearbooks when they're delivered, or distribution day, or when they send some post that goes viral on social media. They can see how their story has reached 10 thousand people. Those are the moments that are worth it. Every work night, and tear, and drama filled moment we had was worth it. Seeing them be proud of their work is something I don't think you can really define.

Advisers indicated their belief for the role of leadership within journalism education can impact their students to become leaders. The advisers' conviction impacts students cultivating the students to hold their own beliefs to have effective student-led production. The students then make the goals their own to encourage creativity and make their own decisions. Advisers perceive teaching leadership in journalism education is vital to engage students. Advisers who embrace genuine convictions and passion have tremendous opportunities for empowering students to meet meaningful goals. Advisers who embrace genuine convictions and passion have tremendous opportunities for empowering students to meet meaningful goals and to become goal-oriented leaders.

\section{RQ4 How do K-12 journalism advisers teach leadership skills?}

Journalism advisers teach leadership skills throughout years of development. Many advisers begin teaching leadership by creating a community of learners. These communities establish partnerships throughout their news labs by progressively building 
upon each student's strengths. Advisers teach leadership by building a community of learners, establishing team work, and maximizing strengths.

\section{Community of Learners}

Because the journalism teachers see learning as a critical process, a common practice advisers employ is engaging leaders who have already established themselves in their high schools to be part of their news lab. In fact, scholastic news labs focused around building a community of learners, creating the news lab as a team, and individualizing their instruction to meet each student's needs.

High Entrance Requirements. Advisers stressed the importance of teaching leadership through community building. All of the advisers created learning communities with strict standards for entry. This added both a sense of pride for those students who met the requirements but also created a level of exclusivity and importance in the work. Likewise, advisers inspired their students to want to learn the technical skills to become a student journalist. Becoming accepted into a scholastic journalism class provides students an opportunity to learn basic skills and become immersed into their news lab norms. Additionally, advisers create learning communities through high standards as well as creating opportunities for students to actively demonstrate their desire to belong.

The adviser build the news labs' goals before the students start the class. Students apply to be in the class. In the application process, advisers ask a variety of questions to determine if they can be admitted in the class. The interviews and artifacts revealed, through written applications and possible other requirements, students have to justify their ability and desire to be accepted. This process has two principal reasons. First the application process allows students the opportunity to demonstrate their already 
established abilities to be in the class. Second, the process shows the students want to be in the class. The high entrance requirements demonstrate the student's ability to juggle a goal and a requirement. Two advisers said applications are the first step to see if students will take on the challenge and then gain the reward to be part of the news lab. Another adviser recognized setting standards as prerequisites to take the course helps create and maintain high expectations. It was apparent through Sam and Sloane's application processes that their focus was on building each news lab's community standards as their application process treats the students as if they were in a professional job interview.

All 24 advisers require a minimum of a written application and a grade point average standard, while four have additional requirements. Advisers shared the process is critical to ensure students are ready to be part of the community of learners as they work to become news lab leaders. Having prerequisites and a written application process establishes value by being accepted in the course as an accomplishment itself. The class's high entrance requirements starts the students' motivation towards their goals.

\section{Establishing Teamwork}

While advisers build a community of learners, ritual celebrations are also used within their news lab's production process to develop a team. Advisers show appreciation for individual as well as team excellence. They celebrate the news lab's values and victories, creating a spirit of community and family. Many advisers use key benchmarks within their production process to celebrate individual and team success, but more importantly to establish partnerships through the news lab. Furthermore, through celebrations and creative traditions advisers form common bonds with their student staff members. Advisers use key points to celebrate with creative traditions to establish the 
news lab into a team of student journalists. The celebrations demonstrate good examples of the students learning teamwork instead of competitiveness, and the student staffers begin to feel part of the news lab team.

Celebrations. Although many advisers claimed their over-arching goal was to distribute their production to audiences, they also placed great importance on completing the workflow set by timely benchmarks. Therefore, advisers make it a priority to celebrate completed deadlines and distribution days with "D-Day" rituals. Similarly, advisers expressed the need to celebrate each deadline accomplishment by congratulating their whole news lab staff. These simple celebrations define the publication cycle, pause for reflection, and encourage improvement by refocusing the team on core values and virtues. The celebrations further define the news lab's leadership.

Advisers shared when their students feel appreciated within the operations of their news lab, they begin to positively manage themselves and each other. From a leadership perspective, these advisers are able to create self-driven teams. Not only are students honored to hold these rituals, an added benefit is a carryover effect that builds upon their positive leadership skills. Also, the advisers create a spirit of community and family by celebrating the news lab's values and victories. The celebrations establish valuable partnerships through the news lab. For example, Laura commented that she embraces each deadline accomplishment with the whole news lab staff, "Distribution Day is the best day. It's such a huge moment when the school is pulling out the yearbooks or newspapers to flip through every page, saying 'Oh, look at that picture!'” This creates the opportunity for organic feedback that engages the entire news lab. Creating this experience pushes the students to creatively involve themselves in the data cycle, 
purposefully making decisions on what was good and what they should continue doing, or deciding on how to improve.

Advisers highlighted specific individual staff accomplishments through timely celebratory feedback as "snaps and brag tags". Emily commented her news lab celebrated a low-functioning student who dealt with depression and drug abuse. She said, "She managed to get done with her one page and was so damn proud of that page and we just loved that page. We said, 'Thank God!' because she was in and out of drug rehab all the time. So, the fact she got anything done at all, we're going to just chalk it up as a win and we're just going to go with it." By creating this system from core values on timeliness, accuracy, and relevance, advisers are able to watch even the less achieving students rise to meet the standards. In the same way, Leah commented she gives her students the recognition they need. She said explained:

It allows the kids to feel that they're in a safe place, that they're allowed to be who they are. I mean, like really who they are. Because a lot of kids, depending on what class and how they feel in their class, will just shut down. For the most part, it's making sure they feel validated and acknowledged. Birthdays are celebrated or even if it's the tiniest little thing that is out of the ordinary that I don't think other kids have noticed about them, I will celebrate it. There's nothing like that feeling when your peers look at you and say, "Oh, my God, that is so awesome".

Leah illustrates how recognizing students relates to leadership by making all the students feel like valued parts of the team. According to 19 respondents, the decision to provide positive experiences and feedback established a benchmark for the students and the advisers throughout their workflow process. In the end, these pillars of successful news 
labs create the cornerstones of leadership for these students. Once they see how it successfully runs, they can take these principal values and apply them to other areas of their lives.

Creative Traditions. Many advisers said news labs provide a positive environment with creative celebrations throughout each step of the process, such as tshirts, pep talks, editors' talk, food, and bonding nights. According to the respondents, the decision to find creative ways to celebrate as a whole news lab helps the group develop a group identity. Sarah explained her news lab annually celebrates with their entire high school with a formal dance, which originally was a fundraiser and has since evolved into a celebration of their publication. The t-shirts and dances are important because it lets the students connect to their core values and have an invested team meaning. Erin also has creative traditions to celebrate. Her senior students have a tradition to wear journalism sashes at their high school's graduation ceremony. She described:

When we got journalism sashes a couple years ago, I was looking at just that special acknowledgement because for a lot of students this might be the only extracurricular type of class that they do, and it's still a class, but it is kind of an extracurricular, and just that sense of community that they build within themselves. It showed they enjoy each other's company, working together. It's special to watching that final product come about and watching how much they grow, both as people and as students, I think that's just the most rewarding part and it's important to celebrate it. 
Through the celebrations and traditions, the news labs begin to create their own culture. Similarly, Elizabeth finds the staff becomes more coherent each time she and her editor present a creative way to celebrate. For example, her previous editor made a hand-crafted sash for their own news lab celebrations, which the awarded student may wear for the week. She said, "Everybody cheers, and claps. They all just love it." These small, seemingly insignificant awards actually define a culture in which students can excel.

A number of advisers are creative with their student celebrations through periodic team-building and reflection exercises. The self-care exercises are used as a motivation for the advisers to help their staff gain comfortability as writers individually and as a team. For example, Elizabeth's news lab takes a break from their typical newsroom routine to ensure self-care. "We take little breaks to build everybody up and make sure the staff's health is okay. If it's not, then nothing's going to get done," Elizabeth further described that she brings in a treat and does psychological exercises to reveal individual character traits through fun traditions. "Everybody enjoys. So, when we are done, we come out with the kids being so much more relaxed," she said. Leah further explained the importance of caring for her students. She said, "That to me it seems like it goes a long way for teenagers to realize that adults do care. Adults outside of their parents." These small acts of kindness were not only common among the different schools, but were purposefully done to help meet the different needs for each student. From a perspective of leadership, this provides opportunities for advisers to establish their concern for their students, but it also allows students to develop the same relationship of trust and empathy between themselves. 
Awards. Although students are awarded state and national recognition, advisers provide in-house awards for every deadline cycle such as best story, best design, as well as leadership awards to find staff members who embody journalism principles and leadership. Advisers explained it is a priority to recognize individual accomplishments and include the whole staff in ritual celebrations. More importantly, it reestablishes the common principals that drive publications. It gets everyone on the same page, and it reunites their commitment to excellence. For example, Mary annually distributes award certificates by reviewing all fall photos and pulling out the 'Best of the Best Photos'. She explained, "You might think sophisticated high school kids would go 'ugh', but they love it, they love that pat on the back. Even if it's just recognition within the class." As a result, rewarding good work sets the standard for best journalism practices. The celebrations, traditions, and rewards teach leadership. Advisers begin creating their own culture and provide allows students to develop the same relationship of trust and empathy between themselves.

Safe Environment. Advisers' interviews revealed many of the participants strive to empower their students to become better learners and leaders within their news lab's safe environment. All the advisers remarked on how they recognized the need to positively influence and motivate their students by creating a news lab environment which provides direction and support. Liza says she writes to her substitute teachers her news lab will seem like a three-ring circus, but it is a well-oiled machine. She said, "Teaching journalism feels like there is so much work to be done the moment the bell rings. The 90 minutes is chaotic, like blow your hair back, 90 minutes. But when it's over, you know you've accomplished something with your kids." So even though it may look 
like chaos, the structure allows students to see clarity in the confusion. The safe environment allows many students the opportunity to assume a leadership role.

While advisers commented on their rigorous atmosphere, an overwhelming majority of interviews revealed advisers strive to create a supportive environment. Advisers shared their news labs are to be a positive influence on developing each student as a leader. Interviews and observations showed that many advisers alter the appearance and design periodically. Many advisers said they have their students help with the set-up, design, theme, and clean-up to make their workflow more interesting and relatable. Comparably, each summer Liza invites students to come and help set up their news lab for the upcoming school year. Take, for example, the fieldnotes description of Madison's deadline board, which is an informational base designed by her editors to provide the master schedules. Including students in these decisions in a fail-safe environment allows them the opportunity to experience how leadership decisions are received and, more importantly, watch how leaders improve future decisions based on evaluating their past decisions.

Supporting Student Decisions. All advisers revealed ways they empower their students by making sure all the decisions are left to the news lab leaders. This commonality was deeply embedded in the majority of these participants' practices. For example, Sarah explained how her news lab is led by her student editors' decisions. She said, "These editors are second teachers in the classroom. They really are because there is no way I can get to everyone specifically during our class period. They are teaching the new kids, helping me because there's only one of me.” This purposeful design is based distinctly on the process. For example, her news lab has a distinct workflow process. 
First, students turn in their rough drafts to their editor to read. The editors give feedback and then Sarah reads the final photos and draft. She will sit down with the editor and talk over missed areas. She said, “They learn it better when they're actually doing it.” By taking students' ideas and helping them take the articles from concept to publication instills a level of confidence in the process, but also solidifies a level of buy in from the stakeholders.

Similarly, Lexy's editors are empowered throughout their work process. She explained, "The kids do the approvals before they ever go out to work and so, by the time I see it on a magazine, it's pretty good." Students convert to believers in the process. This level of confidence is contagious to the newer students. Once they see older students believe in what they are doing, leadership seems to define itself. For example, Lucy trains her editors to fix their problems and find ways to make aspects better by supporting the decisions the editors make on their own. She shared, "It's all about improving. A lot of it is letting them try." In the same degree, Liza empowers her students. She said:

You have to get out of their way and that's scary. When I was coming from being a straight English teacher, that was the scariest thing to me that they were going to go out in the hallway on the other side of the building with a camera. That scared the bejesus out of me.

Likewise, Elizabeth gets out of her editors' way and empowers them to teach the class. She said, "Yes, I'm the adviser. Yes, I'm the adult in charge, but at the end of the day, it's the kids that really take over and run everything." Students believing in the process, and sharing their excitement for journalism through their belief with others, help to establish the news lab as a team. 


\section{Maximizing Strengths}

Advisers build on their students' strengths to not only develop their news lab leaders but to create an effective structure for the lab's work flow. While further developing news lab leaders' strengths, advisers focused on discovering individual potential and providing editorial leadership training for efficient workflow and effective feedback to their students. Advisers search out their students' strengths to develop their news labs leaders. They also use those strengths to develop the staff workflow's structure, production and editor positions each semester. The news lab leaders focus on strengths so students are more engaged to improve their production and have greater success.

Eight advisers identified emphasizing personality quizzes and training to teach leadership and select their news lab editors. Leah focuses on her students' strengths to build teams ready to communicate. On a deeper level, the student can personally reflect on strengths they may not have already realized. Also, Sarah's small staff has used her editor's strengths through all parts of the process. She has found it ensures all students work together as her editors also must lead, write, and do photography.

Experience and staff size have an effect on strengths influencing pedagogy. The majority of the advisers commented their editor selection depends on their student strengths. Editors learn their staff members' strengths and weaknesses and work with them. For example, Sarah's editor positions vary each year based on the upcoming students' talents and strengths. Each year she has an editor -in-chief role, but its expectations vary based on their talent and she bases the responsibilities on their interests. Eli connects his students' strengths to their news lab assignments. He said, "Students' 
personality traits and their assignments are a bit connected." Maximizing the students strengths is important for news lab leadership because it teaches them to trust one another's strengths and encourages them to reflect upon their own abilities.

Elise connects her leadership teaching with her students' strengths in many ways, using personality tests to find her students strengths. The data revealed eight advisers use personality tests to find their students strengths. Elise pointed out:

I've had varied levels of success with that. Some years, it's worked out great. Some years, it always is great just to know. One year, I said. "Good lord, how are we all going to survive this?” But most years, I could effectively put them into little teams, from each category. Those have been really fun years to do that. It's fun to talk through that process. But like I said, some years it comes back to bite you.

Reaching Potential. While further developing news lab leaders' strengths, advisers focused on discovering individual potential. News lab advisers do not just count on strengths that already exist. All the advisers commented on how they find joy in developing their students' potential as well. Advisers teach leadership by having their students to know and grow into who they want to be, whether it is to be a journalist or not. For example, Sloane provides her selected editors with opportunities to build their leadership skills. She clarified that she does not always select "a born leader" editor. She will pick a student with the potential to be a great leader but has not been given that opportunity because they're always up against that born leader. Advisers know there is more than one kind of leader and they are sure to include students with all types of strengths. Lydia notices student potential in and builds upon those strengths. "We offer 
them the opportunity to grow in areas they are already successful. There are many ways for them to put their talent to use in a newsroom and grow. They don't even necessarily have to be the best writer," Lydia rationalized. The advisers find it is most important to see a student's potential and desire to become a leader. In the end, most advisers admitted to developing potential leadership skills within their classes.

Advisers shared they help students discover their strengths to impact their news lab. Emily teachers her students to use their strengths to gain a deep respect of themselves and other staff members to consistently deliver effective leadership. She believes she builds trust through acknowledging each other's strengths and being aware of the students' weaknesses. She explained, "You just have to talk to them straight because as a person, and especially as a leader, you have to know who you are. You have to know your own tolerance." Given the high-stress environment of news labs, students learn to develop a calm confidence in times of higher stress. This leadership skill is vital in both news labs and life, but giving students the opportunity to develop this in a fail-safe environment helps them in the future. In the same way, Leah helps her students make a conscious effort to invest in understanding who they are and those around them. Leaders in life are sometimes thrown together in groups where they do not get along with those around them, or have particularly different strengths than those in the group. Understanding how to work with one another by focusing on what people do well and, how to navigate difficult situations is perhaps the most important lesson in leadership, these news staffers learn. She illuminated, "We are a big family, and we're going to have issues because one personality does not necessarily play nicely with another. But just because it says on a piece of paper doesn't mean that we need to enact it. I want them to 
be aware of it and I will reference it every now and then." This style of commitment to the bigger picture helps students reach their own potential, but more importantly puts their needs behind those of the group, which is another ability effective leaders have.

Advisers indicated the necessity of teaching leadership skills in journalism education. Advisers begin teaching leadership by engaging a community of learners to establish partnerships throughout their news labs. It was evident that a supportive environment helps students use their strengths and develop their potential. Ensuring a news lab is a nurturing environment helps editors take ownership of their production. Ultimately, advisers believe teaching leadership skills helps students take action to have inspiring news coverage and experiment with media, audiences, and distribution.

\section{RQ5 What components of the transformational leadership theory are present within scholastic journalism news labs?}

While a majority of transformational leadership theory components were present, Kouzes and Posner's $(1987,2002)$ model further refines how the advisers used transformational leadership tenets. The primary behaviors included challenging the process, enabling others to act, encouraging the heart, modeling the way, and inspiring a shared vision, with shared vision being the most used. The advisers had an innate ability to engage and draw out the best from their students by creating supportive networks throughout their news lab. Overall, transformational leadership creates valuable and positive change in the editors with the end goal of developing the new students into leaders. 


\section{Transforming Students into Leaders}

The advisers' transformational leadership practices determine the news lab's culture. According to Kouzes and Posner's $(1987,2002)$ practices of celebrating values and victories creates a spirit of community. In scholastic news labs advisers see learning as a critical process focused around building a community of learners and creating the news lab as a team. The advisers' transformational leadership determines the news lab's culture. The advisers understand who their students are, where they come from, what their needs are and how to motivate their news lab staff. The news lab's culture is the rhythm of what their students will follow to determine their personal and team goals.

Encouraging Students' Hearts. While advisers build a community of learners, ritual celebrations are used within their news lab's production process to develop a team. When advisers recognize their students contributions through ritual celebrations and creative traditions, Kouzes and Posner's $(1987,2002)$ research refers to the practice as encouraging the heart. Advisers further engage their students to be part of their news lab community by recognizing student contributions. Additionally, they inspired their students to want to learn the technical skills to become student journalists. According to 19 respondents, the decision to provide positive experiences and feedback established a benchmark for the students and the advisers throughout their workflow process. Advisers show appreciation for individuals as well as team excellence. They celebrate the news lab's values and victories, creating a spirit of community and family.

Celebrations. Although many advisers claimed their over-arching goal was to distribute their production to audiences, they also placed great importance on completing the workflow set by timely benchmarks. Therefore, advisers make it a priority to 
celebrate completed deadlines and distribution days with "D-Day" rituals. Similarly, advisers expressed the need to celebrate each deadline accomplishment by congratulating their whole news lab staff. Lucas revealed his transformational leadership as he is sure to observe staff exceeding the workflow process during a deadline cycle. "We had three kids that have gone above and beyond, so we were going to recognize them by talking about what they did that was beyond what we expect the average student to do." As a direct result of the advisers' transformational leadership, the students were empowered to be leaders.

When students do a job well, transformational advisers create authentic celebrations highlighting specific individual staff accomplishments through each story's feedback as "snaps and brag tags". Expanding on this concept, Lydia explained she permits the staff to edify each individual's work. She said:

Everybody reads through each student's work to make a nice recognition, 'snap', at the end of each production. Then, each staff member gets recognized through the written 'snaps'. The editors do it as a nice recognition at the end of each publication. My editors know, too, when we edit drafts, don't only write what they can improve, acknowledge what they do well, so that they don't get disheartened, because a lot of it, especially in the beginning. Especially, when they like massively to go out of their way, or they had to overcome something, and making sure that they feel like all their hard work is acknowledged, because it is a stressful class, and it's very time consuming. So just making them aware that like all of the hard work they're putting into it is being recognized, one-on-one. 
The advisers help encourage the news lab to have a community spirit. Advisers explained part of their news lab ritual is to give student staffers appreciation and support. Comparatively, when addressing the standard for recognition, two advisers commented on their practice of edifying low-performing student accomplishments. Illustrating this further, Emily said her news lab commended a student who dealt with depression and drug abuse. She said, "She managed to get done with her one page and was so damn proud of that page and we just loved that page. We said, 'Thank God!' because she was in and out of drug rehab all the time. So, the fact she got anything done at all, we're going to just chalk it out as a win and we're just going to go with it."

The advisers' celebrations are a transformational leadership practice that connect themselves to the students. The moments used to encourage the students' hearts show the students that the advisers in the work with them.

\section{Sharing the News Lab Vision}

A shared vision creates a news labs' sense of mutual purpose. Effective transformational advisers examine their shared vision to increase the news lab's productivity and creativity. The role of leadership helps advisers establish a common vision to motivate their student productions. Thus, advisers and students gain a mutual understanding of their leadership goals through a shared vision. News labs develop leadership beliefs in multiple ways. When asked, "How do you inspire a shared vision?" the advisers disclosed a variety of concepts directing the news lab's overall production workflow. During all of the interviews, these award-winning advisers all had one thing in common, a shared vision. Advisers holding a shared vision launches all of their students into the decision making process to define the news lab's customs, beliefs, values, and 
norms. Advisers including their students in decision making creates a positive news lab culture.

All the advisers commented they continually appealed to each student by articulating production goals and their editors pronounced their shared vision to their news lab. The data supported the benefits of a shared vision. Common news lab slogans, positions, and procedures are essential for advisers to influence their students' effective production.

The adviser's motivation drives the news lab's leadership. At the beginning of each school year, advisers facilitate traditions for students to create their news lab motto. The advisers lead their student editors to decide on a catch phrase and ideas to motivate their news lab. All the interviews, observations, and artifacts revealed news lab mottos were promoted through room decorations, posters, student t-shirts, and the overall news lab productions. Some of the advisers reported they reach outside of their news lab through books, music, and social media for their news lab inspiration. Advisers facilitated their traditions at national conferences, leadership retreats, leadership retreats, and boot camps. These camps and retreats are structured to provide the student editors training to make the motto for the upcoming year. There was not one way to do this, but once the school year began, each news lab motivated the students through the continued use of their common vision. The different mottos enforced the news lab's shared vision.

Lucas illustrated how he implemented change by inspiring the students to develop the Create Magic motto. The adviser's inspiration was put in place for the news lab's motto, but to also help provide agreed upon practices for positions and procedures. The advisers facilitate their student editors to decide on their assigned editor positions based 
upon the ideals of their shared vision. Leah believes an understanding of their "News for Students by Students" slogan has transformed her students into their leadership positions. She believes the students' understanding of their shared vision elevated the students to take ownership and effectively lead their workflow. Leah explained the vision helps her editors lead. She further explained her students develop their positions and the news lab procedures. As a result, her editors oversee the news lab before she becomes personally involved. She said, "The editors put out the fires all the time. The kids are aware of it and they understand the dynamic of it because they helped decide it." Leah illustrates how advisers' transformational leadership creates change in their students with the end goal of developing them into leaders.

The importance of the student editor position was reflected through interviews as advisers marked time by their editor's name; rather than publication name or date. Throughout interviews advisers referred to their previous editors. For instance, Leah explained how each editor puts their stamp on the year's production, product, and overall morale throughout the news lab. She further illustrated, "I've had those great student editors throughout my whole career. Each has been part of a thread of students that have built our program throughout the years."

Transformational leadership creates valuable and positive change in the editors with the end goal of developing the new students into leaders. Advisers believe teaching leadership transforms students. The advisers revealed following common visions and expectations help news labs to produce creative work based upon their genuine convictions. Advisers nurture their student leaders who, in turn, further build consensus 
to nurture a next generation of student leaders. Ultimately, high quality programs have a continuous cycle of transformational leadership development that appears effortless.

\section{Modeling the Way}

The advisers breathe life into their shared vision, with optimism and positivity. They strive to have their actions align with their shared values. Advisers model their values through their personal example by having a desire to learn and giving time and energy to their production. During the news lab productions, advisers impact their students' practices and behaviors by building consensus. The advisers' influence can impact the students in and outside the news lab.

Providing a Personal Example. A majority of the advisers shared their leadership philosophy to be "lead by example". In fact, eleven advisers revealed their personal, professional, journalistic values. Modeling leadership was seen through Eleanor's shared experience with her students. She described a huge part for her being a teacher is modeling the behaviors that she wants to see her students emulate. She further described, "I just show those appropriate leadership skills and behaviors in my classroom." In the same way, Eva models by setting her personal example of her expectations. She illustrated, "They will see me talk to every single student walking in the door and have painful conversations. I teach them that even though I don't care what's going on in all the students' lives, I will have those utterly painful conversations because it helps those students." Similarly, Ellen recounts how she shares her value of grace by demonstrating it throughout her news lab consequences. She shared an instance when a student made a bad choice, which resulted in a detention: "I believe in grace. So, we had to have conversations about it to not do that choice and if he did that again, it was going 
to be a problem. But there has to be an understanding that sometimes they make bad choices, and to move on. They're kids," she said.

Dedicating Time and Energy. While further explaining their perspectives, respondents clarified they continually model their belief in advising journalism by putting forth the time and energy to complete the work. Sarah revealed that she shows her students the importance of the news lab's values by not communicating it to her students in words, but as the adviser she spends time and energy making certain her students work to adhere with journalism principles and standards. Laura also shared she teaches her students through her personal example, as she was their high school's first journalism adviser and established the program with her students. She has made sure her editors adhere to their established principles and standards. Ellen shared her actions influence her students' performance. She explained, "I try to hold the same standards for myself as I do for them. I don't ask them to do anything that I'm not willing to do. I mean I've gone out with shoots with the kids before to help them do different things. A few years back we were in a contest and we literally worked over Spring Break. I was with those kids from the beginning of the day to the end of the day." In the end, investing time and energy is a commonality among the award-winning journalism educators in this study. The advisers motivate their students by also being in the news lab's trenches with their students throughout each production.

Demonstrating a Desire to Learn. Advisers' desire to learn influences students. Many advisers interviewed take on the responsibility to make sure their knowledge is up to date with current professional standards. For example, Eli's original training is outside of journalism and he is a self-taught journalism adviser. He brought to light, "I definitely 
had to go through change. This is not my background, but I didn't have to force it. I had to find things that made me realize this will be cool to turn into a lesson that meets our show's end goal." Eli's specialty is in business education. He has used many resources and scholastic journalism to gain the needed skills. He further illustrated, "I didn't go to broadcasting school. I wasn't a journalism major. I was a business education major, and I read books, watched YouTube videos, go to conferences. Now I can say this is how we're going to run it." Eli attributes his successful practice to this one small way he influences his staff. His students are impacted by his commitment to life-long learning.

Transformational leadership empowers student learning as advisers continually support their own intellectual excitement and the news lab's needs.

\section{Enabling Others to Act}

Advisers strive to create their news labs into an atmosphere of trust to help each student feel capable and powerful. Trust in the relationship between advisers and their students is worth emphasizing, due to the significance an adviser has in being a leader in journalism education. Through transformational leadership, advisers establish their most effective student leaders, enabling them to realize their full potential. For example, Liza strives to build relationships by treating editors like adults and being authentic. She concentrates on relationships and believes students have a hard time learning from a teacher they do not have some kind of relationship with them. Enabling students to act develops their competence and offers the advisers visible support. For example, Emily's trust in her students deepened during a long absence. Her editors were able to keep the workflow moving and produce quality work while she was on leave due to a surgery. She shared, "Everything kept moving. I think in education a lot of times, it's the dream of a 
lot of educators to trust their students to keep moving forward and thrive, even when they are not there." Eva also trusted her editors during a bereavement leave to attend a family funeral. She explained, "Initially, I was filled with anxiety. Then, I realized my editors know the programs and would handle the heavy lifting to keep us moving. When they see me as an adult just going, 'Let's do this,' then I think they learn that adaptation skill and that they are trusted." In the same way, when Sloane's baby arrived, her first call outside of her family was to her editor-in-chief ensuring the completion of their upcoming deadlines. She further explained how much she trusted and depended upon her editor in that moment throughout the delivery and the following weeks of maternity leave. She commented, "I was not going to be there, and I needed to call her to let her know because we were on deadline. So, it was a little stressful for me, but good to know they were prepared for it and in safe hands with my editor.” Advisers impact students by establishing strong relationships to build trust through transformational leadership.

Open Communication. Advisers revealed transformational leadership in their news labs as their trust was built upon ongoing communication. Fostering collaboration helped the advisers disclose what they believe and care about. Mia explained, "If our arrows are all pointed in the right direction, we can be a more effective collective." As a result of clearly communicating their goals, the staff developed a strong mutual trust. She welcomed conversations on culture, emphasized publication importance, developed reasons to care, and instilled a desire to participate. She explained:

Through all of this, We came to the central idea, "The bearers of light," to shine a light on good in the community. The positive we want to see more. Sometimes it means shining a light on things that are like, man, this is really messed up, or this 
could be better, or how do we create change? If you're doing it well, you create proof to live your central mission.

Encouraging students to share their goals enables the news lab to promote cooperation. Advisers articulated a focus on open communication with their editors to create a culture of trust. A focus on communication helps advisers create a positive news lab, which is encouraging to students. Emily found communication to be key. She explained, "You have those conversations because it's a job. They don't know how to do a job because they're 16, 17 years old, and 18 years old. They know how to work, but it takes more to lead." To support her students Lydia encourages them to communicate with her regularly. She said, "It's really more if they are struggling and they come and talk with me, we sit down, and we conference, we do a lot of conferencing." Enabling the students to act and establish ongoing communication impacted students and advisers to trust each other to transform their news lab and personal goals.

\section{Challenging the Process}

Once students trust their own decisions, advisers revealed their students take action and create more meaningful student news. Advisers empower students to transform into student journalists instead of just high school students by deciding upon their own goals. Advisers challenge the process within their news labs by taking the initiative by supporting their students' good ideas and encouraging change. Advisers challenge their students to try out new and innovative ways to execute their coverage. There are a variety of ways advisers teach the ability to take action.

Taking Risks. Advisers challenge the process by taking risks, working on the cutting edge, and refusing to accept the status quo. Many advisers said they teach 
different ways to do coverage, so their students can make the final decision. Advisers want students to step outside of their comfort zones when selecting their own story ideas. Lucy pushes her news lab to cover national and international events by connecting the topic to the students in their high school. She referred to this as "localizing a story". This teaching strategy helps her students find meaningful story ideas. She explained, "News values and proximity catches their interests. They think this is just school. I tell them our school is the size of my whole town. For me, there's plenty of stories to connect to the world outside of our school." Sarah encourages her students to take action by covering multiple perspectives in their student news. Sarah expects her editors to search out many student perspectives. She illustrated, "It's good to make them think outside the box for different ways to cover different things."

To further illustrate advisers' approach of taking action, Lydia teaches her students to seek out story ideas even if the topic may test her students' skills. She explained, "Even if the story is more challenging, whenever they come back, they always feel like this huge sense of accomplishment, and they tend to get so much more recognition for those stories. I think that's a huge driving force for finding them." In a similar manner to Lydia's teaching, Mary explained she teaches students to break through their fear:

I am blown away what our students can accomplish. One day, a student was in here talking to somebody in Washington D.C. I'm just looking at him like, 'How did you get that number?' 'Oh, my mom knows somebody who knows somebody.' They have all these connections and you've got to let them fly and try them out. 
Experimenting with Media. While advisers encourage students to take action with innovative story ideas, others also experiment with different forms of media, audiences, and production. Lydia challenges her staff to try new ways to do work. Similarly, Laura experiments by using Google Docs for her students work flow by establishing a virtual news lab. She shared that her virtual news lab was originally a solution to her problem not having a news lab. Like Lydia, Eva shared, "I have a student right now that wanted to start a podcast, so he walked up to my desk the first week of school, 'Ms. Eva, I want to start a podcast.' I said, 'Great, do it, research it, tell me what you want me to go buy.' And he goes, 'What?' I said, 'Stop talking. Go research. Go tell me what you want to do."' Just as Lydia and Eva, Laura also has supported her student's excitement for developing a newspaper and literacy art magazine. She explained, "He was such a visionary and really a leader in every sense of the word. I became the follower." Within each safe and controlled environment, students grow by experimenting with their tools.

When advisers want their students to try new ways to do student news, they have to be ready when the result does not go as expected. Advisers shared when a goal is not met and a mistake occurs, they continually strive to find the lesson in the misstep. Laura shared how her students diligently strive for perfection, but may still experience printed errors. She explained, "We always ask ourselves after each deadline, 'What can we learn?' There can be mistakes in here when we're doing our final proofs. We don't ever know where they are, and I guarantee you, we always try and find them. But there are always mistakes." She further explained she is sure to debrief with the students to learn how to deal with public ridicule and critique. Guiding the students to choose the different 
aspects of the student news empowers them to grow and learn. Challenging the process cultivated scholastic journalism student leaders. Advisers were transformational leaders by taking risks and experimenting with media.

Overall, a majority of transformational leadership theory aspects were present throughout news labs. Kouzes and Posner's $(1987,2002)$ model further refined the role of leadership within journalism education. Ultimately, most of the advisers in this study believe one way leaders impact students is by subscribing to encouraging the heart, modeling the way, and inspiring a shared vision. Kouzes and Posner's practices of transformational leadership, guided the advisers "to get extraordinary things done" (Kouzes \& Posner, 1987, p. 9). Advisers transformational leadership aspects cultivate scholastic journalism student leaders. Ultimately, advisers were transformational leaders, by aiming their students toward effective production, encouraging creativity, and fostering shared decision making.

\section{Discussion and Implications}

This qualitative study identified the range of editorial leadership practices in Missouri high school journalism news labs to contribute a clearer understanding of how advisers utilize many leadership practices. This study explored advisers' perspectives and how they teach leadership in their high school news labs. The findings will benefit high school journalism teachers to develop leadership for effective production, encourage creativity, and foster decision making.

\section{Discussion of the Results}

Little has been known about high school journalism advisers' perspectives and how they teach leadership. This current study supports recently conducted research and 
investments on the value of journalism leaders. However, the recent research has only been focused on professional journalism newsrooms (Callinan, 2001; Herndon \& Krueger, 2016). To date, research has focused on how to train professional newsroom leaders, but not in high school news labs. This present analysis supports the scholarly belief that improving journalism requires leadership training in professional newsrooms (Callinan, 2001; Herndon \& Krueger, 2016; Killebrew, 2003; Mierzejewska, 2011; Mulrennan, 2018; Northouse, 2016; Perez-Latre \& Sanchez-Tabernero, 2003). This current study revealed that high school advisers do teach leadership. Therefore, it is imperative that high school journalism advisers are informed how to effectively teach leadership.

Advisers use transformational practices to teach leadership. The advisers' perspectives were examined through a transformational leadership theory framework (Northouse, 2016.) The findings support the transformational leadership theory. Kouzes and Posner's $(1987,2002)$ model further refines how advisers use transformational leadership by suggesting that leadership is not a position, but a collection of practices and behaviors. The primary factors used were encouraging the heart, enabling others to act, modeling the way, and inspiring a shared vision.

Each participant taught leadership and revealed their passion to develop students into self-aware leaders. Whether an adviser had three years or three decades of experience, all established aspects of editorial leadership throughout their news labs. Advisers lead their news labs by their example to encourage students to follow their common vision. Advisers used shared vision practices to define their news labs motto, positions, procedures, and passion. The current study determined that leadership plays a 
leading role in K-12 journalism education. The current data analysis identified the vital need for editorial leadership in scholastic journalism programs. Editorial leadership provides advisers and students the practices and behaviors to lead an effective, efficient, and vibrant media system within their news labs.

\section{Motivation}

Advisers have the daunting responsibility of leading all students to perform to the best of their ability; however, the motivation lays with student leaders to support the news lab's overall vision. Leadership is important in high school journalism education because advisers must create news lab practices and behaviors to meet production goals. Filak's (2003) study revealed it also to be the case that leadership builds culture by aligning support systems to reinforce learning and student motivation. Therefore, it is imperative advisers enable their students to be trusted leaders through news labs common vision.

Participating advisers inspired their students to be trusted leaders in a variety of ways that illustrates the fluidity of leadership practices. These current results should be taken into account considering how Merits' (2013) previous research found superintendents and principals can provide money and equipment to keep journalism programs working toward their goals, but perhaps the biggest obstacle is trust (Merits, 2013). It is critical for advisers to encourage their students throughout each step of their leadership training. Advisers instill confidence in their students by designing their news labs into a community of learners. Students must become part of the news lab community before they can become a leader. Teaching leadership is not a mandated curriculum standard, but a process where advisers encourage each student to master skills. Advisers 
continually provide their support to students until a skill is mastered within their own timeline, abilities, strengths, and weaknesses. There is an importance for advisers to encourage their students with celebrations. The celebrations develop the students' teamwork, confidence, and passion. Collins (2017) also found that higher education newsroom cultures use transformational ways to help students be encouraged and socialized to challenge one another through the newsgathering processes. Overall, advisers encourage their students to first individually master skills to grow into news lab leaders.

Participants in the current study believed focusing on their student's strengths was important to encourage student leadership development. Advisers must trust students before enabling them to be leaders. First, advisers establish student accountability with clear expectations. The students that consistently meet expectations become news lab leaders. Consequently, advisers claim those rigorous expectations heighten their students' motivation to be leaders. Therefore, once students become accountable to the news lab expectations, advisers motivate selected students to be leaders. Contrary to traditional news lab positions where journalists there are set positions, advisers establish the student leadership roles and expectations depending on their student strengths. Ferguson, Patten, and Wilson's (2005) previous research said traditionally in a high school news lab, organization of the school's production parallels commercial productions mandating the same leadership positions. The current study revealed an interesting finding that advisers discover their student strengths and then define the news lab's leadership positions. Furthermore, advisers establish leadership positions and provide the editors with specialized training and duties. Leadership is taught to the core student leaders and the 
soft skills are expected to trickle down. Advisers instill their student leaders to be teachers and work side-by-side with their student staff, maximizing the news lab's full potential.

Advisers are responsible for creating an atmosphere committed to students knowing they must produce a high-quality product for audiences outside the new lab. Motivation is a key reason students show increased commitment to learning due to their news lab's high professional standards and rigorous work ethic expectations. This finding supports Journalism Educators Association's (2019) standard that high school journalism educators demonstrate the expertise to engage students with effective motivation. Overall, motivation is required for editors to lead their staff members through the completion of their rigorous deadline schedules. While advisers commented on their rigorous atmosphere, an overwhelming majority of advisers advocated connecting their students' work with set achievable goals and creating a supportive environment. Similarly, advisers search for opportunities by seizing the initiatives and looking for innovative ways to improve, experiment, and take risks. Advisers seek out challenging opportunities that test their news lab skills and constantly generate small wins and learn from each experience.

A common vision is an essential feature for advisers to further motivate editors to be leaders. Advisers inspire a common vision throughout their news lab to produce their desired production results, encourage creativity, and foster group decision making. It is importance for advisers and their editors to have shared practices and leadership behaviors. It is imperative for advisers to continually articulate production goals with their editors to then delegate to the student staff. Sharing common visions helps advisers 
create trust and consensus around their news lab's goals. These results build on Streisel's (2007) existing evidence that organizational workings of a scholastic journalism news lab have the potential to teach basic ways to plan content and build trust. Trust boosts a news lab's ability for students to effectively meet expectations on their own. Similarly, trust in the relationship between advisers and their student editors is critical. Relationships further build trust within news labs. Through relationships, advisers establish their most effective student leaders.

The processes and role of leadership in scholastic journalism are important. There are important implications to this current study. The advisers' perspectives likely reflect perspectives of prospective, current, and past advisers. It found that leaders used their strengths to build relationships, motivate fellow students, and develop healthy core values within high school journalism. These participants' perspectives should be considered throughout K-12 journalism education. Implementation of editorial leadership could help journalism programs have effective production, encourage creativity, and foster group decision making. Furthermore, increased editorial leadership leads to more successful journalism programs. Ultimately, successful news lab helps to develop students leadership skills to reach their full potential.

\section{Conclusion}

The current study's findings indicated leadership plays a leading role in scholastic journalism programs, known as editorial leadership. When an adviser establishes leadership as a foundation, news lab production increases, creativity is fostered, and decision making is delegated to the students. Thus, leadership skills are important in journalism education. Advisers said soft skills provided opportunities for students to 
grow into leaders. The student leaders then provided advisers opportunities to articulate their passion and genuine conviction. The advisers interviewed for this study were transformational leaders, creating trust and consensus around their news lab's common vision. Many transformational leadership theory components were present within Missouri's scholastic journalism news labs. Kouzes and Posner's (1987) fundamental practice of inspiring a shared vision was the most utilized.

\section{Implications}

As this current study is one of the first studies on editorial leadership, the resulting recommendations provide a new insight into the relationship between professional newsroom leadership's soft skills, which should be considered transferable to high school journalism news labs. By analyzing how high school teachers teach leadership, the data have shown how advisers directly shape their news labs' effective production, encourages creativity, and fosters shared decision making. The researcher offers suggestions to advisers and future research.

\section{Implications for Practice}

This research identified the unique perspectives of high school journalism educators to highlight their recommendations for other advisers to teach editorial leadership through honed soft skills and a deeper understanding of passion and genuine convictions to transform their students into leaders. The purpose of this qualitative study was to assist journalism educators by exploring scholastic journalism advisers' aspects in teaching editorial leadership. Findings presented to administration, teachers and, ultimately, students can encourage and inspire news lab editors to become leaders. This study led to recommendations for actionable transformational leadership aspects. It was 
found important to understand the perspectives of leadership within high school news labs in order to shape leadership development among instructors. It is imperative that journalism educators can demonstrate their ability to motivate students through their common vision. Overall, findings provide a clear picture of editorial leadership in high school news labs for advisers to engage students to have effective production, encourage creativity, and foster group decision making. Thus, advisers can build their news lab upon a solid vision of editorial leadership. The following presents a set of recommendations to advisers based on the findings of this study.

Advisers' perceptions formed the implication for practicing high school journalism educators that there is a need to teach leadership. The implication that high school journalism educators must teach editorial leadership forms the following four, overarching recommendations for practicing high school journalism advisers:

\section{Recommendation One: Engage Student Leaders}

Engaging students in leadership opportunities and actively learning journalism are critical processes. It is imperative advisers recruit a variety of established high school leaders to be part of their news lab. In fact, in scholastic news labs advisers must teach learning as a critical process focused around building a community of learners, creating a team, and individualizing instruction to meet each student's needs.

Build a Community of Learners. It was imperative for advisers to create learning communities with strict standards for entry. The advisers inspired their students to want to learn the technical skills to become a student journalist. Becoming accepted into a scholastic journalism class provides students an opportunity to learn basic skills 
and become immersed into their news lab norms. Effective recruiting and to be part of the news labs' community of learners and training ensures efficient production.

High Entrance Requirements. It is imperative advisers hold high standards for news lab entry by creating initiation processes and looking for already developed leadership skills in their applicants. Making a high school news lab a community of learners needs to start during each spring semester to establish the upcoming year's admittance standards and learned skills. Advisers can treat the entrance process as if the students were in a professional job interview by requiring a written application, grade evaluation, teacher recommendation, portfolio with writing and photography samples. Editors and advisers need to interview candidates with a 15-minute, face to face interview to make sure the candidate has the basic skills. Also, the editors and advisers need to look for enthusiasm, self-motivation, work ethic, and strengths. Advisers can enhance their understanding of the candidate by using a strengths test as the Myers-Briggs Type Indicator (MBTI) personality test.

Requiring a minimum of a written application, interview and a grade point average standard establishes a value in the news lab community that being accepted in the course is as an accomplishment itself.

Develop Student Journalists. Once students are selected to be part of the news lab, advisers are ready to teach and inspire students to develop their skills. Leadership skills develop through a specific set of hard and soft skills. Initially, advisers need to teach hard skills such as law, ethics, writing, photography, and interviewing. Once hard skills are mastered, advisers need to purposefully teach soft skill aspects such as teamwork, communication, critical thinking, problem solving, and work ethic. 
Specifically, the critical writing and publishing process in the news labs provides advisers with opportunities to teach soft skills. A news lab offers diverse ways to learn soft skills. Advisers should foster their news lab so students can learn soft skills through activities including the communication skills used to conduct a meeting by listening and questioning other students. Students can learn management by leading team building exercises. Also, time management is learned through the news lab's deadline planning, process, and completion. Soft skills are not dictated within scholastic journalism's curriculum standards, soft skills are critical to teaching journalism leadership by setting communication and social standards. Ultimately, soft skills aids in students developing into effective leaders.

Establish Teamwork. While advisers need to build a community of learners, ritual celebrations are also needed within their news lab's production process to develop a team. Advisers engage their students to be part of their news lab community by recognizing student contributions. Advisers show appreciation for individuals as well as team excellence. They celebrate the news lab's values and victories, creating a spirit of community and family. Advisers need to not only use the key benchmarks within their production process to celebrate individual and team success but, more importantly, to establish partnerships through the news lab. Through celebrations and creative traditions, advisers form common bonds with their student staff members. Advisers use key points to celebrate with creative traditions to establish the news lab into a team of student journalists.

Celebrations. Advisers' ritual celebrations within their news lab's production process develop teamwork and confidence. Traditions are made to celebrate throughout each step of the news lab's production process. Advisers must make it a priority to 
celebrate their students. There is a need to celebrate each deadline accomplishment by congratulating students individually and their whole news lab staff. Advisers will also enhance their news lab team by observing staff exceeding the workflow process during a deadline cycle. Celebrating can be done by highlighting student writing by reading through each student story and providing a positive recognition verbally or through a trophy or certificate. The celebration needs to be based upon the students' need and enthusiasm. These recognitions can be done during and at the end of each production.

Creative Traditions. Creative celebrations as a whole news lab helps find the group's identity. News labs will enhance their teamwork by providing creative celebrations, such as t-shirts, pep talks, editors' talk, food, and bonding nights throughout each step of their news lab process. It is essential to be creative with student celebrations through periodic team-building and reflection exercises. Self-care exercises can enhance the motivation for the advisers to help their staff gain comfortability as writers individually and as a team.

Awards. Providing in-house awards for every deadline cycle such as best story, best design, as well as leadership awards to find staff members who embody journalism principles and leadership will reinforce the news. Advisers should practice making awards a priority to recognize individual accomplishments and include the whole staff. Rewarding good work sets the standard for the news lab's best journalism practices.

Meeting Student Learning Needs. Advisers must help each student learn leadership skills in a variety of ways. Differentiating instruction can meet each student's needs and helps students master journalism skills. 
Individual Growth. First, advisers need to develop their students' skills by setting goals with the student based upon the student's performance. Advisers can do this when a student completes a challenging story. The student's success is based on their growth from their initial skill level throughout the year. Consistent skill development and reflection leads to student success because it pushes the student to excel. Advisers can do this when a student completes a challenging story, making sure the students feels a sense of accomplishment.

Determine Goals. Clear, concise goals will keep students focused on mastering their skills. Discussions about the goals push students to excel. Advisers should be differentiating their instruction for each student to help with their overall performance. Each staff member should generate some individual goals. The students' goals need to be challenging, yet attainable. A student's individual goal may be learning a basic hard skill, scheduling a phone interview without help, or improving copy editing. The advisers must begin determining goals at the beginning of the school year. At the start, advisers begin looking at the start of the year of how the students' skills began as a pretest. Then, together they evaluate through a compare and contrast how the skills were mastered at the ended the year.

\section{Recommendation Two: Teach Leadership}

It is imperative advisers teach their student editors to be leaders. Leadership in scholastic news labs impacts individual students. Leadership skills teach practices and behaviors throughout news labs that develop students into leaders.

Focus on Accountability. News labs must have accountability with their leaders to ensure their motivation is maintained throughout their news lab. Accountability with 
clear expectations is a quality necessary for progress and sustained growth. There is a need for student editors to be responsible for the news lab's workflow and ultimately be responsible for their end product. Editors can make a designated area to display the news lab's production schedule with specific dates and names connected to each step of their deadline schedule. While the editors are leading the student staffers, the adviser must constantly make sure each part of the production process is correct and on time.

Editor roles need to be based on news lab needs and student talent. It is important to establish the editors' roles and expectations depending on their student strengths. Advisers discover their student strengths and then define the news lab's leadership positions. An editor may be talented at motivating staffers and photography, so the editor will serve exclusively as a photo editor and delegate all photo assignments throughout the news lab. Once the adviser establishes leadership positions, there is a need to provide the editors with specialized training and duties. Editors must make their leadership training a continual process. Key editors should attend a summer workshop for comprehensive training so that they are ready to lead their news lab production process the first day of the fall semester. Leadership should be taught to the core student leaders and the soft skills are expected to trickle down. Advisers will instill their student leaders to be teachers and work side-by-side with their student staff, maximizing the news lab's full potential.

Establish Editor Expectations. The notion of clear expectations promotes the news lab to be consistently accountable. Establishing accountability requires a commitment from the adviser and editors to have high expectations. Editor accountability with clear expectations is a quality necessary for progress and sustained growth. Each 
year advisers must establish the editors' roles and expectations depending on their student strengths. It is imperative to have clear expectations connecting the scholastic journalism with professional expectations. Establishing clear expectations helps students become strong editors. The expectation should be set by the editors to foster a feeling of ownership and togetherness. The expectations should be attainable, yet challenging. The photo editor's expectations could include working with student staffers to plan and assign photo coverage for productions, copy editor to plan and assign stories and coverage for productions, and editor-in-chief to plan material covered in section and assign deadlines to pages.

Motivate Students. Motivation is a strong facet of how advisers teach leadership. Advisers must take on the daunting responsibility of leading all students to perform to the best of their ability; however, the motivation lays with their student editors to support the news lab's overall vision. Motivation is required to complete their rigorous deadline schedules. Therefore, it is imperative advisers have a common vision in the news lab's rigorous expectations heightening their students' motivation.

Share the Vision. Effective leadership increases productivity and creativity throughout scholastic journalism news labs. The role of leadership helps advisers establish a common vision to motivate their student productions. Thus, advisers and students must gain a mutual understanding of their leadership goals through a shared vision. News labs develop leadership beliefs in multiple ways.

Effective advisers continually articulate their production goals. Then, their editors pronounce their shared vision to their news lab. At the beginning of each school year, advisers must facilitate traditions for students to create their news lab motto. The advisers 
need to lead their student editors to decide on a catch phrase and ideas to motivate their news lab. News lab mottos need to be promoted through room decorations, posters, student $t$-shirts, and the overall news lab productions. Advisers can reach outside of their news lab through books, music, and social media, for their news lab inspiration. Advisers can find further inspiration by attending national conferences, leadership retreats, leadership retreats, and boot camps. These camps and retreats are structured to provide student editors training to make the motto for the upcoming year. There is not one way to do this, but once the school year begins, each news lab must be motivated through the continued use of their common vision. The different mottos will enforce the news labs' shared vision. Common news lab slogans, positions, and procedures are essential for advisers to influence their students' effective production. A common vision and expectations help a news lab to produce creative work based upon their genuine convictions. It is imperative advisers nurture their student leaders who, in turn, will further build consensus to nurture a next generation of student leaders. Ultimately, high quality programs have a continuous cycle of leadership development that appears effortless.

Meet Rigorous Standards. Advisers test their student skills and inspire the news lab to create successful productions. Advisers need to have their news lab have rigorous expectations on a regular basis. Specifically, advisers need to train their editors to effectively delegate the rigorous standards. Editors will need to rise to the news lab's rigorous expectations by delegating responsibility, editors cannot complete the entire production on their own. The rigorous work load needs to be delegated so that the entire news lab is contributing and the editor is not left doing too much of the work. Students 
staffers need a clear outline of what they need from their editors. To effectively delegate, editors need to provide clear instructions, trust others to succeed, check on progress, provide feedback, and reward accomplishments.

Maximize Strengths. Advisers must build on their students' strengths to not only develop their news lab leaders but to create an effective structure for the lab's workflow. Even the editors should learn their strengths and develop them. While further developing news lab leaders' strengths, advisers need to focus on discovering individual potential and providing editorial leadership training for efficient workflow and effective feedback to their students. It is vital for advisers to surround themselves with student leaders who complement their strengths and weaknesses. Advisers need to coach their editors to manage themselves before they manage others. News lab advisers do not just count on their students strengths that already exist. Advisers commented they develop their students' potential, as well, by providing selected editors with opportunities to build their leadership skills.

\section{Recommendation Three: Empower Student Leaders}

Advisers create nurturing environments by helping students make their own decisions to take action. Empowering students to develop as journalists is vital within editorial leadership. Effective advisers positively influence and motivate their students. Creating a safe environment helps journalism students to seize the moment and take risks in their coverage.

Create a Safe Environment. Within a news lab's rigorous atmosphere, an adviser needs to create a supportive environment for discourse. As advisers plan their news lab design, there is a need to define the news lab as a safe place for students to try, 
take action, to succeed, or fail. Advisers have a responsibility for creating an atmosphere committed to students knowing they have the ability to gain confidence in making decisions to produce a high-quality product.

A journalism classroom needs a professional newsroom appearance and nurturing design. Advisers will benefit from their students helping with their news lab set-up, design, theme, and clean-up to make their workflow more interesting and relatable. It is necessary to provide modalities supporting student creativity, such as jars of play dough, baskets of fidgets, stress balls, and a designated creative lounge. As advisers plan their environment's design, they also need to invite students to come and help set up for the upcoming school year. Students can even help with the details such as an editor's bulletin board, which provides information the news lab needs, including the productions deadline schedule, school schedules and goals.

Support Student Decisions. Editors need to take ownership of their news lab's production and decisions. It is essential for advisers to empower their students by making sure all the decisions are left to the news lab leaders. The editors should be expected to oversee the news lab's distinct workflow process. For example, initially, student staffers turn in their rough drafts to their editor to read before the adviser reads them. The editors give feedback and then the adviser reads the final draft. The adviser will sit down with the editor and talk over the students' missed areas. To do this the adviser trains editors to solve problems and find ways to make aspects better by supporting the decisions the editors make on their own. It is essential for the adviser to get out of the students' way and support their decisions. 
Positive Feedback. Advisers should continually communicate feedback and critique with their editors. The editor-in-chief plays the main role in the production process and the adviser ought to make the final decision. The production process must start with the students and then move to the editor-in-chief. Advisers need to create a culture centered around student success, along with an environment which supports a great deal of freedom and choice in deciding how to do their work based on student decisions. Editors must provide feedback in a way that allows student staffers to improve performance and skills; however, the rigorous environment and students not seeing the need for improvement can make this difficult. Advisers need to train their editors to provide feedback in areas that can be improved. Effective editors need to provide timely feedback, praise as often as asking for corrections, be willing to discuss alternatives, and accept feedback themselves. Ultimately, supporting decisions and work through positive feedback helps students gain confidence and empowers the newsroom.

Take Action. The root of creating a safe environment is the adviser helping students trust their own decisions. Once students trust their own decisions, advisers must push their students to take action so they can create more meaningful student news. Advisers should empower students to behave like student journalists instead of just high school students by deciding upon their own goals. Effective advisers challenge their students to try out new and innovative ways to execute their coverage.

Advisers need to teach different ways to do coverage, but still allow their students to make the final decision. Students need to step outside of their comfort zones when selecting their own story ideas. Advisers can enhance their coverage by pushing their news lab to cover national and international events by connecting the topic to the students 
in their high school, which is known as "localizing a story". This teaching strategy helps students find meaningful story ideas. Encouraging students to take action should be a considered condition by requiring covering multiple perspectives in their student news. Editors need to search out different student perspectives to think outside the box for different ways to cover different topics.

Inspire News Coverage. It is crucial for advisers to teach and expose their students to the latest professional standards and trends. Advisers can use textbooks for ethics training and basic skills. There is, however, a need for advisers to continually expose students to expectations outside of the news lab to ensure student growth and empowerment.

Another way to push students to improve their coverage is by showing professional news and award-winning high school news examples. It is important to have students learn by viewing the best news coverage, which cannot be found in a textbook. Students must view posted award winning high school news on scholastic journalism organization web sites, because textbooks do not offer relevant news. Advisers can do this by assigning students to watch videos of journalism examples and review magazines. Students reviewing news stories that even other high school journalism programs create show students the expectation. As advisers may not use textbooks, they must search out many relevant resources to ensure their students can take action to cover their campus with up-to-date skills.

Experiment with Media. While advisers encourage students to take action with innovative story ideas, they also must support experimenting with different forms of media, audiences, and production, as this empowers students. Advisers can do this by 
supporting students to start a campus magazine, podcast, or using Google Docs for the students' workflow by establishing a virtual news lab. It is imperative to make students research their ideas and present their findings before permitting the students to take action. Within each safe and controlled environment, students grow by experimenting with their tools.

When advisers want their students to try new ways to do student news, they should be ready when the result does not go as expected. Advisers should always be prepared for mistakes, they cannot expect perfection, and they need to be satisfied with students striving to produce good work. Students will diligently strive for perfection but may still experience printed errors. When a goal is not met and a mistake occurs, advisers continually strive to find the lesson in the misstep. Each deadline needs to be sure to end with a debriefing with all the students to learn from errors and discuss how to deal with the ensuing public ridicule and critique. In the end, empowering the students to choose the different aspects of the student news empowers them to grow and learn.

\section{Recommendation Four: Impact Student Leaders}

Essentially, advisers must be impactful leaders to their students. Advisers must be impactful leaders for their students, high schools, and communities. Principally, advisers ought to impact their students' through their enthusiasm, influence, and building trust, to be leaders.

Harnessing Enthusiasm. Cooperative relationships and pride in the students' journalism coverage helps the news lab come together and meet deadlines. Advisers' own enthusiasm influences the students satisfaction in the news lab's standards, purpose, and production process. Enthusiasm helps advisers and students have a shared pride in what 
their news lab practices and behaviors. Advisers' visions and strategic goals will help students gain enthusiasm in their decision making processes, as well as in setting priorities and evaluating the progress throughout each deadline.

Build Trust. Advisers will establish their most effective student leaders through deliberate processes designed to encourage students in direct and personal ways. Advisers' strong relationships and ongoing communication maximize the trust throughout their news lab. Trust in the relationship between advisers and their students is worth emphasizing, due to the significance an adviser has being a leader in journalism education. Through relationships, advisers will establish their most effective student leaders. Advisers can build relationships by treating editors like adults and being authentic. Essentially, trust boosts a news lab's ability for students to effectively meet expectations on their own.

The editors know the programs and will handle the heavy lifting to keep the production moving. When students see an adviser say, "Let's do this," they know they are trusted. In the end, advisers impact students by establishing strong relationships to build trust throughout their news lab.

Trust is built upon ongoing communication. As a result of clearly communicating their goals, the staff develops a strong mutual trust. Advisers need to welcome conversations on culture, emphasize publication importance, develop reasons to care, and instill a desire to participate.

A focus on communication helps advisers create a positive news lab, which is encouraging to students. To support open communication, advisers must encourage their students to communicate regularly through scheduled and non-scheduled conferencing. 
Establishing ongoing communication impacts students and advisers to trust each other to reach their news lab and personal goals.

Overall, high school journalism educators must teach editorial leadership in high school journalism education. Students in editor positions need to be provided with specialized training and duties. Teaching editorial leadership is a process throughout a student's years in a news lab. Advisers teaching leadership must motivate their students. A common vision and expectations help a news lab to produce creative work based upon their genuine convictions. It is imperative advisers nurture their student leaders who, in turn, will further build consensus to nurture a next generation of student leaders. Ultimately, high quality programs have a continuous cycle of leadership development that appears effortless.

\section{Implications for Future Research}

The following offers a set of recommendations providing suggestions for future researchers exceeding the scope of this study. The recommendations are based on the study's findings. This present study offers important insights about the research problem, insight and implications for how to effectively utilize editorial leadership within scholastic journalism news labs, all while adding qualitative research to the field. From this research, suggestions for future research are recommended.

While previous research has focused on leadership development in professional and college newsrooms, these results demonstrate high schools integrating leadership skills in news lab throughout Missouri. This study provides recommendations for actionable editorial leadership training, policy and change within Missouri’s high school journalism educators' curriculum. Although editorial leadership is a prevalent concept 
within the scholarly conversation around secondary journalism education, it is a term that was not been researched.

Further research is needed to establish how Missouri's editorial leadership practices may be the same. Future studies may want to identify additional journalism programs teaching editorial leadership. Journalism is taught at all grade levels. This current study focused on high school journalism news labs. Future studies may focus on K-8 or middle schools. In addition, future research could investigate journalism advisers teaching leadership in higher education schools.

\section{Significance of the Study}

It was important to understand the perspectives of leadership within high school news labs in order to shape professional development among instructors. This study could be used to increase awareness and utilization of editorial leadership within scholastic journalism. Currently, there is a lack of studies exploring scholastic journalism advisers' best practices to teach editorial leadership. Findings could be presented to administration and teachers and, ultimately, more teachers could be encouraged and inspired to become leaders.

Although editorial leadership is a prevalent concept within the scholarly conversation around secondary journalism education, it is a term that has not been researched within Missouri's high school news labs. Previous research indicates many student journalism publications become stagnant due to advisers' lack of training (Abrahamowicz,1988).

Within the scholarly conversation, there are two key studies that critique the lack of research regarding effective newsroom pedagogy. Bronstein and Fitzpatrick (2015) 
contend that reform is needed to develop effective ways to engage learning, to gain future-focused academics using curriculum. Second, Collins (2017) argued college newsrooms use transformational leadership theory aspects in their cultures. Collins' study further suggests transformational leadership theory helps encourage and socialize journalism students. The previous research focusing on leadership development in professional and college newsroom relates to high school news rooms. The current study revealed high school journalists also challenge one another through their newsgathering processes, and news judgment decisions. Examining the effective ways high school advisers teach leadership have gleaned further insight for the body of literature.

\section{Summary}

The researcher identified the unique perspectives of high school journalism educators to highlight recommendations for advisers to teach editorial leadership through honed soft skills and a deeper understanding of leadership. Advisers' perceptions of teaching editorial leadership within high school news labs in the midst of a radically transforming journalism industry needed to be explored. The purpose of this qualitative study was to assist journalism educators by exploring scholastic journalism advisers' methods in teaching editorial leadership. Findings may be presented to administration, teachers and, ultimately, students could be encouraged and inspired to become leaders.

Academic leaders need to set new standards for excellence, reflecting how different styles of advisers' leadership affect news labs (Cowan, 2009). Developing editorial leadership approaches to journalism education could help educators to "seize this moment to create alternative models of journalism to invigorate advisers and inspire 
students in ways that would allow journalism education to fully contribute to the next era of journalism” (Mensing \& Ryfe, 2013, p.40) 
SECTION TWO

PRACTITIONER SETTING FOR THE STUDY 


\section{Practitioner Setting for the Study}

\section{Introduction}

Over a century after Walter Williams developed the first journalism school in the world, he could have not predicted his vision would spark 2019 to be The Year of the Student Journalist (Gavankar, 2019; Weinberg, 2008). The relevant history of the role of education in journalism provides a deeper understanding of the transformational context surrounding the advisers leading Missouri’s high school news labs. Particularly, delineating journalism education's background in association with scholastic journalism's impact on their campus and communities advances an indication into the craft's developments, movements in academia, and the changes in the field. Each puts forward a specific context for studying the Missouri's Interscholastic Press Association's AllMissouri advisers.

The organizational analysis further explores how high school journalism teachers teach leadership throughout Missouri's high schools based on MIPA's categories of school district size, the All-Missouri level of success, and geographic region. Furthermore, an organizational analysis will reveal the actual complexity regarding leadership in high school news labs. Specifically exploring the adviser's news labs through transformational leadership theory and Kouzes and Posner's $(1995,2002)$ fundamental practices of leadership model will provide an analysis of scholastic journalism news labs' design to allow further study of the socialization process as well as mimic infrastructures of the professional industry to reveal how advisers teach leadership (Collins, 2017). In the same way, this analysis will investigate the individual and innovative transformational leadership practices within news labs and strong emphasis on 
followers' needs, values, and morals (Northouse, 2016). Similarly, outlining the leadership of Missouri high school news labs within their historical and present contexts will provide the setting for this research study to examine the ways advisers can "initiate, develop, and carry out extraordinary changes in organizations" (Northouse, 2016, p. 175).

\section{Historical Background}

From its earliest conceptions, journalism education has been about training students to work for newspapers and is an important part of leading the next generation in civic engagement and responsible oversight of the public sphere (Becker, 2003; Dickson, 2000; O'Dell, 1935). The skills learned in working in student media help create engaged citizens and lifelong critical thinkers (Gavankar, 2019). As Carey (2000) noted, journalism education came to life in the "age of the reporter", when the role of a journalist was to find information, shape it into an accurate story and transmit it as quickly as possible to a mass audience via a mass medium. This model of journalism, taught in journalism schools and run as a business by news organizations, has remained unchanged for many decades.

\section{The Advent of Journalism Education}

In 1908, Walter Williams could not have predicted that one hundred years after inventing the world's first journalism school his vision would continue through the opening century (Weinberg, 2008). Williams devised a journalism education philosophy that grew as part of a 1920s U.S. reform movement. From the beginning, Williams envisioned a school of journalism that would positively influence the quality of journalism and advertising worldwide. Rural Boonville, Mo., where Williams grew up, was an unlikely epicenter for global change in journalism, but Williams was no ordinary 
newspaperman (School of Journalism, 2019). At age 25, he became the youngest-ever president of the Missouri Press Association, which now is almost 160 years old. After founding the School of Journalism, he went on to become president of the University of Missouri.

Williams made certain that the lessons of Missouri Journalism reached worldwide by training journalists from China and bringing a World Press Congress to Missouri. He also wrote The Journalist's Creed, a statement of journalism and advertising professionalism cherished as the most important pronouncement of its kind, which adorns the walls of the National Press Club in Washington - in bronze (School of Journalism, 2019). Throughout the Progressive Era, Williams' vision to improve journalistic standards by raising the educational level of newspaper employees was shared by others (Gaunt, 1992; O’Dell, 1935; Sutton, 1945; Weinberg, 2008). In 1922, Walter Lippmann likened the news to "a beam of a searchlight that moves restlessly to bring one episode and then another, out of darkness into vision" (Folkerts, 2014, p. 258). In American history, twelve generations have continually experienced the illumination of journalism (Newton, 2018; Rosen, 2018). News leaders have satisfied audiences' needs to know things otherwise not experienced personally (Campbell, Martin, \& Fabos, 2018). Conceivably, Williams' greatest achievement was his establishment of the school around an all-important principle that the best way to learn about journalism and advertising is to practice them (School of Journalism, 2019). Williams could not have predicted that his academic invention "exemplifying the high ideals of journalism: truth, fairness, generosity, devotion to duty, unselfish public service" (Hieman, 2009, p. 18) would be so 
durable- even as the authors of the First Amendment "could have never predicted the durability of their seminal document" (Weinberg, 2009, p. 13).

\section{The Emergence of Scholastic Journalism}

Soon, William's vision grew to match the national trend. Throughout the early 1900s, journalism courses began to be considered a viable subject in almost every high school's curricular or extra-curricular program (Konkle, 2009). William's vision set a foundation in high schools to teach rights and responsibilities. Historical journalism education roots in high schools can be traced back to 1927 , where textbooks on secondary school curriculum, education history and school administration often noted the growing importance of including journalism and student productions in a school's curricular or extra-curriculum program. Koos (1927) gave value to student journalism by stressing "any production that serves as a medium of communication for the school community, if prepared by the student body as a real record of interesting school happenings, and if properly edited, should have an important place among the activities of a modern high school" (Koss, 1927, p. 609).

In the same way, Spears and Lawshe's (1939) first edition of "High School Journalism" defined student journalism by dissecting how news, features, editorials and sports stories should be written. Spears and Lawshe (1939) briefly wrote about design importance and highlighted how national school press associations were structured to assist production advisers and student journalists.

The call for national school press associations inspired such associations as the Missouri Interscholastic Press Association (MIPA) and others across the nation at each state's level to help assist production advisers and student journalists. In 1922, as the 
Missouri School of Journalism Dean, Williams being only a high school graduate himself, had a ground breaking notion to establish MIPA to be an integral part of supporting journalism advisers and students across the state of Missouri.

MIPA was founded in 1923 by Williams and E.W. Tucker with the Kemper Military School (later Academy) (MIPA, 2019). MIPA's board was drafted in the fall of 1922. Then, the first organizational meeting was held on May 5, 1923 through the efforts of students and faculty from 12 high schools from Boonville, Springfield, Hannibal, and Kansas City. Williams labored to form relationships with high school journalists and newsroom professionals to educate youth before they applied for college (Weinberg, 2008). According to the School of Journalism's founder, the purpose of the group, "shall be to further the interests of preparatory school journalism in Missouri and to stand for the highest standards of journalistic effort and achievement among preparatory school students" (Heiman, 2009, p. 26). By 1929, representatives from approximately 300 schools belonged to MIPA (Heiman, 2009). From the start, the group offered internships, printing facilities, and training to students and advisers through the Journalism School (Weinberg, 2008). Williams and future deans valued high school relationships to the point that it was a goal to hire faculty on the basis of their rapport with high school students (Weinberg, 2008). In 1955, some 40 Missouri advisers attended a "First Short Course" sponsored by MIPA.

\section{Scholastic Journalism's Impact}

High school journalism education has a unique contribution to students' civic development and communication competencies (Bobkowski \& Miller, 2016). High school journalists have made such an impact that 2019 was recognized as "The Year of 
the Student Journalist" (Gavankar, 2019; Weinberg, 2008). Students in high school journalism programs report that they follow and engage with important community issues and that by informing their audiences about these issues, they perform civic service and learn to effectively contribute to the civic process. (Bobkowski \& Miller, 2016).

Previous scholastic journalism research suggests high school journalism education benefits students to ensure curriculum remains (Wilderman, Nasrin, \& Davis, 2018). Student journalists are likely to be more engaged citizens than students not involved in journalism, taking deeper interest in current events and establishing free-expression literacy (Bobkowski \& Miller, 2016). Journalism strengthens a society's democratic functions (Siebert, Peterson, \& Schramm, 1963).

Studies show that school-based and non-school journalism programs support civic engagement among young journalists (Clark \& Monserrate, 2011; Graybeal \& Sindik, 2012; Marchi, 2011; Neeley, 2015). Bobkowski and Miller (2016) found that journalism has potential influences of social studies, debate, community service, and student government. Bobkowski, et al., (2016) further showed that students who earn journalism credit in high school tend to vote more frequently than their peers who do not take journalism. "High school journalism extracurricular activities lead students to an early decision to study journalism and that decision is a powerful predictor of job market success" (Becker et al., 2014, p. 354). Bobkowski and Miller (2016) noted there is something about students who take journalism, compared with students who participate in other civic activities, and about journalism education itself that translates into a specific combination of civic outcomes and increased voting. 
Leaders in High School Journalism Classes. Journalism students also make a positive attachment to school, also known as investment or engagement in school (Fredricks, Blumfield, \& Paris, 2004). Students with a positive attachment feel they belong at school, experience being a student as an important component of their identities, and understand doing well in school is a worthwhile goal (Finn, 1989). Positive attachment manifests in school participation, which ranges from basic engagement in assigned classroom activities to involvement in extracurricular activities. Students who are invested in their schools, as opposed to those who feel alienated from school, are likely to participate in school activities beyond the basic curricular requirements. Research demonstrates journalism students' positive attachment to their schools. Half of the production staff members in Dvorak et al., (1994) first ACT study were involved in student government during high school, compared with $24 \%$ of non-staffers. Production staff also had higher rates of involvement in special-interest and academic groups, completing projects, and participating in community service (Bobkowski, Cavanah, Miller, 2017).

Not only do the students in journalism programs engage in school and report on important issues in the life of the school or school district, but as the number of professional journalists has dwindled, student journalists often also fill the gap in reporting on county, state and regional issues (Gavankar, 2019). In 2014, a Pew research study found that student journalists made up $14 \%$ of the overall state house reporting corps (Gavankar, 2019).

Today, high school student journalists play a key role in classroom and the civic life of their communities. According to two national assessments, most U.S. high schools 
offer student journalism programs (Bobkowski, Goodman, \& Bowen, Perkins, 2012). A 1991 survey of journalism educators in 834 schools reported that 79 percent of schools had student newspapers, 13 percent had broadcasting programs, and 93 percent had yearbooks. A 2004 survey of 327 school principals, meanwhile, reported that 74 percent of schools had student newspapers, 3 percent had radio programs, 14 percent had television broadcasts, and 21 percent had online news operations (Bobkowski, Goodman, \& Bowen, Perkins, 2012).

Different communities view the importance of journalism in distinctly different ways and, consequently, some schools drastically under value its role in their community. For example, in recent years, students broke important stories about teacher misconduct in Utah, improper transfer of student athletes in Arkansas and disciplinary charges by a state agency against an administrator in Vermont. In 2009, at Missouri’s Boonville High School, distribution of the student newspaper was stopped because administrators believed stories about homosexual students and crowded buses would be disruptive to the educational process (Brenner, 2009). The superintendent also objected to the word "sucks" in an editorial about cafeteria food, which he described as an obscenity. During the same month, at Timberland High School in Wentzville, Missouri, a principal ordered the removal of all advertising and editorial content about tattoos because of ageappropriateness concerns (Brenner, 2009). Although different newsrooms may produce vastly different production, one can safely draw the conclusion that these student news labs hold the torch of Williams' vision almost 100 years later.

Throughout the last decade, scholastic journalism has made such a resonating impact the Newseum, the Freedom Forum Institute and the Student Press Law Center 
declared 2019 the Year of the Student Journalist to recognize the important role of student journalists, the impact they make, the challenges they face and to mark the 50th anniversary of the 1969 U.S. Supreme Court decision in Tinker v. Des Moines Independent Community School District, which defended the free press and free speech rights of students (Gavankar, 2019). Student journalists report important stories and produce content that shines a light on their community. Sometimes they are the only reporters in the room at important public meetings (Student Law Press Center, 2019). Advisers must teach their students to be leaders in the classroom and in the professional field as their news labs often break stories through diligent investigation and good reporting.

\section{Scholastic Journalism Today}

For nearly a century, the Missouri Interscholastic Press Association (MIPA) continues to educate advisers and administrators in the field of journalism education and production advising for middle and high school students and teachers. MIPA separates the state into four different regions. These four regions of Missouri are divided by Highway 50 and Highway 65. In addition to serving as boundaries within the state for its board leadership, these regions are commonly used to organize state level activities and competition. Two of the four regions are primarily urban areas: Kansas City and St. Louis. In contrast, the other two regions have a variety of rural, urban, and suburban student populations (Missouri Department of Elementary and Secondary Education, 2019).

MIPA represents students in grades 9-12 attending each high school enrolled in journalism courses. Journalism courses encompass Yearbook, Broadcast, Newspaper, 
Advertising, Photography, Multi-media and Social media classes (Missouri Department of Elementary and Secondary Education, 2019). It does not include pre-K-8 or students who are homeschooled. MIPA stratifies Missouri into four different categories which are based on each high school's population. Therefore, schools were divided by the following school population-categories: extra-large schools 1,700+ students; large schools 1,2011,700 students; medium schools 701-1,200 students; and, small schools 1-700 students (MIPA, 2019).Small high school advisers (less than 700 students) report different utilization of professional development and resources than do larger schools $(1,700$ or more students).

Currently, MIPA serves Missouri's smallest of the high school journalism programs, as well as the largest of programs. Advisers across the state collaborate through a mentoring program, production critiques, contests, support student rights, and utilize MIPA's resources, programs, and services. Also, throughout the year, workshops are available for advisers and students. The organization has extensively broadened its mission statement to work with students and advisers around the state of Missouri to further journalism education by providing support and recognition for scholastic journalists, advisers and their schools. The state organization works in association with and is governed by the University of Missouri - Columbia's School of Journalism, Journalism Educators Association (JEA), and the National Scholastic Press Association (NSPA).

In 2019, MIPA's 95th Anniversary marked its partnership with the Missouri School of Journalism at MU, as well as its 50th Annual Scholastic Journalism Day (JDay). J-Day is MIPA's annual journalism celebration held at MU in Columbia each 
March for over 1,500 visiting students. For over 50 years, MIPA has hosted high school students and advisers for a full day of speakers, workshops, and awards. All MIPA member advisers and their students attend for no cost. Dozens of schools from across the state bring their entire staff to MU's campus for speakers and competitions, where students write stories and take photos to submit under deadline pressure on event day in the hopes of earning an award during the awards ceremony. MIPA's highest placement is the All-Missouri award, which is provided to high school productions meeting the highest standards in their journalistic coverage. The All-Missouri Awards are granted to newspaper, photography, yearbook, broadcast and multi-media coverage throughout schools which are divided by the following school population-categories: (a) Extra-large schools 1700+; (b) Large schools 1201-1700; (c) medium schools 701-1200; and, (c) small schools 1-700 (MIPA, 2019).

Small high school advisers (less than 700 students) report different utilization of professional development and resources than do larger schools (1700 or more students). Supplementary instruction is provided through an annual summer workshop for advisers to acquaint students with journalism career and college possibilities. Also, MIPA encourages all production advisers to become state certified in journalism and seek additional certification by the Journalism Education Association. The organization also serves as a liaison for individual schools to approve journalism courses as English courses. The group encourages school administrators to hire certified journalism teachers to serve as journalism instructors and to serve as advisers to productions. There is a significant difference between high school news labs that are large compared to schools that are small. MIPA empowers all journalism advisers through a symbiotic relationship 
investing in advisers learning to build systems and practices for sound editorial leadership philosophies throughout the state into each large and small news labs. Ultimately, the organization encourages all Missouri journalism instructors and advisers to obtain MIPA membership.

\section{Organizational Analysis}

The following organizational analysis employs Bolman and Deal's (2013) structural and human resource frames to analyze how advisers prepare their students to be leaders while encouraging scholastic journalism solutions within the radically transforming journalism industry (Pavlik, 2013). The organizational workings of a scholastic journalism news lab has the potential to teach basic ways to plan content and build trust (Streisel, 2007). The Knight Foundation's review of the future of journalism finds journalism curricula lacking in currency and suggests that the ability to track and adapt to changes in media technology and audience preferences is as important to journalism education as teaching Associated Press style and the inverted pyramid used to be (Wenger, Owens, \& Cain, 2018).

\section{Analysis of News Labs through the Structural Frame}

Specifically examining "right roles and relationships to accommodate collective goals and individual differences" (Bolman \& Deal, 2013, p. 45), the following structural analysis addresses scholastic journalism's responsibility, differentiation across news labs roles, and how the leadership integrates its efforts towards common goals to result in cohesion (Bolman \& Deal, 2013).

High school news labs have a flow of power and an established hierarchy used to move content from one point to another. Much in the same way, manufacturing 
commonly employs a setup with divisions of labor for large scale production. For example, American Industrialist Henry Ford is known as a manufacturer assembly line pioneer. He created a production method that put people in specific roles to be quick, efficient and kept costs down. For years, journalists used this same method when producing the news (Striesel, 2007). First, a reporter would write a story. Then, a photographer would be assigned to take some photos to accompany the story. Finally, the reporter and photographer submit their work to a waiting designer who combines their work to have semblance of order.

Now consider how many professional newsrooms do not use Ford's assembly line method any more, as the news is not a duplicate remake every day (Streisel, 2007). Today's news labs' effectiveness is due in large part to their structural organization. Bolman and Deal (2013) attribute this type of success to the use of the many methods successful organizations use to coordinate individual and group efforts and to link local initiatives with systemwide goals through formal vertical chains of command and lateral network structures of meetings, committees, and coordinating roles.

Roles. Bolman and Deal (2013) establish how successful organizations use many methods, as in news labs, to coordinate individual and group efforts and to link local initiatives with systemwide goals through formal vertical chains of commanding roles and lateral network structures of meetings, committees, and coordinating roles. Today's need for putting the right people in the right position stands on Breed's (1955) landmark claims that a strategic newsroom structure and design allows an editor to effectively empower reporters. More than 30 years later, Vicere and Fulmer's (1998) research postulated the best programs embody a systems perspective. Today's scholars argue 
newsrooms are a developed system of roles having distinct social aspects and a structured hierarchy (Bourdieu, 1984, 1990, 1991; DeBruin \& Ross, 2004).

News labs may struggle with structural decision-making. Bolman and Deal (2013) explain that creating roles and units yields the benefits of specialization, but creates problems of coordination and control of how to ensure that all diverse efforts mesh. Units tend to focus on their separate priorities and strike out on their own. The result is "suboptimization, an emphasis on achieving unit goals rather than focusing on the overall mission. Efforts can become fragmented and performance suffers" (Bolman \& Deal, 2013, p. 51).

Normally, in a professional newsroom information and decision-making flows from a producer out to everyone else. In a high school news lab, organization of the school's production parallels that of commercial productions (Ferguson, Patten, \& Wilson, 2005). At the top is the publisher. The board of education, elected by the public, appoints a superintendent who in turn appoints a principal of the high school. The principal functions as a publisher. The principal, usually working closely with the journalism adviser and the students, sets guidelines - general policies within which the production staff must function. Serving as liaison to the publisher, the public, the faculty, the students, and possibly the printer, is the journalism adviser (Ferguson, Patten, \& Wilson, 2005). He or she has a difficult job and is sometimes caught between conflicting aims of students and administrators (Student Law Press Center, 2019).

In the organization of a production staff, the managing editor is at the top of the pyramid, determining policies and developing story ideas (Ferguson \& Patten, 2005). Subeditors, sometimes organized by the page for which they are responsible, work under 
the managing editor's direction. Sports editors, chief copy editors, and editorial page editors are in this group. All help supervise reporters.

The news lab staff is comprised of student reporters. Students in news lab leadership positions are editors in chief, managing editors, assistant editors, editorial directors, page-section editors. Editorial Leadership is not for news lab staff "rookies". It is a position designed for experienced news lab students who are in leadership roles on their respective productions (Westbrook, 2019). The adviser is the hired high school faculty, which is the news labs' content expert while engaging with students and reflecting upon production (Downes, Hayes, Furnas, \& Newton, 2012).

Reporter Roles. Reporters complete the basic work of writing the stories. Reporters can either cover a beat, returning always to the same sources and subjects, or do general assignment work (Ferguson, Patten, \& Wilson, 2005). General assignment reporters cover whatever is necessary. The real eyes and ears of any production are its reporters at professional newsrooms, the wire services provide a great deal of copy (Streisel, 2007).

Editor Roles. Some news labs choose to assign editorship positions, with editors being in charge of one specific area. According to Osborn (1998), many times the position depends upon the size of the staff and number of stories required. In this case, job descriptions match the content of the news lab's production. The advantage of assigning editorships to a specific area is that it permits an editor to see that reporters follow through and to help with every phase of a story, from inception in pre-production to the final editing in post-production. Once approved for production, some stories may be pooled to use where they are most needed or effective (Osborn, 1998). 
With small staffs, certain positions such as business manager and advertising manager may be combined. Conversely, with larger staffs and bigger news productions, advisers there may be a need for a managing editor in addition to editor in chief, and such positions as feature editor may be divided into several categories, for example, feature and entertainment (Osborn, 1998).

Adviser Role. According to the Journalism Educators Association (2019) advisers are content experts, engage students, and reflect. Advisers understand content, development, and differentiation. These advisers engage students with effective communication, management and motivation, planning, evaluation, and the best instructional strategies. Finally, journalism educators seek professional growth by actively reflecting on their practices individually and in professional learning communities. Scholastic journalism advisers' leadership standards embrace production standards which can meet citizenship expectations. An adviser's job is to be their students' supporter to print the truth and be brave (Stapp, 2013). It is his or her job to be an educator who champions freedom of speech, but may take some heat for what the student journalists produce in their student newspapers, news magazines, and online productions (Merits, 2013). Therefore, advisers must ensure their news lab students are leaders.

\section{Efficient News Gathering}

Seemingly, if there are good working relationships between the adviser, staff, editors and the administration, then the production can work to its full potential. Ideally, the adviser will advise on matters of law, libel, and good taste, and let the students essentially run the program. This leaves the editors as the leaders of the staff, which will 
closely mimic a professional newsroom. While it can be a large responsibility, it is an opportunity for the editors to develop leadership skills that will help them through college and into their careers (Robertson, 2002). Breed's (1955) foundational study reflects the news labs policies and procedures, again, were not part of an overt brainwashing but rather an informal process in which new reporters learned from veterans. Therefore, emerging leaders learn how to define what journalism is and who they are through socialization within the college news lab (Collins, 2017).

\section{Vertical Coordination}

A news lab's vertical apex ensures the staff will meet deadlines, but it is not enough to guarantee audiences receive truthful, diverse, and informative coverage. For example, Mintzberg's organizational model reflects the newsroom roles' structure. The executive producer is at the top of the strategic apex's hierarchy. The top position is over the "middle-line" editors to transmit authority from the top to the bottom towards the “operating-core” reporters (Mintzberg, 1979, p. 220). From the pre-production meeting until the end in post-production, the student-editor oversees the process directly and indirectly, by being in charge of the workflow and key student staffers, such as reporters and photographers (Collins, 2017). The reporters complete the basic work of producing the stories. Yet, the vertical alignment hinders coverage decisions during coverage meetings due to the decision-makers ability to connect with the decisions made by the operating core of reporters (Bolman \& Deal, 2013).

\section{Lateral Coordination}

Often commands, rules, and systems do not motivate behavior, creating a need to have simpler and quicker informal structural coordination with more flexibility than 
authority-bound systems and rules (Northouse, 2014). Today, newsroom productions have started new radical forms of staff planning and organization called "maestro" method, which is an organizational method that coordinates all of the different stakeholders in a story or page or section of the news production. Everyone has a part and an equal say in the news story's production and ensures that everyone is creating. Through the process, the reporter is writing, the photographer is shooting pictures, and the designer enhances the story's point of view. Newsrooms have regular collective meetings, called budget meetings, to make coverage decisions. Bolman and Deal (2013) clarify formal gatherings and informal exchanges are the cornerstone of lateral coordination. Hence, the producers use lateral coordination techniques to delegate to the editors to make many of the decisions in budget meetings. The budget meetings provide the lion's share of lateral harmony in a relatively stable newsroom (Bolman \& Deal, 2013). Conversely, a newsroom's success also depends on the members' ability to work as one unit within the confines of a deadline with vital informal contacts and exchanges to keep the reporters together in their fast paced, turbulent environment (Bolman \& Deal, 2013).

\section{Goals}

Clear, concise goals keep a news lab staff focused on a good production (Lundgren, Cutsinger, \& Herron, 2019). As the objective of a news lab is to produce a scheduled newscast, the adviser and editors have standards and values, which include positions and actions of editorial leadership (Collins, 2017). A news lab emphasizes hands-on craft and provides opportunities for applied learning. "Students learn by doing, by reporting and writing, by photographing, or by making video or audio recordings. 
They should be in charge of editing, designing, managing, and leading their organizations, for this is the essence of experiential learning" ("Threats to the Independence,” 2016, p. 4). Bolman and Deal (2013) assert the news lab's goals play a significant role in the structure of a newsroom because deadlines are crucial to ensure the news cast gets produced and reaches audiences.

The student editors must not only consider one's own motivations and agendas but also the collective action, motivation, and thoughts of others. A highly motivated, energized workforce can socialize others through interaction that continues over time to provide a competitive advantage (Bolman \& Deal, 2013; Charon, 2004). Each student fits into the news lab's culture to complete the students' deadline-driven coverage. The student's work is done within a socialization process (Charon, 2004).

Teamwork. Team goals should be set by the entire staff to foster a feeling of ownership and togetherness (Lundgren, Cutsinger, \& Herron, 2019). Collaboration under tight deadlines and with a strong foundation of web and multimedia skills is pervasive in the profession and raises questions about how much those skills and attributes permeate journalism instruction (Wenger, Owens, \& Cain, 2018). "Physical and organizational accommodations must be made for each group to continue to do its daily work." (Filak, 2003, p.3) Wenger, Owens, and Cain (2018) further explain the need for teamwork aspects in professional newsrooms. The scholars found the majority of 2015 job postings were looking for the attribute of being a team player.

Advisers will instill a continual goal of teamwork as every student must understand what is expected to conquer the news labs' biggest stress factor of deadlines. Networks must be built, policies must be implemented, and staffs must be reorganized. This takes 
"time, energy, and money and must be completed while each organization continues to put out a daily news product" (Filak, 2003, p.3). Each staff member should generate some individual goals by keeping goals attainable, yet challenging (Lundgren, Cutsinger, \& Herron, 2019). For example, individual goals may include improving photographic abilities and practicing listening skills (Lundgren, Cutsinger, \& Herron, 2019). Comparatively, a newsroom's team goals may include improving scheduling to minimize their last-minute deadline rush (Lundgren, Cutsinger, \& Herron, 2019). Deadlines are crucial to ensure the news cast gets produced and reaches audiences. The student editors, staff and the adviser decide the deadline's importance. Consequences may also be set for when deadlines are not met, and they must be followed out for every staff member who misses a deadline (Robertson, 2002).

Communication. The most essential leadership characteristic is listening and trying to understand others. If an editor is not constantly seeking feedback from the staff, then the reporters will lose respect for her and she will become a boss. Collins (2017) explained a prime example to encourage student journalists to speak out. The student editor begins each morning having precedence over the other students to speak to the adviser as much as he or she needs while putting the newscast together. Having meetings where the staff can make suggestions for change and comment on what they like and dislike will make for a good environment and let everybody know that their opinions are valued (Robertson, 2002). When the adviser is able to observe an issue through the structural frame, he or she is able to address the structural dissemination of facts and information to increase the news labs communication effectiveness. 
Environment. Bolman and Deal (2013) also support how news lab environment structure may often be hierarchical and rule oriented; however, recent years have witnessed remarkable inventiveness in designing structures emphasizing flexibility, participation, and quality. For example, Collins' (2017) recent study of a high school broadcast news lab further explains the defining aspects of a student's news lab environment. The study analyzed how the student seating arrangements defined the news lab's structural leadership. The seating arrangement is designed for logistical purposes, and it also establishes a form of hierarchy (Collins, 2017). The adviser and student editor sit side-by-side. Sitting in the same area as the adviser, the student editor is seen to have the same power as the adviser. In other words, the adviser dictates who speaks first by way of a pecking order that correlates with the seating arrangements of the classroom's environment (French \& Raven, 2005). A news lab's environment is imperative to determine an appropriate fundamental team configuration. Bolman and Deal (2013) explain structures must be designed to fit an organization's current environmental circumstances. The structure and organization of the news lab's environment are essential in reaching the news lab's goal for logistical reasons (Bryan \& Joyce, 2007; Nadler, Gerstien, \& Shaw, 1992).

\section{Significance}

Journalism leaders are currently facing unprecedented challenges (Örnebring, 2018). Research implies each organization must continually develop appropriate goals and roles (Bolman \& Deal, 2013). Bolman and Deal's (2013) structural frame explains news labs' fundamental assigned responsibilities, explicit connections and relationships, and aims of the organization's mission, and the specific ways and means designed to help 
the organization achieve its goals. Specifically, this holds true within professional, higher education, and scholastic newsrooms, especially if news organizations want to remain relevant within the digital era (MacDonald, 2006; Robins, 2000). Ultimately, each organization must continually develop appropriate designs and sets of mechanisms to cope with its environment's roles and goals (Bolman \& Deal, 2013).

\section{Analysis of News labs through the Human Resource Frame}

This analysis will use the human resource frame to further focus on the relationship between the news lab's adviser and its editors. News labs advisers' and student leaders have needs. The human resource frame describes a way to emphasize the human side of organizations and the importance of the interpersonal and intrapersonal dynamics involved in organizing and need fulfillment (Bolman \& Deal, 2013). Theories about motivation, human development, personality, and the employment contract provide the backdrop for the emphasis of this frame to build a leadership capacity between the students, adviser, and the news lab. Ultimately, the human resource frame centers on what organizations and people do to and for another (Bolman \& Deal, 2013).

Build and Implement News Lab Philosophy. No matter what the size, a key news lab's practice is establishing a philosophy that makes the news lab's core beliefs explicit about managing students for their present and future effectiveness (Becker \& Hueslid, 1998). Because building a human resource strategy systematically provides sustainable and competitive advantages (Bolman \& Deal, 2013), many advisers develop a shared philosophy with their students to manage their news labs. Many believe the key to successful management is to begin by developing a focused and unified news lab vision shared by all students in the organization. That vision is then used to structure all 
planning, strategies, and activities across the news lab, so all students are working for a common goal, rather than their own (Reading, 2002).

The adviser develops the news lab's credo to translate into specific management practices to provide direction and make it operational (Bolman \& Deal, 2013). Research shows that most organizational mission statements also include references to survival, growth and profitability, the company's philosophy, the company's self-concept, and its goal for its public image (Pearce \& David, 1987). Most experts agree that "vision" is the defining characteristic of a leader - that it separates leaders from mere managers. Applying that idea to business, Wilson (2003) refined the definition to "a coherent, powerful statement of what the business can, and should be" (p. 56). Wilson further argued that a well-crafted vision (a) provides organizations with both a direction and a destination, (b) should be powerful enough to inspire managers and employees, and (c) should be specific enough to be considered a preview of the company's activities for a given time period. Shared understanding and commitment around a philosophy are a "powerful glue" to hold things together in the face of the inevitable stress in a news lab (Bolman \& Deal, 2013).

According to Bobkowski, Goodman, Bowen, and Perkins (2012), school size may be related to the availability of student journalism programs. Larger schools may have an advantage over smaller schools in offering specialized curricular and extracurricular programs such as journalism and student media. The demand for specialized programs is higher in larger schools because their student populations are larger and have more varied interests and talents (Bobkowski, Goodman, Bowen, \& Perkins, 2012). Larger schools can meet the demand for specialized programs more efficiently than smaller schools. 
Research has shown that larger schools offer a wider range of curricular and extracurricular programs (e.g., sports, health programs, special interest clubs) than smaller schools. The 1991 national survey showed that the distribution of school size among schools with journalism programs matched the distribution school size among U.S. schools in general (Bobkowski, Goodman, Bowen, \& Perkins, 2012).

Missouri high schools from differing geographic regions with differing total school populations reinforce their philosophies inversely. Often times, larger schools attend annual sponsored events with nationally acclaimed professional graphic designers and promotion specialists to develop, inspire, and evaluate the news lab and productions team's vision. The philosophy is used as a theme to motivate the news lab and readership to buy into the year's production (Bolman \& Deal, 2016). The philosophy can compete with other high school journalism program's philosophy. Larger schools' news labs tend to explain their production's philosophy in its staff manual and syllabus. However, small schools brainstorm their philosophy during class time, if at all. Many times, the news lab will adopt the school's mascot and motto and reuse each year.

News labs with developed philosophies help build systems and practices to build leaders to help with work flow. Available resources can help a news lab successfully implement a developed philosophy. Consequently, unobtainable resources make it harder for advisers to incorporate a strong vision into their teaching.

Enroll and Keep the Right Students. Strong high school journalism programs know the kinds of students they want to enroll in their courses to fit the mold of their philosophy (Bolman \& Deal, 2014). Effective staff recruitment and selection ensure efficient production (Lundgren, Cutsinger, \& Herron, 2019). 
According to nearly $60 \%$ of advisers responding to Osborn's (1998) survey, acceptance to their staffs required the approval of the adviser alone or a combination of the adviser and the editorial board. To gain acceptance into the class, students must also meet prerequisites according to policies set by nearly $50 \%$ of the high schools. Many advisers and the editors interview possible candidates before students are permitted to enroll within a high school journalism course. Usually, face to face interviews are used to make sure candidates have the skills to do the job. Also, grade requirements of $\mathrm{C}$ or better in prior journalism course, junior and senior status, and enthusiasm, school pride, selfesteem, assertiveness, compatibility and specialized job skills are what the interviewer desired (Lundgren, Cutsinger, \& Herron, 2019; Osborn, 1998). Also, references are checked to ensure candidates are dependable, responsible, and have organizational skills, creativity and interpersonal relationships (Lundgren, Cutsinger, \& Herron, 2019; Osborn, 1998). Other prerequisites include the ability to work outside of class hours and being computer literate. While the selection process and prerequisites vary from school to school, approximately $40 \%$ of advisers surveyed reported staff membership was based on open enrollment: elective, not selective (Osborn, 1998). The makeup of a news lab's staff depends in large part upon the size of the school, the makeup of its student body, and the support and backing the adviser receives or can cajole from the school administration, school board, parent groups and community at large (Osborn, 1998).

Smaller high schools may seek staff positions focused on specific sections. With this approach, a staff member would work on a specific section and complete all the tasks required, including writing, designing and shooting photos. Larger high schools may focus on a functional approach, which is more skill and task directed. A staff member 
might serve exclusively as a designer and create spreads for all sections (Lundgren, Cutsinger, \& Herron, 2019).

Many advisers believe staff training is critical to success. Whether the news lab is part of a class or an extracurricular activity, editors and advisers must make staff training a continuous process. Many advisers invest in their students by taking key staff members to summer workshops for comprehensive training.

Adviser Investment. According to the Journalism Educators Association (2019), advisers are content experts, engage students and reflect. Advisers understand content, development and differentiation. These advisers engage students with effective communication, management and motivation, planning, evaluation and the best instructional strategies. Finally, journalism educators seek professional growth by actively reflecting on their practices individually and in professional learning communities.

Creeping burnout and eroding commitment present challenges to advisers who must deal with weary, disgruntled students while staving off their own personal burnout. Hollifield, Wicks, Sylvie, and Lowrey (2015) defined advisers steady, reliable hands in their news labs to handle day-to-day responsibilities to produce their news labs' coverage (Hollifield, Wicks, Sylvie, \& Lowrey, 2015). A major foundation of the human resource frame is that organizations must provide adequate training for staff members (Bolman \& Deal, 2008). The human resource lens guides this analysis to focus on a tension between "individual satisfaction and organizational effectiveness [to] depend heavily on the quality of interpersonal relationships (Bolman \& Deal, 2008, p. 182). Analyzing high school news rooms from this perspective can explain the present challenges to advisers. 
Many scholars have addressed this relationship and highlight advisers' need for "steady, reliable hands in their news labs to handle day-to-day responsibilities to produce their news labs' coverage" (Hollifield, Wicks, Sylvie, \& Lowry, 2015, p. 68). As a result, Bolman and Deal, (2008) specifically promote employers providing adequate training for staff members as a major foundation of the human resource frame.

Professional Development. Journalism teachers understand the value of professional organizations and associations, conferences, certification and licensure, advanced course work, and other professional opportunities in the journalism field to enhance professional growth and generate classroom research (Downes, Hayes, Furnas, $\&$ Newton 2012). There are a variety of ways to evaluate reflectively their own practice and continue their own learning. Many advisers see the importance of teacher collaboration and cross-disciplinary cooperation to invest value in their dynamic journalism programs (Downes, Hayes, Furnas, \& Newton, 2012).

Advisers demonstrate and promote their vision and goals through strategic professional development for their news labs that is focused on their vision for student learning (Rice et al., 2001). Effective high schools provide teachers with training on preferred instruction and curriculum (Murphy \& Hallinger, 1988). Advisers need students who are experienced and knowledgeable in their crafts and gain professional standards. Excellence in journalism requires detailed understanding of the subject matter, and excellence in entertainment media requires expertise with creative content creation (Hollifield, Wicks, Sylvie, \& Lowrey, 2015). For example, the majority of advisers within larger schools are certified in DESE Journalism Education and have an undergraduate degree in Journalism. Overall, the adviser has an interest in journalism and 
attends quarterly advisers professional development opportunities throughout the United States to address challenges and updated professional practices. Primarily, the larger program's budget is approximately $\$ 150,000$.

Conversely, smaller schools' advisers are typically not DESE certified in Journalism Education and are typically certified in Business Education, English, Art, and do not have an undergraduate degree in Journalism and little to no Journalism interest. However, the adviser will oversee all areas and outlets of a high school's journalism and not have a sequence specialty. Typically, the program budget is in debt.

An increasing number of small school advisers are juggling their daily journalism teaching tasks with extra duty or part-time work and ongoing core-course loads. This presents a challenge to the advisers' ability to attain expertise in their craft. Advisers are spending more time learning new and rapidly emerging skills and knowledge areas. Also, students who are more likely to come and go make it difficult for advisers to plan for the long-term (Hollifield, Wicks, Sylvie, \& Lowrey, 2015). Many new advisers leave or are terminated shortly after joining the workforce, both sides having learned that a typical educator does not fit into a teaching news lab's culture and cannot stand its pace (Simon, 1996).

Professional Performance. Journalism teachers attend conferences, workshops, graduate education classes, and other professional development opportunities in the journalism field (Downes, Hayes, Furnas, \& Newton 2012). Advisers also study professional media and research relevant to journalism instruction on a regular basis and conduct classroom research to improve their practice (Student Law Press Center, 2019). Many advisers participate in continual personal and collegial reflection on practice to 
investigate their own biases and seek to resolve problems that stem from areas of conflict. Their instruction may use a variety of ways to monitor the effects of their practices on students, parents, colleagues and community professionals. Collaboration with colleagues in journalism and other disciplines help to create opportunities for professional and scholastic association critiques of programs' production (Downes, Hayes, Furnas, \& Newton 2012). For example, there is reflection on model storytelling, writing, designing, photographing, and effective journalism/multimedia skills and uses. Many advisers use their professional development opportunities to seek professional licensure, certification and/or an advanced degree in a relevant media-focused field (Downes, Hayes, Furnas, \& Newton 2012).

MIPA empowers advisers seeking professional development opportunities which permit them to refine their advising craft. All school sizes are welcome through professional development opportunities focused on investing in signature events and supplemental instruction, which provides information and support to all school sizes through an open book management style. The resources encourage all schools to think like legitimate news labs, doing whatever they can to improve their journalistic work. MIPA's years of success works for several reasons, as it sends a clear message that MIPA trusts the advisers by creating powerful incentives for advisers to contribute by seeing the big picture of how their work effects the bottom line and how the line affects them. Bolman and Deal (2013) explain how all the advisers at every school size level are provided with an environment to gain understanding that "everyone gets a piece of the action" through membership, contest, and critiques (p. 174). MIPA furnishes information through contests and critiques that advisers can use for their students to 
continually do a better job. If efficiency is seen to be dropping through MIPA's evaluation of the student's work, the advisers can pinpoint the problem and correct it (Bolman \& Deal, 2013).

Bolman and Deal (2013) also used the work of Douglas McGregor (1960) to build their theory of the Human Resource Frame. McGregor focused on the assumptions that managers have about their subordinates. MIPA's autonomy and participation encouragement advocates a Theory Y approach through having the essential task of management to arrange conditions so that all school sizes can achieve their own goals best by directing efforts towards the MIPA's organizational rewards (Bolman \& Deal, 2013; McGregor, 1960). If advisers found no satisfaction in their work, MIPA would need to rely on Theory X; however, the more managers align organizational requirements with employee self-interest, the more they can rely on Theory Y's principle of selfdirection (Bolman \& Deal, 2013). The arranged conditions of all school sizes foster selfmanaging teams so that all high school news labs can achieve their own goals. The group's sociotechnical systems perspective emphasized a close connection between work, design and teamwork by giving the advisers responsibility for meaningful work - a news cast - with ample autonomy and resource with collective accountability for results. Therefore, MIPA establishes an environment where the advisers should leave their external school size status at the door so that every news lab across the state has equal status (Levi, 2017).

MIPA promotes the diversity of all school sizes through its membership base, which explains the importance of tapping into the feeling of belonging that comes with being a part of a group to encourage its members to show up (Hess, 2012). MIPA 
recently revised the organization's bylaws to explicitly include a philosophy to promote the diverse membership of all school sizes. According to Bolman and Deal (2013), being counted matters and in the same way MIPA promotion of egalitarianism implies a counting all types of members by establishing democratic environment where all high school sizes can participate in making decisions.

\section{Significance}

Ultimately, this analysis clarifies the leadership and learning cultures in different sized high schools (small and large) and types of high school news labs. There are significant differences that exist between small high schools compared to large high schools, which have resources supportive towards their professional development in leadership and collaborative cultures (Hollifield, Wicks, Sylvie, \& Lowrey, 2015). Significant differences also existed in small schools' news labs compared to the supportive leadership, collaborative culture, and collective learning and application within the larger schools' news labs (Rice et al., 2001). Larger schools (1700 or more students) have significantly more opportunities to develop leadership through personal professional development and with their students' news labs (Murphy \& Hallinger, 1988). Small school districts (less than 700) have little to no professional development opportunities or resources to take leadership action than do larger schools (Murphy \& Hallinger, 1988).

\section{Leadership Analysis}

This analysis will illustrate how advisers use transformational leadership approaches to initiate, develop, and carry out significant individual and innovative changes within their new labs. Overall, transformational leaders set out to empower their 
followers and nurture them in change by attempting to raise the consciousness and transcending their "own self-interests for the sake of others" (Northouse, 2016, p. 175). The news lab's adviser has certain powers because of the position he or she holds in the high school. The adviser has what French and Raven (2013) refer to as the legitimate power to be the gatekeeper of each news lab by being the individual who controls which story gets in or is left out of the newscast. The adviser's power is derived from the formal position held in the organization's hierarchy of authority. Therefore, this leadership analysis will specifically focus on the process occurring between followers and leaders in high school news labs to find how transformational leadership develops a spirit of cooperation (Northouse, 2016). Essentially, the news lab advisers are not only defined through charisma, but how followers transcend their own self-interests for the good of the team, organization, or community (Northouse, 2016).

Transformational leadership emphasizes the importance of the leader and key constituents sharing a common vision and overall goals (Firestone \& Heller, 1995). The focus of this type of leadership is the change and transformation of people (Northouse, 2016). Transformational leadership is generally defined as including four leadership characteristics of idealized influence, inspirational motivation, intellectual stimulation, and individualized consideration (Northouse, 2016).

Transformational leaders use an exceptional form of influence moving followers to accomplish more than what is usually expected. Thus, transformational leaders evoke their participants to meet their maximum potential and go beyond their expectations to a higher level of achievement and success (Bolman \& Deal, 2013). The journey is a process that often incorporates "charismatic and visionary leadership" (Head \& Alford, 
2013, p. 161). It includes assessing followers' motives, satisfying their needs, and treating them as full human beings (Northouse, 2016).

In the same way, this transformational ideal is supported by the formal model of leadership, which emphasizes the importance of developing goals and pursuing specific objectives in order to benefit the organization as a whole (Bush, 2003). Bush (2003) recognized educational institutions as goal-oriented while consisting of members working toward the achievement of common goals. The foundational work of Gulick and Urwick (1937) supported Bush in the belief that coordinating work achieves greater production goals. The process engages a person with others and creates a connection to raise the level of motivation and morality in both the leader and the follower. The leader is attentive to followers' needs and motives to reach their fullest potential by emphasizing ideals, inspiration, innovations, and individual concerns (Northouse, 2016).

Transformational leaders identify strengths and weaknesses of individuals within an organization by building upon individual considerations, and motivations, (Morgan, 1997; Yukl and Van Fleet, 1992). Along these lines, transformational leadership also supports a common mission and vision for the organization (Bass, 1999; Bush, 2003; Schein, 1992; Yukl \& Van Fleet, 1992.) Transformational leaders understand and value that all individuals bring multiple perspectives, experiences, and bias to an organization, which is critical when recognizing the importance of individual goals and considerations prominent within transformational leadership behavior (Burns, 1978; Yuk1 \& Van Fleet, 1992).

Transformational leaders recognize and support intellectual stimulation and individual considerations in order to promote the overall organizational goals (Bass, 
1990; Bolman \& Deal, 2013; Yukl \& Van Fleet, 1992). Transformational leaders support the idea of overall community goals as the defining purpose of an organization (Bass, 1990; Bush, 2003; Yukl \& Van Fleet, 1992). Yukl and Van Fleet (1992) also contended leaders intentionally influence individuals to guide, structure, and facilitate activities within an organization to achieve the organization's goals. It is a reciprocal process based upon charisma and vision as both leader and follower are inspired and motivated to reach the highest levels of achievement (Northouse, 2016).

Goals exist at many levels within an organization and leaders must ensure personal goals are secondary to the organizational goals of the institution (Bush, 2003). Yukl and Van Fleet (1992) further maintained leaders assist constituents in achieving their goals and providing them with direction and support to ensure individual goals support and sustain the overall goals of the organization. Transformational leaders coordinate efforts of followers toward the achievement of common goals by creating an environment which provides direction and support versus rewards and punishment found within transactional and charismatic leadership (Bass, 1990; Bolman \& Deal, 2013).

Kouzes and Posner (1987) further refined transformational leadership by showcasing the importance of producing exemplary leader follower trust, which is central for transformational leadership. Kouzes and Posner (2002) asserted that leading by example is visible management by enhancing accessibility and promoting the values and principles advocated by the leader. Therefore, leaders who lead by example serve as visible models for those committed to the course of action in the organization (Kouzes \& Posner, 2002). 
Kouzes and Posner's Fundamental Practices of Leadership Model suggests that leadership is not a position, but a collection of practices and behaviors $(1987,2002)$. These practices serve as guidance for leaders to accomplish their achievements or "to get extraordinary things done" (Kouzes \& Posner, 1987, p. 9). Kouzes and Posner's practices are components of the concept of transformational leadership. These practices include challenging the process, inspiring a shared vision, enabling others to act, modeling the way, and encouraging the heart (Kouzes \& Posner, 1995, 2002).

Therefore, Transformational Leadership Theory will be used to explain advisers' processes as well as explore their pedagogical approaches in the newsroom. Kouzes and Posner's model $(1987,2002)$ provides five fundamental practices which enable leaders to meet goals. The model identifies strategies which prove to be a lens showcasing how news labs practice exemplary leadership (Northouse, 2016).

Modeling the Way. Advisers are clear about their own values and philosophies by finding their own voice and expressing it to their editors and students. The advisers lead with a personal example for their students so the newsroom can work as a team not only before the airing of the newscast, but also during and after the show has aired. For example, during a newscast, an adviser may watch the timing of the show along with the student producer, and after the newscast has aired, the student producer begins the critique followed by the adviser. Then, the floor for comments is opened to the rest of the class. After the adviser and student producer have had their morning meeting, the professor announces to the class the goals and objectives for that day's newscast. She then calls on the assignment editor, followed by the video producer, the news anchors, sports anchor, weather anchor, reporters, beat reports (other students), and finally the 
assistant producer/graphics (Collins, 2017). The adviser's exemplary leadership follows through on their promises and commitments and affirm the common values they share with their news lab students (Northouse, 2016).

Inspire a Shared Vision. Effective advisers create compelling visions to guide behavior by evoking positive future outcomes and communicating them to the students. Organization-based individual leadership development programs guide the newsroom's overall design and program implementation (Royal, 2018). Multiple studies associate a program's effectiveness with overall design and implementation of a program (Bronstein \& Fitzpatrick, 2015; Bush, Haygood \& Vincent, 2017; Hopkins, Raymond, \& Carlson, 2011; McGonagill \& Pruyn, 2010; Newton, 2018; Windels et al., 2013). McGonagill and Pruyn (2010) suggest the strongest, effective leadership development programs are designed to respond to the mission-related challenges faced by the organization or the needs of the community being served. Leaders also listen to the dreams of others and show them how their dreams can be realized (Northouse, 2016). It is important to note, effectiveness depends on how well the choices are made, integrated, and linked to newsroom priorities and the readiness of the reporters (McGonagill \& Pruyn, 2010). Ultimately, leaders challenge others to transcend the status quo to do something for others through their inspiring vision (Northouse, 2016).

Challenge the Process. Today, advisers are changing the status quo by stepping into the unknown of the digital era. Exemplary leaders in news labs are like pioneers by wanting to try new strategies and being willing to innovate technology, grow skills, and improve coverage (Northouse, 2016). New technologies, particularly cable television and the Internet, developed so quickly that traditional leaders lost some of their control 
(Campbell, Martin, \& Fabos, 2018). From this perspective, Lowery (2012) argues traditional news leaders, over the past 30 years, have wrung their hands and called for change in the face of financial, technological, and cultural disruption. Pavlik (2013) further explains journalism education is in urgent need of transformative leadership to challenge the process as educators and professionals alike are "groping for a pathway to a future in which they play a vital role" (p. 211). The adviser's ability to innovate, grow, and improve the field of journalism speaks to the core of transformational leadership (Northouse, 2016). Transformational leaders are willing to take risks to make the unknown better and transform media education at every level. When exemplary leaders take risks, they do it one step at a time, learning from their mistakes as they go (Northouse, 2016).

Enable Others to Act. Outstanding leaders are effective at working with people (Northouse, 2016). Advisers lead their news labs by building trust and promoting collaboration with their students. Today, teamwork and cooperation are highly valued, as there is an increased emphasis on working in teams under tight deadlines and with a strong foundation of web and multimedia skills. Teamwork aspects are pervasive in the profession and scholars raise questions about how much these skills and attributes permeate within journalism instruction (Northouse, 2016; Wenger, Owens, \& Cain, 2018).

In fact, scholars derive that those who obtain continued conceptual leadership training attain a higher level of success (Adam 2001; Carey, 2000; Deuze, 2006; MacDonald, 2006; Medsger, 1996; Mensing, 2010; Reese \& Cohen, 2000). Recently conducted research and investments are being made in professional journalism 
newsrooms across the country to train newsroom leaders. Scholars believe in the call to improve journalism leaders to listen closely to diverse points of view and treat others with dignity and respect (Callinan, 2001; Herndon \& Krueger, 2016; Killebrew, 2003; Mierzejewska, 2011; Mulrennan, 2018; Northouse, 2016; Perez-Latre \& SanchezTabernero, 2003). In the end, there is a need for news lab leaders to create environments where students can feel good about their work and how it contributes to their greater community.

Encourage the Heart. Leaders reward others for their accomplishments by being attentive and willing to give praise to their direct reports for jobs well done (Levi, 2014). Advisers do this through rituals to show appreciation and encouragement to their students. Journalism advisers can transform, address, revise, and create curriculum as well as new pedagogical approaches in their news day practices to provide authentic celebration. A journalism educator's transformational influence goes beyond normal role requirements (Cleveland, Murphy, \& Stockdale, 2000, p. 287; Yukl \& Van Fleet, 1992). According to Newton (2018), today's society is at the hundred-year flood mark when it comes to the spread of information. In fact, the internet linked more people to information than any other point in history (Newton, 2018). Scholars refer to the internet as having more influence on news than the printing press, radio, or television. Therefore, Transformational Leadership Theory can explain newsrooms' influence in motivating people beyond what is required of them by their jobs or situations (Cleveland et al., 2000, p. 319). For example, effective leaders create compelling visions that can guide people's behavior. This is very evident in the journalism field in today's society. Through inspiring vision, leaders challenge others to transcend the status quo to do something for 
others (Northouse, 2016). In this particular example, journalism leaders constantly find new ways of accurately reporting the truth. Some scholars document a notion that goes as far as addressing a journalism educator's influence going beyond the normal teacher role requirements (Cleveland, et al., 2000, p. 287; Yukl \& Van Fleet, 1992). The outcome of this kind of support is greater collective identity and community spirit (Northouse, 2016).

\section{Conclusion}

Overall, transformational leadership theory guides educators in creating optimal learning and Posner's model provides the analysis with prescriptive practices for exemplary leaders, which are available to everyone (Northouse, 2016). Pavlik (2013) clarified that educators need to be prepared for a lifelong journey of adaptation in a relentlessly changing media landscape. Journalism course' boundaries and methods of delivery need transformation to better engage students (Pavlik, 2013). Advisers establishing a positive active learning pedagogy to confront the challenges confronting advisers is how to prepare future journalism leadership for an industry in radical transformation (Goh \& Kale, 2015; Pavlik, 2013). Ultimately, transformational leadership is not about personality, it is about practice by building a leadership vision emphasizing both leaders and followers who are transforming (Northouse, 2016).

\section{Implications for Research in the Practitioner Setting}

The data in this study will be used to identify the range of leadership in Missouri high school journalism news labs to find how advisers utilize many leadership practices. This study explored perspectives on leadership training to prepare students for modern day professional newsrooms (Poerksen, 2010). In addition, this study will focus on how advisers teach leadership in scholastic journalism news labs. As this is one of the first 
studies on editorial leadership, the resulting recommendations from this study may be considered transferable to other high school journalism news labs. This study will provide editorial leadership training recommendations to address the industry's changes through management values emphasizing journalists' ethical responsibilities (Herndon \& Krueger, 2016).

Implications for Practice. This research will identify the unique perspectives of journalism educators to highlight recommendations for advisers to teach editorial leadership through honed soft skills and a deeper understanding of leadership to transform the profession (Bronstein \& Fitzpatrick, 2015). Advisers' perceptions teaching editorial leadership within high school news labs in the midst of a radically transforming journalism industry remains to be explored (Pavlik, 2013). The purpose of this qualitative study will be to assist journalism educators by exploring scholastic journalism advisers' aspects in teaching editorial leadership. Findings may be presented to administration and teachers and, ultimately, students could be encouraged and inspired to become leaders. This study may lead to recommendations for actionable editorial leadership training, policy and change within Missouri's high school journalism educators' curriculum. Therefore, the study will showcase MIPA empowering all journalism advisers through a symbiotic relationship investing in advisers learning to build systems and practices for sound editorial leadership philosophies throughout the state into each large to small news labs. Thus, the idea of creating a vision to help guide an organization is not reserved to large high schools; many successful organizations of all sizes are built upon a solid vision (Northouse, 2016). 
It is important to understand the perspectives of leadership within high school news labs in order to shape professional development among instructors. This study could be used to increase awareness and utilization of editorial leadership within scholastic journalism. Currently, there is a lack of studies exploring scholastic journalism advisors' best practices to teach editorial leadership. Findings could be presented to administration and teachers and, ultimately, more teachers could be encouraged and inspired to become leaders.

Implications for Research. This study will lead to recommendations for actionable editorial leadership training, policy and change within Missouri’s high school journalism educators' curriculum. Although editorial leadership is a prevalent concept within the scholarly conversation around secondary journalism education, it is a term that has not been researched within Missouri. Previous research indicates many student journalism productions become stagnant due to advisers' lack of training (Abrahamowicz,1988). Missouri is no stranger to the scholarly conversation. Local critics go as far as arguing that perspectives are important to examine whether journalism educators are embracing transformational leadership (Filak \& Pritchard, 2007). Given the importance of perspectives, it will be important to examine how high schools are teaching editorial leadership and whether journalism educators are embracing transformational leadership (Northouse, 2016).

Also, within the scholarly conversation, there are two key studies that critique the lack of research regarding effective news room pedagogy. First, Bronstein and Fitzpatrick (2015) contended that reform is needed to develop effective ways to engage learning to gain future-focused academics using curriculum. Additionally, Collins (2017) argues that 
higher education newsroom cultures use transformational ways to help students be encouraged and socialized to challenge one another through the newsgathering processes. Consequently, another implication for scholarship for the study to address will be this literature gap to address transformational leadership in high school news labs. Examining effective practices in the traits and values of journalism education will glean further insight to add to this body of literature (Carpenter, Hoag, \& Grant, 2018).

\section{Summary}

This research identifies the unique perspectives of journalism educators to highlight recommendations for advisers to teach editorial leadership through honed soft skills and a deeper understanding of leadership to transform the profession (Bronstein \& Fitzpatrick, 2015). Advisers' perceptions teaching editorial leadership within high school news labs in the midst of a radically transforming journalism industry remains to be explored (Pavlik, 2013). The purpose of this qualitative study was to discover perspectives, skills, and roles of Missouri advisers by examining their pedagogy through the lens of Transformational Leadership Theory.

Academic leaders need to set new standards for excellence, reflecting how different styles of adviser's leadership affect news labs (Cowan, 2009). Developing editorial leadership approaches to journalism education could help educators to "seize this moment to create alternative models of journalism to invigorate advisers and inspire students in ways that would allow journalism education to fully contribute to the next era of journalism” (Mensing \& Ryfe, 2013, p.40). 
SECTION THREE

\section{SCHOLARLY REVIEW FOR THE STUDY}




\section{Scholarly Review for the Study}

\section{Introduction}

Journalism's vital skills and transformational characteristics command tremendously strong leaders as the professional standards evolve (Cowan, 2008; Küng, 2017). In this digital era of transformation, researchers view leadership development as a key to increasing journalistic quality and improving newsroom learning (Mulrennan, 2018).

In this review, the researcher will evaluate recent research that addresses a trend of investments made in professional journalism newsrooms across the country to train newsroom leaders to restore journalism (Callinan, 2001; Herndon \& Krueger, 2016; Killebrew, 2003; Mierzejewska, 2011; Mulrennan, 2018; Perez-Latre \& SanchezTabernero, 2003). The journalism profession has taken on a rigorous examination of its practices towards new forms of news creation, production, editing and community distribution (Herndon, \& Krueger, 2016; Mensing, 2010).

The researcher will contrast the current accountability for leadership in professional newsrooms with high school news labs. Currently, diminutive research has been conducted on high school journalism advisers and how they teach leadership. There is a need to investigate editorial leadership's intentions, aspirations, and challenges. For the purposes of this study, the term "editorial leadership" will mean scholastic news labs organization goals, strategies, skills and practices used to develop students' leadership skills of communication style, management abilities and team focus. The premise is that high school journalism advisers teaching editorial leadership can further advance the future of media excellence. Emboldened by a new vision, journalism advisers can provide 
an engaged scholarship and professional workforce to lead an effective and vibrant media system (Pavlik, 2013).

\section{Theoretical Framework}

Since the 1980s, leadership theory has been recognized as a critical component of effective and successful organizations (Collins, 2001). Burns' (1978) work provided a solid conceptual footing for the work of Bass who, in 1985, presented a formal theory of transformational leadership, as well as models and measurements of their factors in leadership behavior. Transformational leadership emphasizes the importance of the leader and key constituents sharing a common vision and overall goals (Firestone \& Heller, 1995). The focus of this type of leadership is the change and transformation of people (Northouse, 2016). Transformational leadership is generally defined as including four leadership characteristics of idealized influence, inspirational motivation, intellectual stimulation, and individualized consideration (Northouse, 2016).

Transformational leaders use an exceptional form of influence that moves followers to accomplish more than what is usually expected of them. Thus, transformational leaders evoke participants to meet their maximum potential and beyond in order to move to a higher level of achievement and success (Bolman \& Deal, 2013). It is a process that often incorporates "charismatic and visionary leadership" (Head \& Alford, 2013, p. 161). It includes assessing followers' motives, satisfying their needs, and treating them as full human beings (Northouse, 2016).

In the same way, this transformational ideal is supported by the formal model of leadership, which emphasizes the importance of developing goals and pursuing specific objectives in order to benefit the organization as a whole (Bush, 2003). Bush (2003) 
recognized educational institutions as goal-oriented and consisting of members working toward the achievement of common goals. The foundational work of Gulick and Urwick (1937) supported Bush (2003) in the belief that work should be coordinated to achieve goals of greater production. The process engages a person with others and creates a connection that raises the level of motivation and morality in both the leader and the follower. The leader is attentive to the needs and motives of followers to reach their fullest potential by emphasizing ideals, inspiration, innovations, and individual concerns (Northouse, 2016). By building upon individual considerations and motivations, transformational leaders can identify strengths and weaknesses of individuals within an organization (Morgan, 1997; Yukl \& Van Fleet, 1992). In this way, transformational leadership also supports a common mission and vision for the organization (Bass, 1999; Bush, 2003; Schein, 1992; Yuk1 \& Van Fleet, 1992.) Transformational leaders understand and value that all individuals bring multiple perspectives, experiences, and bias to an organization, which is critical when recognizing the importance of individual goals and considerations prominent within transformational leadership behavior (Burns, 1978; Yukl \& Van Fleet, 1992).

Transformational leaders recognize and support intellectual stimulation and individual considerations in order to promote the overall organizational goals (Bass, 1990; Bolman \& Deal, 2013; Yukl and Van Fleet (1992). Transformational leaders support the idea of overall community goals as the defining purpose of an organization (Bass, 1990; Bush, 2003; Yukl \& Van Fleet, 1992). Yukl \& Van Fleet, 1992 also contended that leaders intentionally influence individuals to guide, structure, and facilitate activities within an organization to achieve the organization's goals. It is a 
reciprocal process based upon charisma and vision as both leader and follower are inspired and motivated to reach the highest levels of achievement (Northouse, 2016).

Goals exist at many levels within an organization and leaders must ensure personal goals are secondary to the organizational goals of the institution (Bush, 2003). Yukl and Van Fleet (1992) further maintained leaders assist constituents in achieving their goals and providing them with direction and support to ensure individual goals support and sustain the overall goals of the organization. Transformational leaders coordinate efforts of followers toward the achievement of common goals by creating an environment which provides direction and support versus rewards and punishment found within transactional and charismatic leadership (Bass, 1990; Bolman \& Deal, 2013).

Kouzes and Posner (1987) further refined transformational leadership by showcasing the importance of producing exemplary leader follower trust, which is central for transformational leadership. Kouzes and Posner (2002) asserted that leading by example is visible management by enhancing accessibility and promoting the values and principles advocated by the leader. Therefore, leaders who lead by example serve as visible models for those committed to the course of action in the organization (Kouzes \& Posner, 2002).

Now consider Kouzes and Posner's Fundamental Practices of Leadership Model, which suggest that leadership is not a position, but a collection of practices and behaviors $(1987,2002)$. These practices serve as guidance for leaders to accomplish their achievements or "to get extraordinary things done" (Kouzes \& Posner, 1987, p. 9). Kouzes and Posner's practices are components of the concept of transformational leadership. These practices include challenging the process, inspiring a shared vision, 
enabling others to act, modeling the way, and encouraging the heart (Kouzes \& Posner, 1995, 2002).

Transformational Leadership has been heavily researched; however, the research regarding effective editorial leadership as it relates to high school journalism is lacking. Therefore, this inquiry should provide additional insights for advisers to teach effective leadership skills needed in high school news labs. The conceptual framework of transformational leadership allows for a refined approach to the study (Mertens, 2005). An analysis through the theoretical framework of leadership theory leads to a greater understanding on how scholastic journalism advisers establish good decision-making techniques in student newsrooms.

\section{Literature Summary}

Journalism education answers the great calling to fix professional newsrooms (Newton, 2018). In this paradoxical digital age, scholars reflect a great deal of excitement to lead future newsrooms through editorial leadership. Recent research indicates transformational leadership skills are needed within professional, higher education and scholastic newsrooms to remain relevant within the digital era (MacDonald, 2006; Robins, 2000). In fact, scholars determine those who obtain continued conceptual leadership training attain a higher level of success (Adam 2001; Carey, 2000; Deuze, 2006; MacDonald, 2006; Medsger, 1996; Mensing, 2010; Reese \& Cohen, 2000). Recently conducted research and investments are being made in professional journalism newsrooms across the country to train newsroom leaders to improve journalism (Callinan, 2001; Herndon \& Krueger, 2016; Killebrew, 2003; Mierzejewska, 2011; Mulrennan, 2018; Perez-Latre \& Sanchez-Tabernero, 2003). However, none are reports 
of original research to prepare high school students for the transforming industry.

Miniscule research has been conducted on high school journalism advisers and how they teach leadership. Instead, the authors present anecdotal evidence, such as information on individual high school news labs who are teaching outdated skills (Mulrennan, 2018). This analysis identifies the major factors in current literature to support advisers are missing opportunities to align with professional leadership standards.

\section{Historic Changes in Journalism Leadership}

American Journalism has constantly evolved while remaining grounded in democracy (Campbell, Martin, \& Fabos, 2018). Many journalism leaders have evolved from the print revolution's emergence as a primary communication source to the digital era's convergence of media and information. Change is nothing new in the field of mass media. The changes in the field have ranged from moveable type to the introduction of computers into the newsroom (Filak, 2003). While computers have become a part of everyday life, newsroom studies have shown many editors and reporters initially disliked the addition of technology (Kurtz, 1980).

Each period developed new leaders to cover historical moments using new technologies and channels to communicate (Campbell, Martin, \& Fabos, 2018). Today, journalism education strives to speed up and be the next generation of academic leaders willing to do what must be done (Reed, 2014). Journalism education needs to restore top news leaders to the most respected ranks of academia (Newton, 2018).

\section{Trends in American Journalism}

In 1922, Walter Lippmann likened the news to "a beam of a searchlight that moves restlessly about, bringing one episode and then another, out of darkness into 
vision" ((Folkerts, 2014, p. 258). In American history, twelve generations have

continually experienced the searchlight of journalism (Newton, 2018; Rosen, 2018).

News has satisfied audiences' needs to know things otherwise not experienced personally (Campbell, Martin, \& Fabos, 2018).

Journalism education began as part of a 1920s US reform movement born in the Progressive Era that sought to improve journalistic standards by raising the educational level of newspaper employees (Gaunt, 1992; O’Dell, 1935; Sutton, 1945; Weinberg, 2008). From its earliest conceptions, journalism education has been about training students to work for newspapers (Becker, 2003; Dickson, 2000; O’Dell, 1935).

As Carey (2000) has noted, journalism education came to life in the "age of the reporter", when the role of a journalist was to find information, shape it into an accurate story and transmit it as quickly as possible to a mass audience via a mass medium. This model of journalism, taught in journalism schools and run as a business by news organizations, has remained unchanged for many decades.

\section{Obstacles Faced when Changing the Tools of the Trade.}

Journalists have used technology to achieve speed and increased efficiencies in the production of news since the 1850s (Quinn, 2016). Newsrooms have historically used a flow of power and an established hierarchy to move content from one point to another. Much in the same way, manufacturing commonly employs a setup with divisions of labor for large scale production. For example, American Industrialist Henry Ford is known as a manufacturer assembly line pioneer. He created a production method that put people in specific roles to be quick, efficient and kept costs down. For years, journalists used this same method when producing the news (Striesel, 2007). First, a reporter would write a 
story. Then, a photographer would be assigned to take some photos to accompany the story. Finally, the reporter and photographer submit their work to a waiting designer who combines their work to have semblance of order.

Many newsrooms are transforming away from Ford's assembly line method as the news is not a duplicate remake every day. The digital era's 24 hour news cycle is different each day than Ford's Model T's production line (Streisel, J. (2007). Carr's (1990) study found that many journalists have been unwilling to alter their approach to journalism by technology. In identifying 64 newsrooms in the 1980 s that were moving toward computerization, 42 were viewed as late adopters. The main reason these newsrooms had "failed to innovate was a sense that such wide-scale changes were not worth the effort" (Carr, 1990, p. 33). Today's newsroom effectiveness is due in large part to their structural organization. Bolman and Deal (2013) attribute this type of success to the use of the many methods successful organizations use to coordinate individual and group efforts and to link local initiatives with systemwide goals through formal vertical chains of command and lateral network structures of meetings, committees, and coordinating roles.

Normally, in a newsroom information and decision-making flows from a producer out to everyone else. Professional newsrooms struggle with structural decision-making. Bolman and Deal (2013) explain that creating roles and units yields the benefits of specialization, but creates problems of coordination and control of how to ensure that all diverse efforts mesh. Units tend to focus on their separate priorities and strike out on their own. The result is "suboptimization, an emphasis on achieving unit goals rather than 
focusing on the overall mission. Efforts can become fragmented and performance suffers" (Bolman \& Deal, 2013, p. 51).

Bolman and Deal (2013) establish how successful organizations use many methods, as news labs, to coordinate individual and group efforts and to link local initiatives with systemwide goals through formal vertical chains of command and lateral network structures of meetings, committees, and coordinating roles.

Internet Change. In the early 1990s, journalism scholars and practitioners began discussing the possible impact of the World Wide Web on traditional media (Filak, 2003). Since the arrival of the Internet, online and mobile technologies have created "radical shifts" (Franklin, 2012, p. 663) in the speed and means by which journalists gather, report, and deliver news. Companies such as Amazon.com began to surge (Economist, 2001), with stock prices soaring and splitting and soaring again. News organizations also flocked to the web. CNN, NBC, the New York Times and KnightRidder were just a few of the news agencies that made substantial investments in internet media (Wenner, 2001).

According to Newton (2018), the digital age is the most profound development since movable metal type, which brought the age of mass communication. The connection to the internet is changing everything - who a journalist is, what a story is, which media should be used for which news, and how we engage with communities, the people formerly known as the audience (Newton, 2018)

The $21^{\text {st }}$ century brought the largest collapse in American newsroom history, with vanishing local journalism jobs totaling more than 15,000 (Newton, 2018). Mensing's (2010) research found using revitalized techniques and delivering the product over the 
Internet does not change journalism education's basic model. Students learn this model in courses frequently taught by practitioners using reporting-focused textbooks that have changed little in their basic outline since 1938 (Brennan, 2000). However, the evolution of job postings from 2010 to 2015 supports the notion that the traditional print or TV job is, in many ways, a thing of the past. The increased emphasis on working in teams, under tight deadlines and with a strong foundation of web and multimedia skills, is pervasive in the profession and raises questions about how much those skills and attributes permeate journalism instruction (Wenger, Owens, \& Cain, 2018).

New technologies, particularly cable television and the Internet, developed so quickly that traditional leaders lost some of their control (Campbell, Martin, \& Fabos, 2018). As the news media suffered through the following decades of turmoil and chaos marked by layoffs, bankruptcies, and consolidation, management developed a reputation for fruitless introspection because it rarely led to effective competitive responses (Herndon \& Krueger, 2016). Lowery (2012) summarized this perspective: "Leaders of traditional news outlets over the past 30 years have wrung their hands and called for change in the face of financial, technological, and cultural disruption. And then, so often, they have stayed the course" (p. 214).

The Internet is a driving force in changing the way information is produced, consumed and paid for, affecting news companies in every way imaginable (Mensing, 2010). Society crossed over a threshold. The digital age brought a time of plenty and of paradox with more readers, less advertising revenue, more writing, less journalism, more information, less meaning, more opportunity, and less predictability (Newton, 2018). Traditionally, a central theme of journalism education has been a professionally oriented 
program focused on educating students for jobs in the media industries (Becker, 2003; Dickson, 2000). Dickson (2000) argued that it is not what journalism teachers are teaching, but how journalism teachers are teaching it.

\section{The Role of Professional Newsrooms}

Journalism leaders are still currently facing unprecedented challenges (Örnebring, 2018). Research in professional newsrooms has historically documented that socially learned norms retained order in newsrooms as older staffers policed newer-cub reporters to maintain a common thread of cultural understanding. Going as far back as the penny press of the early $1850 \mathrm{~s}$, reported stories, were once covered in editing marks by established veterans and returned to reporters attempting to not only make the story publishable, but to reinforce what was acceptable (Filak, 2003). In one of the most influential studies on this topic, Breed (1955) showed how newsroom leaders create the culture with their environment that can control what stories are published and how they are presented.

Breed's (1955) newsroom culture investigation remains an important landmark study 70 years later. Subsequent newsroom studies reflect similar results as the $21^{\text {st }}$ century brought the largest collapse in American newsroom history (Newton, 2018). Numerous scholars have suggested that even in crisis, leaders remain central in determining newsroom culture. However, the crisis has left traditional leaders losing control as major media companies restructured and new technologies have quickly developed (Jaakkola, 2014). In order to further explain the interpersonal difficulties due to the digital era, Örnebring (2018) put forward the hypothesis that a great deal of change and new skills are set before young and old staffers to simultaneously master skills in the 
same newsroom environment. Silcock and Keith (2002) found in a digital environment many times new and veteran journalists clash when discussing issues of news quality and story ownership. Camarota (2004) also reported that the digital era presents a significant shift in capabilities, behaviors, and technical skills required of journalists during this transformation towards the new cub-reporter rather than the veteran journalist. Leadership training is helping transform professional newsroom interpersonal behaviors to master capable newsroom connections through relevant soft skills. Scholars assess it is within journalism's power to address meeting the current challenges by being better at being more responsive and more transparent to provide higher quality content (Örnebring, 2018).

Effective Newsroom Culture. Over the years, journalists maintain theoretical and technical training as an ongoing priority because the craft has the expectation to be accurate, timely, and relevant (Filak, 2003). According to MacDonald (2006), journalism is referred to by many as a profession, which would justify a professional model of education. However, unlike the established professional programs of medicine and law, there is no entry standard for those wishing to become journalists (Commission on Freedom of the Press, 1947).

Professional newsrooms recognize the power of executive education and leadership development initiatives as part of a system that can help align managers, workers, and organizational process in pursuit of strategic objectives (Vicere \& Fulmer, 1998). Many working journalists know that the skills that make great journalists are not always the same skills that make great leaders. Scholars summarize a range of aspects to teach leadership skills, which are needed to drive people and enterprises within the 
professional journalism field (Cowan, 2008, Mulrennan, 2018). These strategies have a noble history in this country, and each can lead to a different series of decisions, but all have a common need for good leadership (Cowan, 2008; Mulrennan, 2018).

Today's need for leadership stands on Breed's (1955) landmark finding that a strategic newsroom structure and design allows an editor to effectively empower reporters. The next key study came 30 years later when Vicere and Fulmer's (1998) research said the best programs embody a systems perspective. Today's scholars argue newsrooms are a developed system having distinct social aspects and a structured hierarchy (Bourdieu, 1984, 1990, 1991; DeBruin \& Ross, 2004, p. 197).

Newsrooms have a flow of power and an established hierarchy that is used to move content from one point to another. Normally, information and decision-making flows from the producer or executive producer out to everyone else. Professional newsrooms struggle with structural decision-making. The newsroom's apex ensures the staff will meet deadlines, but it is not enough to guarantee audiences receive truthful, diverse, and informative coverage. For example, Mintzberg's organizational model reflects the newsroom roles structure. The executive producer is at top of the strategic apex's hierarchy. The top position is over the "middle-line" editors to transmit authority from the top to the bottom towards the "operating-core" reporters (Mintzberg, 1979, p. 220). The reporters complete the basic work of producing the stories. Yet, bad decisions can be made during coverage meetings because the reporters do not make decisions. The executive producers delegate the editors to make all the decisions. Conversely, a newsroom's success depends on the members' ability to work as one unit within the confines of a deadline. From the morning meeting until the end of the newscast, the 
producer oversees the newscast and, directly and indirectly, is also in charge of key personnel, such as reporters and videographers (Collins, 2017).

This model illustrates how the producer is really the gatekeeper of the production, the individual who controls which story gets in or is left out of the newscast. Organization-based individual leadership development programs are needed for the newsroom's overall design and program implementation (Royal, 2018). Multiple studies associate a program's effectiveness with overall design and implementation of a program (Bronstein \& Fitzpatrick, 2015; Bush, Haygood \& Vincent, 2017; Hopkins, Raymond, \& Carlson, 2011; McGonagill \& Pruyn, 2010; Newton, 2018; Windels et al., 2013). Of these, the study by McGonagill and Pruyn (2010) is the strongest, suggesting effective leadership development programs are designed to respond to the mission-related challenges faced by the organization or the needs of the community being served. Effectiveness depends on how well the choices are made, integrated, and linked to newsroom priorities and the readiness of the reporters (McGonagill \& Pruyn, 2010).

Many scholars advocate professional development leadership in concepts such as “Journalism as a Hospital” (Newton, 2018), "Lead by Taking People with You" (Novak, 2017), the Practice of Experiential Learning (Charles \& Luce, 2016) and "Essential Skills for Rising Newsroom Leaders" (Poynter, 2019). In the same way, the most impactful and effective programs tend to be sure to involve a range of learning modalities.

Professional Standards for Journalism. Various ways exist to evaluate journalism. Journalists try to meet the "ethical standards that, more than the law, guide their work" (Ferguson, Patten, \& Wilson, 2005, p. 52). Journalist are expected to be 
accurate and objective. Their standards emphasize good taste, fairness, care with attribution, and a devotion to truth (Student Law Press Center, 2019).

Professional journalism associations, individual news organizations, and journalists themselves often have their own standards and code of ethics; however, most share these basic principles: truthfulness, accuracy, objectivity, impartiality, fairness, and public accountability (Society of Professional Journalism Code of Ethics, 2019). Many journalists also abide by the principle of "limitation of harm" which means that they have a responsibility to not harm others while reporting a story (Society of Professional Journalism Code of Ethics, 2019). This is one major difference between professional journalists reporting for "reputable" news organizations as opposed to fringe news sources and fake news creators.

Professionals want to hire journalists whom can meet their own standards, ethical codes and have leadership skills. However, many struggle finding trained students entering the profession, freshly leaving higher education equipped to command a newsroom in the throes of radical change (Bronstein \& Fitzpatrick 2015; Bush, Haygood, \& Vincent, 2017). Furthermore, scholars emphasize the evolution of job postings from 2010 to 2015 reflect the profession's pervasive focus to lead teams (Wenger, Owens, \& Cain, 2018). More than ever, professional newsrooms are looking to academia to better prepare students for the current transforming standards.

\section{Higher Education's Student News Labs}

Professional newsroom cultures are symbiotic to student newsrooms in higher education. The landscape for journalism educators has changed remarkably since Breed's landmark report on newsroom leadership was published in 1955. The last decades have 
brought substantial shifts in expectations; however, Breed's (1955) analysis of social control in newsrooms can be adapted to the current policies and routines in higher education.

Key studies of higher education news labs policy and routines are comparable to the decades-old findings. News labs establish the same policies and routines journalists have developed to help them manage their work and to cope with unpredictability. Niblock (2007) asserts that reflecting on these formal and informal routines are an important part of journalism education (Niblock, 2007). According to Charon (2004), when individuals reflect and interact "cooperatively, a society is formed" (p. 161). News labs can use organizational-learning groups to help students develop accountability, heterogeneous membership, shared leadership, task emphasis, and social skills (Lipschultz, 1990).

Collins' (2017) study furthers Breed's (1955) initial findings of socialization through the claim that student newsrooms have the same hierarchy as a professional newsroom to give the news lab its organizational behaviors of established power based upon subjective-symbolic struggles and social constructs. In Collins' (2017) examination, the adviser must establish news lab culture and empowerment norms for the student staff's learning environment. Each student fits into the news labs' society and culture through the newscast production socialization process (Breed, 1955; Charon, 2004).

Bronstein and Fitzpatrick's (2015) calls for curriculum reform, introducing skills to trailblaze dynamic industries and innovate media revolutions of the twenty-first century. Journalism education needs to do nothing less, at-this-time in news history, than restore top news leaders to the most respected ranks of academia (Newton, 2018). In one 
of Journalism \& Mass Communication Educator's most read studies in 2013, Pavlik argues every assumption about media education deserves and demands reconsideration. Major journalism education research initiatives have been revitalized due to professional newsrooms' search for candidates with leadership and organizational skills. For example, the Carnegie-Knight Corporation's “Vision for Journalism Education,” \$11 million endowment is reinventing journalism education by consistently teaching professional aspects (Carnegie Corporation, 2005).

\section{Higher Education's Journalism Education Standards}

Journalism education standards aim to further benefit students as citizens and also being producers. In an era when effective citizenship increasingly requires digital media proficiency (Jenkins, 2009; Levine, 2008), youth journalism may serve not only as a conduit to concurrent and subsequent civic engagement, but also as a blueprint for programs that train youth to use digital communication tools for civic action (Bobkowski, $\&$ Miller, 2016). After weighing the evidence, it is certain both those are needed standards. Laufer et al., (2018) found although educating students to think critically about their community and cultivating social-responsible community coverage can be complicated by politics and public relations, it must be realized that it is possible and necessary to manage both interests. Therefore, scholastic journalism advisers need further standards to embrace a pedagogy to distill leadership skills to conquer both.

Recent research would reflect production is a key journalism education standard, as many journalism schools have an institutional commitment to production (Mensing \& Ryfe, 2013). Nelson and Lewis (2015) found journalism education needs to start with production, which focuses on how participants reported, edited, and published their 
stories. Hypothetically, student news labs can fill the resulting gap in local coverage. This is the reason that discussions of the teaching hospital model quickly turn to questions about how to fill production gaps between semesters, fund positions for professional editors and directors, deal with legal complications, and develop distribution and marketing strategies (Mensing, 2010). Just as teaching hospitals are actual hospitals, the "teaching hospital" model would have journalism schools become actual news production operations. The most successful scholastic journalism programs teach duty, honor, and professional responsibility - key components of civic education in a democratic society (Merits, 2013).

\section{Practical Pedagogy}

Student media can serve as an excellent source for first-hand reporting on issues relevant to their schools and education, as well as serve as a practice ground for future media professionals (West, Whitehurst \& Dionne, 2009). Experiential learning benefits students to learn by doing (Charles, M., \& Luce, A., 2016). In an era when effective citizenship increasingly requires digital media proficiency (Jenkins, 2009; Levine, 2008), youth journalism may serve not only as a conduit to concurrent and subsequent civic engagement, but also as a blueprint for programs that train students to use digital communication tools for civic action. Positive attachment to school also corresponds with extracurricular journalism in a positive manner (Fredricks, Blumenfeld, \& Paris, 2004).

Early journalism involvement also motivates students to pursue journalism careers (Becker et al., 2014; Bobkowski et al., 2012). Beyond simply motivating students to choose majors in journalism or similar fields of study, journalism participation also indicates more success in finding a journalism job after college (Becker et al., 2014). 
News Lab Practical Learning. Journalism has long recognized a duty to community (Fallows, 1997; Kovach and Rosenstiel, 2001). Royal (2018) said quality journalism education must have an impact on the quality of citizenship and society. Nelson and Lewis' (2015) research stated that journalism education needs to ensure collaboration focuses on how student journalists did or did not work together to cover their community. Similarly, journalism education can promote media and information literacy (UNESCO, 2014) by "building capacity for journalistic participation among nonmedia professionals, such as with community media volunteers and social media users" (p.259). A community-centered journalism education needs to deepen student understanding of what constitutes community from local to global, from place based to interest based, and the role that journalism can play within various types of community (Mensing, 2010). Mensing (2010) reflected if journalists cling to a vague sense of public, they will increasingly be out of touch with the ways that their imagined communities are actually functioning. Real coverage of communities is needed to empower student journalists and citizens, from political power to cultural and economic power (Rheingold, 1993).

Royal (2018) said “journalism education needs to empower not only students, but ultimately journalism itself" (p.258). Nelson and Lewis' (2015) research stated their final journalism education standard to debrief conceptual inconsistencies on how student journalists may struggle to pin down understandings of the abstract concepts underlying journalism, and how this struggle affected the way in which the students engaged with their stories. Literature outlines the dearth of opportunities for students to practice leadership skills and learn "soft" skills such as critical thinking, problem solving, and 
team collaboration to be successful in their careers (Bronstein \& Fitzpatrick, 2015; Pavlik, 2013). Soft skills are found to be critical to students' careers and that student-run productions provided these necessary skills more so than classroom learning (Bush, Haygood, \& Vincent, 2017). Laufer et al., (2018) said the value and even the paradox of democratic education have never been illustrated more clearly than at this moment in history (p. 255).

\section{Secondary Education's Student News Labs}

High school journalists share the same objectives as professional and high education newsrooms--finding the story, writing the story, and packaging the story so that it appeals to an audience (Streisel, 2007). Understanding how to best accomplish these objectives is key to the students on the newspaper, yearbook or Web site staff. However, the fundamental art of storytelling and story presentation are not always at the center of all high school journalism classes (Streisel, 2007). Student journalists must first understand that storytelling, at its most basic level, is about people, and that understanding the audience is essential in deciding how to present the story (Streisel, 2007).

\section{Scholastic Journalism's Value}

Journalism education has a unique contribution to civic development and civic communication competence (Bobkowski \& Miller, 2016). Students in these programs report they follow and engage with important community issues and that by informing their audiences about these issues they perform civic service and learn to effectively contribute to the civic process (Bobkowski \& Miller, 2016). 
Engaging in scholastic journalism positively affects students. Previous scholastic journalism research suggests student media can serve as an excellent source for first-hand reporting on issues relevant to schools and education and serve as a practice ground for future media professionals. (Wilderman, Nasrin, \& Davis, 2018). Student journalists are likely to be more engaged citizens than students not involved in journalism, taking deeper interest in current events and establishing free-expression literacy (Bobkowski \& Miller, 2016). Journalism strengthens a society's democratic functions (Siebert, Peterson, \& Schramm, 1963).

Studies show that school-based and non-school journalism programs support civic engagement among young journalists (Clark \& Monserrate, 2011; Graybeal \& Sindik, 2012; Marchi, 2011; Neeley, 2015). Bobkowski and Miller's (2016) research support that journalism has potential influences of social studies, debate, community service, and student government. Bobkowski, et al.'s (2016) research further showed that students who earn journalism credit in high school tend to vote more frequently than their peers who do not take journalism. "High school journalism extracurricular activities lead students to an early decision to study journalism and that decision is a powerful predictor of job market success" (Becker et al., 2014, p. 354). Bobkowski and Miller (2016) said there is something about students who take journalism compared with students who participate in other civic activities, and about journalism education itself, that translates into a specific combination of civic outcomes and increased voting.

\section{Leaders in Scholastic Journalism Classes}

Research also shows students enrolled in journalism classes are typically high achieving student leaders (Newspaper Association of America Foundation, 2008). 
Scholastic journalism classes push students to further develop into leaders. Stapp's research found journalism courses need to teach students to use the Society of Professional Journalists' Code of Ethics to report stories honestly and with balance. As Stapp (2013) identified the hard skills taught within journalism courses, he further suggests key soft skills help students grow as leaders, such as: responsibility, time management, organizational skills, writing skills, fairness, integrity, and being responsive. Additionally, he found teaching soft skills can provides journalism education that pursues truth (Stapp, 2013).

Many soft skills are taught within journalism classrooms. Larke and Monserrate (2011) showed soft skills training in journalism classes lead to a sense of collective decision making. Similarly, Bruschke and George (1999) showed a positive correlation between scholastic journalism classes and students improved verbal skills. Student leaders managing their work in a professional manner was a fundamental skill required. Bush, Haygood and Vincent (2017) further explained the importance of people skills through their study of student run organizations, such as being a good listener, being empathetic, being able to connect with a diversity of people, and working well in a team. Additionally, providing students with real-world leadership experiences impacted their organizational skills. Their study found a strong detail orientation to manage their work. The student-run classroom also emphasized the importance of knowing how to manage a project from concept to completion (Bush, Haygood, \& Vincent, 2017). More specifically, they found students believed building relationships, being a good counselor, and having the ability to work within a team setting were crucial for their student leadership development (Bush, Haygood, \& Vincent, 2017). 


\section{High School Courses Taught as Journalism}

Written and approved by the Journalism Education Association (2019), advisers use the organization's standards to show high school administrators the various tasks and approaches carried out in their programs (Student Law Press Center, 2019). In the spirit of the First Amendment, the guidelines focus on the process of producing student media, not the student product.

Overall, secondary school journalism teachers must have a broad range of knowledge and performance abilities (Student Law Press Center, 2019). Although their courses are frequently found in a school's English Department, their teaching responsibilities go beyond what most English or Language Arts curriculum requires (Downes, Hayes, Furnas, \& Newton, 2012). Therefore, advisers' curriculum standards reflect a need to be skilled in teaching storytelling, writing, listening, speaking, researching and reporting, leadership, cooperative processes, press law and ethics, fiscal responsibility, and multimedia design and production (Downes, Hayes, Furnas, \& Newton, 2012). The mastery of these skills helps advisers prepare their students to become knowledgeable media producers and consumers essential to democracy (Student Law Press Center, 2019).

Scholastic Journalism Course Curriculum. High School Journalism courses offer practical skills for high school journalists and teachers for all elements of school journalism (Streisel, 2007). Advisers cover the essential components that students must understand information gathering, writing, standard and alternative coverage and packaging (Streisel, 2007). Students learn about identifying news, interviewing, research, narrative writing style, editing, visual presentation and layout (Streisel, 2007). The 
courses also cover the legal rights of student journalists, objective vs. opinion writing, staff planning and organization and Web-based journalism.

Journalism advisers understand key principles of journalism and mass media as they function in a product-based curricula, which gives value to technology for producing and disseminating multimedia content (Downes, Hayes, Furnas, \& Newton, 2012). Overall, advisers strive to focus on the news lab's process to be more important than the product, thus allowing for continuous student learning. High school advisers are usually given the expectation to teach desktop publishing, design and layout, staff management, advertising, photography, and media law and ethics (Osborn, 1998). Law and ethics objectives are also taught as it relates to scholastic media and its importance in practice.

Educating students to think critically about their environment and cultivating social responsibility can be complicated by politics and public relations; however, Laufer, Butler-Vanderlinden, Carlin, Saker, and Taylor (2018) explain it is possible and necessary to manage both interests through each news labs procedures and policy. One of the most overlooked and misunderstood polices news labs follow is the First Amendment. Free speech instills democracy within public school news labs through the First Amendment. Public schools embody a key goal of the First Amendment by creating an informed citizenry capable of self-governance and political debate. As many commentators have observed, a democracy relies on an informed and critical electorate to prosper (National Coalition Against Censorship, 2019). High school journalism programs give students hands-on experience with the law and utilizing the rights afforded by the First Amendment (Haynes, Chaltain, Ferguson, Hudson, \& Thomas, 2003; LoMonte, Goldstein, \& Hiestand, 2013). Some journalism programs may face disheartening 
challenges in the way of censorship and other First Amendment issues, but research suggests this builds civic engagement by inspiring further investigation of individual rights and responsibilities (Bobkowski, Cavanah, \& Miller, 2017). More than simply teaching journalism skills or basic politics, journalism programs serve students by providing a way to learn how they fit within the world around them (Clark \& Monserrate, 2011).

A variety of effective instructional strategies help students become active scholastic journalists (Downes, Hayes, Furnas, \& Newton, 2012) Also, advisers strive to teach the role of leadership training, fiscal responsibility, conflict resolution and time management in student media production (Student Law Press Center 2019).

Student News Production Curriculum. According to the Journalism Education Association (2019), advisers utilize technology (including computers, mobile media devices, cameras, the Internet) as teaching and production tools. Bolman and Deal (2013) illustrate that organizations have core technologies of raw materials, activities that turn inputs into outputs, and underlying beliefs about the links between each (Dornbusch \& Scott, 1975) Core technologies often evolve and significant innovation calls for corresponding structural alterations. For example, the $21^{\text {st }}$ century brought the largest collapse in American newsroom history, with more than 15,000 local journalism jobs vanishing (Newton, 2018). Journalists have used technology to achieve speed and increased efficiencies in the production of news since the 1850s (Quinn, 2016). Carr's (1990) study found that many journalists have been unwilling to alter their approach to journalism by technology. In identifying 64 newsrooms in the 1980s, which were moving toward computerization, 42 were viewed as late adopters. The main reason these 
newsrooms had "failed to innovate was a sense that such wide-scale changes were not worth the effort" (Carr, 1990, p. 33). The news lab productions use text, graphics, photography, radio, television, and news media as appropriate ways to emphasize a range of story-telling possibilities (Ferguson, Patten, \& Wilson, 2005).

The production process encourages creative approaches to information design and packaging for student media (Downes, Hayes, Furnas, \& Newton, 2012). Additionally, the production process utilizes financial guidelines for scholastic media relating to subscriptions, advertising, activity funds, and fund raising (Student Law Press Center, 2019).

Classes within journalism programs construct and utilize staff organizational models that emphasize responsibility, risk-taking and problem-solving (Streisel, 2013). In the same way, production schedules are utilized to encourage scholastic journalists to mirror that of professional journalists (Ferguson, Patten, \& Wilson, (2005). Ultimately, the news lab's production strives for students to understand their roles as informational gatekeepers in school-based media, and their rights and responsibilities as journalists (Journalism Education Association, 2019).

\section{Limits on Scholastic Journalism Curriculum}

Recent research in other educational domains suggests that smaller schools, for instance, have less student demand for diverse curricular and extracurricular programs and fewer personnel and other resources to offer such programs (Bobkowski, Goodman, Bowen, \& Perkins, 2012). The makeup of a news lab's staff depends in large part upon the size of the school, the makeup of its student body, and the support and backing the adviser receives or can cajole from the school administration, school board, parent groups 
and community at large (Osborn, 1998). Superintendents and principals can do many things to keep journalism programs working toward such lofty goals. Money and equipment are obvious needs, but perhaps the biggest obstacle is trust (Merits, 2013).

In the same way, high school newsrooms are bound by the law and policy. In 1988, the legal situation for scholastic journalists changed greatly with the U.S. Supreme Court's ruling in the Hazelwood case (Student Law Press Center, 2019). In that case, the

court said school officials can legally censor student news productions and other forms of student expression if the censorship is related to educational needs (Ferguson, Patten, \& Wilson, 2005).

The decision permits a school principal to assume the role of publisher of the student news production (Student Law Press Center, 2019). In this position, the principal can control the productions content. Nothing in the decision requires censorship and many school districts continue to grant students and advisers final say over the paper (Ferguson, Patten, \& Wilson, 2005). Some states have passed legislation reaffirming this freedom. School news productions that are open forums for the exchange of ideas are generally considered exempt from the Hazelwood ruling (Student Law Press Center, 2019). Both sides of Hazelwood agree that the responsibility of student journalists is unchanged to emphasize accuracy, fairness, objectivity, balance, good taste, good judgment, and good sense (Ferguson, Patten, \& Wilson, 2005)

\section{Editorial Leadership in Scholastic Journalism}

Editorial leadership teaches students soft skills and transformational characteristics to be student leaders in their news labs (Cowan, 2008; Küng, 2017). Advisers can escalate leadership training to fill the current leadership education 
curriculum gap. Editorial leadership can provide advisers and students the capabilities to lead an effective, efficient, and vibrant media system within their news labs (Pavlik, 2013). Ultimately, each news lab can develop leadership skills that will help student editors and staff through college and into their careers (Robertson, 2002).

Scholars have proven leadership development to be one of the best ways to build a culture by aligning support systems to reinforce learning and student motivation (Filak, 2003). The extensive body of professional journalism education literature has gained support in emerging research with higher education journalism education. In spite of this, the model's applicability to high school newsrooms is still needed. Almost a century ago, journalist John Buchan proclaimed, "the task of leadership is not to put greatness into humanity, but to elicit it, for the greatness is there already" (Buchan, 1930, p. 24). Although there is a lack of research addressing editorial leadership, throughout history, journalists have referred to a comprehensive set of editorial guidelines when making decisions in the newsroom (Fowler-Watt \& Wilson, 2004). In the same way, many high school journalism programs have engaged in innovative approaches to teach their news lab leaders to respond to their news lab's challenges and to build editorial and personal confidence through editorial leadership.

Editorial Leadership Purpose. Editorial leadership training emphasizes soft skills and communication to share and exchange ideas, to problem solve, and to produce news by giving students soft-skill tools to carry out duties as news lab leaders (Streisel, 2007; Westbrook, 2019). The ultimate goal of editorial leadership is to make student leaders more clearly defined for each news lab. Advisers teach soft skills to students to help grow their confidence to carry out their duties efficiently and effectively. 
Additionally, Fowler-Watt and Wilson (2004) found success in their course setting out to use editorial leadership criteria to apply to the challenges faced by editors as they lead their teams, by identifying the most effective approach in a given situation.

Teaching leadership contributes to students' success because it fosters an awareness of their capabilities beyond their own. Student journalists investigate to identify patterns and to tell stories with honesty and accessibility (Laufer, ButlerVanderlinden, Carlin, Saker, \& Taylor, 2018). Students' experiences in journalism uniquely contribute to the practice of producing the news to stimulate leadership skills and strengthen their sense of civic efficacy (Beaumont, 2011). Leadership education helps students develop the knowledge and skills to lead groups efficiently (Bronstein \& Fitzpatrick, 2015). High school leadership training helps students attain a high level of behavior success, as many new college graduates are typically ineffective leaders.

Leadership is a necessary part of any organization, and the quality of leadership is a significant factor in the success of that organization (Robertson, 2002). Leadership makes people want to achieve high goals, while bosses tell people that they must get something done (Robertson, 2002). This is an important distinction. People who are merely bosses may have a disciplined staff who meet deadlines, but the morale will be low and there might be quite a bit of grumbling going on (Robertson, 2002). A dictatorship is not a desired way to govern the staff (Robertson, 2002). On the other end of the spectrum is the editor whom everyone has fun with, but who can never really get his staff to get down to work. A delicate balance of being a friend, coach, diplomat, and teacher is needed. The staff should respect its editor, and this is one of the most key fundamentals (Robertson, 2002). Journalism education curriculum does not require 
editorial leadership; however, many advisers feel it is the hardest skill to teach (Hare, 2018).

Editorial Leadership Value. Studies found many journalism educators value editorial leadership training. The best journalism programs appear to be designed and implemented in accordance with leadership training. A comprehensive review of leadership development across all professional and academic sectors found investing in leadership development adds value and gives journalists a competitive advantage. According to Robertson's (2002) essay, teaching the leadership process is valuable because a position of power as an editor does not automatically make someone a leader. An editor must influence others to accomplish a task and direct the news lab to be cohesive and successful (Robertson, 2002).

Scholars identified fostering a culture of supportive leadership development as being beneficial (Filak, 2003; Newton, 2018). Leadership development has proven to be one of the best ways to build a culture by aligning support systems to reinforce learning and student motivation (Filak, 2003). According to Robertson's research (2002), motivation ensures each staffer wants to be part of the newsroom through desire and energy directed at achieving a goal. For example, an editor has the power to influence motivation through rewarding good behavior and by keeping the staff members' jobs as a team challenging, exciting, and meaningful (Robertson, 2002). In the same way, editors, staff, and the adviser must communicate expectations of deadlines, distribution, and community, which leads to productions' biggest stress factor (Robertson, 2002). Additionally, newsroom leaders must permit suggestions for changes to ensure staffers feel appreciated and gain respect (Bush, Haygood \& Vincent, 2017). 
Editorial leadership strengthens the relationship between advisers, student editors, and news lab staffers to build mutual confidence to produce journalism, which is worthy of the audience's trust (Fowler-Watt \& Wilson, 2004). Serving in a key leadership position on a student news lab production can be an empowering experience. Westbrook (2019) believes not only will students have the opportunity to exercise their journalistic passions, but they may maximize their tenure as editor, managing editor, or page editor to find many ways in which editorial leadership can challenge them as leaders and find ways to grow as people.

Editorial Leadership Skills. Leadership education helps students develop the knowledge and skills to lead groups efficiently (Bronstein \& Fitzpatrick, 2015). Advisers and student editors have autonomy in their decisions to establish newsroom culture (Collins, 2017). Advisers are training not only technically adept, thoughtful practitioners, but also individuals who have the interpersonal skills, the psychological attributes, and the global sensitivities to be the next generation of mass communication leaders. To that end, leadership training ought to be consciously integrated as a core element of a reinvigorated mass communication education (Bronstein \& Fitzpatrick, 2015).

Scholars summarize a range of aspects to teach leadership skills, which are needed to drive people and enterprises within the journalism field (Cowan, 2008; Mulrennan, 2018). These strategies have a noble history in this country, and each can lead to a different series of decisions, but all have a common need for good leadership (Cowan, 2008; Mulrennan, 2018). There is a need to further design comprehensive leadership development programs to ensure a pipeline of qualified students are ready for professional newsrooms. Good leaders can be made and do not have to be born and if a 
student editor has the desire and will power, he or she can strategically become an effective leader (Northouse, 2016).

Effective principles and leadership development will be identified in this study. Several studies showed a need to ensure support for leadership development from professional mentors to aid in preparing students for the leadership roles essential in innovating and shaping changing media structures (Bush, Haygood, \& Vincent, 2017). Research identified an interesting illustration of this correlation in newsrooms as professional newsrooms are looking for candidates with leadership and organizational skills (Bush, Haygood, \& Vincent, 2017). There are leadership opportunities for students to learn soft skills by working in teams, critical thinking, coordinating, and communicating with diverse individuals (Bronstein \& Fitzpatrick, 2015; Bush, Haygood, \& Vincent, 2017). Being effective at soft skills can lead to a competitive advantage for graduates entering their careers (Bronstein \& Fitzpatrick, 2015; Bush, Haygood, \& Vincent, 2017; Hopkins, Raymond, \& Carlson, 2011; Windels et al., 2013;).

Several studies have identified the ingredients that are the most common to programs regarded as effective (Bronstein \& Fitzpatrick, 2015; Bush, Haygood, \& Vincent, 2017, Hopkins, Raymond, \& Carlson, 2011; Windels et al., 2013; Newton, 2018). Effective leadership development programs are designed to respond to the mission-related challenges faced by the organization or the needs of the community being served. Effectiveness depends on how well the choices made are integrated with one another and how well they are linked to the priorities of the sponsoring organization and the readiness of the participants. At the same time, these studies show that not all effective programs employ all these ingredients. No single approach or combination of 
approaches is a guarantee of "best practice." According to Vicere and Fulmer's (1998) research the best programs seem to embody a trend: they "are evolving toward a systems perspective - a recognition that training or education alone cannot develop leaders, nor can assignments without adequate coaching and career plans, nor can experiences that are unrelated to corporate strategic objectives. Corporations are recognizing the power of executive education and leadership development initiatives as part of a system that can help align managers, workers, and organizational process in pursuit of strategic objectives (Vicere \& Fulmer, 1998).

Editorial Leadership is Different than Management. Effective news lab leaders often wear many hats (Covey, 2012). There are times when an editor will be a coach building a team and reinforcing desired behavior (Lundgren, Cutsinger, \& Herron (2019). Other times they will be a counselor, encouraging and empathetic (Blachard \& Johnson, 2016). Also, supporting the news lab team, and a manager, organizing and planning activities. Editors should practice guiding and critiquing staff members effectively (Lundgren, Cutsinger, \& Herron (2019). Also, the news lab student leaders provide each other with pointers on how to compliment and criticize another student's work (Blachard \& Johnson, 2016). It is also important to expose staff to experiences designed to develop leadership abilities (Blachard \& Johnson, 2016).

Efficiently Gathering Students through Editorial Leadership. When it comes to giving editors a clear technique to become more successful as leaders, advisers aim to demonstrate how journalism principles can provide an effective guide to dealing with management and leadership issues (Fowler-Watt \& Wilson, 2004). So, when production begins, students will be empowered to hit the ground running with professional and 
personal confidence to develop a first instinct to think collaboratively and communicate reasons to publish editorially justified content, rather than worry first about getting things wrong (Fowler-Watt \& Wilson, 2004; Streisel, 2007; Westbrook, 2019).

The first requirement for an efficient news gathering operation is a well-organized staff. The organization of school production parallels that of commercial productions (Ferguson, Patten, \& Wilson, 2005). At the top is the publisher. The board of education, elected by the public, appoints a superintendent who in turn appoints a principal of the high school. The principal functions as a publisher. The principal, usually working closely with the journalism adviser and the students, sets guidelines - general policies within which the production staff must function. Serving as liaison to the publisher, the public, the faculty, the students, and possibly the printer, is the journalism adviser (Ferguson, Patten, \& Wilson, 2005). He or she has a difficult job and is sometimes caught between conflicting aims of students and administrators (Student Law Press Center, 2019).

In the organization of a production staff, the managing editor is at the top of the pyramid, determining policies and developing story ideas (Ferguson \& Patten, 2005). Subeditors, sometimes organized by the page for which they are responsible, work under the managing editor's direction. Sports editors, chief copy editors, and editorial page editors are in this group. All help supervise reporters.

The news lab staff is comprised of student reporters. While students in news lab leadership positions are editors in chief, managing editors, assistant editors, editorial directors, page-section editors. Editorial leadership is not for news lab staff "rookies" it is a position designed for experienced news lab students who are in leadership roles on their 
respective productions (Westbrook, 2019). The adviser is the hired high school faculty, which is the news labs' content expert while engaging with students and reflecting upon production (Downes, Hayes, Furnas, \& Newton, 2012).

Reporter Positions. Reporters complete the basic work of writing the stories. Reporters can either cover a beat, returning always to the same sources and subjects, or do general assignment work (Ferguson, Patten, \& Wilson, 2005). General assignment reporters cover whatever is necessary. The real eyes and ears of any production are its reporters at professional newsrooms, the wire services provide a great deal of copy (Streisel, 2007).

Reporter Practices and Qualities. Student productions have no wire services and have to be staffed by people willing to dig for stories. The reporters are on the front lines. How good a production becomes depends on its reporters and how well they are supported. Helpful editors who maintain good communication are great contributors to any production (Streisel, 2007). Teamwork is essential to a smooth journalistic operation (Lundgren, Cutsinger, \& Herron (2019). Yet, the vertical alignment hinders coverage decisions during coverage meetings due to the decision-makers ability to connect with the decisions made by the operating core of reporters (Bolman \& Deal, 2013).

Editor Positions. Selected students are provided with responsibility of deciding which news stories are produced in the news lab. Long before the production is complete, the editor assigns reporters to cover the news, checks for accuracy and fairness in the stories. Some news labs choose to assign editorship positions, with editors being in charge of one specific area. According to Osborn (1998), the position often depends upon the size of the staff and number of stories required. In this case job descriptions match the 
content of the news lab's production. The advantage of assigning editorships to a specific area is that it permits an editor to see that reporters follow through and to help with every phase of a story, from inception in pre-production to the final editing in post-production. Once approved for production, some stories may be pooled to use where is most needed or effective (Osborn, 1998).

With small staffs, certain positions such as business manager and advertising manager may be combined. Conversely, with larger staffs and bigger news productions, there may be a need for a managing editor in addition to editor in chief, and such positions as feature editor may be divided into several categories, for example, feature and entertainment (Osborn, 1998).

Editor Practices and Qualities. Leaders inspire others and have tested their skills and inspire other people to work with them to create success (Northouse, 2016). The best staffs have a clear outline of what they need from their staff leaders (DePress, 2008). People skills are a necessary component of leadership (DePress, 2008). In addition to common leadership qualities, there are unique adaptable needs for each group, depending on the makeup of the staff for the leaders to address possible challenges (Northouse, 2016). Leaders are people who other people want to follow, even in journalism classes, to inspire creativity and loyalty, which is helpful for work sessions (Lundgren, Cutsinger, \& Herron, 2019). They effectively share their goal or vision of a great news production with staff members (Covey, 2012). The adviser will empower the student editors to set up regular discussion time or get monthly evaluations from the staff offering constructive feedback on performance (Blachard \& Johnson, 2016). The entire 
staff can look up to them for what to do or say to support a constructive, productive and pleasant even fun news lab experience (Lundgren, Cutsinger, \& Herron, 2019).

Adviser Position. According to the Journalism Educators Association (2019) advisers are content experts, engage students and reflect. Advisers understand content, development and differentiation. These advisers engage students with effective communication, management and motivation, planning, evaluation and the best instructional strategies. Finally, journalism educators seek professional growth by actively reflecting on their practices individually and in professional learning communities. Scholastic journalism advisers leadership standards embrace production standards which can meet citizenship expectations. An adviser's job is to be their students' supporter to print the truth and be brave (Stapp, 2013). It is his or her job to be an educator who champions freedom of speech, but may take some heat for what the student journalists produce in their student newspapers, news magazines, and online productions (Merits, 2013). Therefore, advisers must ensure their news lab students are leaders. If there are good working relationships between the adviser, staff, editors and the administration, then the production can work to its full potential. Ideally, the adviser will advise on matters of law, libel and good taste, and let the students essentially run the program. This leaves the editors as the leaders of the staff, which will closely mimic a professional newsroom. While it can be a large responsibility, it is an opportunity for the editors to develop leadership skills that will help them through college and into their careers (Robertson, 2002). Breed's (1955) foundational study reflects the news labs policies and procedures, again, were not part of an overt brainwashing but rather an informal process in which new reporters learned from veterans. Therefore, emerging 
leaders learn how to define what journalism is and who they are through socialization within the college news lab (Collins, 2017).

Adviser Practices and Qualities. Advisers teach courses, attend workshops and empower editors with a deep understanding of what is involved in editorial leadership by applying key journalistic principles (Fowler-Watt \& Wilson, 2004). Journalism Educator Association Curriculum Chair Rebecca Pollard empowers her students by teaching leadership and training student leaders. Pollard believes "it is not just about the skills, but about talking as people" (Johnson, 2017, p. 28). Pollard enforces a definitive timeline to train effective leaders to inspire and sustain her news lab's future at Lovejoy High School in Lucas, Texas.

First, she will begin her students' editorial leadership training by her students taking Myers-Briggs personality tests to bring students' personality traits to life, which helps students feel confident of their personal strengths. In addition, she will have her students complete a love language quiz to get further context to themselves and to their daily work. Upon completion, she is sure to discuss the results by putting the results into context and give them meaning. Then, she will have her designated leadership team give the tests to the news lab staffers and lead the same discussion she had with them about their traits and how they will impact their work and the Lovejoy High School High School program (Johnson, 2017). The test results are used for the entire news lab to become aware of skills needed for a successful year. The results are also used to train the staff in the areas where they have weaknesses.

According to Pollard (2017), part of an editorial approach is to verbalize and make the staff communicate how each contributes to the news labs production process. 
Pollard believes it is also is important to train and to invest in news lab leaders so they will be in charge of the staff to work smarter, not harder. Once the leaders have been nurtured and trained, they will, in turn, pay that forward to staff members, which frees up the adviser to oversee the news lab's operation and take care of the logistical items students cannot touch.

Leadership training has been impactful for Pollard's program. She emphasized, "I learned that when we set the cameras down for a minute and back away from computers, I have trained the students how to be leaders with life skills that last long after being in high school" (Johnson, 2017, p. 28). Ultimately, Pollard found her program runs smoother, the staff members are less frustrated and "best of all, there is autonomy" (Johnson, 2017, p. 28). Editorial leadership techniques provide an environment for advisers to empower his or her student editors (Northouse, 2016; Streisel, 2007; Westbrook, 2019). Advisers empower the editors to have a level of engagement in the decision-making processes with their reporters to better enable the editors to embrace the challenges presented by their news lab environment (Fowler-Watt \& Wilson, 2004;

Johnson, 2017; Northouse, 2016; Streisel, 2007; Westbrook, 2019).

\section{Current Gap in Editorial Leadership Research}

Due to the deficiency of scholarly recommendations, high school journalism teachers lack set criterions to teach professional leadership skills, resulting in irresolute advisers not knowing which leadership skills should be taught to ensure their students are ready for newsrooms demanding urgent decisions to be acted upon. A rationale for investing in scholastic journalism leadership specifically stems from the underdeveloped scholarly research of editorial leadership. 
One of scholastic journalism's biggest advocates, Laurence Campbell, examined high school newspaper's influences. His historic 1969 study examined high school journalism in seven Midwest states investigating curricular and co-curricular activities and related topics. Campbell's study indicated the presentation of news was the high school newspaper's most important objective and the students' leadership objective ranked second (1969). The decades-old study claimed that leadership was a priority, but it does not contribute or establish high school leadership standards. There has not been research focusing on editorial leadership in the last 40 years. In result, the qualitative data in this study will be used to identify the range of leadership in Missouri high school journalism news labs to find how advisers utilize many leadership practices. This study will explore perspectives on leadership training to prepare students for modern day professional newsrooms (Poerksen, 2010). In addition, this study will focus on how advisers teach leadership in scholastic journalism news labs. As this is one of the first studies on editorial leadership, the resulting recommendations from this study may be considered transferable to other high school journalism news labs. This study will provide editorial leadership training recommendations to address the industry's changes through management values emphasizing journalists' ethical responsibilities (Herndon \& Krueger, 2016).

Respectively, there are no reports of original research to prepare high school students for the transforming journalism industry. Instead, they present anecdotal evidence, such as Robertson's (2002) essay on teaching the leadership process is valuable because a position of power as an editor does not automatically make someone a leader. This and other reported information on individual high school news labs is showcasing 
outdated leadership skills. Advisers are missing opportunities to align with professional standards because students are moving into a workforce with outdated skills (Mulrennan, 2018).

\section{Summary}

All journalism education facets need a commitment to great journalism and a responsibility to the importance of good journalism leadership (Cowan, 2008). As this is one of the first studies on editorial leadership, the resulting recommendations from this study may be considered transferable to other high school journalism news labs. This study will provide editorial leadership training recommendations. The adviser's perspectives accentuate leadership training as a priority to transform student news labs technical capabilities and digital behaviors through leadership (Camarota, 2004). Teaching leadership at the high school level contributes to students' success because it fosters an awareness of their capabilities beyond their own. This current study sought to find how advisers teach leadership to encourage students' newsrooms behaviors and capabilities.

There is a need for further research to investigate high school news labs by citing relevant skills advisers use and the concordant challenges of training, educating and building student leaders in problem-solving, decision-making, and effective group interaction skills (Bronstein \& Fitzpatrick, 2015). Further research can escalate leadership training to fill the current leadership education curriculum gaps. Editorial leadership can provide advisers and students the capabilities to lead an effective, efficient, and vibrant media system within their news labs (Pavlik, 2013). 
News labs strive to stay relevant while passionately upholding the value and purpose of journalism in a world ever more in need of the kind of accurate, substantive and insightful information upon which our democracy and culture depend (Lynch, 2013). Leadership training can provide high school journalism programs with needed coping strategies to address the industry's changes through principles exploring management values and emphasizing the ethical responsibilities of news media leaders (Herndon \& Krueger, 2016). These reflections can potentially illuminate future journalism education and leadership practices. Therefore, the study will focus on existing news labs patterns to develop systematic transformational leadership practices and offer unique editorial leadership. 
SECTION FOUR

CONTRIBUTION TO PRACTICE 


\section{Plan and Rationale for Dissemination}

The researcher plans to share this current study's findings in the form of a PowerPoint presentation and executive summary to high school advisers attending the $51^{\text {st }}$ annual Missouri Interscholastic Press Association (MIPA) Journalism Day (J Day) at the University of Missouri - Columbia, School of Journalism.

J Day is MIPA's annual journalism professional development conference that takes place in March and focuses on providing effective practices in journalism education and news labs. According to MIPA's website, 2,000 students and advisers annually attend the convention. $\mathrm{J}$ day focuses on including all sizes of urban, suburban, and rural high schools. MIPA's purpose statement includes their focus to ensure all journalism advisers and students are provided with resources and support. The day is full of speakers, workshops, competition and awards for area students and advisers.

Plan for Dissemination of Practitioner Contribution. The researcher's presentation format will allow for open dialogue between Missouri's journalism advisers and the researcher. An executive summary of findings will be provided to the study participants as follow-up information to the participants in the study. The following PowerPoint presentation and executive summary will be used. 


\section{EXPLORING EDITORIAL LEADERSHIP: Transforming Students into Leaders

\author{
Executive Summary
}

Little has been known about how high school journalism teachers teach leadership. Advisers perspectives helped identify the significant need for the role of leadership in their scholastic journalism programs. Soft skills provide many opportunities for students to grow into leaders. When an adviser establishes leadership as a foundation, news lab production increases, creativity is fostered, and decision making is delegated to the students. Leadership also provides opportunities to articulate the adviser's passion and genuine convictions with their students. Thus, leadership skills are important in journalism education. As this is one of the first studies on editorial leadership, the resulting recommendations from this study may be considered transferable to other high school journalism news labs.

\section{Historical Background}

In 1908, Walter Williams developed the first journalism school in the world at the University of Missouri-Columbia. He was a driving force in supporting all students to become journalists. Williams founded Missouri Interscholastic Press Association (MIPA) in 1923 to support high school journalism advisers. He could have not predicted his vision would spark 2019 to be The Year of the Student Journalist (Gavankar, 2019; Weinberg, 2008).

\section{Design of the Study}

Data were collected to answer the following research questions:

1. What role does leadership play in K-12 journalism education?

2. What leadership skills are important in K-12 journalism education?

3. What are high school advisers' perspectives regarding teaching leadership skills?

4. How do K-12 journalism advisers teach leadership skills?

5. What components of the transformational leadership theory are present within scholastic journalism news labs?

Setting. The researcher visited news labs in Missouri public high schools. The participants were selected from MIPA's membership, which separates the state into four different regions. These four regions of Missouri are divided by Highway 50 and Highway 65 (MIPA, 2019).

Participants. Advisers were MIPA All-Missouri award winners within the last two years. The 24 participants were selected through representative non-random, purposeful sampling (Creswell, 2014). In the current study each adviser was given a pseudonym connected to the size of their school. The researcher used MIPA school categories to decipher the school divisions. The following school population-categories pseudonyms included: E names for Extra-large schools 1700+; L names for Large schools 1201-1700; M names for medium schools 701-1200; and, S names for small schools 1700 (MIPA, 2019).

Data Analysis and Collection Tools. Data were collected via interviews, observations, and artifacts from 24 MIPA All-Missouri advisers. Data were coded according to themes. The lens of the transformational leadership theory was used to create the categories connecting to the research questions 


\section{Summary of Findings}

This study revealed the significant role of leadership in K-12 journalism education. All research-based perspectives showed how advisers effectively developed, strengthened, and sustained their student leadership. The advisers interviewed for this study were leaders who created trust and consensus around their news lab's common vision. The dominant role of leadership is important in journalism education. When an adviser establishes leadership as a foundation, effective production increases, creativity is fostered, and decision making is delegated to the students.

\section{Recommendations}

Advisers perceptions revealed there is a need for high school journalism educators to teach leadership. The implication that high school journalism educators must teach editorial leadership forms the following recommendations for practicing high school journalism advisers:

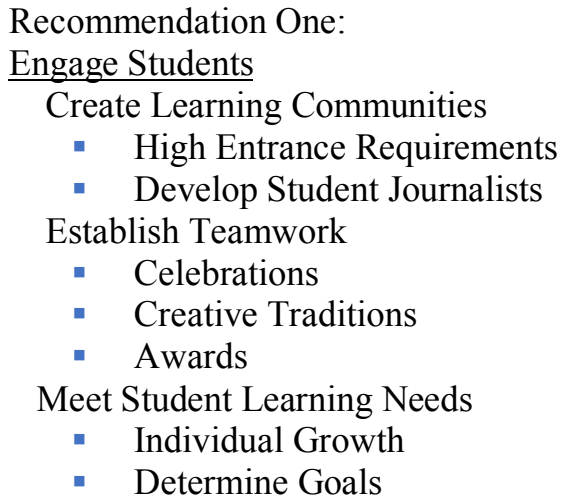

Recommendation Three:

Empower Student Leaders

Safe Environment

- Support Student Decisions

- Positive Feedback

Take Action

- Inspire News Coverage

- Experiment with Media
Recommendation Two:

Teach Leadership

Focus on Accountability

- Define Leadership Roles

- Establish Editor Expectations

Motivate Students

- Share the Vision

- Meet Rigorous Standards

- Maximize Strengths

- Reaching Potential

\author{
Recommendation Four: \\ Impact Student Leaders \\ Harness Enthusiasm \\ - Developing a Sense of Pride \\ Build Trust \\ - Establish Relationships \\ - Open Communication
}

\section{Significance of the Study}

The qualitative study identified the range of editorial leadership practices in Missouri high school journalism news labs to contribute a clearer understanding of how advisers utilize many leadership practices. This study explored advisers' perspectives and how they teach leadership in their high school news labs. The findings will benefit high school journalism teachers to develop leadership for effective production, encourage creativity, and foster decision making. This current study will increase awareness and utilization of editorial leadership within scholastic journalism. Developing editorial leadership approaches to journalism education could help educators to "seize this moment to create alternative models of journalism to invigorate advisers and inspire students in ways that would allow journalism education to fully contribute to the next era of journalism" (Mensing \& Ryfe, 2013, p. 40) Findings will be presented to administration, teachers and, ultimately, students to encourage and inspire editorial leadership.

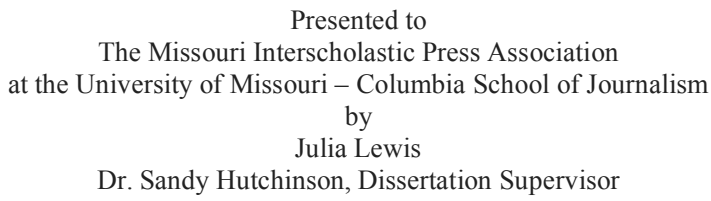




\section{EXPLORING EDITORIAL LEADERSHIP: \\ Transforming Students into News Lab Leaders}

A Dissertation Presentation

Presented to

The Missouri Interscholastic Press Association at Journalism Day

at the University the University of Missouri - Columbia, School of Journalism

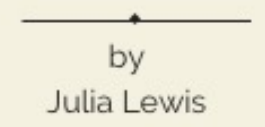

Dr. Sandy Hutchinson, Dissertation Supervisor

March 2020

1 


\title{
Statement of the Problem
}

\section{Unknown LEADERSHIP STANDARDS}

\author{
Little was known about how high \\ school journalism advisers teach \\ leadership skills.
}

UNKNOWN

LEADERSHIP SKILLS

* Students are moving into a workforce with outdated skills (Mulrennan, 2018).

\section{UNKNOWN}

\section{LEADERSHIP CURRICULUM}

* Many believe advisers do not know what to teach because their goals are moving targets (Wenger, Owens, \& Cain, 2018).

Adviser leadership standards were unknown. Little was known about how high school journalism teachers were teaching their students professional leadership skills. So, many teachers were left unsure of how and which leadership skills to teach within their news labs. Similarly, there was a lack of research regarding leadership in high school news labs. As there were no known leadership standards being taught within high school news labs, research was needed to explore how advisers prepared their students to be leaders. The researcher explored how advisers transformed their students to be news lab leaders. 


\title{
Gap in the Literature
}

\section{LACK OF EDITORIAL LEADERSHIP RESEARCH}

\author{
There are few reports of original research \\ addressing editorial leadership or how \\ advisers teach leadership in $\mathrm{K}-12$ news labs.
}

3

Currently, research presents anecdotal evidence on individual high school news labs are showcasing outdated leadership skills. The education and training of journalists is a subject much debated but rarely researched in scholastic journalism. A few published studies have addressed professional and higher education newsroom leadership, but the number of scholarly studies on scholastic journalism leadership has been completely void. 


\section{Design of the Qualitative Study}

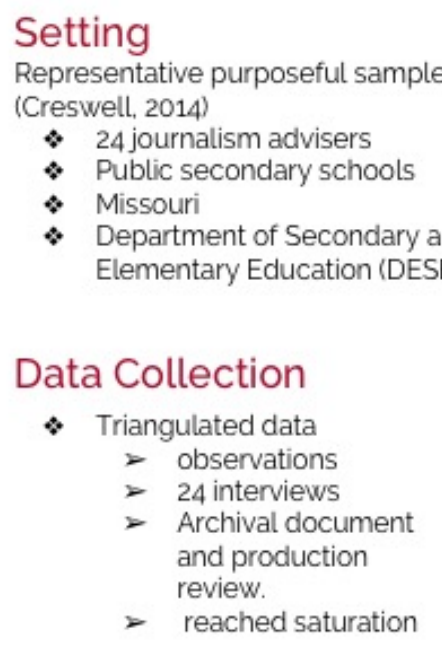

\section{Participants}

Selected Missouri Interscholastic

Press Association (MIPA) Advisers

* All-Missouri Award Winning

* Missouri

* School size

* Geographic region

The researcher visited news labs in Missouri public high schools. The researcher connected to news labs throughout the entirety of the state. The setting was also determined by MIPA's membership, which separates the state into four different regions. These four regions of Missouri are divided by Highway 50 and Highway 65 (MIPA, 2019). The data collection was done by the researcher triangulating data through a series of systematic observations, 24 interviews, and document reviews and production review. The participants included selected MIPA Award winning advisers from across Missouri by their school size and geographic region. The adviser had to be an MIPA All-Missouri award winner within the last two years to be part of the study. There were 24 participants throughout Missouri's four quadrants. In the current study advisers were given a pseudonym connected to the size of their school. The researcher used MIPA school category to decipher the school divisions. The following school population-categories pseudonyms included : E names for Extra-large schools 1700+; L names for Large schools 1201-1700; M names for medium schools 701-1200; and, (c) S names for small schools 1-700 (MIPA, 2019). The lens of transformational leadership theory was used to create the categories to connect to the research questions. 


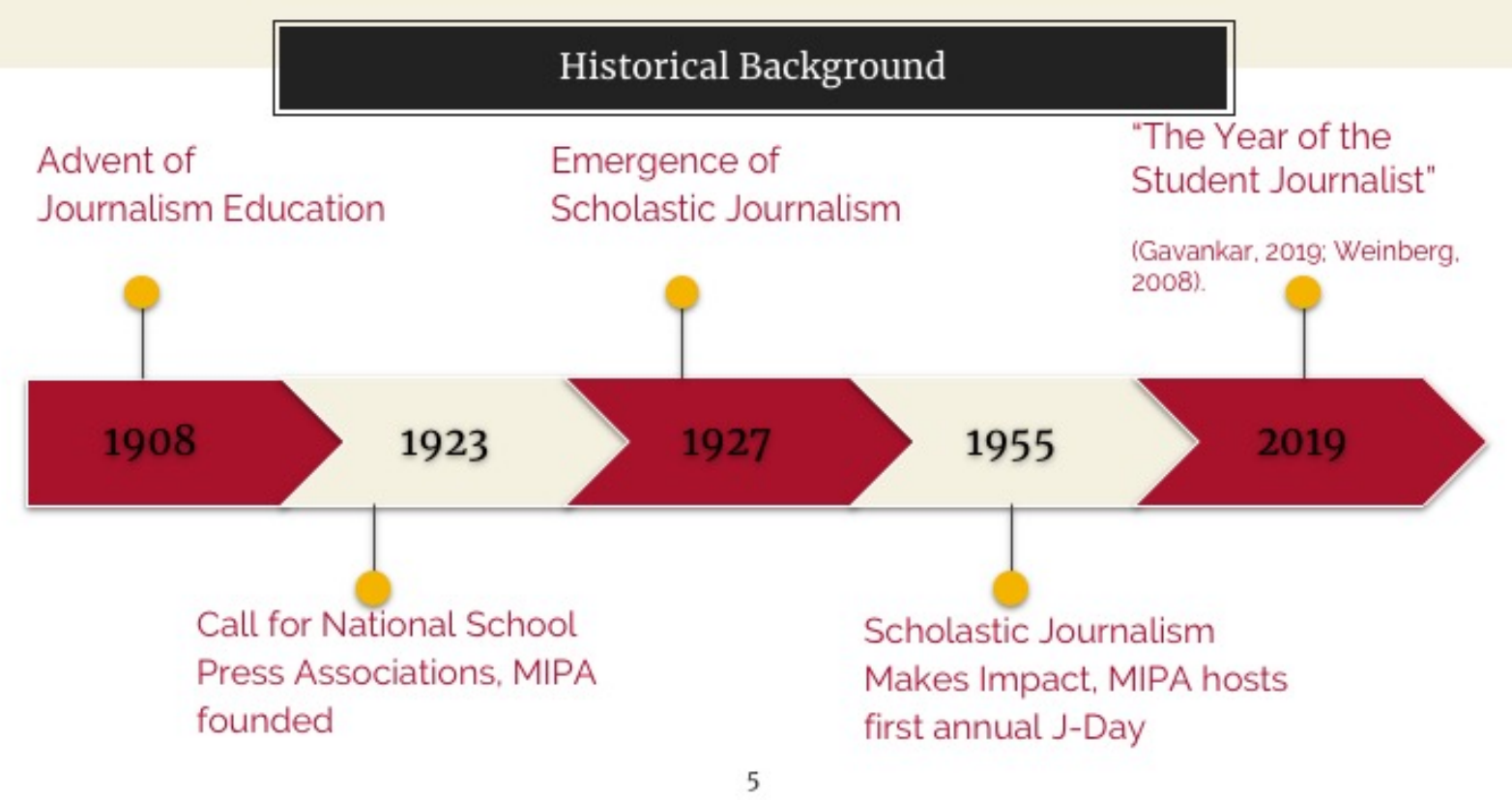

The study took the researcher throughout Missouri's high school news labs. Missouri is a good fit for this research because much journalism history originated in Missouri. Walter Williams started Missouri School of Journalism at the University of Missouri in 1908. He was a driving force in supporting students to become journalists. Williams founded MIPA in 1923 to support high school journalism advisers. Over a century after Walter Williams developed the first journalism school in the world, he could have not predicted his vision would spark 2019 to be The Year of the Student Journalist (Gavankar, 2019; Weinberg, 2008). The relevant history of the role of education in journalism provides a deeper understanding of the transformational context surrounding the advisers leading Missouri's high school news labs. Particularly, delineating journalism education's background in association with scholastic journalism's impact on their campus and communities advances an indication into the craft's developments, movements in academia, and the changes in the field. Each puts forward a specific context for studying MIPA advisers. 


\section{Purpose of the Study}

\section{GAIN KNOWLEDGE AND INSIGHT TO REVEAL ADVISERS' PERSPECTIVES ON HOW THEY TEACH LEADERSHIP \\ * Investigate leadership skills students gain from training programs. \\ * Acknowledge the significant role of journalism education in academic growth. \\ * Showcase leadership dynamics involved in producing scholastic journalism. \\ * Address the leadership gaps between high school news labs, and professional newsrooms}

6

This study investigated news labs by citing skills students gained from participating in leadership training programs. Acknowledging the significant role of journalism education in academic growth, stresses the need for school districts and secondary education to invest in scholastic journalism initiatives. Showcasing the leadership dynamics involved in producing news in educational environments helps educate and build student leaders. The current study addressed the editorial leadership gaps existing between secondary education news labs and professional newsrooms. 


\section{RESEARCH QUESTIONS}

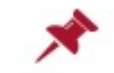

$\mathrm{RQ}$ \#1

What role does leadership play in $\mathrm{K}-12$ journalism education?

\section{(C)}

RQ \#3

What are high school advisers' perspectives regarding teaching leadership skills?

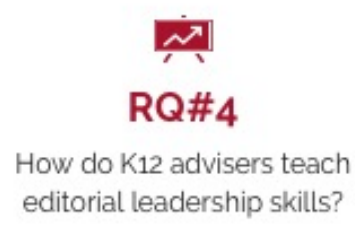

How do K12 advisers teach

7

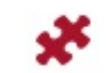

$\mathrm{RQ} \# \mathbf{2}$

What leadership skills are important in $\mathrm{K}-12$ journalism education?

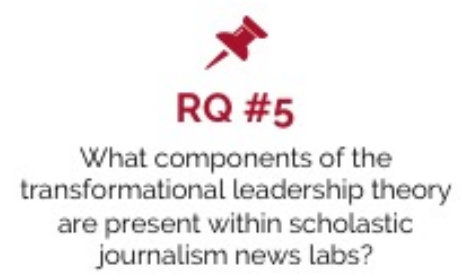
journalism news labs?

Focusing on these areas led to the research questions getting answered. 


\section{RESEARCH QUESTIONS ANSWERED}

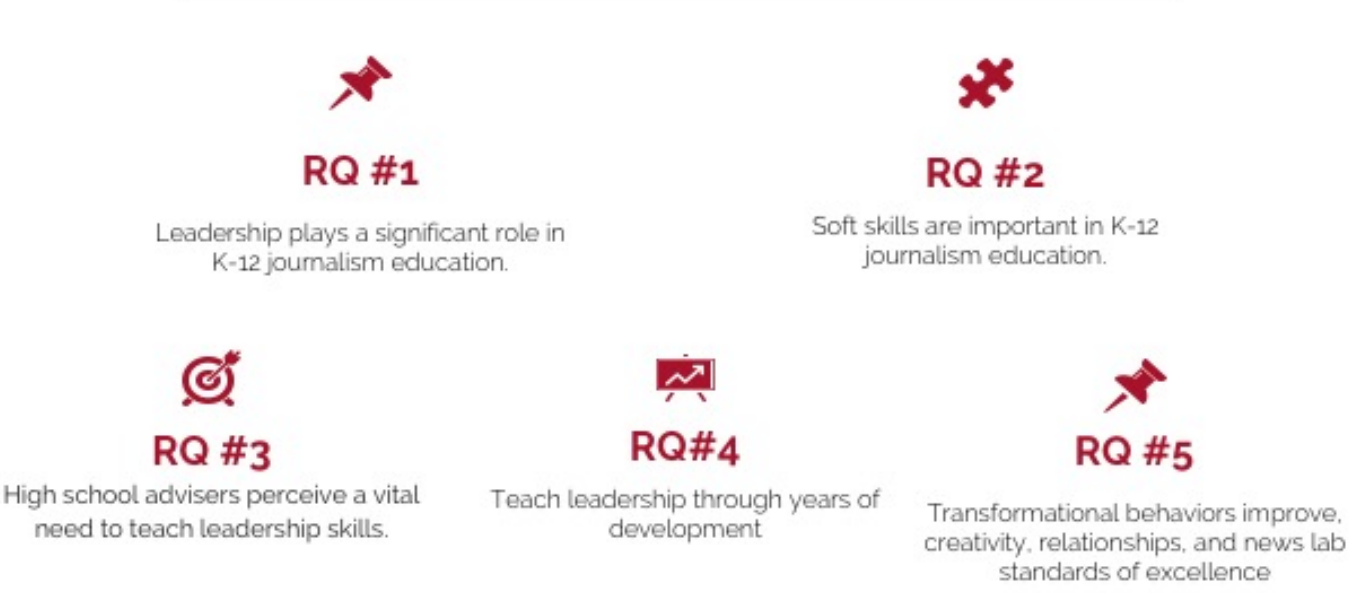

8

The study's findings revealed advisers' perceptions about teaching leadership to not only define it, but also providing advisers' recommendations. High school advisers perceive a vital need to teach leadership skills. 


\title{
Discussion
}

\section{Leadership plays a leading role in scholastic journalism programs, known as editorial leadership.}

\author{
When an adviser establishes leadership as a foundation, news lab \\ production increases, creativity is fostered, and decision making is \\ delegated to the students.
}

9

The current study's findings indicated leadership plays a leading role in scholastic journalism programs, known as editorial leadership. When an adviser establishes leadership as a foundation, news lab production increases, creativity is fostered, and decision making is delegated to the students. Thus, leadership skills are important in journalism education. Advisers said soft skills provided opportunities for students to grow into leaders. The student leaders then provide advisers opportunities to articulate their passion and genuine conviction. The advisers interviewed for this study were transformational leaders, creating trust and consensus around their news lab's common vision. Many transformational leadership theory components were present within Missouri's scholastic journalism news labs. 


\section{Recommendations}

\section{Engage Student \\ * Build a Community of Learners \\ * Establish Teamwork \\ * Meet Student Learning Needs \\ Empower Student Leaders \\ * Safe Environment \\ * Take Action}

\section{Teach Leadership \\ * Focus on Accountability \\ * Establish Editor Expectations}

\author{
Impact Student Leaders \\ * Harness Enthusiasm \\ * Build Trust
}

10

Adviser perceptions revealed practicing high school journalism educators believe that there is a need to teach leadership. The following recommendations are suggested for practicing high school journalism advisers.

The first recommendation is to engage students in leadership opportunities and actively learning journalism. It is imperative advisers recruit students to be part of their news lab. In fact, in scholastic news labs advisers must teach learning as a critical process focused around building a community of learners, creating a team, and individualizing instruction to meet each student's needs.

The second recommendation is for advisers to teach leadership. It is imperative advisers teach their student editors to be leaders. Leadership in scholastic news labs impacts individual students. Leadership skills instill practices and behaviors throughout news labs that develop students into leaders.

The next recommendation is to empower student leaders. Advisers create nurturing environments by helping students make their own decisions to take action. Advisers must build nurturing news labs so students learn leadership behaviors. Creating a safe environment helps journalism students to seize the moment and take risks in their coverage.

The final recommendation is to impact student leaders. Advisers must be impactful leaders for their students, high schools, and communities through their enthusiasm, influence, and trust. 


\section{Recommendation One: Engage Student Leaders}

\section{Build a Community of Learners}

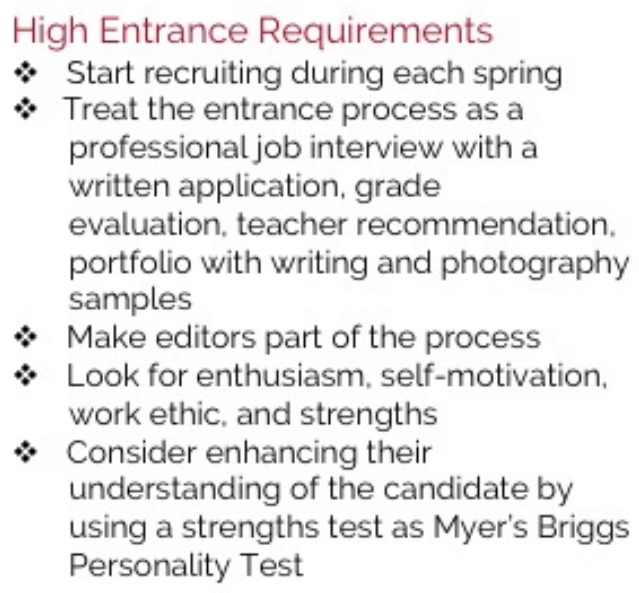

Develop Student Journalists

* First teach hard skills as law, ethics, writing. photography. and interviewing

* Then teach soft skill aspects such as teamwork, communication, critical thinking. problem solving, interpersonal, and work ethic

Advisers need to transform their news labs to be learning communities with strict standards for entry. Additionally, participants inspired their students to want to learn the technical skills to become a student journalist. Becoming accepted into a scholastic journalism class provides students an opportunity to learn basic skills and become immersed into their news lab norms. Effective recruiting and to be part of the news labs' community of learners and training ensures efficient production. Advisers need to hold high standards for news lab entry by creating initiation processes and looking for already developed leadership skills in their applicants. Advisers must develop student journalists. Once students are selected to be part of the news lab, advisers are ready to teach and inspire students to develop their skills. Leadership skills develop through a specific set of soft skills. Even though soft skills are not dictated within scholastic journalism's curriculum standards, soft skills are critical to teaching journalism leadership by setting communication and social standards. Mastering soft skills is an intense focus on professionalism to better communicate and work with other people. Ultimately, soft skills aid in students developing into effective leaders. 


\title{
Recommendation One: Engage Student Leaders
}

\section{Build a Community of}

\section{Learners}

\author{
Lydia \\ * "The students feel a high \\ accomplishment just coming into this \\ class. They know they have achieved \\ their spot. The application process \\ helps a lot to acknowledge each \\ student belongs and have the ability \\ to meet the news labs' challenges."
}

\author{
Sandy \\ * "I look for a kid's work ethic. If they're \\ willing to put in the work, be responsible, \\ show up, that's the kid that I want to \\ gravitate toward yearbook. I don't \\ necessarily get that at the first, but some \\ of the kids surprise me. Some of them I \\ take on as a chance because I have a gut \\ feeling about them, that they are really \\ into yearbook. They gravitate toward it." \\ 12
}

Building news labs into learning communities were important to advisers. 


\section{Recommendation One: Engage Student Leaders}

\section{Establish Teamwork}

\author{
Celebrations \\ * Establish throughout each step of \\ production process. \\ * Make it a priority \\ * Celebrate each deadline \\ accomplishment by congratulating \\ students individually and their whole \\ news lab staff \\ * Observe staff exceeding the workflow \\ process during a deadline cycle. \\ * Base upon the students' needs and \\ enthusiasm
}

\author{
Creative Traditions \\ * Use during each step of production \\ * Make periodic team-building, reflection \\ exercises, and self-care exercises \\ enhance the motivation for the advisers to \\ help their staff gain comfortability as \\ writers individually and as a team \\ Awards \\ * Provide in-house awards for every \\ deadline cycle such as best story, best \\ design, as well as leadership awards
}

13

While advisers need to build a community of learners, ritual celebrations are also needed within their news lab's production process to develop a team. Advisers engage their students to be part of their news lab community by recognizing student contributions. Advisers show appreciation for individuals as well as team excellence. They celebrate the news lab's values and victories, creating a spirit of community and family. Advisers need to use the key benchmarks within their production process to celebrate individual and team success, but more importantly to establish partnerships through the news lab. Through celebrations and creative traditions, advisers form common bonds with their student staff members. Advisers use key points to celebrate with creative traditions to establish the news lab into a team of student journalists. Advisers' ritual celebrations within their news lab's production process develop teamwork and confidence. Celebrating as a whole news lab helps find the group's identity. News labs will enhance their teamwork by providing creative celebrations throughout each step of their news lab process. Individual awards also help engage students as leaders. 


\section{Recommendation One: Engage Student Leaders}

\section{Establish Teamwork}

Lucas

* "We had three kids that have gone above and beyond, so we were going to recognize them by talking about what they did that was beyond what we expect the average student to do."

Emily

* "We said, 'Thank God!' because she was in and out of drug rehab all the time. So, the fact that she got anything done at all, we're going to just chalk it out as a win and we're just going to go with it."

14

It was apparent advisers use ritual celebrations within their news lab's production process to develop teamwork, confidence, and passion. 


\section{Recommendation One: Engage Student Leaders}

\section{Meet Student Learning Needs}

Individual Growth

* Develop their students' skills by setting goals with the student based upon the student strength and performance

* Reflect with students about their progress and goals

* Base students' success on their growth from their initial skill level throughout the year

Determine Goals

* Provide clear concise goals to keep students focused on mastering their skills

* Determine goals at the beginning of the school year by looking at the start of the year. Then, together evaluate at the end the year

* Discuss making individual goals being challenging. yet attainable

-Learning to schedule a phone interview without help, or improve copy editing

15

Advisers must help each student learn leadership in a variety of ways. Differentiating instruction can meet each student's needs and helps students master journalism skills. First, advisers need to develop their students' skills by setting goals with the student based upon the students' performance. Then, reflect with students about their progress and goals. The students' success is based on their growth from their initial skill level throughout the year. Consistent skill development and reflection leads to student success because it pushes the student to excel. Advisers can do this when a student completes a challenging story, making sure the students feel a sense of accomplishment. Clear concise goals will keep students focused on mastering their skills. Discussions about the goals push students to excel. Advisers should be differentiating their instruction for each student to help with their overall performance. Each staff member should generate some individual goals. The students goals need to be challenging, yet attainable. A student individual goal may be to learn basic hard skills, schedule a phone interview without help, or improve copy editing. The advisers must begin determining goals at the beginning of the school year. 


\section{Recommendation One: Engage Student Leaders}

\section{Meeting Student Learning Needs}

Sally

* I do a lot to see where a student started and where they are now. A lot of people use rubrics, I don't get that picky. I think you're either growing or you're not. And that's where that compare contrast comes from."
Laura

"My biggest success watching them develop through the program and bloom so much. Especially, because I see most of my kids go through three or four years of high school. So, I see them I see them develop. My most recent editor, who graduated last year, she started in the class as a freshman, and she was very shy. She would turn red whenever she had to talk to people. Now she is able to be a leader."

16

Advisers shared it is imperative the adviser must accommodate each participant's needs to ensure individualized success. 


\section{Recommendation Two: Teach Leadership}

\section{Accountability}

Define Leadership Roles

* Base roles on news lab needs and student talent

* Discover student strengths and then define the news lab's leadership positions

* Editors must make their leadership training as a continual process.

* Key editors should attend a summer workshop for comprehensive training
* Teach leadership to core student leaders and the soft skills are expected to trickle down

* Instill student leaders to work side-by-side with their student staff, maximizing the news lab's full potential.

* Clear expectations should be set by the editors to foster a feeling of ownership and togetherness

News labs must have accountability with their leaders to ensure their motivation is maintained throughout their news lab. Accountability with clear expectations is a quality necessary for progress and sustained growth. There is a need for student editors to be responsible for the news lab's workflow and ultimately be responsible for their end product. This can be done by the editors making a designated area to display the news lab's production schedule with specific dates and names connected to each step of their deadline schedule. While the editors are leading the student staffers, the adviser must constantly make sure each part of the production process is correct and on time. Editor roles need to be based on news lab needs and student talent. It is important to establish the editors' roles and expectations depending on their student strengths. Advisers discover their student strengths and then define the news lab's leadership positions. The approach is skills and personal strengths directed. An editor may be talented at motivating staffers and photography, so the editor will serve exclusively as a photo editor and delegate all photo assignments throughout the news lab. Once the adviser establishes leadership positions, there is a need to provide the editors with specialized training and duties. Editors must make their leadership training a continual process. Key editors should attend a summer workshop for comprehensive training so that they are ready to lead their news lab production process the first day of the fall semester. Leadership should be taught to the core student leaders and the soft skills are expected to trickle down. Advisers will instill their student leaders to be teachers and work side-by-side with their student staff, maximizing the news lab's full potential. 


\section{Recommendation Two: Teach Leadership}

\section{Accountability}

\begin{abstract}
Elise
* Holding them accountable is super important. Even though my editors are overseeing stories and tracking deadlines, I'm constantly making sure each are correct and on time. Even though I really know, I have to ask the editor because they need to be accountable to communicate it."
\end{abstract}

Mary

'There's a huge need for editorial leadership. I think we just expect kids to know, but no, they don't know. They're not shy about asking for help or how to approach a student that hasn't turned in anything on time. It's hard for high school kids to be in charge of a peer. I remember back in the 80 s and the gos there were leadership classes in every school, you were trained in the rules of order and how you conduct a meeting. We don't do that anymore."

18

Accountability was evident through the observations and interviews. Many advisers believe they must have accountability with their leaders to ensure motivation is maintained throughout their news lab. 
Recommendation Two: Teach Leadership

\section{Accountability with Clear Expectations}
Mia
* The goal is to make the grade irrelevant by moving away from a punitive structure. So, the goal is get to drive motivation, then the grade is not a factor. They are taking a class that they love and they want to be a part of it, and not because they are trying to get an $\mathrm{A}$ in this class. The grade is secondary to a good story. So even the grade is secondary to their passion and love for journalism.

Sarah

"My editor-in-chief, she's got it, she'll teach them. Right away, even my intro students are seeing that this is a studentled publication. Yes, I'm the adviser. Yes, I'm the adult in charge, but at the end of the day, it's the kids that really take over and run everything."

19

Advisers had the notion of clear expectations promotes the news lab to be consistently accountable. 


\section{Recommendation Two: Teach Leadership}

\section{Motivate Students}

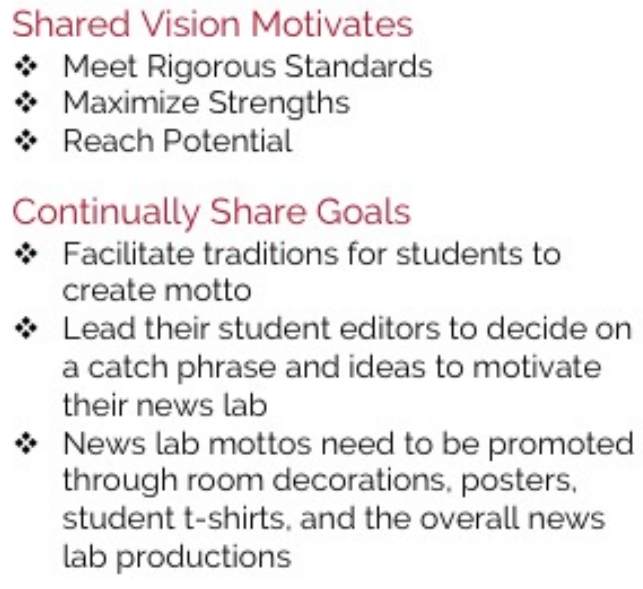

Shared Vision Motivates

* Meet Rigorous Standards

* Maximize Strengths

* Reach Potential

Continually Share Goals

* Facilitate traditions for students to create motto

* Lead their student editors to decide on a catch phrase and ideas to motivate their news lab

* News lab mottos need to be promoted through room decorations, posters. student t-shirts, and the overall news lab productions
* Reach outside of news lab through books. music, and social media, for slogan inspiration
* Attend national conferences, leadership retreats, leadership retreats, and boot camps
* Not one way to do this
* Possible mottos include: Story is King. Create Magic, Hands off, Journalist 24/7. Beacon of Light, Make Good Choices, It sucks to suck. Don't suck, Get Out of the Way, Everyone has a Story, Be Coachable. For Us by Us, News For Students by Students, and Journalism Matters.

20

Motivation is a strong facet of how advisers teach leadership. Advisers must take on the daunting responsibility of leading all students to perform to the best of their ability; however, the motivation lays with their student editors to support the news lab's overall vision. Motivation was required to complete their rigorous deadline schedules. A common vision and expectations helps news labs to produce creative work based upon their genuine convictions. It is imperative advisers nurture their student leaders who, in turn, will further nurture a next generation of student leaders. Ultimately, high quality programs have a continuous cycle of leadership development that appears effortless. Advisers must build on their students' strengths to not only develop their news lab leaders but to create an effective structure for the lab's work flow. It's vital for editors to learn their strengths and develop them, while finding their weaknesses and compensating for them. Advisers commented they develop their students' potential as well by providing selected editors with opportunities to build their leadership skills. Students will become leaders when they are accountable to their established norms and practically used their students' strengths in multiple ways. 


\section{Recommendations Two: Teach Leadership}

\section{Motivate Students}

Eli

* My kids are put into their leadership roles in the class. I'll let them run with it, and then watch them. I'll go check in on them to make sure they've done what they're supposed to do. It essentially establishes the leaders to believe in what they are doing."

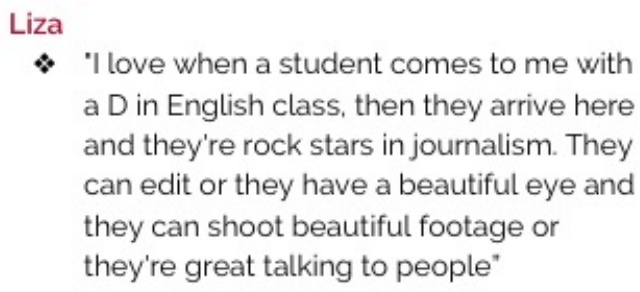

- 'I love when a student comes to me with a $D$ in English class, then they arrive here and they're rock stars in journalism. They can edit or they have a beautiful eye and they can shoot beautiful footage or they're great talking to people"

21

Advisers shared their students were motivated when they constantly shared their goals and were able to lead themselves toward them. 


\section{Recommendations Two: Teach Leadership}

\section{Motivate Students}

Sam

* "I love my job. Most teachers are in it because they love kids and they love their job. And we all know that we don't get paid a ton of money. But that's not necessarily why we're in it. It's about, for me, for sure, the journey and how you feel while you go through the journey."

\section{Elizabeth}

* I can teach all the skills students need, but you can't teach passion. There is something about working hard until it works. That's a lot of what journalism is. Because you're going to have the bad days, the bad interviews. But when it does finally click and come all together, it's really cool to be part of that with all of my students.

22

Advisers shared they motivate their students through their passion and the news lab process. 


\section{Recommendation Three: Empower Student Leaders}

\section{Create a Safe Environment}

\author{
Support Student Decisions \\ * Editors need to take ownership of their \\ news lab's production and decisions \\ * Decisions are left to the news lab \\ leaders \\ * Editors need to be second in \\ command \\ * Train editors to solve problems by \\ supporting the decisions the editors \\ make on their own
}

Positive Feedback

* Continually communicate feedback and critique

* Editors play main role in production process and the adviser ought to make final decisions as process must start with the students and then move to the editor.

* Train editors to provide feedback in areas that can be improved

* Effective editor need to provide timely feedback, praise as often as asking for corrections, be willing to discuss alternatives, and accept feedback themselves

23

Advisers create nurturing environments by helping students make their own decisions to take action. Empowering students to develop as journalists is vital within editorial leadership. Advisers must build nurturing news labs so students learn leadership behaviors. Effective advisers positively influence and motivate their students. Creating a safe environment helps journalism students to seize the moment and take risks in their coverage. Editors need to oversee news lab's distinct workflow process. For example, initially, student staffers turn in their rough drafts to their editor to read before the editor reads them. The editors give feedback and then the adviser reads the final draft. The adviser will sit down with the editor and talk over the students' missed areas. To do this, the adviser needs to train editors to solve problems and find ways to make aspects better by supporting the decisions the editors make on their own. It is essential for the adviser to get out of the students way and support their decisions. Creating supportive learning environments committed to students knowing they are safe empowers students. Advisers empower their students by transforming their classrooms into nurturing learning environments. Advisers should create a safe environment because it sets the stage for supporting student decisions and learning how to provide positive feedback. Student reassurance will help advisers teach leaders to create high-quality news productions. Then the students will gain confidence to be leaders within their news lab. 


\section{Recommendation Three: Empower Student Leaders}

\section{Safe Environment}

Leah

* "The kids feel that they're in a safe place here, that they're allowed to be who they are, like really who they are. A lot of kids, depending on what class and how they feel in their class, will just shut down. For the most part, it's making sure they feel validated and acknowledged. There's nothing like seeing a student walk in and their peers say, 'Oh, my God, that is so awesome'."

\section{Eleanor}

* "It's their place. I work really hard to make this their safe haven away from home. They spend so much time and effort pouring so much of their heart and soul into our publication. I normally have kids eat lunch in here, because they need somewhere to eat lunch that they feel like is home, and this is it for them."

24

Advisers shared they empower their students to become better learners and better leaders within a safe environment. 


\section{Recommendation Three: Empower Student Leaders}

\section{Take Action}

Inspire News Coverage

* Expose students to the latest professional standards and trends by showing professional news and awardwinning high school news examples

* Use textbooks for ethics training and basic skills

* View the best news coverage through posted award winning high school news on scholastic journalism organization web sites

* Assign students to watch videos of journalism examples, review magazines and other forms
Experiment with media, audiences, and production

* Support student ideas, such as starting a campus magazine, podcast, or using Google Docs for her students' work flow by establishing a virtual news lab

* Imperative for students to research their idea and present their findings before advisers give permission

* Within each safe and controlled environment, students grow by experimenting with their tools

25

The root of creating a safe environment is the adviser helping students trust their own decisions. Once students trust their own decisions, advisers must push their students to take action so they can create more meaningful student news. Advisers should empower students to behave like student journalists instead of just high school students by deciding upon their own goals. Effective advisers challenge their students to try out new and innovative ways to execute their coverage. Advisers need to teach different ways to do coverage, but still allow their students to make the final decision. Students need to step outside of their comfort zones when selecting their own story ideas. Advisers can enhance their coverage by pushing their news lab to cover national and international events by connecting the topic to the students in their high school, which is known as "localizing a story". This teaching strategy helps students find meaningful story ideas. Advisers must continually inspire their students' story ideas so they can make sound decisions in their own coverage. As advisers may not use textbooks, they must search out many relevant resources to ensure their students can take action to cover their campus with up-to-date skills. Encouraging students to take action should be a considered condition by requiring covering multiple perspectives in their student news. Editors need to search out different student perspectives to think outside the box for different ways to cover different topics. 


\section{Recommendation Three: Empower Student Leaders}

\section{Take Action}

Lucy

* l love to start class to tell my students, 'Okay, it's $11: 17$ and the class is starting and, at 11:30, our Superintendent of our entire school district will be in this room for an interview. Try to be good."
Sloane

* "People say oh wow, that company is helping out. We should see what we can do, but then at the same time. I am thanking them in front of everybody. I will have community members from our local newspaper come in."

26

Advisers shared their news lab's leadership takes action to do key initiatives, stories, and projects. 


\section{Recommendation Three: Empower Student Leaders}

\section{Take Action}

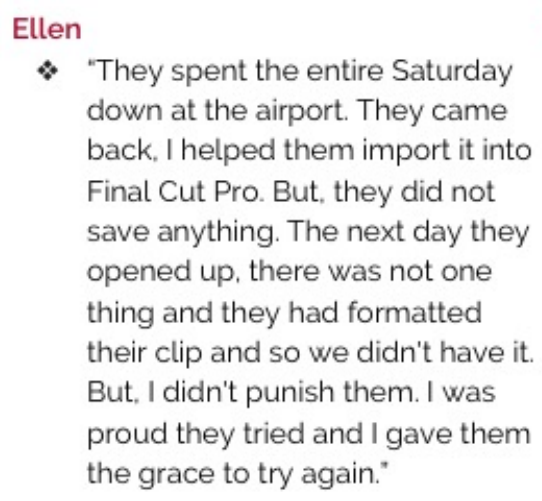

Erin

\begin{abstract}
When we have our meetings, the editors decide which stories go in. Some cover school news, while others go out into the community. I've got one in the magazine class who always wants something big that is being nationally discussed. So. she's doing a gun safety story. I've had ones do human trafficking stories and they found a student here who felt like she was almost abducted and so she shared her story and it was interesting. We cover things affecting students.
\end{abstract}

27

Many described a news lab stakes are high so it is imperative for each editor and staffers to have achievable goals and also be empowered to provide the news labs motivations. Mia said. "Let them fly and try them out." As advisers support innovation and creativity, they make certain they set achievable goals, make concrete plans, and establish measurable milestones for their journalism programs. Lucy spends a lot of class time talking to her students editors so they can master working with their student staff. Many advisers also shared they experiment and take risks, even when there is a chance of failure. Erin's news lab publishes once a quarter and it's inserted into the community newspaper. Even though she and her staff feel very vulnerable, she reflected upon its positive impact. 


\section{Recommendation Four: Impact Student Leaders}

\section{Harness Enthusiasm}

\section{Develop Sense of Pride}

* Vision and strategic goals help students gain enthusiasm in their decision making processes

* Set priorities and evaluate the progress throughout each deadline.

* Key element in leading students and impacting the news lab's practice.
* Advisers own enthusiasm influences the students satisfaction in the news lab's standards, purpose, and production process.

* Develop cooperative relationships and pride in the students' journalism coverage helps the news lab come together and meet deadlines.

Advisers must be impactful leaders for their students, high schools, and communities. Principally, advisers ought to impact their students through their enthusiasm, influence, and building trust, to be leaders. Overall, high school journalism educators must teach editorial leadership in high school journalism education. Students in editor positions need to be provided with specialized training and duties. Teaching editorial leadership is a process throughout a student's years in a news lab. Advisers teaching leadership must motivate their students. A common vision and expectations helps a news labs to produce creative work based upon their genuine convictions. Advisers' personal connections with their editors help the news labs' production and their teaching experience. Specifically, advisers will establish their most effective student leaders through deliberate processes designed to encourage students in direct and personal ways. Advisers' strong relationships and ongoing communication maximize the trust throughout their news lab. It is imperative advisers nurture their student leaders who, in turn, will further build consensus to nurture a next generation of student leaders. Ultimately, high quality programs have a continuous cycle of leadership development that appears effortless. Advisers must begin teaching their students leadership from their first moment of a high entrance written application to their final creative scholastic journalism tradition with a journalism graduation sash. 


\section{Recommendation Four: Impact Student Leaders}

\section{Harness Enthusiasm}

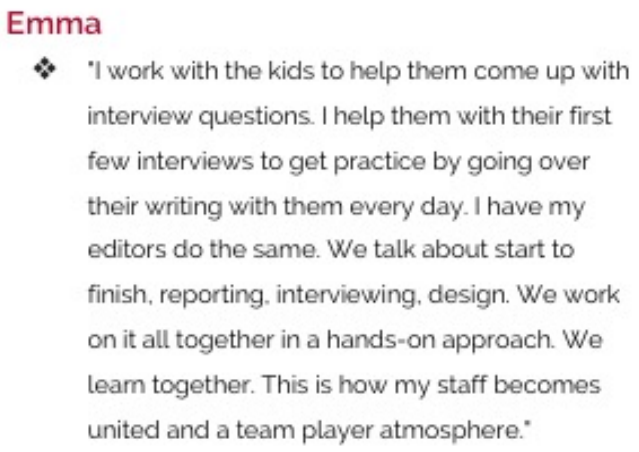

* "I work with the kids to help them come up with interview questions. I help them with their first few interviews to get practice by going over their writing with them every day. I have my editors do the same. We talk about start to finish, reporting, interviewing, design. We work on it all together in a hands-on approach. We leam together. This is how my staff becomes united and a team player atmosphere."

Lexy

* 'I love journalism, I'm passionate about storytelling. I like beautiful filmmaking, but I don't think I would want to do it at a different level. I think the relationship piece is the most important part to me. I think that's why I'm teaching at a high school."

29

Advisers shared they impact their students with their own enthusiasm, work ethic, and passion. 


\section{Recommendation Four: Impact Student Leaders}

\section{Harness Enthusiasm}
Madison
* "The student feedback was there. and they said they wanted more pages. So, I supported them and we went for it."

Mia

* "If you're doing it well, then the what, the thing that you create will be the proof that you're living what your central mission or idea is. The publication itself becomes a vehicle to bring in students that also have those same interests and passions"

30

Advisers inspire a shared vision throughout their news lab. 


\section{Recommendation Four: Impact Student Leaders}

\section{Build Trust}

Establish Relationships

* Treat editors like adults and be authentic

* Boost the ability for students to effectively meet expectations on their own

* Know editors are competent in programs and can handle the heavy lifting to keep production moving

* Editors keep the workflow moving and produce quality work

\section{Open Communication}

* Articulate a focus on open communication with editors to create a culture of trust

* Encourage students to communicate regularly through scheduled and nonscheduled conferencing

* Welcome conversations on culture, emphasizing publication importance, developing reasons to care, and instilling a desire to participate

31

Advisers' personal connections with their editors help the news labs' production and their teaching experience. Specifically, advisers will establish their most effective student leaders through deliberate processes designed to encourage students in direct and personal ways. Concentrating on trusting relationships because students have a hard time learning from a teacher they do not have some kind of relationship with them. Trust is built upon ongoing communication. As a result of clearly communicating their goals, the staff develops a strong mutual trust. Advisers need to welcome conversations on culture, emphasized publication importance, developed reasons to care, and instilling a desire to participate. Advisers must articulate a focus on open communication with their editors to create a culture of trust. A focus on communication helps advisers create a positive news lab, which is encouraging to students. To support open communication advisers must encourage their students to communicate regularly through scheduled and non-scheduled conferencing. Establishing ongoing communication impacts students and advisers to trust each other to reach their news lab and personal goals. Advisers' strong relationships and ongoing communication maximize the trust throughout their news lab. Trust in the relationship between advisers and their students is worth emphasizing, due to the significance an adviser has being a leader in journalism education. 


\section{Build Trust}

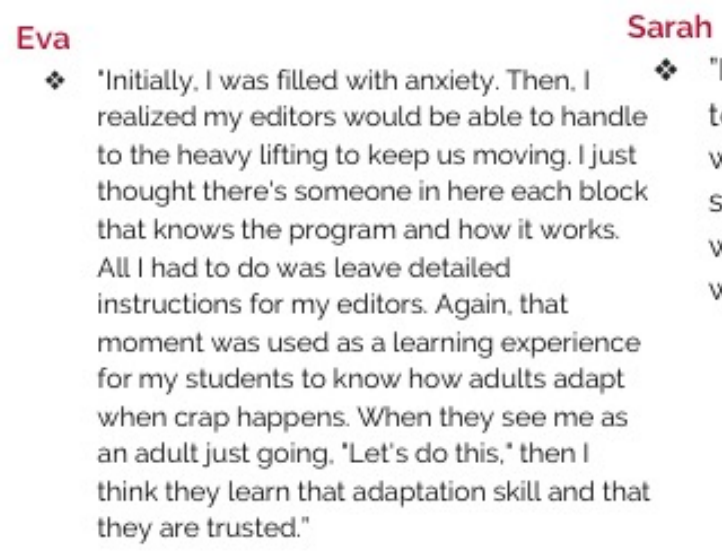

* "I was not going to be there and I needed to call her to let her know because we were on deadline. So, it was a little stressful for me, but good to know they were prepared for it and in safe hands with my editor."

32

The data collected reflected how trust between an adviser and editor may be leveraged to influence the news lab's overall trust. Many advisers shared how their trustworthy behavior paralleled their news lab's organizational trust, mediated by the editor's trustworthiness and their trust in their adviser. 


\section{Significance of the Study}

\section{REVEALED TRAINING}

* Recommendations for actionable editorial leadership training for $\mathrm{K}-12$ journalism educators

\section{REVEALED SKILLS}

Used to increase scholastic journalism's awareness and utilization of editorial leadership

\section{Examining effective practices in the traits and values of journalism education will glean further insight to add to this body of literature (Carpenter, Hoag, \& Grant, 2018).}

33

This study has led to up to date skills and standards. Although editorial leadership is a prevalent concept within the scholarly conversation around secondary journalism education, it is a term that was not researched within Missouri. There was a lack of studies exploring scholastic journalism advisers' best practices to teach editorial leadership. Findings could be presented to administration and teachers and, ultimately, more students could be encouraged and inspired to become leaders. 


\section{Summary}

The study identified editorial leadership practices in high school journalism news labs for a clearer understanding of how advisers utilize many leadership practices. The findings will benefit high school journalism teachers to develop leadership for effective production, encourage creativity, and foster decision making

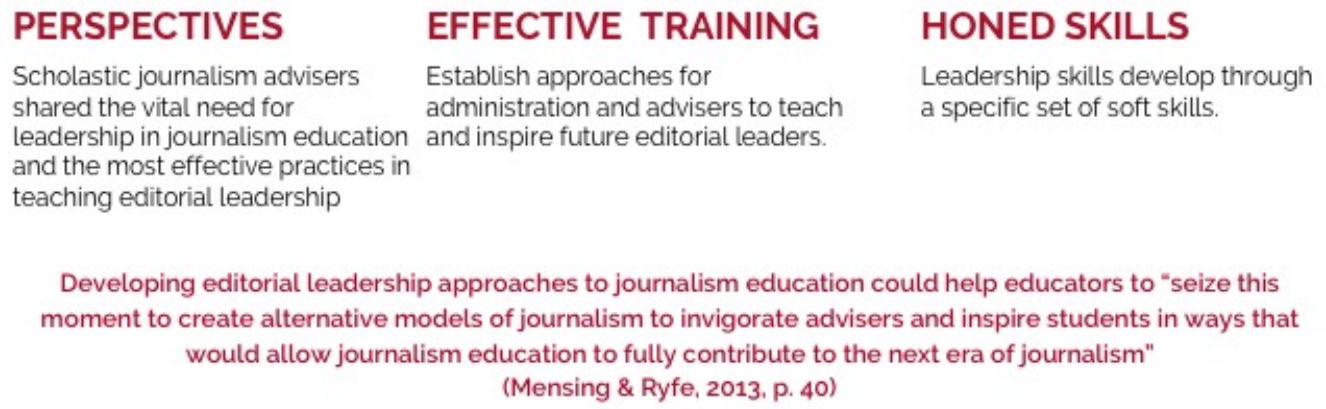

34

It was important to understand the perspectives of leadership within high school news labs in order to shape professional development among instructors. This study could be used to increase awareness and utilization of editorial leadership within scholastic journalism. Currently, there is a lack of studies exploring scholastic journalism advisers' best practices to teach editorial leadership. Findings will continue to be presented to administration, teachers and, ultimately, students could be encouraged and inspired to become leaders. Academic leaders need to set new standards for excellence, reflecting how different styles of adviser's leadership affect news labs (Cowan, 2009). Developing editorial leadership approaches to journalism education could help educators to "seize this moment to create alternative models of journalism to invigorate advisers and inspire students in ways that would allow journalism education to fully contribute to the next era of journalism" (Mensing \& Ryfe, 2013, p.40). 


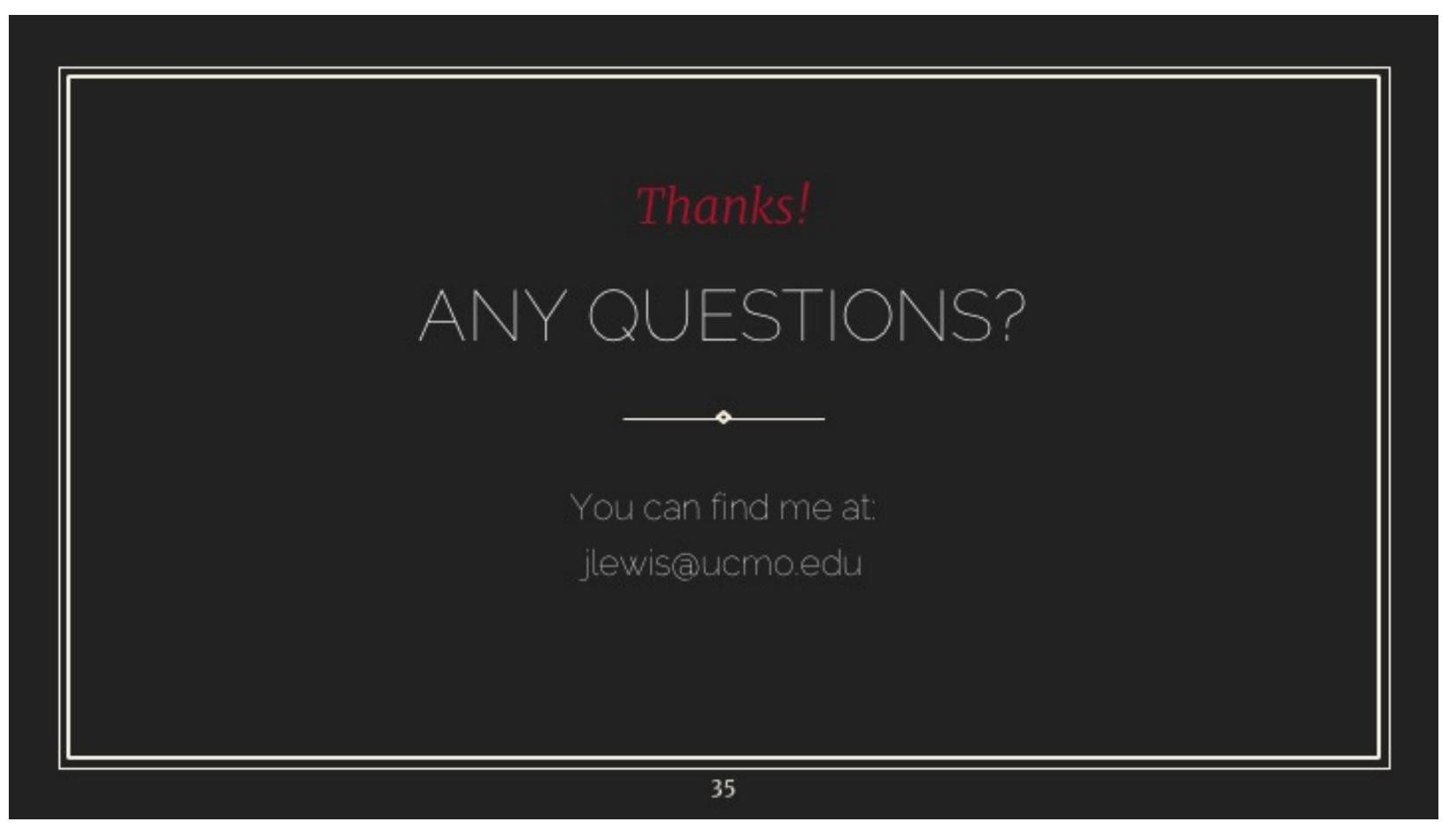


@ Copyright by Julie Lewis 2020

\section{All Rights Reserved}


SECTION FIVE

\section{CONTRIBUTION TO SCHOLARSHIP}




\section{Plan and Rationale for Dissemination}

\section{Established in 1944, Journalism \& Mass Communication Educator}

(JMCE) addresses the professional needs of the journalism and mass communication educator and administrator on both collegiate and secondary levels. Publishing quarterly, $J M C E$ is the largest, highest circulation, and oldest of any scholarly journal in the world devoted to education in journalism, public relations, advertising, mass communication, media studies and scholastic journalism. JMCE is published on behalf of the Association for Education in Journalism and Mass Communication 


\begin{abstract}
This qualitative study explored advisers' perspectives on teaching leadership. This study identified the significant need for the role of leadership in scholastic journalism programs. Advisers illustrated soft skills provide many opportunities for students to grow into leaders. The leadership skills provide advisers opportunities to articulate their passion and genuine convictions with their students. This current study focused on editorial leadership practices in high school journalism news labs for a clearer understanding of how advisers utilize many leadership practices. The findings will benefit high school journalism teachers to develop leadership for effective production, encourage creativity, and foster decision making. Thus, leadership skills are important in journalism education.
\end{abstract}

Key Words: editorial leadership, leadership, soft skills, advisers, scholastic journalism, high school, Missouri 


\section{The Role of Leadership in Journalism Education}

This study was designed to address the significant role leadership has within high school journalism education, which is known as editorial leadership (Newton, 2018). Recent scholarship states leadership plays a central role in positively shaping changemanagement outcomes (Herndon \& Krueger, 2016, Killebrew, 2003; Mierzejewska, 2011; Perez-Latre \& Sanchez-Tabernero, 2003). Nonetheless, journalism education research focusing on leadership is significantly necessary to address media management disciplines (Mierzejewska \& Hollifield, 2006). Under these circumstances, this current study revealed advisers' perceptions of the role leadership plays within high school news labs. The body of evidence reviewed in this article will suggest emphasizing leadership is a path for increasing students' success within scholastic journalism news labs (Bronstein \& Fitzpatrick, 2015; Herndon, \& Krueger, 2016; Mensing, 2010; Newton 2018; Pavlik, 2013).

\section{Review of Literature}

\section{Editorial Leadership in Scholastic Journalism}

Advisers teach students soft skills and transformational tenets to be leaders in their news labs (Cowan, 2008; Küng, 2017). Advisers escalate leadership training to fill the current leadership education curriculum gap. Editorial leadership provides advisers and students the capabilities to lead an effective, efficient, and vibrant news lab (Pavlik, 2013). Ultimately, teaching leadership develops student skills through college and into their careers (Robertson, 2002).

Editorial Leadership Purpose. Editorial leadership training emphasizes soft skills, which helps students gain open communication to share and exchange their ideas. 
By teaching students editorial leadership to carry out duties as news lab leaders, the soft skills also help students problem solve and produce news (Streisel, 2007; Westbrook, 2019). Advisers teach soft skills to students to help grow their confidence to carry out their duties efficiently and effectively, as the ultimate goal of editorial leadership is to make student leaders more clearly defined for each news lab.

Editorial Leadership Value. Studies found many journalism educators value editorial leadership training. The best journalism programs appear to be designed and implemented in accordance with leadership training. A comprehensive review of leadership development across all professional and academic sectors found investing in leadership development adds value and gives journalists a competitive advantage. Scholars identified fostering a culture of supportive leadership development as being beneficial (Filak, 2003; Newton, 2018). Leadership development has proven to be one of the best ways to build a culture by aligning support systems to reinforce learning and student motivation (Filak, 2003). Newsroom leaders must permit suggestions for changes to ensure staffers feel appreciated and gain respect (Bush, Haygood \& Vincent, 2017).

Editorial leadership strengthens the relationship between advisers, student editors, and news lab staffers to build mutual confidence to produce journalism, which is worthy of the audience's trust (Fowler-Watt \& Wilson, 2004). Serving in a key leadership position on a student news lab production can be an empowering experience. Westbrook (2019) believes not only will students have the opportunity to exercise their journalistic passions, but they may maximize their tenure as editor, managing editor, or page editor to find many ways in which editorial leadership can challenge them as leaders and find ways to grow as people. 


\section{Design of the Study}

This qualitative study investigated the methods Missouri scholastic journalism advisers used to teach leadership skills. Data were collected on advisers' current skills, practices, and experiences to answer the research questions.

Qualitative research allows for the existence of multiple realities that are constructed in one of two ways, socially or individually (Heppner \& Heppner, 2004). Creswell's definition of qualitative research provided the foundation for this study. As Creswell (2007) stated, qualitative researchers strive for understanding. Creswell (2007) additionally noted that qualitative researchers try to develop a complex picture of the problem or issue under study. In the same way, this study involved reporting multiple perspectives, identifying the factors involved in advisers teaching leadership, and sketching the larger picture that emerged, bound not by cause-and-effect relationships among factors, but rather by identifying the complex interactions of factors in any adviser's situation (Heppner \& Heppner, 2004). Furthermore, qualitative research contends the knower interacts with the known and cannot be separated (Heppner \& Heppner, 2004). Therefore, qualitative research granted the researcher more involvement within the contextual situation of the study, creating the opportunity for understanding the contextual reality found within the research setting (Creswell, 2007; Heppner \& Heppner, 2004).

\section{Setting}

The setting was a representative sample (Creswell, 2014) of 24 public secondary schools with journalism news labs from across the state of Missouri. Each setting was determined by a set criteria and location for the researcher to collect data. The setting 
provided the researcher opportunities to observe, interview, and review artifacts within each adviser's high school news lab. For this study, journalism news labs were defined as a high school classroom serving as a newsroom, using a grading criterion for assessment, and without collecting payments for publications (Collins, 2017). The setting was also determined by the Missouri Interscholastic Press Association's (MIPA) membership. MIPA separates the state into four different regions. These four regions of Missouri are divided by Highway 50 and Highway 65 (MIPA, 2019). In addition to serving as boundaries within the state for its board leadership, these regions are commonly used to organize state level activities and competitions. Kansas City and St. Louis, primarily urban areas, are in two of the four regions. In contrast, the other two regions have a variety of rural, urban, and suburban student populations (Missouri Department of Elementary and Secondary Education, 2019).

Protections were put in place to ensure the participants' safety, security, and anonymity by requesting all interviews occur when the adviser was not teaching (Krueger \& Casey, 2015). Each interview was followed by an opportunity for the adviser's to show the researcher their news lab and production artifacts.

\section{Participants}

The study's sample was 24 journalism advisers. The researcher used a representative non-random and purposeful sample, all explained by Creswell (2016) as a sampling frame to "discover, understand, and gain insight and select a sample from which the most can be learned" (Merriam \& Tisdell, 2016, p. 96). The study's 24 participants were advisers from MIPA's membership, who received the All-Missouri 
award. The membership fees for MIPA may range from $\$ 40$ to $\$ 300$. The All-Missouri award is based on an award scale.

Only All-Missouri advisers were asked for an initial interview. Each adviser interviewed was granted the All-Missouri award in the last two years.

MIPA's highest placement is the All-Missouri award, which is earned by high school's productions meeting the highest standards in their journalistic coverage. The All-Missouri awards are granted in the following categories: newspaper, photography, yearbook, and broadcast and multi-media coverage. Each of those categories are divided by each school's population. MIPA recognizes many awards including the All-Missouri, as well as Superior, Excellent and Honorable Mention rankings. The students are awarded certificates at the annual Journalism Day (J-Day) celebration hosted at the University of Missouri's School of Journalism. The free day-long event includes an awards ceremony where the All-Missouri Award is the highest award, as MIPA judges choose roughly the top $10 \%$ of the entries to recognize as All-Missouri award winners.

The entries are judged on the news lab production's overall merits through a point system. In an effort for MIPA to increase the rigor in the state contest, MIPA follows the national Journalism Education Association standards regarding how the winners place at each award level. All contest entries are evaluated by an experienced professional using the same rubric-type rating system. Over 50 judges select the winners from approximately 1,400 entries. Judges range from journalism teachers and professors to professional journalists from across the country. The entries are ranked to determine their award using the following scale: All-Missouri 450-500 points; Superior 400-449 points; 
Excellent 350-399 points; Honorable Mention 300-349 points; and, No Award - below 299 points.

Size. The participating high schools were categorized by MIPA's overall school size with the following student population categories: extra-large schools $1,700+$ students; large schools 1,201-1,700 students; medium schools 701-1,200 students; and, small schools 1-700 students (MIPA, 2019).

Only All-Missouri advisers were selected to participate in the study. The participants represented multiple school sizes from all four quadrants of the state. The non-random selection of the All-Missouri advisers throughout the last two years provided for the selection of some of Missouri's most effective advisers. Thus, the participant selection and practical issues were strategic to ensure adequate sampling of advisers from all school sizes from parts of Missouri (Krueger \& Casey, 2015).

\section{Data Collection Tools}

The researcher used the study's criteria to select 24 journalism news labs with representation from each of Missouri's four geographic quadrants. This qualitative study explored advisers' leadership interpretations, perspectives, and experiences (Creswell, 2014; Merriam, 2015). After IRB approval from the University of Missouri, the researcher triangulated data through a series of systematic observations, interviews, and artifact review (Creswell, 2016; Merriam \& Tisdell, 2016).

Data were collected from 24 respondents via interviews, observations, and artifacts during a two-month period. Secondary schools were selected from MIPA's AllMissouri advisers from the past two years. Permission was acquired from MIPA through an email to gain access to their data base. 
Additionally, the MIPA Director provided the MIPA's member's contact information. The initial research stage addressed scheduling interviews to gain advisers leadership perspectives. Participants were contacted by email to set up and confirm the personal interviews.

Twenty-three interviews took place at high school journalism news labs and one by phone. At the beginning of each interview, the researcher received the adviser's consent for the study and permission to audio record. Each interview was recorded and then transcribed verbatim. The interview questions were based upon the research questions and focused on editorial leadership, teaching journalism, and advising their various news labs. The conceptual framework influenced this stage through Kouzes and Posner's practices of transformational leadership, which guide leaders "to get extraordinary things done" (Kouzes \& Posner, 1987, p. 9). The interviews were designed in a semi-structured nature, so that the researcher could keep some control of the proceedings, while participants were able to "pursue their own interests" (Hesse-Biber, 2004, p. 277). The original goal of the study was to strive to collect data from 20 advisers throughout all four quadrants. Although saturation occurred after fourteen interviews, the researcher had 24 advisers participate in the study to ensure all high school sizes and quadrants were represented.

Throughout each interview, the adviser observed social behaviors in the news lab as they occurred by gathering field notes. At no time did the researcher interfere or include herself as an active member of the advisers' culture during situations of day-today operations. The researcher focused on the advisers' actions connected to both the person and the professional position and the news lab environment. The observations 
further explored the advisers' leadership pedagogy "that the body, history, and power are doubly articulated in classrooms" (Bell \& Blaeuer, 2006, p. 18). Therefore, both the role of leadership and editorial leadership skills were explored in the advisers' news lab setting. Current artifacts of the adviser's curriculum, assignments, student publications, and productions were also reviewed. The purpose was to further observe how the adviser's editorial leadership aspects reflected students' work. The documents enabled the researcher to obtain the language and words of the participants. Also, it was a way for the advisers to directly share their instructional reality (Creswell, 2014).

\section{Data Analysis}

The qualitative study analysis systematically incorporated reliable and valid strategies through the triangulated data. Validity was increased using interviews, artifact analysis, and observations (Yin, 2003). The researcher gathered data from interviews, observations, and artifacts to enhance the researcher's ability to assess the findings' accuracy (Creswell, 2014).

Throughout the data analysis process, all relevant evidence was valued and treated fairly in order to produce compelling conclusions (Yin, 2003). Furthermore, the study's qualitative research produced a vast amount of data, so it was important to have the data organized to allow for timely analysis (Creswell, 2007; Merriam, 1998).

The data analysis process ensued immediately after collection of the data (Merriam, 1998). Transcriptions were made of all the interviews. Once all transcriptions were completed, the researcher emailed each adviser to ensure the validity and reliability of their background data was correct. The accuracy check provided participants the opportunity to review the data for accuracy (Merriam, 1998). 
The researcher read through transcriptions and noted common trends and themes. Then, "working back and forth between the themes and data" until a "comprehensive set of themes" surfaced. Next, the researcher ensured the participants' voices were clear to make recommendations (Creswell, 2014, p. 186). Various themes emerged, were assigned codes, and were labeled on the transcripts. The practice of coding included the identification of each item in the research and then organizing them into individual themes (Creswell, 2007; Emerson, 1995; Merriam, 1998). Initial codes were determined by connecting aspects of the five research questions. The coding process allowed for the identification of emergent themes and was completed in a logical manner and conducted by the researcher in order to increase consistency throughout the data (Creswell, 2007; Merriam, 1998; Yin, 2003). Themes and patterns were established through checked transcripts, field notes and artifacts. Next, the themes were connected to the research questions. Finally, the researcher began the process of answering the research questions through further analysis and the triangulation of data. Triangulation refers to the use of various sources of data and of data collection methods to confirm the emergence of data (Creswell, 2007; Fowler, 2008). The implementation of triangulation increased the reliability and validity of the data collected during the study (Creswell, 2007; Fowler, 2008; Merriam, 1998). The researcher completed this process to have a systematic and meaningful conclusion within the findings. Furthermore, Stake (1995) suggested qualitative data should be interpreted as a reflective process and a researcher should be committed to the reevaluation process and continually reinterpret the data. Thus, the data analysis process was ongoing throughout the research study and through the use of 
multiple sources of data for a clearer picture to capture and identify the key elements of editorial leadership.

\section{Findings}

\section{The role of leadership in $\mathrm{K}-12$ journalism education}

Leadership plays a significant role in K-12 journalism education to empower students. The role of leadership empowered students to be trusted and effectively meet expectations on their own. The advisers interviewed for this study created trust and consensus around their news lab's common vision to inspire students. The importance of this role was evident in supporting the students to do their best and reach their goals.

Empowering students does not happen overnight. Leadership training plays an important role within the news labs, as advisers in this study specifically establish not only leadership positions among their staffers, but create training as well. Advisers considered the role of leadership as a behavioral process influencing their students towards set goals. As such, advisers have the dual function of steering their students to produce a high-quality product while ensuring strong student relationships. Overall, when leadership is exhibited the adviser is striving for an established goal through built trust and built consensus.

\section{Inspiring Students Toward Goals}

When asked, "How do you inspire a shared leadership vision?" the advisers disclosed concepts directing the news lab's overall production workflow. In fact, leadership plays such a strong role among news lab practices that all of the advisers articulated the importance of teaching leadership in deadlines, work sessions, and

decision making. The advisers in this study built their award-winning practices off one 
common foundational component: a vision statement. Advisers and students developing their vision together demonstrates the significant role leadership plays in news labs.

Advisers and students gain a mutual understanding of their goals through collaborating on a vision. Advisers inspire their students to work with them to create success. Effective advisers shared they have a clear outline of goals and what they need to accomplish through their vision. Leadership plays a supporting role in helping advisers establish common goals to motivate their student productions. Advisers considered leadership as a behavioral process that influences their students and whole news lab towards set goals. As such, an adviser has the dual function of ensuring each student's satisfaction while steering the news lab to success.

Advisers revealed that leadership skills can be taught, practiced and improved. An adviser's primary role is to enable the success of everyone in the news lab. All the advisers commented they continually appealed to each student by articulating production goals and their editors pronounced their shared vision to their news lab. The data supported the benefits of inspiring creativity and loyalty because it is helpful for effective production.

Effective advisers explained they share their production goals with their students by calling it a vision. The vision is used to raise the students' aspirations and devise a plan for what they want to become. Common news lab slogans, positions, and procedures are essential for advisers to influence their students effective production. Advisers use their news lab motto to inspire their entire staff. Students will consult their shared vision for what to do, or say to make sure all they do meet the mottos ideals. 
News labs develop leadership beliefs in purposeful ways. At the beginning of each school year, advisers facilitate traditions for students to create their news lab motto. The advisers lead their student editors to decide on a catch phrase and ideas to motivate their news lab. All the interviews, observations, and artifacts revealed news lab mottos were promoted through room decorations, posters, student t-shirts, and the overall news lab productions. Some of the advisers reported they reach outside of their news lab through books, music, and social media for their news lab inspiration. Advisers went as far as to facilitate their traditions at national conferences, leadership retreats, leadership retreats, and boot camps. These camps and retreats are structured to provide the student editors training to make the motto for the upcoming year. There was not one specific way to do this, but once the school year began, each news lab motivated the students through the continued use of their common vision. The different mottos enforced the news lab's shared vision. The data revealed many news lab mottos, including: Story is King, Create Magic, Hands off, Journalist 24/7, Beacon of Light, Make Good Choices, Get Out of the Way, Everyone has a Story, Be Coachable, For Us by Us, News For Students by Students, and Journalism Matters.

Specifically, Liza's news lab has a motto made by her students. She commented that her news lab earned her trust by continually producing high quality work. She explained, "Story is king. If students can't tell me a good story with a beginning and middle and end, I don't care how much your camera costs or what you're editing with. Story is what drives everything." The data illustrate the students are invested in their news labs and are empowered to put a name on their work. 
Advisers are intentional in designing their shared vision. Elise's student editors attend a summer camp each year. She explained how her shared vision of, "Hands Off" was found during the students' summer camp and translated into having a completely student driven news lab, "My editors organize our coverage. Our staff wants to all be part of our Friday night football games. The editors know where the staffers can be on the field and how to get the good shots. I just love watching. They definitely are like little moms helping our young ones." Elise further stated the editors know their common vision and the staffers can be intimidated, but they mentor them. She said, "They don't mind going to a softball game by themselves because they face their fear and learn how journalism works. It's huge growth that can't be taught in a classroom. Just watching it is perfection. We're showing them how to be leaders."

Similarly, Lucas has his student editors annually attend a national conference to make their motto. Recently, in preparation for their national conference at Disneyland they read the book "Creating Magic: 10 Common Sense Leadership Strategies from a Life at Disney" by Lee Cockerell. The book inspired the students to create their catch phrase of Create Magic. He explained how the book led to their news lab's vision to be a wonderful publication:

Disney was their answer because everybody wanted to go to Disney and be part of an idea that it's a wonderful, wonderful world. They wanted that wonderful, wonderful publication. They worked to create that magic and make their publication magic essentially. Something that everyone would want to be a part of and talk about. 
The traditions that were put in place for the news lab's motto also helped advisers provide agreed upon structure for positions and procedures. The advisers facilitate their student editors to decide on their assigned editor positions based upon the ideals of their shared vision. Leah believes an understanding of their "News for Students by Students" slogan has transformed her students into their leadership positions. She believes the students understanding of their shared vision elevated the students to take ownership and effectively lead their workflow. Leah explained the vision helps her editors lead. She further explained her students develop their positions and the news lab procedures. As a result, her editors oversee the news lab before she becomes personally involved. She said, "The editors put out the fires all the time. The kids are aware of it and they understand the dynamic of it because they helped decide it." The importance of the student editor position was reflected through interviews as advisers marked time by their editor's name rather than publication name or date. Throughout interviews advisers referred to their previous editors. For instance, Leah explained how each editor puts their stamp on the year's production, product, and overall morale throughout the news lab. She further illustrated, "I've had those great student editors throughout my whole career. Each has been part of a thread of students that have built our program throughout the years."

Advisers believe teaching leadership motivates students. The advisers revealed following a common vision and expectations helps students produce creative work based upon their genuine convictions. Advisers nurture their student leaders who, in turn, further build consensus to nurture a next generation of student leaders. The role of leadership was evident in supporting the students to make their own vision to take 
ownership and produce a high-quality product. Ultimately, high quality programs have a continuous cycle of leadership development that appears effortless.

\section{Building Trust}

Trusting relationships between advisers and their students are significant in the role of leadership in journalism education. Advisers shared personal connections with their editors helps the news labs' production and their teaching experience. Specifically, the study found that advisers established their most effective student leaders through deliberate processes designed to encourage students in direct and personal ways. Advisers shared strong relationships and ongoing communication maximize the trust throughout their news lab.

Madison believes her editors trust her because she puts trust in them and they feel they have a personal stake in their news lab and it is more than just a class. Other advisers had similar perspectives. Like Madison, Eva commented, "You can actually trust to take

the reins off. It is amazing what they will do if you just say, 'I believe in you, go do it and I'm here if you fall down. I probably won't pick you up, but I'm going to be here if you fall down.' It's really cool to just see what they do."

Establishing Relationships. Through relationships, advisers establish their most effective student leaders. Essentially, the data showed trust boosts a news lab's ability for students to effectively meet expectations on their own. For example, Emily's trust in her students deepened during a long absence. Her editors were able to keep the workflow moving and produce quality work while she was on leave due to a surgery. She shared, "Everything kept moving. I think in education a lot of times, it's the dream of a lot of educators to trust their students to keep moving forward and thrive, even when they are 
not there." Eva also trusted her editors during a bereavement leave to attend a family funeral. She explained, "Initially, I was filled with anxiety. Then, I realized my editors know the programs and would handle the heavy lifting to keep us moving. When they see me as an adult just going, 'Let's do this,' then I think they learn adaptation skills and that they are trusted." In the same way, when Sloane's baby was soon to be delivered, her first call outside of her family was to her editor-in-chief ensuring the completion of their upcoming deadlines. She further explained how much she trusted and depended upon her editor in that moment throughout the delivery and the following weeks of maternity leave. She commented, "I was not going to be there, and I needed to call her to let her know because we were on deadline. So, it was a little stressful for me, but good to know they were prepared for it and in safe hands with my editor." The role of leadership empowered the students to be trusted and effectively meet expectations on their own.

Open Communication. Trust is built upon ongoing communication. Mia explained, "If our arrows are all pointed in the right direction, we can be a more effective collective." As a result of clearly defining the vision and goals, the staff developed a strong mutual trust. She welcomed conversations on culture, emphasized publication importance, developed reasons to care, and desire to participate. Through all of this, she said, "We came to the central idea, 'The bearers of light,' to shine a light on good in the community. The positive we want to see more. Sometimes it means shining a light on things that are like, 'Man, this is really messed up, or this could be better, or how do we create change?' If you're doing it well, you create proof to live your central mission."

Numerous advisers revealed their appreciation and emphasis on the importance of trust. Advisers establish trust through ongoing communication and providing freedoms 
based upon the news lab's common vision. Earned trust permits students to make independent decisions. Advisers articulated they trust their students to work throughout their news lab and community.

\section{Building Consensus}

Leadership plays a role in advisers building a consensus throughout journalism news labs. After advisers create a common vision and trust, the advisers' role shifts from decision making to empowering students to make decisions. Advisers revealed intentionally influencing news labs towards consensus enhanced their ability to reach goals.

Advisers shared once they first shape the news lab to be productive and creative, the students shape the news lab's goals from a collaborative consensus. Twenty-two advisers shared the fundamental practice of establishing professional habits, where the student editors lead the news lab by, leading budget meetings, enforcing expectations, rubric reviews, and establishing work session goals. Through this student leadership at the beginning of each class time, advisers shared it is much easier to gain consensus.

In fact, advisers commented they rely on student buy-in to establish leadership roles and encourage proper decision making. Mary explained how the role of leadership helps her trust editor decisions. She explained, "Our editors have the leadership opportunity to stand up for what they believe in. Our kids have great pride and respect for what they do. They know Hazelwood versus Kuhlmeier, and the kids respect that they have the ability to make decisions." Similar to Mary, Elizabeth explained how she builds consensus around journalism values and skills to teach her staff the big picture of future news lab leadership. Elizabeth said, "I can teach you all the skills you need, but you can't 
teach passion about something, or working hard until it works, because that's a lot of what journalism is. Because you're going to have the bad days, the bad interviews. But when it does finally click and come all together, it's really cool to be part of that with all of my students." So, whether advisers are building consensus around law, ethics, values, morals, or skills, the bottom line is that these learning communities are firmly planted in the solid ground of a common set of higher ideals.

The data revealed the role of leadership generates consensus as advisers and students share convictions for their productions and program. Additionally, Elizabeth continually directs her students towards their shared purpose. Each year, she sees her students return to her news lab. She illustrated, "All come in as novices, but by the time they're done, they'll be an amateur or expert. I feel like if they take my class a second year they become a professional level." The news lab's shared decision making grows students into leaders. Similarly, Elise explained, "I always have my editors as returning staff members. They've been on staff before and know what's expected. I feel like they have a good grasp on it and just have to use their knowledge." Likewise, Erin believes her editors are invested and want their news lab to be a reflection of their agreed upon decisions. She explained:

They have a personal investment in this program. It's not just me, it's not just my program. It doesn't belong to anybody but them. They have that personal stake in it. I just put some structure to it. They want to have a say in what happens. Because they know that if they're not there, the kids who are there will decide how to steer the boat and they want that stake in it. 
The role of leadership within their news lab supports the students opportunity to invest in their work. Similarly, Leah believes her students are invested and strive to be part of the news lab's big picture, starting at their beginning steps as staffers. She explained, "The editors get it and they understand how they are part of the big picture because they took those first two years and they were in an environment that allowed them to take their time to learn the process to become a leader not only for themselves, but for other people, and other people will want to be them."

Advisers indicated the leading role of leadership within journalism education. It cultivates effective production, encourages creativity, and fosters shared decision making. The role of leadership helps establish a quality journalism program.

\section{Discussion of the Results}

Little has been known about high school journalism advisers' perspectives and how they teach leadership. To date, research has focused on how to train professional newsroom leaders, but not in high school news labs. This present analysis supports the scholarly belief that improving journalism requires leadership training in professional newsrooms (Callinan, 2001; Herndon \& Krueger, 2016; Killebrew, 2003; Mierzejewska, 2011; Mulrennan, 2018; Northouse, 2016; Perez-Latre \& Sanchez-Tabernero, 2003). High school advisers do teach leadership. Therefore, it is imperative that high school journalism advisers are informed how to effectively teach leadership.

Advisers use transformational practices to teach leadership. The advisers' perspectives were examined through a transformational leadership theory framework (Northouse, 2016.) The findings support the transformational leadership theory. Kouzes and Posner's $(1987,2002)$ model further refines how advisers use transformational 
leadership by suggesting that leadership is not a position, but a collection of practices and behaviors. The primary factors used were encouraging the heart, enabling others to act, modeling the way, and inspiring a shared vision.

Each participant taught leadership and revealed their passion to develop students into self-aware leaders. Whether an adviser had three years or three decades of experience, all established aspects of editorial leadership throughout their news labs. Advisers lead their news labs by their example to encourage students to follow their common vision. Advisers used shared vision practices to define their news labs motto, positions, procedures, and passion. The current study determined that leadership plays a leading role in K-12 journalism education and identified the vital need for editorial leadership in scholastic journalism programs. Editorial leadership provides advisers and students the practices and behaviors to lead an effective, efficient, and vibrant media system within their news labs.

\section{Motivation}

Advisers have the daunting responsibility of leading all students to perform to the best of their ability; however, the motivation lays with student leaders to support the news lab's overall vision. Leadership is important in high school journalism education because advisers must create news lab practices and behaviors to meet production goals. Filak's (2003) study revealed it also to be the case that leadership builds culture by aligning support systems to reinforce learning and student motivation. Therefore, it is that imperative advisers enable their students to be trusted leaders through news labs common vision. 
All participating advisers inspired their students to be trusted leaders in a variety of ways that illustrate the fluidity of leadership practices. It is critical for advisers to encourage their students throughout each step of their leadership training. Advisers instill confidence in their students by designing their news labs into a community of learners. Students must become part of the news lab community before they can become a leader. Teaching leadership is not a mandated curriculum standard, but a process where advisers encourage each student to master skills. Advisers continually provide their support to students until a skill is mastered within their own timeline, abilities, strengths, and weaknesses. There is an importance for advisers to encourage their students with celebrations. The celebrations develop the students' teamwork, confidence, and passion. Collins (2017) also found that higher education newsroom cultures use transformational ways to help students be encouraged and socialized to challenge one another through the newsgathering processes. Overall, advisers encourage their students to first individually master skills to grow into news lab leaders.

Participants in the current study believed focusing on their students' strengths was important to encourage student leadership development. Advisers must trust students before enabling them to be leaders. First, advisers establish student accountability with clear expectations. The students that consistently meet expectations become news lab leaders. Consequently, advisers claim those rigorous expectations heighten their students' motivation to be leaders. Therefore, once students become accountable to the news lab expectations, advisers motivate selected students to be leaders.

Ferguson, Patten, and Wilson's (2005) previous research said traditionally high school news lab's production parallels professional newsrooms by mandating the same 
editor positions. Contrary to traditional news lab positions where journalists there are set editor positions, the interviewed advisers shared they establish their student leadership roles and expectations depending on their student strengths. The current study revealed an interesting finding that advisers discover their student strengths and then define the news lab's leadership positions. Furthermore, advisers establish leadership positions and provide the editors with specialized training and duties. Leadership is taught to the core student leaders and the soft skills are expected to trickle down. Advisers encourage their student leaders to be teachers and work side-by-side with their student staff, maximizing the news lab's full potential.

Advisers are responsible for creating an atmosphere committed to students knowing they must produce a high-quality product for audiences outside the new lab. Motivation is a key reason students show increased commitment to learning due to their news lab's high professional standards and rigorous work ethic expectations. This finding supports Journalism Educators Association's (2019) standard that high school journalism educators demonstrate the expertise to engage students with effective motivation. Overall, motivation is required for editors to lead their staff members through the completion of their rigorous deadline schedules. While advisers commented on their rigorous atmosphere, an overwhelming majority of advisers advocated connecting their students' work with set achievable goals and creating a supportive environment. Similarly, advisers search for opportunities by seizing the initiatives and looking for innovative ways to improve, experiment, and take risks. Advisers seek out challenging opportunities that test their news lab skills and constantly generate small wins and learn from each experience. 
A common vision is an essential feature for advisers to further motivate editors to be leaders. Advisers inspire a common vision throughout their news lab to produce their desired production results, encourage creativity, and foster group decision making. It is important for advisers and their editors to have shared practices and leadership behaviors. It is imperative for advisers to continually articulate production goals with their editors to then delegate to the student staff. Sharing common visions helps advisers create trust and consensus around their news lab's goals. These results build on Streisel's (2007) existing evidence that organizational workings of a scholastic journalism news lab have the potential to teach basic ways to plan content and build trust. Trust boosts a news lab's ability for students to effectively meet expectations on their own. Similarly, trust in the relationship between advisers and their student editors is critical. Relationships further build trust within news labs. Through relationships, advisers establish their most effective student leaders.

\section{Implications}

The processes and role of leadership in scholastic journalism are important. There are important implications to this current study. The advisers' perspectives likely reflect perspectives of prospective, current, and past advisers. Leaders used their strengths to build relationships, motivate fellow students, and develop healthy core values within high school journalism. These participants' perspectives should be considered throughout K12 journalism education. Implementation of editorial leadership could make journalism programs gain effective production, encourage creativity, and foster group decision making. Furthermore, increased editorial leadership leads to more successful journalism 
programs. Ultimately, successful news lab helps to develop students leadership skills to reach their full potential.

\section{Conclusion}

The current study's findings indicated leadership plays a leading role in scholastic journalism programs, known as editorial leadership. When an adviser establishes leadership as a foundation, news lab production increases, creativity is fostered, and decision making is delegated to the students. Thus, leadership skills are important in journalism education. Advisers said soft skills provided opportunities for students to grow into leaders. The student leaders then provided advisers opportunities to articulate their passion and genuine conviction. The advisers interviewed for this study were transformational leaders, creating trust and consensus around their news lab's common vision. Many transformational leadership theory components were present within Missouri's scholastic journalism news labs. Kouzes and Posner's (1987) fundamental practice of inspiring a shared vision was the most utilized. 


\section{References}

Becker, B.E., \& Hueslid, M. A. (1998). High performance work systems and firm performance: A synthesis of research and managerial implications. Research in Personnel and Human Resource Management, 16, 53-101.

Bell, E. \& Blaeuer, D. (2006). Performing gender and interpersonal communication research. In J. L. Wood \& B. Dow (Eds.), The Gender and Communication Handbook, (pp. 9-23). Thousand Oaks, CA: Sage.

Bobkowski, P. S., Goodman, M., \& Bowen, C. P. (2012). Student media in U.S. secondary schools: Associations with school demographic characteristics. Journalism and Mass Communication Educator, 67(3), 252-266.

Bobkowski, P. S., Cavanah, S. B., \& Miller, P. R. (2017). Who are the "journalism kids"? Academic predictors of journalism participation in secondary schools. Journalism and Mass Communication Educator. 72(1), 68-82. doi.org/10.1177/1077695815622770

Breed, W. (1955). Social control in the newsroom: A functional analysis. Social Forces, $33,326-335$.

Bronstein, C., \& Fitzpatrick, K. R. (2015). Preparing tomorrow's leaders: Integrating leadership development in journalism and mass communication education. Journalism \& Mass Communication Educator, 70(1), 75-88.

Bruschke, J., \& George, M. H. (1999). Verbal skills and the value of scholastic journalism. Journalism \& Mass Communication Educator, 54(3), 65-72. doi:10.1177/107769589905400305

Buchan, J., (1930). Montrose and leadership, Oxford University Press 
Bush, L., Haygood, D., \& Vincent, H. (2017). Student-run communications agencies: Providing students with real-world experiences that impact their careers. Journalism and Mass Communication Educator, 72(4), 410-424. doi: $10.1177 / 1077695816673254$

Callinan, T. (2001). TV reports next step in Phoenix convergence strategy. Gannett News Watch. Available at website: www.gannett.com/go/newswatch/2001/august/nw0824-1.com.

Camarota, A.G. (2004). Finding the leader in you: A practical guide to expanding your leadership skills. Milwaukee, WI: ASQ Quality Press.

Carlin, L. Saker, S. \& Taylor, M. (2018). The making of a symposium: Democratic education, student leadership, and professional mentorship in high school journalism. Education Leadership. 15(2), 247-265.

Charles, M., \& Luce, A. (2016). US 2012 live: When the classroom becomes a newsroom. Cambridge Journal of Education, 46(1), 113-130.

Clark, L. S., \& Monserrate, R. (2011). High school journalism and the making of young citizens. Journalism, 12, 417-432. doi:10.1177/1464884910388225

Cowan, G. (2009). Leading the way to better news: The role of leadership in a world where most of the powers that be became the powers that were. Politics and Public Policy. Retrieved from Harvard Kennedy School, Joan Shorenstein Center on the Press website www.hks.harvard.edu/presspol/publications/papers/discussion_papers/d44_cowan .pdf.

Emerson, R., Fretz, R., \& Shaw, L. (1995). Writing ethnographic fieldnotes. 
Chicago: University of Chicago Press.

Filak, V. F. (2003). Conflict and convergence: A study of intergroup bias and journalists. Institute: University of Missouri-Columbia.

Fowler-watt, K. \& Wilson, A. (2013). Editorial leadership in the newsroom. Journalism Challenges, 1(1), 203-221.

Fowler, F. C. (2013). Policy studies for educational leaders: An introduction. Boston, MA: Pearson.

Graybeal, G., \& Sindik, A. (2012). Journalism students and civic engagement: Is there still a connection? Community Journalism, 1(1), 29-46. Retrieved from http://journal.community- journalism.net/articles/journalism-students-and-civicengagement-there-still-connection

Herndon, K., \& Krueger, V. (2016). Leadership training in an industry context: Preparing student leaders for a chaotic news media. Journal of Leadership Education, 15(2), 48-57.

Killebrew, K. C. (2003). Culture, creativity and convergence: Managing journalists in a changing information workplace. International Journal on Media Management, $5(1), 39-46$.

Kouzes, J.M. \& Posner, B.Z. (2002) The leadership challenge: How to get extraordinary things done in organizations. San Francisco: Jossey-Bass.

Lynch, D. (2015). Above and beyond: Looking at the future of journalism education. Knight Foundation. Retrieved from John S. and James L. Knight Foundation website www.knightfoundation.org/features/journalism-education

Macdonald, I. (2006). Teaching journalists to save the profession: A critical assessment 
of recent debates on the future of US and Canadian journalism education. Journalism Studies, 7(5), 745-764. doi.org/10.1080/14616700600890414.

Marchi, R. (2012). From disillusion to engagement: Minority teen journalists and the news media. Journalism, 13, 750-765. doi:10.1177/1464884911431379

Mensing, D. (2010). Rethinking [again] the future of journalism education. Journalism Studies. 11(4): 511-523. doi.org/10.1080/14616701003638376.

Merriam, S.B., \& Tisdell, E. J. (2016). Qualitative research: A guide to design and implementation (4th ed.). San Francisco, CA.: Jossey-Bass.

Mierzejewska, B. I., \& Hollifield, C.A. (2006). Theoretical approaches in media management research. In A. Albarran, S. Chan-Olmsted, and M.O. Wirth (Eds.), Handbook of media management and economics (pp. 37-65). Mahwah, NJ: Erlbaum.

Mierzejewska, B.I. (2011). Media management in theory and practice. In M. Deuze (Ed.), Managing Media Work (pp. 13-30). Thousand Oaks, CA: Sage.

Missouri Department of Higher Education. (2011). Statewide academy program review: Report to the governor. Jefferson City, MO: Missouri Department of Higher Education.

Mulrennan, D. (2018). Mobile social media and the news: Where heutagogy enables journalism education. Journalism \& Mass Communication Educator, 73(3), 322333. doi.org/10.1177/1077695817720762

Newspaper Association of America Foundation. (2008). Lifelong Readers: Driving Civic 
Engagement. Newspaper Association of America Foundation. Retrieved from Newspaper Association of America Foundation website at http://www.naafoundation. org/docs/Foundation/Research/LR_civic.pdf Newton, E. (2018). Journalism education reform: How far should it go? Knight Foundation. Retrieved from John S. and James L. Knight Foundation website www.knightfoundation.org/speeches/journalism-education-reform-how-farshould-it-go

Northouse, P. G. (2016). Leadership: Theory and practice (7th ed.). Los Angeles, CA: Sage.

Pavlik, J. V. (2013). A vision for transformative leadership: Rethinking journalism and mass communication education for the twenty-first century. Journalism \& Mass Communication Educator, 68(3), 211-221.

Perez-Latre, F. J., \& Sanchez-Tabernero, A. (2003). Leadership, an essential requirement for effecting change in media companies: An analysis of the Spanish market. International Journal of Media Management, 5(3), 198-208.

Robertson, S. (2002). In student publications, leadership is necessary, and its quality is a significant success factor. Quill and Scroll, 76(3), 10-11.

Siebert, F. S., Peterson, T., \& Schramm, W. (1963). Four theories of the press. Chicago, IL: The University of Illinois Press.

Stake, R. (1995). Qualitative research: Studying how things work. News York. The Guilford Press

Stapp, M. (October, 2013). Scholastic journalism: Skills for the $21^{\text {st }}$ century. The Education Digest. America Association of School Administrators, 30-34. 
Streisel, J. (2007). High school journalism: A practical guide. Jefferson, North Carolina. McFarland \& Company, Inc. Publisher.

Wilderman, M., Nasrin, S., \& Davis, J. (2018). Budget cuts in scholastic media: A focus group study of Oklahoma journalism advisers' survival skills, Journalism \& Mass Communication Educator. 1-14. doi.org/10.1177/1077695818787066

Windels, K., Mallia, K. L., \& Broyles, S. J. (2013). Soft skills: The difference between leading and leaving the advertising industry. Journal of Advertising Education, $17(2), 17-27$.

Westbrook, R. (2019) SJW editorial leadership. Columbia Scholastic Press Association. Retrieved from https://cspa.columbia.edu/summer-journalismworkshop/classes-offered/sjw-editorial-leadership

Yin, R. (2003). Case study research: Design and methods. Los Angeles. Sage.

Yukl, G., \& Van Fleet, D. D. (1992). Theory and research on leadership in organizations. In M. S. Dunnette \& L. M. Hough (Eds.), Handbook of Industrial and Organizational Psychology. 3(2), 147-198. Palo Alto, CA: Consulting Psychologists Press. 
SECTION SIX

SCHOLARLY PRACTIONER REFLECTION 


\section{Scholarly Practioner Reflection}

My dissertation journey has provided me with clarity that we are provided with seasons of life to learn and then we use those experiences to truly live our potential. The dissertation presented a moment to purge myself from our course instruction and group collaboration to trust my own new rhythm as a researcher to build myself as a scholarly practitioner in journalism education. To a working mother of three, my dissertation was more than an education. It has been a revelation, exposing me to an inward confidence to constitute decisions for myself and journalism education.

\section{Valuing My Journey}

Throughout my dissertation, I was required to research, write, observe, triangulate data, and interview high school advisers across Missouri. Although I was unaware of it then, the dissertation's challenges and victories empowered me. I found myself inwardly gaining confidence as a researcher by not only defining my study's reliability and validity through consistent and accurate measures, but as I reached out to find editorial leadership studies and data at the University of Missouri's School of Journalism. I was surprised at how passionate and supportive faculty throughout my alma mater were in automatically trusting my instincts to encourage me throughout my process to find additional interviews and content of peer-reviewed journals to help provide factual background information.

Beginning the fieldwork by interviewing dozens of high school journalism advisers across Missouri could have been quite daunting to find, connect, schedule, and travel across Missouri; however, conducting my research process was quite fulfilling. I needed to step out of the fray to find new perspectives in the challenging midst of not having existing literature on editorial leadership (Northouse, 2016). Not only did I get to 
use my fieldwork skills acquired through my doctoral degree course work, but I also used my previous first-hand experience conducting interviews as a reporter. I found I quickly reconnected to my previous profession's passion as a reporter. It was enjoyable to get the opportunity to use my interviewing skills. It was an exhilarating experience the power of collecting data coupled with transparency, accountability, and a diversity of interpretation (Gagliardi, 2018).

My transformation to a scholar pushed me to continually reframe my referent power with my colleagues throughout my dissertation's fieldwork (Northouse, 2016). I was able to access more advisers than initially anticipated, which was due to the support and collegiality provided by Cohort 11 ELPA colleagues and the MIPA's organization's leadership. In the same way, Dr. Sandy Hutchinson's previous fieldwork throughout Missouri provided me with substantial insight and strategy to efficiently cover the state. Their support and excitement for this study fueled my passion and reconnected me to a tribe of distinguished educators dedicated to the craft of journalism. I quickly learned their cooperative spirit helped me to not waste any significant amount of time scheduling interviews, when a lot of the responses helped to build into the study and showcase Missouri's advisers' passion for the craft and developing their students. Bit by bit, I developed a range of influencing relationships to gain referent power to get different people with different perspectives to support the findings of this study (Northouse, 2014). It was invigorating to connect with kindred spirits' turbulent determination to motivate their student journalists.

As mentioned, MIPA's support and collegiality provided me access to the awardwinning advisers. I discovered that my previous experience as a high school journalism 
adviser did not cause bias, but provided a collaboration, openness, and trust to further gain a great deal of nuanced insight into this study's understanding of editorial leadership (Bruffee, 1999; Gill, 2010). It was very beneficial for this study as my past experience helped me to understand their language, victories, and struggles, which were depicted within their interviews. The combination of my former adviser experience and my copious research of scholastic journalism helped the advisers become comfortable with me; first, through email communications and then, helped each open up to the idea of participating in this study. I realized that my association with MIPA and as a former adviser gave me a greater deal of legitimacy in the eyes of my potential research respondents. Harvey (2011) has highlighted how field researchers must endeavor to earn the trust of their respondents to gain access to high quality data and, looking at the qualitative findings I garnered, I believe I was able to do this successfully. After traveling to the dozens of research sites over a period of two months, I reconnected to my skills and passion for people's stories, while never forgetting I began as a high school journalism adviser.

\section{Unveiling Significance}

My dissertation has further empowered me from a student to a scholar and has fundamentally readied me to be a leader (Kofman \& Senge, 1993). My dissertation process helped me spend significant time strategically edging towards my goal of completion. I learned to go to bed very late and wake up very early to do the needed coding, analysis, and writing work. I became very efficient at burning the candle at both ends. I had to plan each day, hour to hour, and had to do all of my work strategically, which helped me divulge I must abandon pleasing others and relinquish doubting my 
abilities. Being a working mom, teaching an overload of five classes, I was pulled from all directions, but I could not stop. As a result, I discovered motivation is seldom my problem because of my delight in successful achievements (Clifton \& Anderson, 2006). Knowles' (1984) research specifically resonates with me as a 40-year-old adult. I am mostly driven by internal motivation, rather than external motivators. For example, drawing on insights from the coursework throughout each benchmark of growth I never over focused on the group dynamics or the program's objectives. I am most proud through each met goal showcasing my growing achievements. As a result of the program, I realize my motivation is part of my positive-character trait and it is not superficial. I am only pleased to achieve my targets once I believe I gave all my efforts towards the project's goal. Moving forward, I can use these traits through my transition from student to scholar.

In the same way, I found the importance to stay focused on thinking and acting systematically by seeing the big picture of looking forward to completing this study (Bolman \& Deal, 2013). To do so, I had used my referent power by negotiating my course load to accommodate this study's fieldwork throughout the state (Northouse, 2014). As an advocate for myself, I had to also establish how an accommodation would be a benefit for all of our department's various parts to function together (George, et. al, 2011).

My transformative process has moved me further beyond my comfort zone. Each step of the dissertation, I adapted to the needs and motives of others, but remained resilient to my goal to finish. Throughout my dissertation, I found myself shifting the way I think about my personal learning to provide myself with grace, which I have not 
provided myself in the past because "removing the long-standing, self-blaming belief allows myself to experience learning in a different way and to exhibit learning ownership" (Chen, 2014, p.414).

My path of self-discovery's center is a journey, which is defined through my transformation from a student into a scholarly practitioner and journalism education leader. I will continue to strive to cultivate each and begin to refine my traits within my professional practices to gain motivation, grace, and not discontent (Clifton \& Anderson, 2006; Chen, 2014).

\section{Navigating Epiphany}

The dissertation organically fostered conditions, pushing me toward my learning edge, thus challenging and encouraging me to critically reflect on my potential (Ettling, 2012). My dissertation has presented the opportunity to use the study's findings as a vehicle towards authentic leadership in order to revitalize the University of Central Missouri's Journalism Education program (George, Sims, McLean, \& Mayer, 2011; Kofman \& Senge, 1993). My academic identity from student to research scholar is complex and challenging, but through completing my dissertation I have experienced a unique adaptive progression and am gaining competence. Now, I am poised to be a leader by focusing on the dynamics of mobilizing people to address change (Northouse, 2016). Ultimately, throughout my dissertation journey, I learned to trust my instincts and share in shaping a fruitful educational experience for UCM's students within our overall Journalism Education program. I discovered my potential is right now and I do not have to be at the top of my organization. As a result, I found myself within an encompassing journey of learning to inspire others to accomplish great things (Northouse, 2016). 
My dissertation's journey inspired my vision for adult learning to be for every member to grow. Each journalism educator must be supplied with aspects for them to thrive through consistent content and application going hand in hand to produce maturing advisers (Roland, 2008). It is critical that I employ what I have learned throughout my dissertation to position myself as a scholar. From that place of understanding, I will provide healthy learning experiences for advisers by listening to their stories and learning their perspectives, exploring possibilities respectfully to empower our informed choices to build UCM's Journalism Education program.

As I learned throughout my fieldwork interviews, I will remain committed to fostering adult-learner relationships based upon compassion and trust (Gill, 2010). I subscribe that learners will rise to meet high expectations when there is an established environment of mutual respect and communication. My leadership must constantly call on the adult learners to be ethically astute, culturally aware, and theologically reflective. As I still need to lead from the middle, I can use my new scholarly point of view to help. I have found developing effective adult education can best be accomplished by collaborating with current leaders who are gifted and passionate about journalism education. Specifically, since embarking on my dissertation I have used my relevant work practice as a UCM instructor. My transformation has already begun by teaching, coaching, and mentoring editorial leadership skills by becoming the lead adviser for UCM's student publication the "Muleskinner", creating a "Journalism Today" advisers workshop, relaunching Central Missouri’s Journalism Educator's Association, developing a UCM Journalism Education certificate, establishing UCM's DESE 
certification for Journalism Education, and even running as a candidate within our upcoming school board election.

\section{Conclusion}

While completing the dissertation presented may challenges, I remained focused

and learned many lessons, permitting me to strive to live towards my immense potential. When I began my doctoral journey, I was so fearful of failure, but my committee chair and mentor, Dr. Hutchinson instilled in me that I am a strong woman and have the skills and expertise to succeed. Throughout my journey I have found when I thought I was falling, I was actually flying towards my potential to be a more effective leader.

As I begin to live within a scholar identity, my dissertation experiences have proven to provide me with tools to gain momentum with UCM's Journalism Education program. I will strive to live towards my potential by developing a new generation of journalism educators and mentoring new talent and affirming veteran advisers through collaboration, openness, and trust (Bruffee, 1999; Gill, 2010). Ultimately, my teaching, professional experience, and doctoral scholarship have armed me to strive towards my potential to teach and empower adult learners. My heightened self-awareness will help me trust myself and continue acquiring the needed support for change with area key stakeholders and throughout Missouri reinvigorating journalism education. After all I have learned, I am excited to embark on my life's next journey while using my strengths as a two-track leader, focusing on trust and data driven-decision making, which will propel me towards my true potential. 


\section{References}

Abrahamowicz, D. (1988). College involvement, perceptions and satisfaction: A study of membership in student organizations. Journal of College Student Development, 29(3), 233-38.

Adam, S. (2001). The education of journalists. Journalism, 2(3), 315-139.

Bass, B. (1985). Leadership and performance beyond expectations. New York: Free Press.

Bass, B. (1990). From transactional to transformational leadership: Learning to share the vision. Organizational Dynamics, 3(18), 19-31.

Beaumont, E. (2011). Promoting political agency, addressing political inequality: A multilevel model of internal political efficacy. The Journal of Politics, 73(3), 216231. doi:10.1017/ S0022381610000976

Becker, B.E., and Hueslid, M. A. (1998). High performance work systems and firm performance: A synthesis of research and managerial implications. Research in Personnel and Human Resource Management, 16(5), 53-101.

Becker, L.B. (2003). Introduction: Developing a sociology of journalism education. In R. Froehlich, \& C. Holtz-Bacha (Ed.), Journalism education in Europe and North America: An international comparison (pp. 11-17). Creskill, NJ: Hampton Press.

Bell, E. \& Blaeuer, D. (2006). Performing gender and interpersonal communication research. In J. L. Wood \& B. Dow (Eds.), The Gender and Communication Handbook, (pp. 9-23). Thousand Oaks, CA: Sage.

Blachard, K. \& Johnson, S. (2016). The one minute manager. Harper Collins Publisher New York, NY. 
Bobkowski, P. S., Goodman, M., \& Bowen, C. P. (2012). Student media in U.S. secondary schools: Associations with school demographic characteristics. Journalism and Mass Communication Educator, 67(3), 252-266.

Bobkowski, P. S., Cavanah, S. B., \& Miller, P. R. (2017). Who are the "journalism kids"? Academic predictors of journalism participation in secondary schools. Journalism and Mass Communication Educator. 72(1), 68-82. doi.org/10.1177/1077695815622770

Bolman, L. G., \& Deal, T. E. (2013). Reframing organizations: Artistry, choice and leadership (5th ed.). San Francisco, CA: Jossey-Bass.

Bourdieu, P. (1984). Distinction: A social critique of the judgment of taste. London, England: Routledge \& Kegan Paul.

Bourdieu, P. (1990). In other words: Essays towards a reflexive sociology. Stanford, CA: Stanford University Press.

Bourdieu, P. (1991). Language and symbolic power. Cambridge, MA: Harvard University Press.

Breed, W. (1955). Social control in the newsroom: A functional analysis. Social Forces, $33,326-335$.

Brennan, B. (2000). What the hacks say. Journalism, 1(1), $106-113$.

Brenner, J. (2009). High school students permitted to distribute previously censored newspaper. Student Press Law Center. Retrieved from http://www.splc.org/newsflash.asp?id=1974.

Bronstein, C., \& Fitzpatrick, K. R. (2015). Preparing tomorrow's leaders: Integrating 
leadership development in journalism and mass communication education. Journalism \& Mass Communication Educator, 70(1), 75-88.

Bruschke, J., \& George, M. H. (1999). Verbal skills and the value of scholastic journalism. Journalism \& Mass Communication Educator, 54(3), 65-72. doi:10.1177/107769589905400305

Bryan, L. \& Joyce, C. (2007, May). Better strategy through organizational design: Chief executive officers through strategic planning of business operations. McKinsey Quarterly, Retrieved from: www.mckinseyquarterly.com/article_page.aspx.

Buchan, J., (1930). Montrose and leadership. Oxford University Press

Burns, J.M. (1978). Leadership. New York, NY: Harper \& Row.

Bush, T. (2003). Theories of educational leadership and management (3rd Ed.). Thousand Oaks, CA: Sage.

Bush, L., Haygood, D., \& Vincent, H. (2017). Student-run communications agencies: Providing students with real-world experiences that impact their careers. Journalism and Mass Communication Educator, 72(4), 410-424. doi: $10.1177 / 1077695816673254$

Callinan, T. (2001). TV reports next step in Phoenix convergence strategy. Gannett News Watch. Available at website: www.gannett.com/go/newswatch/2001/august/nw0824-1.com.

Camarota, A.G. (2004). Finding the leader in you: A practical guide to expanding your leadership skills. Milwaukee, WI: ASQ Quality Press.

Campbell, L. (1969). Journalism in Middle West High Schools in 1969. Quill and Scroll, 26(1), 2-26. 
Campbell, R., Martin, C. R., \& Fabos, B. (2016). Media \& culture: Mass communication in a digital age (10th Ed). Boston: Bedford St. Martin's.

Carey, J. (2000). Some personal notes on U.S. journalism education, Journalism. 1(1), $12-23$.

Carlin, L. Saker, S. \& Taylor, M. (2018). The making of a symposium: Democratic education, student leadership, and professional mentorship in high school journalism. Education Leadership. 15(2), 247-265.

Carr, D. (1990). Adopting the new: Computers in the television newsroom. Unpublished Dissertation, University of Missouri.

Carnegie Corporation of New York, 26 May, www.carnegie.org/sub/program/initiativemanifesto.html, accessed 9 December 2018.

Carpenter, S., Hoag, A., \& Grant, A. (2018). An examination of print and broadcast journalism students' personality traits. Journalism \& Mass Communication Educator, 73(2); 147-166.

Charles, M., \& Luce, A. (2016). US 2012 live: When the classroom becomes a newsroom. Cambridge Journal of Education, 46(1), 113-130.

Charon, J. (2004). Symbolic interactionism: An introduction, an interpretation, an integration (8th Ed). Upper Saddle River, NJ: Pearson Prentice Hall.

Clark, L. S., \& Monserrate, R. (2011). High school journalism and the making of young citizens. Journalism, 12, 417-432. doi:10.1177/1464884910388225

Cleveland, J., Murphy, K.R., \& Stockdale, M.S. (2000). Women and men in organizations: Sex and gender issues at work. Mahwah, NJ: Lawrence Erlbaum. Collins, J. M. (2017). Leadership development in college newsroom labs: It is 
transactional. Journalism and Mass Communication Educator, 72(1), 4-23.

Creswell, J. W. (2014) Research design: Qualitative, quantitative, and mixed methods approaches $\left(4^{\text {th }}\right.$ ed.). Thousand Oaks, CA: Sage.

Collins, J. (2001). Good to great: Why some companies make the leap... and others don't. New York, NY: Harper Business.

Commission on Freedom of the Press (1947). A free and responsible press: A general report on mass communication: newspapers, radio, motion pictures, magazines, and books. Chicago: University of Chicago Press.

Covey, S. (2012). The seven habits of highly effective people: Powerful lessons in personal change. New York: Free Press.

Cowan, G. (2009). Leading the way to better news: The role of leadership in a world where most of the powers that be became the powers that were. Politics and Public Policy. Retrieved from Harvard Kennedy School, Joan Shorenstein Center on the Press website www.hks.harvard.edu/presspol/publications/papers/discussion_papers/d44_cowan .pdf.

De Bruin, D., \& Ross, K. (2004). Gender and newsroom cultures: Identities at work. Cresskill, NJ: Hampton Press.

DePree, M. (2008). Leadership jazz: The essential elements of a great leader. New York: Crown Business.

Deuze, M. (2006). Global Journalism Education: A conceptual approach, Journalism Studies 7(1), 19-34.

Dickson, T. (2000). Mass media education in transition: Preparing for the 21st century, 
Mahwah, NJ: Lawrence Erlbaum.

Dornbusch, S. and Scott, W.R. (1975). Evaluation and the Exercise of Authority. San Francisco: Jossey-Bass.

Downes, M., Hayes, B., Furnas, K., Newton, M. (2012). Standards for Journalism Educators. Association for Education in Journalism and Mass Communication: Journalism Education Association and Scholastic Journalism Division. Retrieved from: http://jea.org/wp/home/for-educators/standards/.

Emerson, R., Fretz, R., \& Shaw, L. (1995). Writing ethnographic fieldnotes. Chicago: University of Chicago Press.

English, E. (1988). Journalism education at the University of Missouri-Columbia. Marceline, Mo.: Walsworth.

Fallows, J. (1997). Breaking the news: How the media undermine american democracy, New York: Vintage Books.

Ferguson, D., Patten, J. Wilson, B. (2005). Journalism today ( $7^{\text {th }}$ Ed.). New York, NY: Glencoe.

Fowler, F. C. (2013). Policy studies for educational leaders: An introduction. Boston, MA: Pearson.

Fowler-watt, K. \& Wilson, A. (2013). Editorial leadership in the newsroom. Journalism Challenges, 1(1), 203-221.

Filak, V. F. (2003). Conflict and convergence: A study of intergroup bias and journalists. Institute: University of Missouri-Columbia.

Filak, V. F., \& Pritchard, R. S. (2007). The effects of self-determined motivation and 
autonomy support on advisers and members of a journalism student organization. Journalism \& Mass Communication Educator, 62(1), 62-76.

Firestone, W.A. \& Heller, M.F. (1995). Who's in charge here? Sources of leadership for change in eight schools. The Elementary School Journal, 96(1), 65-86.

Franklin, B. (2012). The future of journalism. London: Routledge.

Fredricks, J. A., Blumenfeld, P. C., \& Paris, A. H. (2004). School engagement: Potential of the concept, state of the evidence. Review of Educational Research, 74(1), 59109. doi.org/10.3102/00346543074001059

Froke, P., Bratton, A. J., Garcia, O., Minthorn, D., Ritter, K., \& Schwartz, J. (2017). The Associated Press Stylebook. (52nd ed.). New York: Basic Books.

Folkerts, J. (2014). History of journalism education. Journalism and Communication Monographs, 16(4), 227-299. doi.org/10.1177/1522637914541379

Gaunt, P. (1992). Making the newsmakers: International handbook on journalism training, Westport, CT: Greenwood Press.

Gavankar, S. (2019). The year of the student journalist this year will highlight the importance of these students and the need to support them and their work. Newseum, p. 2. Retrieved from https://www.newseum.org/press-info/pressreleases/pr/367/

Goh, D., \& Kale, U. (2015). From print to digital platforms: A PBL framework for fostering multimedia competencies and consciousness in traditional journalism education. Journalism \& Mass Communication Educator, 70(3), 307-323. doi:10.1177/1077695815589473

Graybeal, G., \& Sindik, A. (2012). Journalism students and civic engagement: Is there 
still a connection? Community Journalism, 1(1), 29-46. Retrieved from http://journal.community- journalism.net/articles/journalism-students-and-civicengagement-there-still-connection

Gulick, L. \& Urwick, L. (1937). Papers on the science of administration. Institute of Public Administration. New York, NY: Columbia University.

Hannum, K., \& Martineau, J. (2008). Evaluating the impact of leadership development. Center for Creative Leadership, San Francisco: Jossey-Bass.

Hare, K. (October, 2018). Notebooks are magic and other lessons from working with kid journalists. Poynter. Retrieved from the Poynter Institute website www.poynter.org/news/notebooks?are?magic?and?other?lessons?working?kid?jo urnalists?twitter_impression=true

Harvey, W.S., 2011. Strategies for conducting elite interviews. Qualitative Research, 11(4), pp. 431-441. Available at: http://qrj.sagepub.com/content/11/4/431.abstract

Haynes, C. C., Chaltain, S., Ferguson, J. E., Jr., Hudson, D. L., Jr., \& Thomas, O. (2003). The first amendment in schools: A guide from the first amendment center. Alexandria, VA: Association for Supervision and Curriculum Development.

Head, B. W., \& Alford, J. (2013). Wicked problems: Implications for public policy and management. Administration \& Society, 47(6), 711-739. Sage doi: $10.1177 / 0095399713481601$

Heifetz, R. A. (1994). Leadership without easy answers. Cambridge, MA: Belknap Press of Harvard University Press.

Heiman, S. (2010). The J-School: Celebrating one hundred years in journalism and the 
reynolds journalism institute dedication, Virginia Beach, VA: Donning Company Publishers.

Herndon, K., \& Krueger, V. (2016). Leadership training in an industry context: Preparing student leaders for a chaotic news media. Journal of Leadership Education, 15(2), $48-57$.

Hess, K. (2015). Making Connections. Journalism Studies, 16(4), 482-496. doi:10.1080/1461670X.2014.922293

Hesse-Biber, S. (2004). Approaches to qualitative research. New York, NY: Oxford University Press.

Hollifield, C. A., Wicks, J. L., Sylvie, G., \& Lowrey, W. (2015). Media management: A casebook approach (5th ed.). New York: Routledge.

Hopkins, D., Raymond, M. and Carlson, L. (2011). Educating Students to Give Them a Competitive Advantage, Journal of Marketing Education 33(3), 337-47.

Jaakkola, M. (2014). Dismantling the crisis of journalism: Outline of an analytical approach. Teaching Journalism \& Mass Communication, 4(2), 1-14.

Jenkins, H., (2009). Confronting the challenges of participatory culture: Media education for the 21st century. Cambridge, MA: MIT Press.

Johnson, P. R. (2017). Communication: Journalism education today, going onward and upward, Journalism Educator Association. 51(1), 28-30.

Killebrew, K. C. (2003). Culture, creativity and convergence: Managing journalists in a changing information workplace. International Journal on Media Management, $5(1), 39-46$.

Konkle, B.E. (August 2008). "“Periodical' pursuits: A bibliographical listing of 
scholastic journalism articles published in noteworthy national education journals." Presented at the Association for Education in Journalism and Mass Communication convention, Chicago.

Koss, L.V. (1927). The American secondary school. 609-613, Boston: Ginn and Co.

Kouzes, J.M. \& Posner, B.Z. (2002) The leadership challenge: How to get extraordinary things done in organizations. San Francisco: Jossey-Bass.

Kovach, B., \& Rosenstiel, T. (2014). The elements of journalism: What news people should know and the public should expect (3rd ed.). New York, NY: Three Rivers Press.

Krueger, R. A., \& Casey, M. A. (2015). Focus groups: A practical guide for applied research (5th ed.). Los Angeles, California: Sage.

Küng, L. (2017). Going digital: A roadmap for organizational transformation. Digital News Publication. Retrieved from Oxford University, Reuters Institute for the Study of Journalism website www.digitalnewsreport.org/publications/2017/goingdigital/

Kurtz, L. (1980). The electronic editor. Journal of Communication, 30(3) 54-57.

Laufer, S., Butler-Vanderlinden, M., Carlin, E., Saker, L., \& Taylor, M. (2018). The making of a symposium: Democratic education, student leadership, and professional mentorship in high school journalism, Education, 15(2), 247-265.

Levine, P. (2008). A public voice for youth: The audience problem in digital media and civic education. In W. L. Bennett (Ed.), Civic life online: Learning how digital media can engage youth (pp. 119-138). Cambridge, MA: MIT Press.

Lipschultz, J. H. (1990). Group work adds perspective in news, broadcasting classes. 
Journalism Educator, 45, 63-68.

Lockheed, M., Finkelstein, K., \& Harris, A. (1979). Curriculum and research for equity: Model data package. Princeton, NJ: Educational Testing Service.

LoMonte, F. D., Goldstein, A., \& Hiestand, M. (2013). Law of the student press (4th ed.). Washington, DC: Student Press Law Center.

Lowery, W. (2012). Journalism innovation and the ecology of news production: Institutional tendencies. Journalism \& Communication Monographs. 14(4), 211287.

Lundgren, G., Cutsinger, J., \& Herron, M. (2019). Journalism curriculum. Yearbook Guide, $10^{\text {th }}$ Ed. Marceline, MO: Walsworth.

Lynch, D. (2015). Above and beyond: Looking at the future of journalism education. Knight Foundation. Retrieved from John S. and James L. Knight Foundation website www.knightfoundation.org/features/journalism-education

Macdonald, I. (2006). Teaching journalists to save the profession: A critical assessment of recent debates on the future of US and Canadian journalism education. Journalism Studies, 7(5), 745-764. doi.org/10.1080/14616700600890414.

Marchi, R. (2012). From disillusion to engagement: Minority teen journalists and the news media. Journalism, 13, 750-765. doi:10.1177/1464884911431379

McCotter, Lynch, D. (2015). Above and beyond: Looking at the future of journalism education. Knight Foundation. Retrieved from www.knightfoundation.org/features/ journalism-education McGonagill, G., \& Pruyn, P. W. (2010). Leadership development in the U.S: Principles and patterns of best practice. ILA Webinars. Retrieved from Bertelsmann Stiftung 
Leadership Series website www.ilanet.org/members/directory/

downloads/webinars/2010.05-LeadershipDevelopmentinUSPresentation

McGregor, D. (1960) The human side of enterprise. New York: McGraw-Hill.

Medsger, B. (1996). Winds of change: Challenges confronting journalism education. Arlington, VA: Freedom Forum. Mensing, D. (2010). Rethinking [again] the future of journalism education. Journalism Studies. 11(4): 511-523. doi.org/10.1080/14616701003638376.

Mensing, D. (2010). Rethinking [again] the future of journalism education. Journalism Studies. 11(4): 511-523. doi.org/10.1080/14616701003638376.

Mensing, D., \& Ryfe, D. (2013). Blueprint for change: From the teaching hospital to the entrepreneurial model of journalism education. The Official Research Journal of the International Symposium on Online Journalism. Retrieved from University of Nevada, Reynolds School of Journalism website https://www.isoj.org/journal/volume-3-issue-2/

Merriam, S.B., \& Tisdell, E. J. (2016). Qualitative research: A guide to design and implementation (4th ed.). San Francisco, CA.: Jossey-Bass.

Mertens, D. M. (2005). Research and evaluation in education and psychology; Integrating diversity with quantitative, qualitative and mixed methods (2nd ed.). Thousand Oaks, CA: Sage Publications.

Mierzejewska, B. I., \& Hollifield, C.A. (2006). Theoretical approaches in media management research. In A. Albarran, S. Chan-Olmsted, and M.O. Wirth (Eds.), Handbook of media management and economics (pp. 37-65). Mahwah, NJ: Erlbaum. 
Mierzejewska, B.I. (2011). Media management in theory and practice. In M. Deuze (Ed.), Managing Media Work (pp. 13-30). Thousand Oaks, CA: Sage.

Mintzberg, H. (1979). The five basic parts of the organization. In J.M. Shafritz, J. S. Ott, \& Y. S. Jang (2005) (Eds.), Classics of Organization Theory (pp. 219-230). Belmont, CA: Wadsworth.

Missouri Interscholastic Press Association. (2019). J-Day Awards List [Data file]. Retrieved from www.mipajournalism.com/j-day-awards-lists/

Missouri Interscholastic Press Association, (2019) It's All Journalism. Missouri School of Journalism. Retrieved from https:/mipajournalism.com/about-us/mipa-history/ Missouri Department of Higher Education. (2011). Statewide academy program review: Report to the governor. Jefferson City, MO: Missouri Department of Higher Education.

Mulrennan, D. (2018). Mobile social media and the news: Where heutagogy enables journalism education. Journalism \& Mass Communication Educator, 73(3), 322333. doi.org/10.1177/1077695817720762

Murphy, J., \& Hallinger, P. (2001). Characteristics of instructionally effective school districts. The Journal of Educational Research, 81(3), 175-181.

Nadler, D.A., Gerstien, M.S., \& and Shaw, R.B. (1992). Organizational architecture: Designs for changing organizations. San Francisco: Jossey-Bass.

National Coalition Against Censorship, (2019) The First Amendment in schools: A resource guide. National Coalition Against Censorship. Retrieved from https://ncac.org/resource/first-amendment-in-schools

Neeley, J. C. (2015). Plugging in: Possibilities for connecting teens and communities 
through scholastic and non-scholastic youth media websites. Youth \& Society, 47, 565-585. doi:10.1177/0044118X13483776

Nelson, J., \& Lewis, D. (2015). Training social justice journalists: A case study. Journalism \& Mass Communication Educator. 70(4) 394-406. Thousand Oaks, CA: Sage. doi:10.1177/1077695815598613

Newton, E. (2018). The teaching hospital: A goal for journalism education. Knight Foundation. Retrieved from John S. and James L. Knight Foundation website www. knightfoundation.org/speeches/teaching-hospital-goal-journalismeducation.

Newton, E. (2018). Journalism education reform: How far should it go? Knight Foundation. Retrieved from John S. and James L. Knight Foundation website www.knightfoundation.org/speeches/journalism-education-reform-how-farshould-it-go

Niblock, S. (2007). From knowing how to being able, Journalism Practice, 1(1). 2032.doi:10 .1080/17512780601078829

Northouse, P. G. (2016). Leadership: Theory and practice (7th ed.). Los Angeles, CA: Sage.

Novak, D. (2013). Take people with you. Leadership Excellence, 30(2), 13.

O'Dell, D. (1935). The history of journalism education in the United States, New York: Teachers College, Columbia University.

Örnebring, H. (2019). Journalism cannot solve journalism's problems. Journalism, 20(1), 226-228. doi.org/10.1177/1464884918808690

Osborn, P. (1998). School newspaper advisers: Survival Guide. Prentice-Hall 
International Limited: London.

Pavlik, J. V. (2013). A vision for transformative leadership: Rethinking journalism and mass communication education for the twenty-first century. Journalism \& Mass Communication Educator, 68(3), 211-221.

Pearce II, J.A. \& David, F. (1987). Corporate mission statements: The bottom line. The Academy of Management Executive, 1(2): 109-116.

Perez-Latre, F. J., \& Sanchez-Tabernero, A. (2003). Leadership, an essential requirement for effecting change in media companies: An analysis of the Spanish market. International Journal of Media Management, 5(3), 198-208.

Poerksen, B. (2010). The didactic challenge. Journalism Practice. 4(2), 180-191, doi:10.1080/17512780903172056

Posetti, J. (2018). Time to step away from the bright, shiny things: Towards a sustainable model of journalism innovation in an era of perpetual change. Digital News Publication. Retrieved from Oxford University, Reuters Institute for the Study of Journalism website www.reutersinstitute.politics.ox.ac.uk/ourresearch/time-step-away-bright-shiny-things-towards-sustainable-modeljournalism-innovation-era

Quinn, S. (2016). Mojo and the mobile journalism revolution. In I. Burum \& S. Quinn (2016) (Eds.), Mojo: The mobile journalism handbook: How to make broadcast videos with an iphone or ipad (pp. 10-25). Burlington, MA: Focal Press.

Reading, C. (2002). Strategic business planning: A dynamic system for improving performance and competitive advantage. London, England: Kogan.

Reed, K. (2014). Before the "teaching hospital model" of journalism education: Five 
questions to ask. Nieman Lab Retrieved from the website doi:

www.niemanlab.org/2014/10/before-theteaching-model-of-journalism-education5-questions-to-ask/

Reese, S. D. \& Cohen, J. (2000). Educating for journalism: The professionalism of scholarship, Journalism Studies. 1(2), pp. 213-227.

Rheingold, H. (1993). The virtual community: Homesteading on the electronic frontier, Reading, MA: Addison-Wesley.

Rice, D., Delagardelle, M., Buckton, M., Jons, C., Lueders, W., Vens, M., Joyce, B., Wolf, J., \& Weathersby, J. (2001) The lighthouse inquiry: School board/superintendent team behaviors in school districts with extreme differences in student achievement. Paper presented at the annual meeting of the American Educational Research Association, Seattle, WA.

Robertson, S. (2002). In student publications, leadership is necessary, and its quality is a significant success factor. Quill and Scroll, 76(3), 10-11.

Robins, W. (2000). King of convergence. Editor \& Publisher, 133(42) 12-17.

Robinson, S. (2013). Teaching "journalism as process": A proposed paradigm for Jschool curricula in the digital age. Teaching Journalism \& Mass Communication, 3(1), 1-12.

Rosen; J. (2018). Part of our world: Journalism as civic leadership. Journal of Discourse Leadership. 1-16. Retrieved from http://www.upenn.edu/pnc/ptrosen.html Royal, C., (2018). Coding the curriculum: Journalism education for the digital age. Global Journalism Education in the 21st Century Challenges \& Innovations. 
Retrieved from Knight Center for Journalism in the Americas website www.knightcenter.utexas.edu/ books/GlobalJournalism.pdf.

Ryfe, D. (2012). Can journalism survive: An inside look at American newsrooms. Cambridge, UK: Polity Press.

School of Journalism (2019). A brief history. Missouri School of Journalism. Retrieved from https://journalism.missouri.edu/jschool/

Scott, K. (1986). Learning sex-equitable social skills. Theory into Practice, 25, 243-249.

Siebert, F. S., Peterson, T., \& Schramm, W. (1963). Four theories of the press. Chicago, IL: The University of Illinois Press.

Silcock, B. W. \& Keith, S. (August, 2002). Translating the tower of babel: Issues of language and culture in converged newsrooms a pilot study. Paper presented at the Association for Educators in Journalism and Mass Communication conference, Miami, Florida.

Simon, H. A. (1996). The sciences of the artificial. 3. Cambridge, MA: MIT Press.

Stake, R. (1995). Qualitative research: Studying how things work. News York. The Guilford Press.

Stapp, M. (October, 2013). Scholastic journalism: Skills for the $21^{\text {st }}$ century. The Education Digest. America Association of School Administrators, 30-34. Streisel, J. (2007). High school journalism: A practical guide. Jefferson, North Carolina. McFarland \& Company, Inc. Publisher.

Student Law Press Center (2019). Law of the student press, (6 ${ }^{\text {th }}$ Ed.) Arlington, VA: Student Press Law Center.

Student Law Press Center (2019). Courage in student journalism award: Goes to Utah 
couriers of democracy who launched a news website after their school censored them. Student Press Law Center. Retrieved from https://splc.org/?s=student+journalism

Spears, H.J. and C. H. Lawshe. (1939). High school journalism: A course of study built around the school newspaper. New York: Macmillan.

Sutton, A. (1945). Education for journalism in the united states from its beginning to 1940, Evanston, IL: Northwestern University.

Unknown author. (2001a). Dotgone. Economist, 358, 8215, 56- 57.

UNESCO (2007). Model curricula for journalism education. Retrieved from http://unesdoc.unesco .org/images/0015/001512/151209E .pdf

Vicere, A. A., \& Fulmer, R. M. (1998). Leadership by design. Boston, MA: Harvard Business School Press.

Weinberg, S. (2008). A journalism of humanity: A candid history of the world's first journalism school. Columbia: University of Missouri Press.

Wenger; D., Owens; L., \& Cain, J. (2018). Help wanted: Realigning journalism education to meet the needs of top U.S. news companies. Journalism and Mass Communication Educator; 73(1); 18-36. doi.org/10.1177/1077695817745464.

Wenner, K. (2001). Downsized dotcoms. American Journalism Review, 23(2) 40-41.

West, D. M., Whitehurst, G. J., \& Dionne, E. J., Jr. (2009). Invisible: 1.4 percent coverage for education is not enough. Governance Studies, Brookings Institution.

Westbrook, R. (2019). SJW editorial leadership. Columbia Scholastic Press Association. Retrieved from https://cspa.columbia.edu/summer-journalismworkshop/classes-offered/sjw-editorial-leadership 
Wilderman, M., Nasrin, S., \& Davis, J. (2018). Budget cuts in scholastic media: A focus group study of Oklahoma journalism advisers’ survival skills, Journalism \& Mass Communication Educator. 1-14. doi.org/10.1177/1077695818787066

Windels, K., Mallia, K. L., \& Broyles, S. J. (2013). Soft skills: The difference between leading and leaving the advertising industry. Journal of Advertising Education, $17(2), 17-27$.

Yin, R. (2003). Case study research: Design and methods. Los Angeles. Sage.

Yukl, G., \& Van Fleet, D. D. (1992). Theory and research on leadership in organizations.

In M. S. Dunnette \& L. M. Hough (Eds.), Handbook of Industrial and Organizational Psychology. 3(2), 147-198. Palo Alto, CA: Consulting Psychologists Press. 


\section{APPENDIX}

\section{APPENDIX A \\ IRB APPROVAL FORM}

October 04, 2019

Principal Investigator: Julia Lewis (MU-Student)

Department: Educational Leadership-EDD

Your IRB Application to project entitled A qualitative study of scholastic journalism advisers teaching leadership in Missouri secondary schools was reviewed and approved by the MU Institutional Review Board according to the terms and conditions described below:

$\begin{array}{ll}\text { IRB Project Number } & 2016361 \\ \text { IRB Review Number } & 251502 \\ \text { Initial Application Approval Date } & \text { October 04, 2019 } \\ \text { IRB Expiration Date } & \text { October 04, 2020 } \\ \text { Level of Review } & \text { Exempt } \\ \begin{array}{l}\text { Project Status } \\ \text { Exempt Categories (Revised Common }\end{array} & \text { Active - Exempt } \\ \text { Rule) } & \text { 45 CFR 46.104d(2) } \\ \text { Risk Level } & \text { Minimal Risk }\end{array}$

The principal investigator (PI) is responsible for all aspects and conduct of this study. The PI must comply with the following conditions of the approval:

1. No subjects may be involved in any study procedure prior to the IRB approval date or after the expiration date.

2. All changes must be IRB approved prior to implementation utilizing the Exempt Amendment Form.

3. The Annual Exempt Form must be submitted to the IRB for review and approval at least 30 days prior to the project expiration date to keep the study active or to close it.

4. Maintain all research records for a period of seven years from the project completion date.

If you are offering subject payments and would like more information about research participant payments, please click here to view the MU Business Policy and Procedure: http://bppm.missouri.edu/chapter2/2_250.html

If you have any questions or concerns, please contact the MU IRB Office at 573-882-3181 or email to muresearchirb@missouri.edu.

Thank you,

MU Institutional Review Board 


\section{APPENDIX B}

\section{INTERVIEW PROTOCAL INTERVIEW QUESTIONS FOR HIGH SCHOOL JOURNALISM ADVISERS}

1. Tell me about yourself.

a. What is your name and how do you spell it? b. Where did you grow up?

c. What was your major? d. Hobbies/Interests?

2. Tell me about your position here?

a. Which courses do you teach? b. Grade levels? c. Content areas? d. How long have you been in this position? e. Why did you become a journalism teacher?

3. How is learning defined within your news labs structure?

a. How is learning measured in this context - grades, deadlines, production in your news lab?

4. How do you approach leadership in your news lab?

5. How is leadership defined within your news labs structure?

6. What inspires your leadership practices within your news lab?

7. Who are the external stakeholders (people/organizations) that inform or shape how your students leadership is demonstrated in your news lab?

a. What are the connections between decision making and students' leadership in your production process?

8. What forms of leadership assessment or evaluation are used in your news lab overall?

a. What are the connections between leadership and data collection, learning, and/or your organizational success?

9. What defines your news lab's success?

10. How do you believe your leadership aspects promote or hinder equitable access and outcomes for those within your news lab?

11. What resources help you develop leaders within your news lab?

12. What is your leadership philosophy?

a. How do you see it inspiring a shared vision?

b. How does it encourage your students' hearts? 
13. How do your students learn by doing journalism?

a. How does their learning challenge the process in your news lab?

14. How do your students become leaders by doing journalism?

a. How do you model the way for your students to be leaders?

b. How do you enable your students to act?

15. What else do I need to know? 
APPENDIX C

INTERVIEW QUESTIONS LINKED TO RESEARCH QUESTIONS

Interview Questions Linked to Research Questions

\begin{tabular}{|c|c|}
\hline Interview Question & Research Questions \\
\hline 1 & 3,4 \\
\hline 2 & 3,4 \\
\hline 3 & 1,2 \\
\hline 4 & $1,2,3,4$ \\
\hline 5 & 1,2 \\
\hline 6 & 3,4 \\
\hline 7 & 3,4 \\
\hline 8 & 3,4 \\
\hline 9 & $1,2,3,4$ \\
\hline 10 & $1,2,3,4$ \\
\hline 11 & 4 \\
\hline 12 & 3,4 \\
\hline 13 & $1,2,3,4$ \\
\hline 14 & $1,2,3,4$ \\
\hline
\end{tabular}




\section{APPENDIX D}

\section{PERMISSION REQUEST LETTER FOR MIPA ORGANIZATION}

\section{Dear Christina Geabhart,}

It was such a pleasure to connect this summer. You significantly helped me gather information for my recently approved Dissertation Proposal. Overall, my study will strive to reveal Missouri's journalism advisers' editorial leadership teaching methods. I will investigate high school news labs by citing skills students gain from participating in leadership training programs.

I would like to request your permission to further explore MIPA aspects through my upcoming research, which is needed for my IRB approval. It would be greatly appreciated if I could use the organization's online database and interview MIPA high school advisers. I am excited to begin scheduling interviews and observations with MIPA's award winning advisers during October and November. Please grant my study your permission to include MIPA within my research by simply replying with your consent via email, by "Julie Lewis has permission to access the Missouri Interscholastic Press Association online database and interview high school advisers for her upcoming study".

In addition to fulfilling my dissertation requirements, I hope it can provide you with some useful information to help guide advisers' effective practices. As I move forward, I am looking forward to presenting at MIPA's upcoming J-Day to offer the study's findings. I will get you the items you requested and confirm the finalized dates and times, as March 25 approaches.

Don't hesitate to reach me via email or phone at 816.813 .0446 if you have any questions or desire further information.

Thank you in advance kindly, Julie Lewis 


\title{
APPENDIX E \\ INDIVIDUAL INTERVIEW CONSCENT FORM \\ Individual Interview Consent Form CONSENT FORM TO PARTICIPATE IN A RESEARCH STUDY
}

\author{
Researcher's Name(s): Julia Lewis \\ Project Number: \#2016361 \\ Project Title: Exploring editorial leadership: A qualitative study of scholastic journalism advisers teaching \\ leadership in secondary schools in Missouri
}

\section{STUDY SUMMARY}

You are being asked to participate in a research study that I am doing to investigate the methods of Missouri scholastic journalism advisers use to teach leadership skills. We are doing this study to gain data on advisers' current skills, practices, and experiences. We invite you to take part in this research study, because you are an MIPA award winning journalism adviser When you are invited to participate in research, you have the right to be informed about the study procedures so that you can decide whether you want to consent to participation. Please ask me any questions you have as we go through this form. If you decide to take part in this study, you will receive a copy of this form

Your participation in this study is voluntary. You do not have to be in the study if you do not want to. You may refuse to be in the study and nothing will happen. If you do not want to continue to be in the study, you may stop at any time without penalty.

\section{WHAT AM I BEING ASKED TO DO?}

You will be asked to answer questions during an interview with the researcher about your current skills, practices, and experiences as a Missouri scholastic journalism adviser. During the interview, I will take notes and use an audio recorder to record the interview. Interviews will last approximately 30-60 minutes and you may be contacted for follow up questions in the weeks following the interview.

\section{WHO DO I CONTACT IF I HAVE QUESTIONS, CONCERNS, OR COMPLAINTS?}

You may ask questions, voice concerns or complaints to the researcher, Julia Lewis, jlewis@ucmo.edu. Additionally, you may contact Sandy Hutchinson, Dissertation Chair, Hutchinson@ucmo.edu if you have questions about the research.

If you have any questions regarding your rights as a participant in this research you may contact the University of Missouri Institutional Review Board at (573) 882-3181 or rb@missouri.edu. If you have any questions right now, I'd be happy to answer them.

\section{Signature of Participant}

By signing my name below, I confirm the following:

- I have $\mathrm{read} / \mathrm{had} \mathrm{read}$ to me this entire consent form.

- All of my questions were answered to my satisfaction.

- The study's purpose, procedures/activities, potential risks and possible benefits were explained to me.

- I voluntarily agree to take part in this research study. I have been told that I can stop at any time. 


\section{APPENDIX F \\ PARTICIPANT INTERVIEW REQUEST EMAIL}

Hello, Ms. XXXX,

I hope all is going well at SCHOOL.

After two decades of teaching journalism, I am officially jumping into my dissertation. Currently, I am a doctoral student at the University of Missouri's Educational Leadership Policy and Analysis Cooperative Program. My research is striving to reveal how journalism advisers effectively teach journalism. Your involvement and students' awardwinning work with the Missouri Interscholastic Press Association (MIPA) has put me in your direction.

I would appreciate the opportunity to ask you a few questions about your expertise to greatly enrich the study. We can connect at SCHOOL or over the phone. Please let me know which of the following dates are a fitting time from 7 a.m. to 4 p.m., to meet the convenience of your schedule for an interview within the next few weeks:

- DATE

- DATE

- DATE

Our brief time together should take no longer than 20 minutes. It is important to note that this study is intended to be for my dissertation and all of your responses will be kept confidential. If you choose to participate, I would like to offer you an executive summary of the study's results. Additionally, I will be presenting the findings at MIPA's upcoming J-Day.

Don't hesitate to reach me via email or phone at PHONE if you have any questions or desire further information.

Thank you in advance kindly,

Julia Lewis 


\section{APPENDIX G}

\section{CONFIRMATION EMAIL}

\section{Dear XXX,}

Thanks so much for your prompt response.

It would be fantastic to connect TIME, DATE at PLACE.

Also, before then, I have attached a few questions if you wish to reflect a bit before we meet.

Looking forward to hearing your expertise and perspectives in a few weeks. Thank you very much for your time as well as opening your news lab for my upcoming study. It is my honor and I am looking forward to be working with you.

Please feel free to connect with me via email or phone at PHONE if you have any questions or desire further information.

Best -- Julia 


\section{APPENDIX H}

THEMES

Four emergent themes were identified from the analysis of data and the implemented coding system: Advisers Engaging Students, Advisers Teaching Leadership, Advisers Empowering Students, and Advisers Impacting Students. These

themes were supported, respectively, by the ideas of a community of learners, establishing teamwork, and meeting student learning needs; ideas of accountability, expectations, motivation, and strengths; ideas of safe environment, and taking action; and ideas of enthusiasm, trustworthiness, and influence.

Theme I: Advisers Engaging Students

Advisers engage already a variety of established leaders in their high schools to be part of their news lab. Relatedly, the Journalism teachers see learning as a critical process. They actively engage students in leadership opportunities by building a community of learners, creating the news lab as a team, and individualizing their instruction to meet each student's needs.

\section{Building a Community of Learners}

Community emerged as a central concept for supporting the theme of Advisers Engaging Leaders. All of the award-winning advisers created learning communities with strict standards for entry. Additionally, they inspired their students to want to learn the technical skills to become a student journalist. Becoming accepted into a scholastic journalism class provides students an opportunity to learn basic skills and become immersed into their news lab norms. 
High Entrance Requirements. Advisers hold high standards for news lab entry by creating an initiation process and looking for leadership skills in their applicants. Annually, advisers recruit students to be part of their news labs' community of learners. All 24 advisers require a minimum of a written application and a grade point average standard, while four have additional requirements. Having prerequisites and a written application process establishes value by being accepted in the course as an accomplishment itself. Liza expressed her gratitude in having an admittance process. She said, "I love that I have the ability to select students that will be the right fit. I think it makes a huge difference. The high standards actively prove the students desire to belong and build into the news labs' achievements before starting class, then proving how much they want to be part of the news lab."

Advisers create learning communities through high standards and having prospective students actively show their desire to belong through applying to be in the class. In the application process, advisers ask a variety of questions to determine if student shall be admitted in the class. Advisers shared the process is critical to ensure students are ready to be part of the community of learners as they work to become news lab leaders. Having prerequisites and a written application process establishes value by being accepted in the course as an accomplishment itself.

Two advisers revealed applications to be their news labs' first step providing a challenge and a reward. Lydia believed, "the students feel a high accomplishment just coming into this class. They know they have achieved their spot. The application process helps a lot to acknowledge each student belongs and has the ability to meet the news labs challenges." Another adviser recognized the set application standards and class 
equipment provide a design that presents very little resistance to the admittance decision process. Eli teaches two sections and has to limit to 20 students enrolled because the news lab has 20 computers. He explained, "I want to say 60 or 70 students sign up for the class. So that means there are several that get cut, there's probably anywhere between 40 and 50 kids not getting into the course." He further explained, "the student selection process brings competition, while setting our standards. Our grade policy makes the decision for us that we don't need to admit a D- student."

Advisers shared their journalism class prerequisites reveal how much students want to be part of the class. Another adviser recognized their written application standards to be objective and professional. For instance, Sloane said her yearbook class' written application treats the process as if the students were in a professional job interview by requiring the following: application, grade evaluation, teacher recommendation, portfolio with writing and photography samples, and a practice interview with the interviewee's feedback form.

The advisers further shared that, each year, many keep their same written application but change their process. For example, Sam includes her student editors in their application process by having the editors do interviews while she observes.

Developing Student Journalists. Advisers teach and inspire students to develop their skills. In journalism education, leadership skills develop through a specific set of soft skills. Initially, advisers teach hard skills such as law, ethics, writing, photography, and interviewing. Second, students engage in opportunities to develop their soft skills such as critical thinking, problem solving, team collaboration, interpersonal skills, and work ethic. Specifically, the critical writing and publishing process in the news labs 
provides advisers with opportunities to teach soft skills, but ultimately aid students in developing into effective leaders. For example, Sandy confirmed how soft skills are essential for her news lab. "The basics essentially come down to the soft skills, which are talked about so much in my business classes. We cover our standards: be on time, help others, set a good example, and be confident," she said. All advisers commented specifically on the importance of journalism standards and ethics being taught in the first semester. Additionally, during the first year, students are supported with verbal praise and incentives. The veteran team members are provided with the opportunity to teach and support the news students.

Once hard skills are mastered, advisers teach soft skills. Through a variety of ways, advisers teach leadership by developing soft skills. Lydia believes her staff grows in journalism by learning new skills and developing their personal traits, "There is individual growth with each of the staffers when they go from their first issue to their third, or they take on a more challenging story that is a fantastic idea. That's when I really notice, and we're being successful."

Advisers identified the practical application of soft skills as a critical process that better prepares students to be effective leaders throughout their production process. More specifically, Eva's techniques strongly represent the vast majority of advisers who set a standard for editorial leadership by teaching the nuances of professional journalism that people seldom mention, but all professionals know. Specifically, the All-Missouri journalism instructors in this study created successful news labs through developing students to instill a sense of etiquette, respect, and preparation. Lydia explained, "There is individual growth with each of the staffers when they go from their first issue to their 
third, or they take on a more challenging story that is a fantastic idea, that's when I really notice, and we're being successful."

\section{Establishing Teamwork}

While advisers build a community of learners, ritual celebrations are also used within their news lab's production process to develop a team. Advisers further engage their students to be part of their news lab community by recognizing student contributions. Advisers show appreciation for individuals as well as team excellence. They celebrate the news lab's values and victories, creating a spirit of community and family. Many advisers use key benchmarks within their production process to celebrate individual and team success, but more importantly to establish partnerships through the news lab. Furthermore, through celebrations and creative traditions, advisers form common bonds with their student staff members. Advisers use key points to celebrate with creative traditions to establish the news lab into a team of student journalists.

Celebrations. Although many advisers claimed their over-arching goal was to distribute their production to audiences, they also placed great importance on completing the workflow set by timely benchmarks. Therefore, advisers make it a priority to celebrate completed deadlines and distribution days with "D-Day" rituals. Similarly, advisers expressed the need to celebrate each deadline accomplishment by congratulating their whole news lab staff. Lucas said he is sure to observe staff exceeding the workflow process during a deadline cycle. "We had three kids that have gone above and beyond, so we were going to recognize them by talking about what they did that was beyond what we expect the average student to do." 
Similarly, advisers highlighted specific individual staff accomplishments through each story's feedback as "snaps and brag tags". Lydia also explained she permits the staff to edify each individual's work. She said, 'Everybody reads through each student's work to make a nice recognition, 'snap', at the end of each production. Then, each staff member gets recognized through the written "snaps"”.

The editors do it as a nice recognition at the end of each publication. My editors know, too, when we edit drafts, don't only write what they can improve, acknowledge what they do well, so that they don't get disheartened, because a lot of it, especially in the beginning. Especially, when they like massively to go out of their way, or they had to overcome something, and making sure that they feel like all their hard work is acknowledged, because it is a stressful class, and its very time consuming. So just making them aware that like all of the hard work they're putting into it is being recognized, one-on-one.

Advisers explained part of their news lab ritual is to give student staffers appreciation and support. According to 19 respondents, the decision to provide positive experiences and feedback established a benchmark for the students and the advisers throughout their workflow process.

Creative Traditions. Many advisers said news labs provide a positive environment with creative celebrations throughout each step of the process, such as tshirts, pep talks, editors' talk, food, and bonding nights. According to the respondents, the decision to find creative ways to celebrate as a whole news lab helps the group find a group identity. Sarah explained her news lab annually celebrates with their entire high 
school with a formal dance, which originally was a fundraiser and has since evolved into a celebration of their publication.

Erin also has creative traditions to celebrate. Her senior students have a tradition to wear journalism sashes at their high school's graduation ceremony. She described: When we got journalism sashes a couple years ago, I was looking at just that special acknowledgement because for a lot of students this might be the only extracurricular type of class that they do, and it's still a class, but it is kind of an extracurricular, and just that sense of community that they build within themselves. It showed they enjoy each other's company, working together. It's special to watching that final product come about and watching how much they grow, both as people and as students, I think that's just the most rewarding part and it's important to celebrate it.

Lydia also has a journalism sash tradition for their school's senior graduation ceremony. She explained, "I was looking for that special acknowledgement for our graduating seniors. It started because for a lot of or students this might be the only extracurricular they do. They need that sense of community that they build within themselves." Similarly, Elizabeth finds the staff becomes more coherent each time she and her editor present a creative way to celebrate. For example, her previous editor made a hand-crafted sash for their own news lab celebrations, which the awarded student may wear for the week. She said, "Everybody cheers, and claps. They all just love it."

A number of advisers are creative with their student celebrations through periodic team-building and reflection exercises. The self-care exercises are used as a motivation for the advisers to help their staff gain comfortability as writers individually and as a 
team. Elizabeth's news lab takes a break from their typical newsroom routine to ensure self-care. "We take little breaks to build everybody up and make sure the staff's health is okay. If it's not, then nothing's going to get done," Elizabeth further described that she brings in a treat and does psychological exercises to reveal individual character traits through fun traditions. "Everybody enjoys. So, when we are done, we come out with the kids being so much more relaxed," she said. Leah further explained the importance of caring for her students. She said, "That to me it seems like it goes a long way for teenagers to realize that adults do care. Adults outside of their parents." These small acts of kindness were not only common among the different schools, but were purposefully done to help meet the different needs for each student.

Awards. Although students are awarded state and national recognition, advisers provide in-house awards for every deadline cycle such as best story, best design, as well as leadership awards to find staff members who embody journalism principles and leadership. Advisers explained it is a priority to recognize individual accomplishments and include the whole staff. For example, Mary annually distributes award certificates by reviewing all fall photos and pulling out the 'Best of the Best Photos'. She explained, "You might think sophisticated high school kids would go 'ugh', but they love it, they love that pat on the back. Even if it's just recognition within the class." As a result, rewarding good work sets the standard for best journalism practices.

\section{Meeting Student Learning Needs}

Advisers help each student learn leadership skills in a variety of ways. Many advisers shared that differentiating instruction meets each student's needs and helps students master journalism skills. 
Individual Growth. Advisers also revealed their success is developing their students into leaders. Laura explained:

My biggest success is watching them develop through the program and bloom so much, especially, because I see most of my kids go through three or four years of high school. So, I see them I see them develop. My most recent editor, who graduated last year, she started in the class as a freshman, and she was very shy. She would turn red whenever she had to talk to people. Now she is able to be a leader.

Lydia revealed she has a passion to develop students' success. "It is awesome watching the staff throughout their journey. I know when they leave they have skills they're going to need for real life. They don't need to sit in a desk and read out of a book, but they can manage their time, seek out sources, and communicate with people well," she said.

Many advisers commented they first develop their students' skills by setting goals with students based upon the student's performance. Additionally, advisers also reflect with students about their progress and goals. Advisers said success is when they see a student develop into a leader. Advisers further explained they view each student's success based on growth from their initial skill level throughout the year. Eva viewed her students' true learning as coming from an "organic skill development." She explained that there is no way for her to put in place specific times for each of her students to master a specific skill. So, she looks to find how each student develops each skill as they learn. Ultimately, she and the majority of advisers believed that consistent skill development and reflection leads to success. The majority of advisers believed that consistent development discussion pushed the staff to excel. The advisers believe when 
students complete a challenging story they feel a sense of accomplishment and tend to get recognition for those stories which become a driving force for development. Laura explained:

My biggest success watching them develop through the program and bloom so much. Especially, because I see most of my kids go through three or four years of high school. So, I see them I see them develop. My most recent editor, who graduated last year, she started in the class as a freshman, and she was very shy. She would turn red whenever she had to talk to people. Now she is able to be a leader.

Determining Goals. Advisers believe discussion about the goals pushes their students to excel. Differentiating instruction helps student's overall performance. This thought was reiterated by Sam, "I conference with them and sit down, and we talk about their grades. We talk about what they've done this semester. So, in that conference, I sit there, and we have dialogue, and we have conversation. Then, I can gauge that aspect of their learning. It is just a verbal confirmation that they know what they're doing and they're doing well." Additionally, five advisers look at the start of the year of how the staff started and ended the year. Sarah compares and contrasts students' products to see visible improvement throughout each year. "I do a lot to see where a student started and where they are now. A lot of people use rubrics, I don't get that [inaudible] picky. I think you're either growing or you're not. And that's where that compare contrast comes from." While Emily responded:

It's really developing the practical skills. And then from there, it's just their progress throughout the semester. At the very end of the year, their final project is 
to go back and scrapbook their stories and re-evaluate. They can rewrite their leads or talk about what they were most proud, and how they would have changed their stories. It's really amazing to see how much they've grown as writers and as journalists.

This thought was reiterated by Sam, "I conference with them and sit down, and we talk about their grades. We talk about what they've done this semester. So, in that conference, I sit there, and we have dialogue, and we have a conversation. Then, I can gauge that aspect of their learning and that is just verbal confirmation that they know what they're doing and they're doing well.” Erin believes accountability tools, as scoring guides, are needed to keep high standards of her school's highly driven culture. "I have to use rubrics. I have to justify the student's grade with rubrics because they're very serious. Almost too high stress, because these are the kids arguing about two points," she said.

Differentiated Instruction. Numerous advisers articulated differentiating instruction teaches the same journalism material to all students by using a variety of instructional strategies and delivering targets at varying levels of difficulty based on each student. If a student is actively engaged in mastering a skill, then the learning objective may be met.

The data revealed it is imperative to accommodate each student needs to ensure individualized success. Ellen believes true learning comes from development and oversees her students' progress to evaluate whether students "get it or they do not". She further explained,

If my kids feel good about what they've done, and I can see improvement, and really that's what it's about. Success is, do they feel good at the end of the year? 
Are they proud of what they've done? The show airs to everybody in the school. And so, I send it home to parents and everything. So, to me I think that's the success. I increase the kids that enter contest, we will enter every year. And do I like to win? Absolutely. But is that the defining piece for me? No, it's not. Lucas defined learning targets as short-term goals, which clearly state what students expect to know and be able to do at the end of the deadline cycle. He believes learning is a set of targets and the end product is the target goal. Eva further explained each year she connects her targets to her students' strengths and believes her grading system benefits the news lab. The majority of advisers shared their journalism course curriculum guided their learning and then they differentiate the instruction to impact students and the overall performance of the news lab. They further spoke of using targets to establish defined learning goals within their elective journalism classes. A minority of individuals identified grades to determine the context of workflow and product within each of the news labs' productions.

Similarly, Eva attempts to quantify her grading by using her "organic skill development" methods and communication. She permits each student to master each target within their own timeline, abilities, strengths, and weaknesses. In the same way, Ellen communicates instruction with students throughout each deadline process. She has found students may turn in a bad package, but she will not punish them with a grade. When comparing the adviser's sentiments on grading, there is a direct link in developing students' basic work skills through defined and accommodated targets, reflection, and one-on-one development methods. 
Ellen also finds grading to be an organic process and a difficult part with publications. She said, "There are certain criteria, which is fairly easy to grade. I've got a rubric to go through and that's fairly easy. When it comes to my producers and directors, they're either getting it together or they're not. So usually it's an A or it's an F. That's pretty much how I deal with those in those leadership positions."

Lexy explained her evaluation does not use a traditional grading process, "I very rarely grade because they all pass. We've never failed a $\mathrm{J} 2 \mathrm{kid}$. They produce the magazine, they produce a yearbook on time, meeting deadlines with minimal mistake. They think they've done their job. They earned their paycheck." When comparing the adviser's sentiments on grading, there is a direct link in developing student's basic work skills through defined and accommodated targets.

\section{Theme II: Advisers Teaching Leadership}

Teaching student editors to be leaders emerged as another common practice among news lab advisers, specifically the impact of advisers who teach leadership in scholastic news labs to individual student editors-in-chief (EICS). Supporting the identification of this theme, advisers elaborated on how the leadership skills they teach as well as their behaviors through news labs contributed to their development into leaders. Ultimately, these students become engaged members of their much larger learning community. Upon examining the way news lab advisers teach leadership, three specific fields emerged as almost a common curriculum: accountability, motivation, and developing individual strengths. 


\section{Focusing on Accountability}

Many advisers shared a common commitment to instilling accountability in their news lab leaders in order to maintain motivation in their labs. Four advisers specifically spoke to the need for student editors to be responsible for the news lab's workflow and

ultimately be responsible for their end product. The research specifically observed that all news labs had a designated area to display the news lab's production schedule with specific dates and names connected to each step of their deadline schedule.

To illustrate, Elise believes editors are responsible for the news lab workflow and accountable to the end product. She confirmed:

Holding them accountable is super important. Even though my editors are overseeing stories and tracking deadlines, I'm constantly making sure each are correct and on time. Even though I really know, I have to ask the editor because they need to be accountable to communicate it."

All of the 24 advisers commented they have students in editor positions throughout their news lab and provide them with specialized training and duties. Twelve of the advisers responded they have an editorial leadership class to permit editors to learn to be leaders. One respondent is even working with school district curriculum directors to develop advanced leadership classes as well. Eli believes there is a need to keep students accountable to specific soft skills. He teaches his students to be leaders. "It's all student led, but the students who are leading need to know how to lead. They need to be taught how to lead." Mary also expressed there is much discussion during her editorial leadership class to help editors work through keeping their staff accountable. There was 
such commitment to teaching accountability as a leadership trait that many advisers incorporated editorial leadership training as soon as they establish their goals.

Defining Leadership Roles. The data revealed each year the majority of the advisers establish the editors' roles and expectations depending on their student strengths. Sloane shared:

I give the editors roles; whether it's the editor-in-chief, assistant editor, daily news editor, or photo editor. The roles shift depending on how many kids I have in the class, but the expectations don't change. So, if I only have five kids, everybody's going to be a photo editor.

Advisers discover their student strengths and then define the news labs' leadership positions. Furthermore, advisers establish leadership positions and provide the editors with specialized training and duties. Leadership is taught to the core student leaders and the soft skills are expected to trickle down. Advisers instill their student leaders to be teachers and work side-by-side with their student staff, maximizing the news lab's full potential. In a similar manner, Sandy establishes levels of duty for each editor's role: It's not only a leadership role, there's a lot of layers to each expectation. An editor has the responsibility to double check everything from information to business ads. Then, I double check the editors' layers to make sure it's all edited and properly sent out.

Eleanor traditionally permits her students to start with small role opportunities to help build their leadership skills and, by the time they get to their senior year, she finds they have built the skills they need to be a strong editor. Similarly, Ellen watches for freshmen staffers to develop into news lab leaders. "I have really talented kids and I watch their 
talent grow," she explained. "Then, I wait to see how well they get along with the rest of the students and then I go from there.” Ellen further explained:

I have a senior editor and she is just a kid that kicks butt. She's never missed a deadline, never dropped the ball in four years. She demonstrated strong skills when she was a freshman. Her sophomore year, she helped with directing. Then, her junior year, she was already a producer and that doesn't happen a lot because

usually I have the seniors be producers. You don't find kids with that kind of work ethic very often, you just don't.

\section{Establishing Editor Expectations}

Advisers establishing accountability requires the students to be commited to the news lab's high expectations. Participants communicated editor accountability with clear expectations is a quality necessary for progress and sustained growth. Many advisers establish clear expectations students must meet to become news lab editors. The notion of clear expectations promotes the news lab to be consistently accountable. For example, Eli explained that his leaders must have the expertise of being in a journalism course for a full year before becoming an editor to know their expectations: "We get a lot of 'repeaters' not because of grades, but because they want to take on a leadership role. We have established expectations, so our leaders must have experience.” Establishing clear expectations for leaders of the news lab connects scholastic journalism with clear professional expectations.

\section{Motivating Leadership Instruction}

The researcher identified motivation as a strong facet of how advisers teach leadership. Once students became accountable to the news lab expectations, advisers 
begin motivating selected students to be leaders. Many advisers revealed they have the daunting responsibility of leading all students to perform to the best of their ability; however, the real motivation lies with their student editors to support the news lab's overall vision. All advisers commented motivation was required to complete their rigorous deadline schedules. Sarah continually coached her leaders and believes they are already self-motivated but need focus. Similarly, Laura explained the news lab's rigorous work flow and meeting these high expectations requires motivation: "It's overwhelming, but there are students that love what they do and that is half of the battle." Advisers cite motivation as a reason students show increased commitment to learning due to their news labs' common commitment to high professional standards and rigorous work ethic expectations.

Shared Vision. Effective leadership increases productivity and creativity throughout scholastic journalism news labs. The role of leadership helps advisers establish a common vision to motivate their student productions. Thus, advisers and students gain a mutual understanding of their leadership goals through a shared vision. News labs develop leadership beliefs in multiple ways. When asked, "How do you inspire a shared vision?" the advisers disclosed a variety of concepts directing the news lab's overall production workflow. During all interviews, these award-winning advisers all had one thing in common, a shared vision.

All the advisers commented they continually appealed to each student by articulating production goals and their editors pronounced their shared vision to their news lab. Common news lab slogans, positions, and procedures are essential for advisers to influence their students' effective production. 
Advisers' motivation drives the news lab's leadership. At the beginning of each school year, advisers facilitate traditions for students to create their news lab motto. The advisers lead their student editors to decide on a catch phrase and ideas to motivate their news lab. All the interviews, observations, and artifacts revealed news lab mottos were promoted through room decorations, posters, student t-shirts, and the overall news lab productions. Some of the advisers reported they reach outside of their news lab through books, music, and social media, for their news lab inspiration. Advisers went as far to facilitate their traditions at national conferences, leadership retreats, leadership retreats, and boot camps. These camps and retreats are structured to provide the student editors training to make the motto for the upcoming year. There was not one way to do this, but once the school year began, each news lab motivated the students through the continued use of their common vision. The different mottos enforced the news lab's shared vision. News lab mottos included Story is King, Create Magic, Hands off, Journalist 24/7, Beacon of Light, Make Good Choices, It sucks to suck. Don't suck, Get Out of the Way, Everyone has a Story, Be Coachable, For Us by Us, News for Students by Students, and Journalism Matters.

Elise's student editors attend a summer camp each summer. She explained how her shared vision of "Hands Off" was found during the students summer camp and translated into having a completely student driven news lab: "My editors organize our coverage. Our staff wants to all be part of our Friday night football games. The editors know where the staffers can be on the field and how to get the good shots. I just love watching. They definitely are like little moms helping our young ones." Elise further stated the editors know their common vision and the staffers can be intimidated, but they 
mentor them. She said, "They don't mind going to a softball game by themselves because they face their fear and learn how journalism works. It's huge growth that can't be taught in a classroom. Just watching it is perfection. We're showing them how to be leaders," she said.

Similarly, Lucas, has his student editors annually attend a national conference to make their motto. Recently, in preparation for their national conference at Disneyland they read the book "Creating Magic: 10 Common Sense Leadership Strategies from a Life at Disney" by Lee Cockerell. The book inspired the students to create their catch phrase of Create Magic. He explained how the book led to their news lab's vision to be a wonderful publication:

Disney was their answer because everybody wanted to go to Disney and be part of an idea that it's a wonderful, wonderful world. They wanted that wonderful, wonderful publication. They worked to create that magic and make their publication magic essentially. Something that everyone would want to be a part of and talk about.

The traditions that were put in place for the news lab's motto also help advisers provide agreed upon structure for positions and procedures. The advisers facilitate their student editors to decide on their assigned editor positions based upon the ideals of their shared vision. Leah believes an understanding of their "News for Students by Students" slogan has transformed her students into their leadership positions. She believes the students' understanding of their shared vision elevated the students to take ownership and effectively lead their workflow. Leah explained the vision helps her editors lead. She further explained her students develop their positions and the news lab procedures. As a 
result, her editors oversee the news lab before she becomes personally involved. She said, "The editors put out the fires all the time. The kids are aware of it and they understand the dynamic of it because they helped decide it." The importance of the student editor position was reflected through interviews as advisers marked time by their editor's name; rather than publication name or date. Throughout interviews advisers referred to their previous editors. For instance, Leah explained how each editor puts their stamp on the year's production, product, and overall morale throughout the news lab. She further illustrated, "I've had those great student editors throughout my whole career. Each has been part of a thread of students that have built our program throughout the years."

Advisers believe teaching leadership motivates students. The advisers revealed following common visions and expectations helps news labs to produce creative work based upon their genuine convictions. Advisers nurture their student leaders who, in turn, further build consensus to nurture a next generation of student leaders. Ultimately, high quality programs have a continuous cycle of leadership development that appears effortless.

Rigorous Standards. The data suggest advisers, while perhaps unintentionally, facilitate rigorous learning experiences in their practice on a regular basis. Specifically, advisers base their news lab's rigor on professional standards. For instance, Erin structures her advanced journalism classes with the same professional standards she experienced while working as a journalist in a newsroom. "What we do is a job, so they must get the job done. I tell them, 'I used to work in a newsroom, here's how it works"', she said. 
Intrinsic Motivation. Many advisers shared their need for student leaders to be self-motivated. Elise said, "I don't really have to convince them at all. I really think for most journalism kids, it is more an intrinsic motivation of, 'I want to do a good job because I feel responsible to my adviser, staff, and school."” Ellen supports a motivating environment for her students to want to do well and be present: "There is that innate desire in them, even though it might be a lot of work, but it's also a lot of fun, and the leaders have to continually ask 'What can I do to stay in' and 'Why did I take this class?"' she said. In the same way, Lucy and Mia commented on wanting students to have a personal passion for their goals. Lucy said, "They have to want it. When they're just handed something, or if they don't really have a passion for it, they're not always going to step up." Additionally, Lucy explained it can take time to cultivate a love for journalism. "I think it comes with time, I think it comes with experience." Most participants considered an editor's inner drive is necessary to meet the position's criteria. Also, advisers believed their elective course further develops students' personal desires because the class is not required by Missouri's Department of Elementary and Secondary Education.

Extrinsic Motivation. Although there are a variety of ways to implement a student-led news lab, the study highlights a variety of different practices. For example, the practice of being in a newsroom serves as the instruction for high achieving student leaders. Specifically, Sarah's student editors extrinsically motivate her staff. "Sometimes you just have to relieve some pressure. So, I have my editors, in their leadership role, nominate a journalist of the month and give a little candy bar or a gift card reward to somebody they want to recognize for outstanding work." 
Many advisers interviewed said they continually connect the news lab common vision and rigorous expectation to motivate students. Advisers are driven to connect the news labs to rigorous professional newsrooms expectations. Student leaders are motivated to make all news story decisions and be able to effectively communicate those decisions with their student staff members.

Advisers constantly communicate feedback during the writing process and at the end of each deadline. Emily establishes her professional standards by doing a critique process with her students. She explained how the critique process is needed to help students learn how to relate to the critique: "What's hard for the kids is when, I say 'No. Not good enough yet. We have to keep rethinking that.' And that's really hard because you're basically telling them their baby is ugly."

Elise motivates her students with rigorous professional newsroom expectation for her news lab. Her students are expected to go cover a story with her having to assign the student reporter. She revealed, "When those big things happen, that's when they run with it. They can see the big picture of, hey, let's do this. It's more of me just sitting back and advising, making sure that they're falling in line with school policy." Similar to Elise, Eleanor strives for her news lab to be student run. In the same way, Liza believes it is imperative to let students make their own decisions to follow their own established goals: “Advisers have to get out of their students' way. These kids who are passionate, have stories to tell or they're good at getting out of the way and letting somebody tell their story." In the end, most advisers agreed that setting up their news labs like a professional news room provided a more valuable authentic experience than just simply telling their kids what story to write. 


\section{Maximizing Strengths}

Advisers build on their students' strengths to not only develop their news lab leaders but to create an effective structure for the lab's work flow. While further developing news lab leaders' strengths, advisers focused on discovering individual potential and providing editorial leadership training for efficient workflow and effective feedback to their students.

Leah focuses on her students' strengths to build a team ready to communicate through their work flow. "It's a team with me constantly saying a lot to the editors like 'I think we should probably do this?"' I am always talking with them through most decisions. I do not tell the students what to do." Sarah uses her editors' strengths to lead, but ensures all of the students work together as a team as her editor's also have to write and do photography. She shared, "I have students who have different strengths, but when they get a story assignment, they're expected to do any photography elements for it as well as report the story. It's a small staff, so they are all part of the process." Lydia looks at her students' strengths to see how they may be a good editor and whether they have the experience. However, she is ready to adapt the editor roles if there is not a student with the strengths and experience needed.

Eli connects his students' strengths to their news lab assignments. He said, “Students' personality traits and their assignments are a bit connected." Elise also connects her leadership teaching with her students' strengths in many ways. The data revealed eight advisers use personality tests to find their students' strengths. Elise pointed out: 
I've had varied levels of success with that. Some years, it's worked out great. Some years, it always is great just to know. One year, I said. "Good lord, how are we all going to survive this?" But most years, I could effectively put them into little teams, from each category. Those have been really fun years to do that. It's fun to talk through that process. But like I said, some years it comes back to bite you.

Reaching Potential. News lab advisers do not just count on strengths that already exist. All the advisers commented on how they find joy in developing their students' potential as well. For example, Sloane provides her selected editors with opportunities to build their leadership skills. Like Sloane, Lydia notices potential in students to build their talent upon their current strengths. Sloane clarified that her process does not always select "a born leader" for her editor. She explained, "I strive to pick a student with the potential to be a great leader, but hasn't been given that opportunity because they're always up against that born leader."

Advisers help students discover their strengths to impact their news lab. Emily makes sure her editors reflect upon their own strengths. She explained, "You just have to talk to them straight because as a person, and especially as a leader, you have to know who you are. You have to know your own tolerance." In the same way, Leah helps her students make a conscious effort to invest in understanding who they are and those around them. She illuminated, "We are a big family, and we're going to have issues because one personality does not necessarily play nicely with another. But, just because it says on a piece of paper doesn't mean that we need to enact it. I want them to be aware of it and I will reference it every now and then." 


\section{Theme III: Advisers Empowering Students}

Advisers create nurturing environments helping students make their own decisions to take action. Empowering students to develop as journalists emerged as a common practice among advisers. Advisers build nurturing news labs so students learn leadership behaviors. This theme recognizes the need for advisers to positively influence and motivate their students. Creating a safe environment helps journalism students to seize the moment and take risks in their coverage.

\section{Creating a Safe Environment}

While advisers commented on their rigorous atmosphere, an overwhelming majority of advisers strive to create a supportive environment for discourse. A majority of advisers said they create supportive learning environments committed to students knowing they are safe. The news lab becomes a safe place to try, take action, to succeed, or fail. Advisers expressed a responsibility for creating an atmosphere committed to students knowing they have the ability to gain confidence in making decisions to produce a high-quality product.

All the advisers referred to their classrooms as either a newsroom, news lab, studio, lab, or second home. The advisers said their classrooms must resemble a professional news room and be a safe learning space.

The safe environment is created from the ground up. Many advisers used their students to help with their news lab set-up, design, theme, and clean-up to make their work flow more interesting and relatable. For example, each summer, Liza invites students to come and help set up her news lab for the upcoming school year. Likewise, 
Madison's deadline board was designed by her editors to provide student and teacher schedules.

Advisers create their news labs to continually develop student ideas. Eleanor sets up her news lab by providing student activities, such as jars of playdough, baskets of toys, stress balls, and a "designated creative seating lounge". She said, "Ten years ago, there were lines of desks in rows. I said, 'Oh God, I can't do it.' That reaction of mine came from walking off a career in journalism where I was used to thriving in a newsroom's chaos. My room is an organized chaos system. I found that if kids sat in desks, they couldn't brainstorm.” Like Eleanor, advisers believe even though their news labs are organized chaos it is a safe, nurturing place.

Liza knows her news lab can be chaotic and tells her substitute teachers her news lab will seem like a three-ring circus, but it is a well-oiled machine. She said, "Teaching journalism feels like there is so much work to be done the moment the bell rings. The 90 minutes is chaotic, like blow your hair back, 90 minutes. But when it's over, you know you've accomplished something with your kids." Advisers set their environments to help students feel comfortable within their rigorous deadline driven news labs.

Supporting Student Decisions. Advisers revealed they strive for their editors to take ownership of their news lab's production and decisions. All advisers revealed ways they empower their students by making sure all the decisions are left to be the news lab leaders. Sarah said, "These editors are second teachers in the classroom. They really are because there is no way I can get to everyone specifically during our class period. They are teaching the new kids by helping me because there's only one of me." In a similar fashion, Lucy wants her editors to make decisions making each production better. She 
supports her editors' decisions by letting them make them on their own. She shared, "It's all about improving. A lot of it is letting them try." The advisers support editors' decisions to make the news lab a safe environment. The advisers believe nurturing editor decisions within their safe environment helps build the students into leaders.

Promoting student autonomy of story ideas and supporting those decisions is a common way that advisors empower students. For instance, students are taught to generate story ideas and make their own decisions on how the stories will be produced. Advisers give their student editors a great deal of ownership and choice in deciding how to do their work and select story topics.

Similarly, Lexy's editors are empowered throughout their work process. She explained, "The kids do the approvals before they ever go out to work and so, by the time I see it on a magazine, it's pretty good." Likewise, Elizabeth gets out of her editors' way and empowers them to teach the class. She said, "Yes, I'm the adviser. Yes, I'm the adult in charge, but at the end of the day, it's the kids that really take over and run everything."

Six advisers illustrated how they gave students opportunities to make their own decisions about how to present their work. Liza finds one of the best ways to empower her students is to give them options for how they might present their stories. She shared an instance when a student did not know how to identify interviewed students: "She did not know what to do, so I asked her how do you think we can make it work? I don't want to tell them here's how you need to do it, but I want them to figure it out." She further explained, "When you get out of their way and give them the storytelling and tell them 'just do what you need to do to tell your story. If you're uncertain, if you think it's breaking any rules, come talk to me." Ellen also makes sure the student editors lead her 
news lab processes. She explained, "I have some guidelines that I want, but for the most part, they go out and they bring it together. Everybody will pitch their ideas. Then the editors go through and tell me what they choose. They choose their own partners or work alone. They put it all together."

Positive Feedback. Advisers shared they continually communicate feedback and critique with their editors. Sloane supports her editors' decisions that they make on their own through her final approval or critique. Her editor-in-chief plays the main role in her production process. "I make the final decision, but the process starts with the kids and then my editor-in-chief leads the news lab." In the same way, many create a culture centered around student success, along with an environment which supports a great deal of freedom and choice in deciding how to do their work based on student decisions. Ultimately, supporting decisions and work through positive feedback helps students gain confidence and empowers the newsroom.

Many advisers create supportive learning environments committed to students knowing they are safe. Advisers in this study recognized how they empower their students by transforming their classrooms into nurturing learning environments. Specifically, the advisers shared that by creating a safe environment they set the stage for supporting student decisions and learning how to provide positive feedback. Student reassurance helps advisers teach leaders to create high-quality news productions. From this reassurance the students gain confidence to be leaders within their news lab.

\section{Taking Action}

The root of creating a safe environment is helping students trust their own decisions. Once students trust their own decisions, advisers revealed their students take 
action and create more meaningful student news. Advisers empower students to behave like student journalists instead of just high school students by deciding upon their own goals. Advisers challenge their students to try out new and innovative ways to execute their coverage. There are a variety of ways advisers teach the ability to take action.

Advisers want students to step outside of their comfort zones when selecting their own story ideas. Lucy pushes her news lab to cover national and international events by connecting the topic to the students in their high school. She referred to this as "localizing a story". This teaching strategy helps her students find meaningful story ideas. She explained, "News values and proximity catches their interests. They think this is just school. I tell them our school is the size of my whole town. For me, there's plenty of stories to connect to the world outside of our school." Sarah encourages her students to take action by covering multiple perspectives in their student news. Sarah expects her editors to search out many student perspectives. She illustrated, "It's good to make them think outside the box for different ways to cover different things."

To further illustrate advisers' approach of taking action, Lydia teaches her students to seek out story ideas even if the topic may test her students' skills. She explained, "Even if the story is more challenging, whenever they come back, they always feel like this huge sense of accomplishment, and they tend to get so much more recognition for those stories. I think that's a huge driving force for finding them.” In a similar manner to Lydia's teaching, Mary explained she teaches students to break through their fear:

I am blown away what our students can accomplish. One day, a student was in here talking to somebody in Washington D.C. I'm just looking at him like, "How 
did you get that number?" "Oh, my mom knows somebody who knows

somebody." They have all these connections and you've got to let them fly and try them out.

Inspiring News Coverage. Advisers shared the importance of encouraging students to make their own story decisions and providing the appropriate training. Advisers suggested textbooks were lacking in both leadership instruction and exposure to the latest professional standards and trends. However, some advisers retain using textbooks for ethics training and basic skills. Overall, there is a need for advisers to continually expose students to expectations outside of the news lab to ensure student growth and empowerment. Advisers search outside the formal boundaries of their high school and school district for innovative ways to improve their coverage.

Interviews further revealed a majority of advisers do not use textbooks. Due to the lack of instructional resources, advisers have their students learn through viewing journalism examples. Advisers said they show their students professional news and award-winning high school news. For example, Lucy shared her belief it is important to have her students learn by viewing the best news coverage, which cannot be found in a textbook. She revealed how her students view posted award-winning high school news on scholastic journalism organization web sites. Madison goes as far as assigning her students to watch videos of journalism examples and review magazines. She explained why her students review news stories that other schools create: "Instead of me saying how things work, I can show students, here's what all of these other schools are doing that we are not." 
Liza sees exposure as key to her students' learning and also assigns her students to watch examples of news stories, such as 'CBS Sunday Morning' and 'On the Road with Steve Hartman'. She explained how showing the best long form journalism examples help her students: "I will share good story examples, while I show them my excitement. It's important because when they see you're super excited they love it and get inspired."

Overall, advisers continually inspire their students story ideas, so they can make sound decisions in their own coverage. As advisers do not use textbooks, they search out many relevant resources to ensure their students can take action to cover their campus with up to date skills.

\section{Experimenting with Media}

While advisers encourage students to take action with innovative story ideas, others also experiment with different forms of media, audiences, and production. Lydia challenges her staff to try new ways to do work. Similarly, Laura experiments by using Google Docs for her students' work flow by establishing a virtual news lab. She shared that her virtual news lab was originally a solution to her problem of not having a news lab. Like Lydia, Eva shared, "I have a student right now that wanted to start a podcast, so he walked up to my desk the first week of school, 'Ms. Eva, I want to start a podcast.' I said, 'Great, do it, research it, tell me what you want me to go buy.' And he goes, 'What?' I said, 'Stop talking. Go research. Go tell me what you want to do.'” Just as Lydia and Eva, Laura also has supported her student's excitement for developing a newspaper and literacy art magazine. She explained, "He was such a visionary and really 
a leader in every sense of the word. I became the follower." Within each safe and controlled environment, students grow by experimenting with their tools.

When advisers want their students to try new ways to do student news, they have to be ready when the result does not go as expected. Advisers shared when a goal is not met, and a mistake occurs they continually strive to find the lesson in the misstep. Laura commented, as an adviser you are always prepared for mistakes and cannot expect perfection and need to be satisfied with students striving to produce good work. She shared how her students diligently strive for perfection, but may still experience printed errors. She explained, "We always ask ourselves after each deadline, 'What can we learn?' There can be mistakes in here when we're doing our final proofs. We don't ever know where they are, and I guarantee you, we always try and find them. But there are always mistakes." She further explained she is sure to debrief with the students to learn how to deal with public ridicule and critique. In the end, guiding the students to choose the different aspects of the student news empowers them to grow and learn.

\section{Theme IV- Advisers Impacting Students}

The final theme that emerged from the data defined how advisers' leadership impacts students. Three subthemes link how advisers have been impactful leaders for their students, high schools, and communities. Principally, advisers impact their students' through their enthusiasm, influence, and building trust, to be leaders.

\section{Harnessing Enthusiasm}

Advisers indicated their enthusiasm was a key element in leading their students and impacted their news lab's practice. Lydia develops cooperative relationships and pride in her students' journalism coverage to come together and meet their deadlines. 
Advisers said their own enthusiasm influenced the students' satisfaction in the news lab's standards, purpose, and production process.

Developing a Sense of Pride. Many advisers have significant pride in teaching journalism and say they prefer teaching journalism over any other class they teach. Lucy explained, "I take the word adviser seriously. There's a difference between being a journalism adviser and being a journalism teacher." As a result, advisers described how their vision and strategic goals helped them gain enthusiasm in their decision-making processes, as well as in setting priorities and evaluating the progress throughout each deadline.

Finding Significance. Advisers established a strategic direction for each production to generate importance. Erin provides choices and autonomy while helping her editors focus their energies and engage in significant practices. Moreover, the adviser's pedagogy was a strong driving force to establish a culture favoring effective production, encouraging creativity, and fostering group decision making.

Sharing Passion. While further explaining their leadership philosophy, all 24 respondents clarified their passion for advising journalism. The advisers articulated their love for their profession and serving their school for the greater good of journalism. Sam shared she stays motivated to teach her students through her passion. She said, "I love my job. Most teachers are in it because they love kids and they love their job. And we all know that we don't get paid a ton of money. But that's not necessarily why we're in it. It's about, for me, for sure, the journey and how you feel while you go through the journey." Similarly, Lexy commented, "I love journalism, I'm passionate about storytelling. I think 
the relationship piece is the most important part to me." Advisers impact their students through their personal passion for teaching the craft of journalism.

Through advisers' passion students are impacted to grow as leaders. Sarah loves teaching journalism because she wants to see editors grow as leaders. She said:

I love journalism and I love teaching it. I want them to be successful. I've seen how much their success helps them blossom. In journalism, you get to know those kids so much more than just in English class or another class, that's why I love it. I really do love it.

Like Sarah, Sandy shared she has always had a turbulent passion for journalism. She said: I'm always excited about yearbook. I am one of those few and rare yearbook advisers that loves yearbook. A lot of advisers that are asked to do the yearbook have it dumped in their lap. I knew whenever I was hired I was going to have that responsibility, and I was fine with it. I actually love the process of putting together a yearbook, seeing it come together, seeing the kids working together, and seeing them grow in the process.

Sandy further shared she devotes herself to find many different students to be part of her staff to grow their shared passion and love for journalism. Sandy explained:

It's why I gravitate toward it, and I also gravitate toward those kids. I also know with the yearbook staff I need a variety of kids on the staff. I have three band kids. I have one former soccer player. I have a tennis player. I have one girl that's in art, and so she's very strong with design ideas and photography. There's just a wide variety that you need in yearbook, and a couple of them are really strong in writing. You need that to come together to put together a good yearbook. I kind of 
look for kids that have these abilities, and putting them together sometimes works, and this year so far, it's working.

Many advisers shared their devotion to teaching journalism can also jump into the other classes they teach. For example, Lydia also teaches English with her class load and finds ways to bring Journalism into her English class. She has witnessed many students' communication skills develop within her Journalism classroom. She explained, "Seeing the students' growth as communicators and becoming prepared for the outside world is amazing. I think our students would be better writers and readers, and more prepared for college, if every student in English would do a Journalism class." Elise elaborated on her passion is seeing her students succeed:

Success for me is the kids opening the box of yearbooks when they're delivered, or our distribution day, or when they send some post that goes viral on social media. They can see how their story has reached 10 thousand people. Those are those moments that are worth it. Every work night, and tear, and drama filled moment we had was worth it. Seeing them be proud of their work is something I don't think you can really define.

Emily illustrated how she also adores the journey and reaching her students' goal:

The best part is when they actually open the book and they realize how good and they like it. One year was really hard. I mean, we were pushing and pushing and honestly, it ended up being one of the best books we've ever done. I love the 2016 book. It's one of my favorites.

Mia strives to find students with the same belief and same goals she has. She explained, "The goal for me is to find the students who believe in what I believe in and what we 
believe is supposed to be in service of this globe community. Like what sort of service are we putting forward into the world?" For Lucy, advising means that you get to step back:

You have to step back or it's not their publication. I think that misperception is out there. They don't understand that in the yearbook, yes, you have to cover all the things, but how you cover them and how you choose to cover them is up to the students. They choose the story lines, the photos.

Many advisers believe their advising position differs from teaching, and it is superior and preferred. Emily articulated:

It's the hardest job you're ever going to love, but when you're going to hate it when you're going through it because it's on your shoulders and this is so much responsibility. It's so different because what you're doing for the first time ever, for many of these kids, really matters. Real people read our stuff.

\section{Building Trust}

Advisers shared personal connections with their editors' help the news labs' production and their teaching experience. Specifically, the study found that advisers established their most effective student leaders through deliberate processes designed to encourage students in direct and personal ways. Advisers shared strong relationships and ongoing communication maximize the trust throughout their news lab.

Madison believes her editors trust her because she puts trust in them and they feel they have a personal stake in their news lab and it is more than just a class. Other advisers had similar perspectives. For example, Eva commented: 
You can actually trust to take the reins off. It is amazing what they will do if you just say, "I believe in you, go do it and I'm here if you fall down. I probably won't pick you up, but I'm going to be here if you fall down." It's really cool to just see what they do.

Establishing Relationships. Trust in the relationship between advisers and their students is worth emphasizing, due to the significance an adviser has in being a leader in journalism education. For example, Liza strives to build relationships by treating editors like adults and being authentic. She concentrates on relationships and believes students have a hard time learning from a teacher they do not have some kind of relationship with. Essentially, trust boosts a news lab's ability for students to effectively meet expectations on their own. For example, Emily's trust in her students deepened during a long absence. Her editors were able to keep the workflow moving and produce quality work while she was on leave due to a surgery. She shared, "Everything kept moving. I think in education a lot of times, it's the dream of a lot of educators to trust their students to keep moving forward and thrive, even when they are not there." Eva also trusted her editors during a bereavement leave to attend a family funeral. She explained, "Initially, I was filled with anxiety. Then, I realized my editors know the programs and would handle the heavy lifting to keep us moving. When they see me as an adult just going, 'Let's do this,' then I think they learn that adaptation skill and that they are trusted." In the same way, when Sloane's baby arrived, her first call outside of her family was to her editor-in-chief ensuring the completion of their upcoming deadlines. She further explained how much she trusted and depended upon her editor in that moment throughout the delivery and the following weeks of maternity leave. She commented, "I was not going to be there, and I 
needed to call her to let her know because we were on deadline. So, it was a little stressful for me, but good to know they were prepared for it and in safe hands with my editor." In the end, advisers impact students by establishing strong relationships to build trust throughout their news lab.

Open Communication. Advisers revealed trust is built upon ongoing communication. Mia explained, "If our arrows are all pointed in the right direction, we can be a more effective collective." As a result of clearly communicating their goals, the staff developed a strong mutual trust. She welcomed conversations on culture, emphasized publication importance, developed reasons to care, and instilled a desire to participate. She explained:

We came to the central idea, "The bearers of light," to shine a light on good in the community. The positive we want to see more. Sometimes it means shining a light on things that are like, man, this is really messed up, or this could be better, or how do we create change? If you're doing it well, you create proof to live your central mission.

Advisers articulated a focus on open communication with their editors to create a culture of trust. A focus on communication helps advisers create a positive news lab, which is encouraging to students. Emily found communication to be key. She explained, "You have those conversations because it's a job. They don't know how to do a job because they're 16, 17 years old, and 18 years old. They know how to work, but it takes more to lead." To support her students Lydia encourages them to communicate with her regularly. She said, "It's really more if they are struggling and they come and talk with me, we sit down, and we conference, we do a lot of conferencing." Establishing ongoing 
communication impacted students and advisers to trust each other to reach their news lab and personal goals.

\section{Intentional Influence}

Advisers strive to model their values through their personal example by having a desire to learn and giving time and energy to their production. During the news lab productions, advisers impact their students' practices and behaviors by building consensus. The adviser's influence can impact the students in and outside the news lab.

Providing a Personal Example. A majority of the advisers shared their leadership philosophy to be "lead by example". In fact, eleven advisers revealed their personal, professional, journalistic values. Eleanor described a huge part for her being a teacher is modeling the behaviors that she wants to see her students emulate. She further described, "I just show those appropriate leadership skills and behaviors in my classroom." In the same way, Eva models by setting her personal example of her expectations. She illustrated:

They will see me talk to every single student walking in the door and have painful conversations. I teach them that even though I don't care what's going on in all the students' lives, I will have those utterly painful conversations because it helps those students.

Ellen recounts how she shares her value of grace by demonstrating it throughout her news lab consequences. She strives to help her relationships by giving grace to her students. She shared an instance when a student made a bad choice, which resulted in a detention: "I believe in grace. So, we had to have conversations about it to not do that choice and if 
he did that again, it was going to be a problem. But there has to be an understanding that sometimes they make bad choices, and to move on. They're kids," she said.

Dedicating Time and Energy. While further explaining their perspectives, respondents clarified they continually model their belief in advising journalism by putting forth the time and energy to complete the work. Sarah revealed that she shows her students the importance of the news lab's values by not communicating it to her students in words, but as the adviser she spends time and energy making certain her students work to adhere with journalism principles and standards. Laura also shared she teaches her students through her personal example, as she was their high school's first journalism adviser and established the program with her students. She has made sure her editors adhere to their established principles and standards. Ellen shared her actions influence her students' performance. She explained:

I try to hold the same standards for myself as I do for them. I don't ask them to do anything that I'm not willing to do. I mean I've gone out with shoots with the kids before to help them do different things. A few years back we were in a contest and we literally worked over Spring Break. I was with those kids from the beginning of the day to the end of the day."

In the end, investing time and energy is a commonality among the award-winning journalism educators in this study.

Demonstrating a Desire to Learn. Many advisers interviewed take on the responsibility to make sure their knowledge is up to date with current professional standards. For example, Eli's original training is outside of journalism and is a self-taught journalism adviser. He brought to light, "I definitely had to go through change. This is 
not my background, but I didn't have to force it. I had to find things that made me realize this will be cool to turn into a lesson that meets our show's end goal." Eli's specialty is in business education. He has used many resources and scholastic journalism to gain the needed skills. He further illustrated, "I didn't go to broadcasting school. I wasn't a journalism major. I was a business education major, and I read books, watched YouTube videos, go to conferences. Now I can say this is how we're going to run it." Eli attributes his successful practice to this one small way he influences his staff. His students are impacted by his commitment to life-long learning. Much like Eli, many advisers demonstrated a desire to learn influences students to make them want to grow as journalists.

Building Consensus. Advisers shared once they first shape the news lab to be productive and creative, the students shape the news lab's goals from a collaborative consensus. Twenty-two advisers shared the fundamental practice of establishing professional habits, where the student editors lead the new lab, such as leading budget meetings, enforcing expectations, rubric reviews, and work session goals.

In fact, advisers commented they rely on student buy-in to establish leadership roles and encourage proper decision making. Mary explained how she impacts her students by establishing consensus around the higher commitments to journalism law and ethical standards. The students' knowledge helps her trust the students' decisions. For example, she explained, "Our editors have the leadership opportunity to stand up for what they believe in. Our kids have great pride and respect for what they do. They know Hazelwood versus Kuhlmeier and the kids respect that they have the ability to make decisions." 
Similarly, Elizabeth builds consensus around journalism values and skills. She focuses on the big picture of future news lab leadership. Elizabeth said:

I can teach you all the skills you need, but you can't teach passion about something, or working hard until it works, because that's a lot of what journalism is. Because you're going to have the bad days, the bad interviews. But when it does finally click and come all together, it's really cool to be part of that with all of my students.

So, whether advisers are building consensus around law, ethics, values, morals, or skills, the bottom line is that these learning communities are firmly planted in the solid ground of a common set of higher ideals.

The data revealed the role of leadership generates consensus as advisers and students share convictions for their productions and program. Additionally, Elizabeth continually directs her students towards their shared purpose. Each year, she sees her students return to her news lab. She illustrated, "All come in as novices, but by the time they're done, they'll be an amateur or expert. I feel like if they take my class a second year they become a professional level journalist." The news labs' shared goals grow students into leaders. Elise explained, "I always have my editors as returning staff members. They've been on staff before and know what's expected. I feel like they have a good grasp on our goals and just have to use their knowledge." Erin believes her editors are invested and want their news lab to reflect their agreed upon decisions. She explained:

They have a personal investment in this program. It's not just me, it's not just my program. It doesn't belong to anybody but them. They have that personal stake in 
it. I just put some structure to it. They want to have a say in what happens. Because they know that if they're not there, the kids who are there will decide how to steer the boat and they want that stake in it.

Similarly, Leah believes her students are invested and strive to be part of the news lab's big picture, starting at their beginning steps as staffers. She explained:

The editors get our goals and they understand how they are part of the big picture because they took those first two years and they were in an environment that allowed them to take their time to learn the process to become a leader not only for themselves, but for other people, and other people will want to be them. In the end, advisers shared there is the necessity for advisers to impact students by building consensus within journalism education. Advisers' passion impacts students to cultivate effective production, it encourages creativity, and it fosters reached goals. The role of leadership helps establish a quality journalism program. Ultimately, most of the advisers in this study believe one way leaders impact students is by subscribing to a shared enthusiasm, creating trustworthiness, and building consensus throughout the news labs. 


\section{APPENDIX I}

VITA

Julia (Julie) Lewis was born in Iowa City, Iowa, but spent the earliest part of her life in Atlantic, Iowa. She was the editor of her high-school newspaper The Jaywalker in Urbandale, Iowa. After high school, Julia attended the University of Missouri - Columbia (MU) School of Journalism in Columbia, Missouri. She majored in Journalism, with a minor in Political Science. As a student reporter at MU's school newspaper, The Missourian, she experienced the importance of journalism which ultimately fueled her passion for the craft and journalism education.

First, as a professional journalist, she found how news coverage can play a powerful role in connecting communities, restoring hope and giving people a reason to care about social issues. Soon, she found her next calling and began her teaching career as a high school journalism adviser. In 2005, she first earned a Master of Arts in Teaching degree at the University of Central Missouri (UCM). She advised news labs throughout mid-Missouri and found advising takes time, patience and the love of a student newsroom. She spent hours at work on production nights, listening to debates over attributes, and the beauty and nobility of combing through and cross-checking information - all in pursuit of education.

After eleven years advising, she became an instructor at UCM, teaching courses related to journalism, mass communication, strategic communication, media, and multimedia. She also, was the lead adviser of The Muleskinner student newspaper. While teaching at UCM, she earned her second masters of arts degree emphasizing Communication at UCM in December 2015 and a doctoral degree in Educational Leadership and Policy Analysis program through MU in May 2020. 